Michael Sauer (Hg.)

\title{
Denkmäler in Göttingen
}

Handreichungen für den Geschichtsunterricht
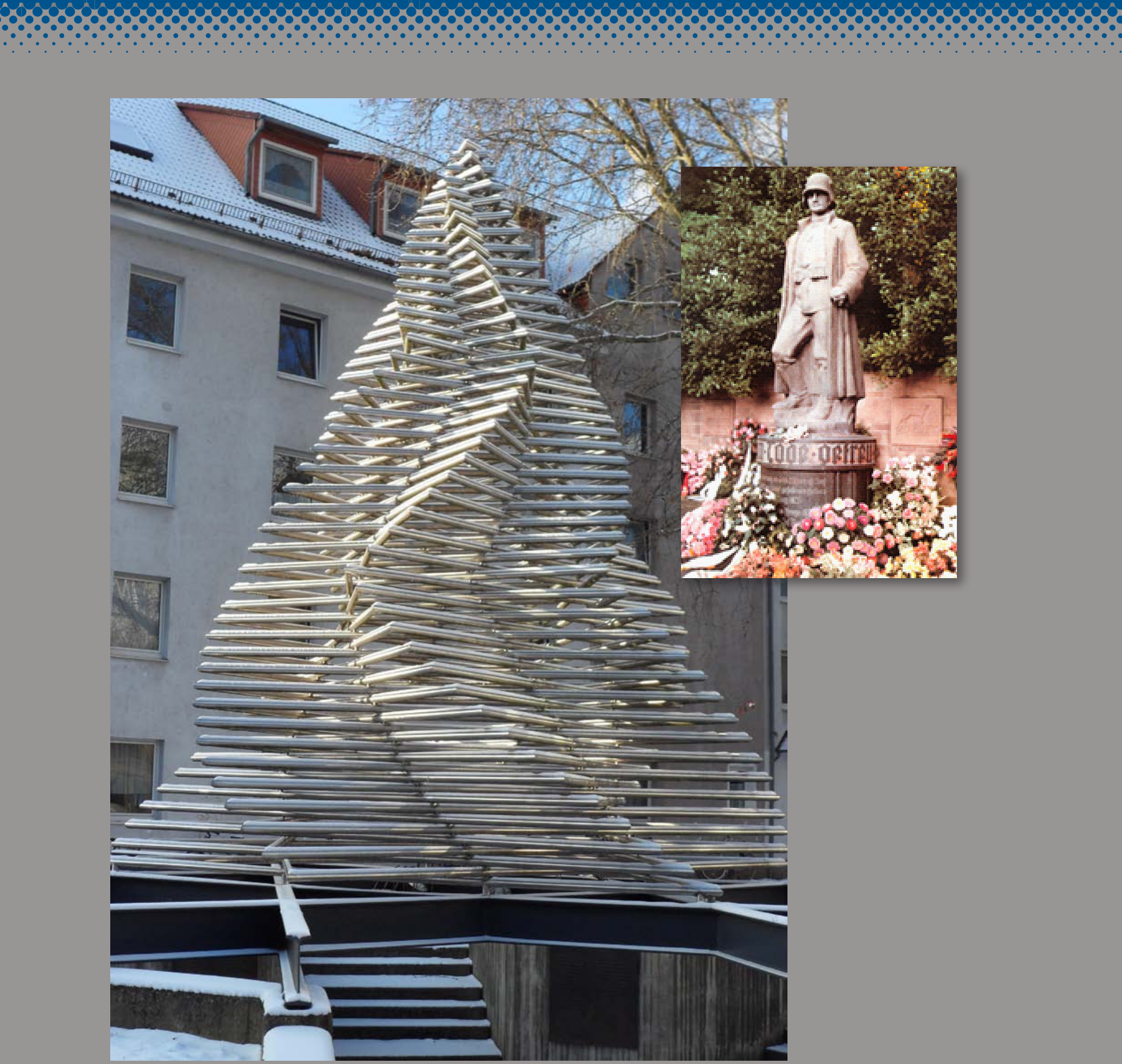

Universitätsdrucke Göttingen 

Michael Sauer (Hg.)

Denkmäler in Göttingen

This work is licensed under the Creative Commons License 3.0 "by-nd", allowing you to download, distribute and print the document in a few copies for private or educational use, given that the document stays unchanged and the creator is mentioned.

You are not allowed to sell copies of the free version. 
erschienen in der Reihe der Universitätsdrucke

im Universitätsverlag Göttingen 2012 
Michael Sauer (Hg.)

\section{Denkmäler in Göttingen}

Handreichungen

für den Geschichtsunterricht

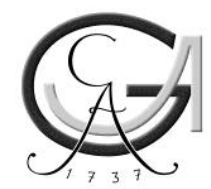

Universitätsverlag Göttingen 2012 


\title{
Bibliographische Information der Deutschen Nationalbibliothek
}

Die Deutsche Nationalbibliothek verzeichnet diese Publikation in der Deutschen Nationalbibliographie; detaillierte bibliographische Daten sind im Internet über < http://dnb.ddb.de> abrufbar

\author{
Anschrift des Herausgebers \\ Prof. Dr. Michael Sauer \\ Georg-August-Universität Göttingen \\ Seminar für Mittlere und Neuere Geschichte \\ Didaktik der Geschichte \\ Waldweg 26 \\ 37073 Göttingen
}

Erstellt und gedruckt mit Mitteln aus Studienbeiträgen der Universität Göttingen

Dieses Buch ist auch als freie Onlineversion über die Homepage des Verlags sowie über den OPAC der Niedersächsischen Staats- und Universitätsbibliothek (http://www.sub.uni-goettingen.de) erreichbar und darf gelesen, heruntergeladen sowie als Privatkopie ausgedruckt werden Es gelten die Lizenzbestimmungen der Onlineversion. Es ist nicht gestattet, Kopien oder gedruckte Fassungen der freien Onlineversion zu veräußern.

Satz und Layout: Alexander Tietz

Umschlaggestaltung: Jutta Pabst

Titelabbildungen: Mahnmal Synagoge, Foto: Kempe 2010

Das Ehrenmal des Infanterieregiments 82, Foto: Städtisches Museum Göttingen

\section{(C) 2012 Universitätsverlag Göttingen}

http: / / univerlag.uni-goettingen.de

ISBN: 978-3-86395-050-7 


\section{Inhaltsverzeichnis}

Michael Sauer

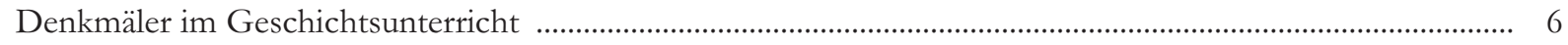

Katja Bartsch

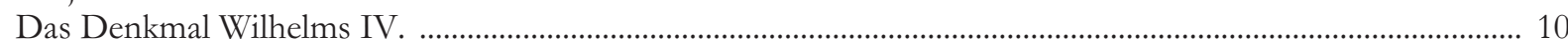

Franziska Frome-Ziegler, Daniela Kempe, Theresa Nawroth

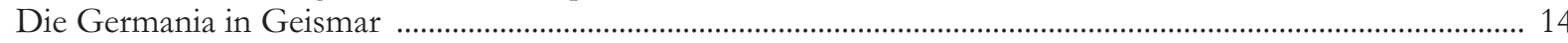

Anja Groß

Der Bismarckstein

Melanie Mai

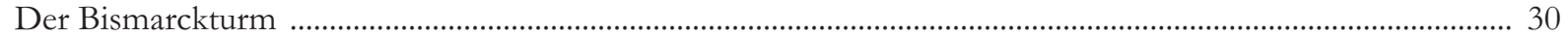

David Meiser

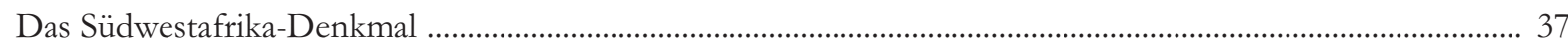

Alexander Tietz

Das Ehrenmal für die Gefallenen des Reserve-Infanterie-Regiments 91

Marco Dräger

Das Ehrenmal des Infanterie-Regiments Nr. 82

Carina Marunde

Das Ehrenmal für die Gefallenen der Universität

Franziska Frome-Ziegler, Daniela Kempe, Theresa Nawroth

Das Mahnmal Synagoge

Lageplan

Abbildungsverzeichnis 


\title{
Denkmäler im Geschichtsunterricht
}

\author{
Michael Sauer
}

\section{Funktion und Rezeption von Denkmälern}

Denkmäler sind gewissermaßen Knotenpunkte von öffentlichem Geschichtsbewusstsein und Erinnerungskultur. Denn sie verknüpfen die drei Zeitebenen von Gegenwart, Vergangenheit und Zukunft miteinander: Errichtet in einer früheren Gegenwart, sollen sie an eine davor liegende Vergangenheit erinnern; mit ihrer Deutung dieser Vergangenheit richten sie zugleich eine Botschaft an die (damalige) Zukunft. Denkmäler sollen festhalten, was für einen Kreis von Menschen - vom Dorf bis zur Nation - erinnerungswürdig erscheint und Eingang ins kollektive Gedächtnis finden soll.

Auch wenn wir bei Denkmälern vielleicht zunächst an die großen Bauten - die Nationaldenkmäler des 19. Jahrhunderts oder die zentralen Mahnmalsbauten der jüngeren Zeit - denken, so hat doch auch jeder Ort seine eigene Denkmalslandschaft, in der sich allgemeine und lokale Erinnerungsbezüge mischen.

Bei ihrer Errichtung hatten Denkmäler üblicherweise eine affirmative, eine legitimierende und traditionsstiftende Funktion. So sollte etwa das 1875 fertiggestellte Hermannsdenkmal im Teutoburger Wald nicht nur an die Niederlage der Römer im Jahre 9 n. Chr. erinnern, sondern diese zugleich mit dem deutschen Sieg über Frankreich 1870/71 zu einer erfolgreichen germanisch-deutschen und ,antiwelschen" Traditionslinie verbinden. Neu ist ein kritisches Gedenken, wie wir es etwa beim Berliner Holocaust-Denkmal finden. Dass eine Nation durch eine Denkmalssetzung an ihre eigene historische Schuld erinnert, ist äußerst ungewöhnlich, wenn nicht sogar weltweit einzigar-

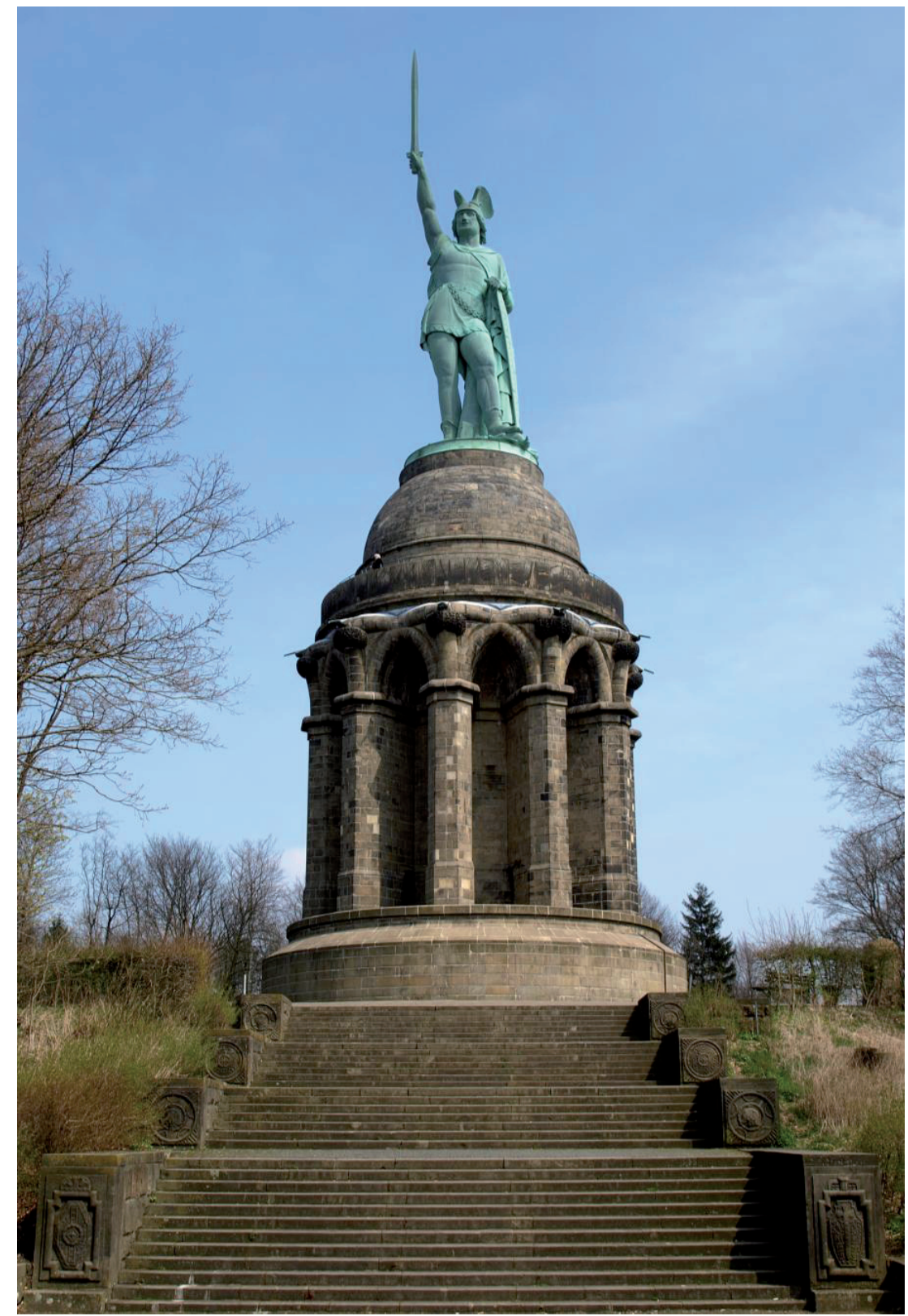

Hermannsdenkmal im Teutoburger W ald, 2008

tig. Solch eine neue Art des Gedenkens lässt sich auch nicht mehr in der traditionellen Formsprache von Denkmälern ausdrücken und bedarf neuer Gestaltungskonzepte.

Mit Denkmälern verbindet sich häufig eine Erinnerungspraxis in Form von einschlägigen Inszenie- rungen, Feiern oder Aufmärschen. Ein solches ritualisiertes Gedenken findet vor allem anlässlich von Jahrestagen oder Jubiläen statt. Zur Rezeptionsgeschichte von Denkmälern gehören aber auch oft - und gerade in jüngerer Zeit - Auseinandersetzungen und Debatten darüber, ob 


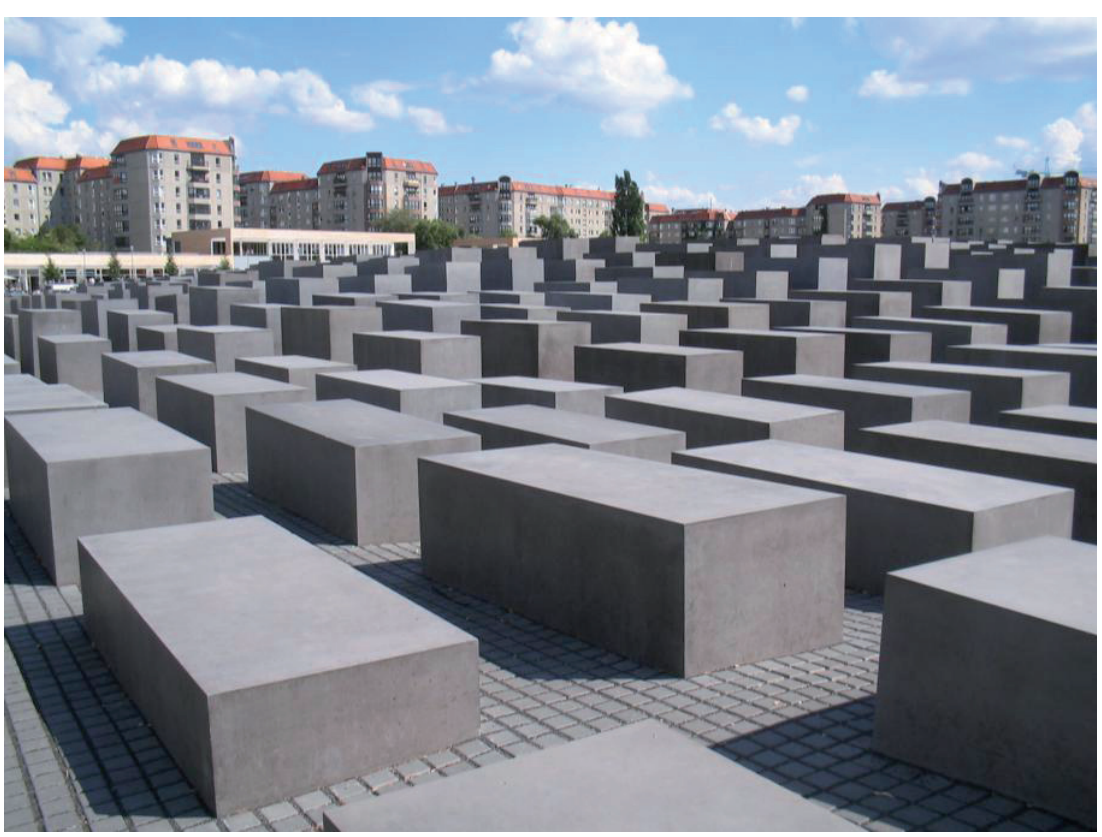

Holocaust-Denkmal in Berlin, 2006

historische Ereignisse oder Personen überhaupt noch erinnerungswürdig sind bzw. wie heutzutage ihrer gedacht werden soll. Das hat nach der deutschen Wiedervereinigung vereinzelt zur Demontage von Denkmälern in der ehemaligen DDR geführt; Denkmalsstürze hat es auch in den Ländern des ehemaligen Ostblocks oder im Irak gegeben. Dass solche Objekte, die - wie die Statuen Lenins oder Saddam Husseins - unmittelbar als Herrschaftszeichen diktatorischer Regimes fungieren und so wahrgenommen werden, nach deren Ende beseitigt werden, ist gewiss nachvollziehbar.

In vielen anderen Fällen kann man darüber streiten, wie man mit Denkmälern umgeht, die in einem anderen gesellschaftlichen Kontext, auf der Basis anderer Wertmaßstäbe und Geschichtsbilder errichtet worden sind. Ist ein Denkmal für den Grafen Waldersee, von 1888 bis 1891 Chef des deutschen Generalstabs und 1900/01 Oberbefehlshaber der Interventionstruppen im sog. Boxerkrieg, heutzutage völlig inakzeptabel? Für die Beseitigung eines Denkmals muss es schon sehr schlagkräftige Gründe geben. In der Regel sollte man gewachsene öffent- liche Erinnerungslandschaften, zu denen neben Denkmälern auch Straßennamen gehören, nicht zerstören oder allzu eilfertig aktueller politischer Correctness anzupassen versuchen. Sinnvoll erscheint eher eine angemessene Historisierung und Kontextualisierung: also Hinweise und Erläuterungen vor Ort, warum in einer vergangenen Zeit eine Person oder ein Geschehen erinnerungswürdig erschien und inwiefern heutige Urteile anders ausfallen.

\section{Historischer Abriss}

Denkmäler gibt es bereits seit der Antike. Bis ins 18. Jahrhundert bleiben sie fast ausschließlich Herrschern und Feldherren vorbehalten, an deren siegreiche Schlachten und Kriege sie erinnern sollen. Das 19. Jahrhundert als Zeitalter des Nationalismus bringt in ganz Europa die großen Nationaldenkmäler hervor, in denen sich die Gründungsmythen und Legitimationsgeschichten der Staaten verdichten. Ebenfalls im 19. Jahrhundert werden aber allmählich auch Denkmäler für die großen (bürgerlichen) „Dichter und Denker" errichtet - in Deutschland natürlich vor allem Goethe und Schiller. Und seit den dreißiger Jahren je- nes Jahrhunderts, mit dem allgemeinen Übergang zu den Bürgerarmeen, kommen die Kriegerdenkmäler für den einfachen Soldaten auf, die insbesondere nach dem Ersten Weltkrieg die weiteste Verbreitung finden; nach dem Zweiten Weltkrieg gibt es weniger Neubauten als vielmehr Erweiterungen und „Fortschreibungen" der schon vorhandenen Kriegerdenkmäler.

Nach 1945 spielen zwei neue Erinnerungsanlässe eine wichtige Rolle: Zunächst die Flucht und Vertreibung der Deutschen aus dem Osten, dann - zögerlich und nach immer neuen Debatten - der Holocaust, dessen heutzutage von den ,Stolpersteinen" bis zum zentralen Mahnmal auf unterschiedlichen Ebenen und in unterschiedlichen Formen gedacht wird.

Seit der Wiedervereinigung Deutschlands hat es verschiedene Debatten um Denkmalserrichtungen gegeben: vom Holocaustdenkmal, den Denkmälern für die ermordeten Sinti und Roma und die verfolgten Homosexuellen bis hin $\mathrm{zu}$ einem zentralen Vertriebenendenkmal und einem Denkmal für die Gefallenen der Bundeswehr. Während in vormodernen und totalitären Gesellschaften Denkmäler als Herrschaftszeichen von Landesherren und Diktatoren gesetzt werden, entstehen sie in demokratischen Gesellschaften als Ergebnis eines öffentlichen Aushandlungsprozesses zwischen gesellschaftlichen Gruppierungen und in politischen Gremien. Der intensive Diskurs darüber stellt ein zentrales Element der historischpolitischen Bewusstseinsbildung dar.

\section{Unterricht}

Für einen Geschichtsunterricht, der sich intensiver mit Geschichte als gedeuteter Vergangenheit befassen will, bieten Denkmäler erhebliche Lernpotentiale. Sie sind Manifestationen vergangener oder auch gegenwärtiger Geschichtskultur. Sie geben Auskunft über intendierte Sinnstiftungen, vielfach auch über Funktio- 
nalisierungen von Vergangenheit. Und auf die Beschäftigung mit einer lokalen Denkmalslandschaft trifft in besonderer Weise zu, was das niedersächsische Kerncurriculum für die Sekundarstufe I ganz allgemein über Themen und Zeugnisse der Lokal- und Regionalgeschichte sagt: Diese seien zu berücksichtigen, „weil sie sowohl das historische Interesse am eigenen Lebensraum fördern als auch Ausgangspunkt übergreifender Untersuchungen und Erkenntnisse sein können" (Kerncurriculum Geschichte Niedersachsen, Sekundarstufe I, S. 8).

Denkmäler vor Ort lassen sich mit unterschiedlichem Aufwand (und Ertrag) untersuchen. Am anspruchsvollsten ist ein Projekt, in dem Schülerinnen und Schüler selber ein Denkmal unter allen möglichen Aspekten - von der Entstehungsgeschichte bis zur heutigen Wahrnehmung - erforschen. Dies verlangt eine Fülle von Erkundungen, deren Spektrum von der fotografischen Dokumentation des heutigen Bauzustandes bis zur Suche nach Archivalien reichen kann. Das Gegenteil davon ist eine Erarbeitung, die ausschließlich auf schon von anderer Seite zusammengestellten Materialien basiert - eine solche Erarbeitung ermöglicht das vorliegende Heft. Einen Mittelweg bildet die sehr empfehlenswerte Variante, die Arbeit mit fertigen Materialien um eine Ortsbegehung zu ergänzen. Diese bietet die Möglichkeit, das Objekt selber und seine heutige Umgebung genauer in Augenschein zu nehmen, seine ästhetische Gesamtwirkung zu erfahren wie auch gestalterische Details zu überprüfen.

Wenn Schülerinnen und Schüler Denkmäler untersuchen, können sie sich an den folgenden Gesichtspunkten und Fragen orientieren (die natürlich nicht komplett abgearbeitet werden müssen):

\section{Erscheinungsbild des Denkmals}

- Um welchen Typus von Denkmal handelt es sich (Mahnmal,
Siegesdenkmal, Heldendenkmal, Standbild etc.)?

- Wo befindet sich das Denkmal (Standort und Umgebung: Platz, Friedhof, Hain, Park etc.)?

- Welche Gestalt hat das Denkmal (Größe, Material, figürliche Plastik, Relief, Bauform wie Säule, Kubus, Wand etc.)?

- Welche Inschriften finden sich an dem Denkmal?

- Welche Zeichen, Symbole, Allegorien, Schmuckelemente finden sich an dem Denkmal (Kreuz, Adler, Fahne etc.)?

\section{Entstehung und Intention}

- Wer waren der oder die Auftraggeber, wer hat das Denkmal erstellt?

- Was war der Anlass für die Errichtung des Denkmals und welche Funktion sollte es erfüllen?

- Gab es darüber Debatten?

- In welchem politischen und gesellschaftlichen Kontext stand die Errichtung?

- Wie sahen oder sehen andere Denkmäler mit gleicher oder ähnlicher Intention aus?

(Quellen: öffentliche Debatten in Zeitungen und Zeitschriften, Broschüren, Ausschreibungstexte, Wettbewerbsunterlagen, Vereinsmaterialien, Spendenaufrufe, Ratsprotokolle, Zeitungsberichte über die Einweihungsfeier)

\section{Geschichte und Rezeption}

- Wie wurde das Denkmal in seiner Geschichte wahrgenommen und beurteilt? Welche Veränderungen oder ggf. Konflikte gab es bis heute?

- Wurde das Denkmal als Ort für Gedenkveranstaltungen genutzt?

- Hat es in seiner Geschichte Veränderungen der baulichen Gestalt und der Nutzung gegeben?

(Quellen: Ansichtskarten, Zeitungsberichte, Buchveröffentlichungen, Interviews mit Zeitzeugen, Befra- gung zur Wahrnehmung und Einschätzung heute, Graffiti)

Die Auseinandersetzung mit Denkmälern und ihren Geschichten lässt sich intensivieren durch handlungsorientierte Verfahren. Sie können verschiedenen Zielen dienen: einer vertieften Wahrnehmung des Objekts; dem Nachvollziehen von Debatten und Entscheidungen über Denkmäler, die unterschiedliche Perspektiven auf Geschichte zum Vorschein treten lassen; der eigenen Stellungnahme und Aktion im Umgang mit bestehenden Denkmälern und Denkmalsideen. In diesem Sinne lassen sich

- bauliche Details dokumentieren: Fotografien, Nachzeichnungen

- Entscheidungssituationen nachspielen: Diskussion im Stadtrat, öffentliche Podiumsdiskussion, Demonstration mit Plakatgestaltung

- Denkmäler umgestalten oder ergänzen: Kommentierung, Ausstellung, Diskussionsteilnahme

- Denkmäler entwerfen: Diskussion über „Denkmalswürdigkeit“, Gestaltungskonzept.

\section{Zu diesem Heft}

Die Beiträge dieses Heftes sind aus einem Didaktik-Seminar hervorgegangen, das im Wintersemester 2010/11 an der Universität Göttingen stattgefunden hat. Ziel des Seminars war es, zu ausgewählten Denkmälern Göttingens Unterrichtsmaterialien $\mathrm{zu}$ erarbeiten, die Schülerinnen und Schülern die exemplarische Beschäftigung mit dieser lokalen Erinnerungslandschaft ermöglichen. Bei den meisten dieser Denkmäler handelt es sich um Vertreter von Typen, die sich in ganz Deutschland finden: Das gilt für die Germania in Geismar, für die Bismarckdenkmäler - Bismarckstein und -turm - sowie für die Denkmäler für die Gefallenen des Ersten Weltkriegs, die - ihrer allgemeinen Verbreitung entsprechend - gleich mit drei Beispielen vertreten sind. 
Das Denkmal Wilhelms IV. ist einerseits ein klassisches Herrscherdenkmal, andererseits steht es für die historische Besonderheit der englisch-hannoverschen Personalunion. Denkmäler zur Kolonialgeschichte sind in Deutschland nicht allzu verbreitet - in Göttingen handelt es sich um ein eher bescheidenes Exemplar, das dennoch zum Gegenstand einschlägiger Debatten geworden ist. Mit Abstand das jüngste Objekt ist das 1973 errichtete Synagogen-Mahnmal, an dem auch der Wandel der Formensprache von Denkmälern nachvollziehbar wird. Alle Beispiele - mit Ausnahme des regionalen Sonderfalls Wilhelm IV. - können im Kontext klassischer Themen in den Geschichtsunterricht einbezogen werden.
Die Beiträge des Heftes sind nach einem festen Muster aufgebaut. Einführend dokumentieren sie das aktuelle Erscheinungsbild jedes Denkmals (Typus, Gestalt, Standort, Inschriften), erschließen seine Entstehungsgeschichte und beschreiben seine weitere Geschichte und Rezeption bis in die Gegenwart. Im Anschluss daran werden Hinweise für die Einbettung und Behandlung im Unterricht gegeben. Es folgt eine Zusammenstellung (kopierbarer) Materialien, die unmittelbar im Unterricht eingesetzt werden können. Ein Steckbrief fasst die wichtigsten Daten zum Denkmal zusammen, ein Zeitstrahl oder eine Zeittafel ordnen die Geschichte des Objekts chronologisch ein. Text- und Bildquellen bieten die Möglichkeit, die Geschichte seiner Entstehung und
Nutzung zu erarbeiten. Dabei wurde besonders darauf geachtet, ein weites Spektrum unterschiedlicher Quellen zu berücksichtigen. Alle Materialien sind mit Arbeitsaufträgen versehen, bei denen entsprechend heutigem Standard Operatoren Verwendung finden. Besonderer Wert wurde auf handlungsorientierte Anregungen gelegt, die einen perspektivierenden Zugang zu den Materialien und den damit verbundenen Fragen ermöglichen (z. B. Simulation einer Debatte im Stadtrat, Entwurf eines kommentierenden Schildes, Verfassen eines Zeitungsartikels). Einige der Entwürfe wurden im Unterricht erprobt.

\section{Literatur}

Gottschalk, Carola (Hrsg.), Verewigt und vergessen. Kriegerdenkmäler, Mahnmale und Gedenksteine in Göttingen, Göttingen 1992.

Grillparzer, Eberhard u.a. (Hrsg.), Denkmäler. Ein Reader für Unterricht und Studium, Hannover 1994.

Kirsch, Jan-Holger, Nationaler Mythos oder historische Trauer? Der Streit um ein zentrales „Holocaust-Mahnmal“ für die Berliner Republik, Köln u.a. 2003.

Koselleck, Reinhart/Jeismann, Michael (Hrsg.), Der politische Totenkult. Kriegerdenkmäler in der Moderne, München 1994.

Nissen, Walter, Göttinger Denkmäler, Gedenksteine und Brunnen, Göttingen 1978.

Reeken, Dietmar von, „Das Auffallendste ist nämlich, dass man sie nicht bemerkt“. Denkmäler als gegenständliche Quellen des Geschichtsunterrichts, in: Geschichte lernen H. 121 (2008), S. 2-11.

Schlie, Ulrich, Die Nation erinnert sich. Die Denkmäler der Deutschen, München 2002.

Schmid, Hans-Dieter, Den künftigen Geschlechtern zur Nacheiferung. Denkmäler als Quellen der Geschichtskultur, in: Praxis Geschichte H. 6/2003, S. 4-11.

Schmid, Hans-Dieter, Denkmäler als Zeugnisse der Geschichtskultur, in: Horn, Sabine/Sauer, Michael (Hrsg.),

Geschichte und Öffentlichkeit. Orte - Medien - Institutionen, Göttingen 2009, S. 51-60.

Schneider, Gerhard, Kriegerdenkmäler als Unterrichtsquellen, in: Pandel, Hans-Jürgen/Schneider, Gerhard (Hrsg.), Handbuch Medien im Geschichtsunterricht, Schwalbach/Ts. 1999, S. 525-578.

Thünemann, Holger, Denkmäler als Orte historischen Lernens im Geschichtsunterricht - Herausforderungen und Chancen, in: Handro, Saskia/Schönemann, Bernd (Hrsg.), Orte historischen Lernens, Berlin 2008, S. 179-208.

Würfel, Maria, Denkmäler im Geschichtsunterricht, in: Geschichte für heute H. 1/2009, S. 5-19.

\section{Internet}

http://www.denkmale.goettingen.de/denkmale/index.html. http://www.kaee.uni-goettingen.de/studium/denkmal/index.htm. 


\title{
Das Denkmal Wilhelms IV.
}

\author{
Katja Bartsch
}

Das Denkmal Wilhelms IV. wurde 1837 im Rabmen der 100-Jahr-Feier der GeorgAugust-Universität Göttingen enthüllt. Es stebt gegenüber der Universitätsaula, die Wilhelm IV. der Universität zu ihrem 100-jährigem Bestehen geschenkt hatte. Das Denkmal bietet Schülern die Möglichkeit, die Geschichte der Stadt, in der sie leben, zu erkunden und sich mit den Besonderbeiten von Personendenkmälern auseinanderzusetzen.

\section{Erscheinungsbild und Standort}

Das Bronzestandbild König Wilhelms IV. ist fast drei Meter hoch und steht auf einem mehrere Meter hohem Sockel. Es zeigt Wilhelm im Königsmantel, die rechte Hand zum Segensgruß ausgestreckt. Die Gebärde ist dem Marc-Aurel-Standbild in Rom nachempfunden. Im Sockel befindet sich die Inschrift „Guilielmus / Quartus / Rex / Pater Pa- triae", darunter eine Bronzetafel mit der Inschrift „,Wilhelm IV. / König von / Grossbritannien / Irland u. Hannover / 1830-1837“. Das Standbild steht umgeben von Grünanlagen an der Südseite des Wilhelmsplatzes im Zentrum Göttingens und blickt auf das Portal der Universitätsaula, die sich an der Nordseite des Platzes befindet. Der genaue Standort auf dem Platz und die Ausrichtung des Standbildes wurden seit der Einweihung mehrfach verändert. Das Denkmal stand ursprünglich mittig auf dem Platz und blickte die Barfüßer Straße hinunter. 1900 wurde es an die Südseite des Platzes versetzt und um 90 Grad gedreht, so dass es nun auf das Portal der Aula blickte. Außerdem erfolgte zu dieser Zeit die gärtnerische Ausgestaltung des Platzes. In den 1960er Jahren wurden dort Parkplätze eingerichtet (siehe Foto), 1987 wurde dann die Grünanlage

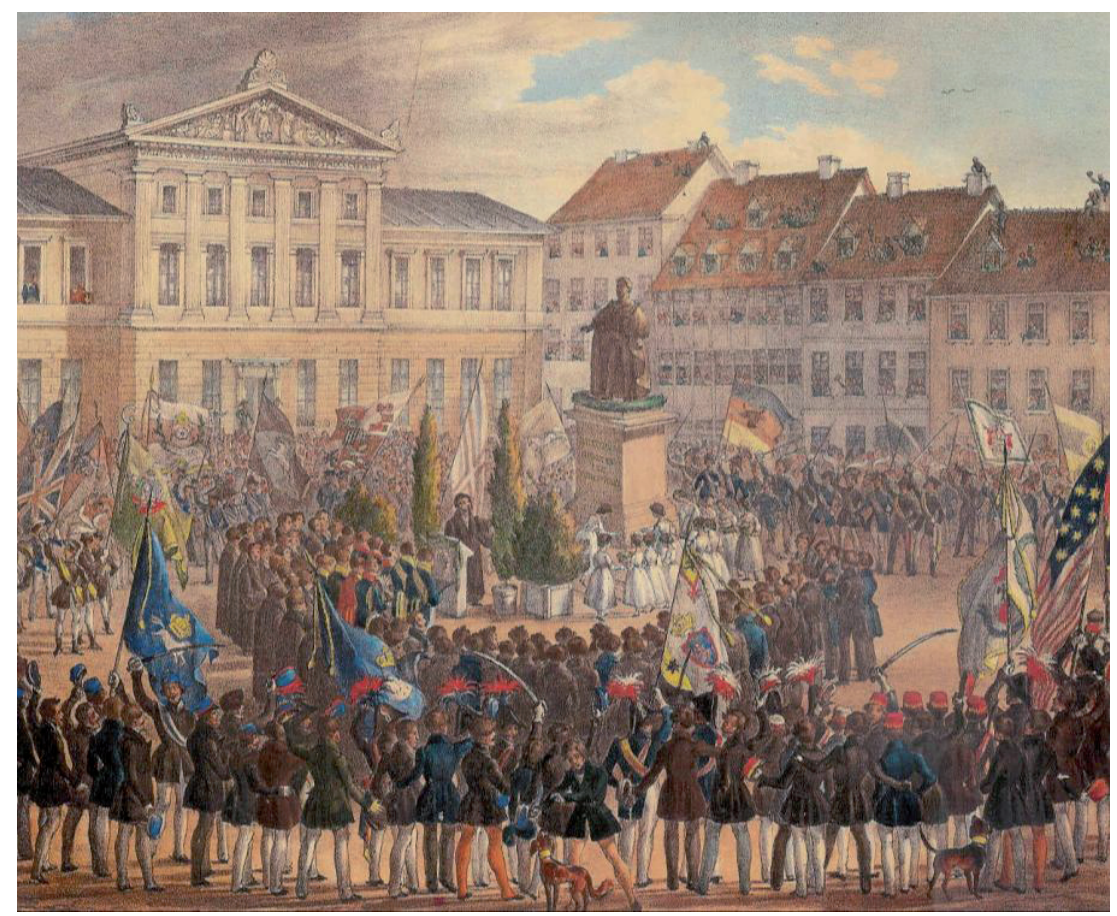

Die Enthüllung des Wilhelmsdenkmals am 17. September 1837, kolorierte Lithographie von C. Rohde und Lange, um 1837

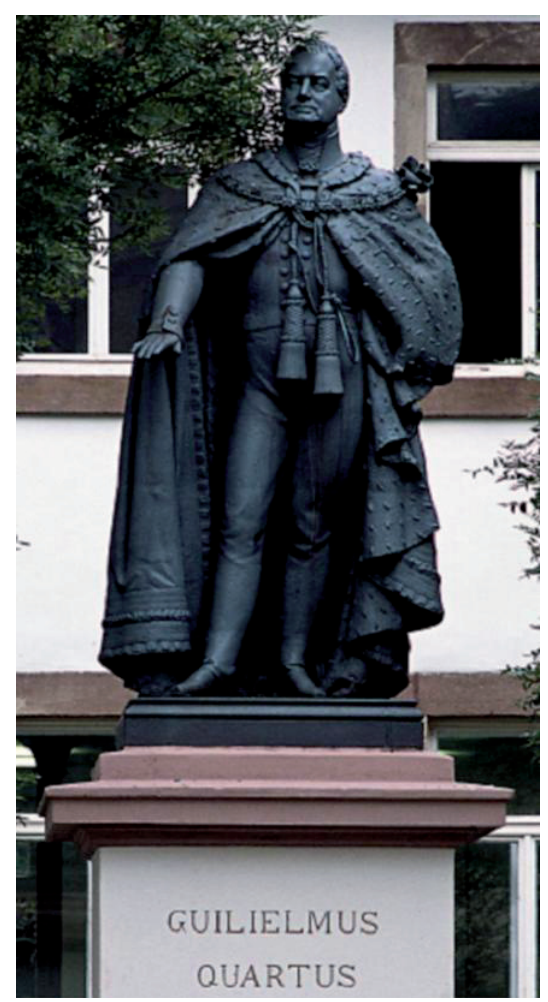

Standbild Wilhelms IV., 2007

nach dem Vorbild von 1901 wiederhergestellt.

\section{Geschichte und Entstehung}

Im Jahr 1837 - dem Jahr des 100jährigen Bestehens der Georg-August-Universität Göttingen - stiftete der damalige Landesherr Wilhelm IV. für 3000 Pfund eine neue Aula für die Universität. Diese wurde am „Neuen Markt“ errichtet. Als Dank für die großzügige Spende des Königs schenkte die Stadt Göttingen der Universität daraufhin ein Standbild Wilhelms IV. zum 100. Geburtstag.

Den Auftrag zur Gestaltung des Denkmals erhielt der Bildhauer Ernst von Bandel (1800-1876), der später auch das Hermannsdenkmal im Teutoburger Wald gestalten sollte. Bandel übernahm auch die Gestaltung des Giebelreliefs der neuen 


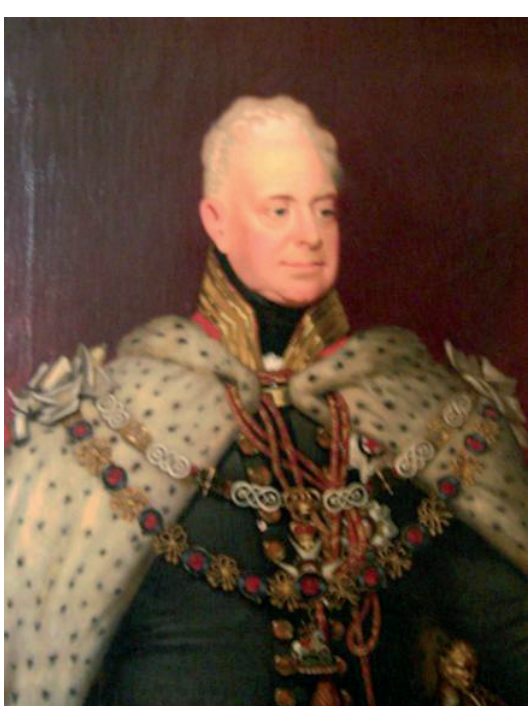

Porträt Wilhelms IV., 19. Jh.

Universitätsaula. Im Rahmen der 100-Jahr-Feier vom 16. bis 18. September wurden Aula und Denkmal eingeweiht und der Neue Markt in Wilhelmsplatz umbenannt.

Wilhelm IV. (1765-1837), König von Großbritannien und Hannover, war der dritte Sohn von König Georg III. Er erbte die Krone von seinem älteren Bruder, König Georg IV., der 1830 kinderlos verstarb. Mit dem Tod von König Wilhelm IV. am 20. Juni 1837 endete die 123jährige Personalunion zwischen Hannover und Großbritannien. In Hannover bestieg nun sein jüngerer Bruder Ernst August I. den Thron, in Großbritannien seine Nichte Victoria.

\section{Internet}

http://www.uni-goettingen.de/de/90607.html.

http://www.stadtarchiv.goettingen.de.

http://www.uni-goettingen.de/de/314257.html.

\section{Didaktische Überlegungen}

Das Denkmal Wilhelms IV. ist Ausdruck zeittypischer Herrscherverehrung. Sie kann hier an einem lokalen Beispiel nachvollziehbar gemacht werden. Die Beschäftigung mit dem Denkmal kann außerdem die Folie für eine Behandlung der Göttinger Sieben bilden, die als landesgeschichtlicher Bezug im Kerncurriculum ausdrücklich angesprochen wird und vor Ort besonders auf der Hand liegt.

\section{Materialseite 1}

Dieses Blatt bietet allgemeine Informationen zum Erscheinungsbild des Denkmals und zu seiner Entstehung. Es sollte als Ergänzung zu den weiteren Materialien genutzt werden.

\section{Materialseite 2}

Auf diesem Blatt wird das Wilhelmsdenkmal als Personendenkmal analysiert. Die Erscheinung und Wirkung der Person soll betrachtet werden und die Schülerinnen und Schüler sollen über die möglichen Gründe zum Aufstellen eines Herrscherdenkmals nachdenken. Beim Bearbeiten dieses Blattes ist auch eine Exkursion sinnvoll, damit die Schülerinnen und Schüler das Denkmal und seine Umgebung authenti-

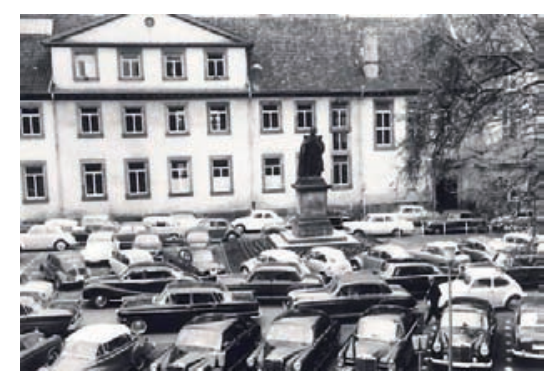

Der Wilhelmsplatz in den 1960 er Jahren

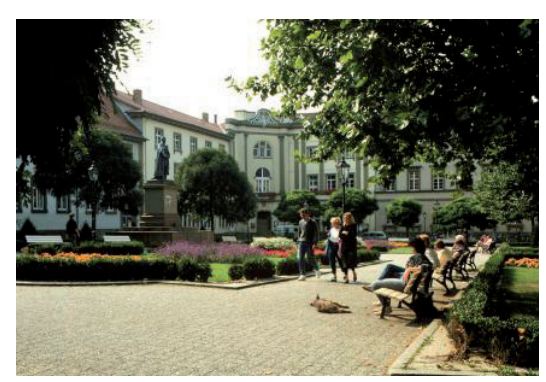

Der Wilhelmsplatz in aktueller Gestaltung

scher wahrnehmen können als auf Fotos. Ergänzt wird die Materialseite um einige weiterführende Rechercheaufgaben zu der Person Wilhelms, der Stadt- und der Universitätsgeschichte.

Eine übersichtliche Chronik zur Geschichte der Universität findet sich auf der Webseite der Universität (http://www.uni-goettingen.de/ de/90607.html), reichhaltige Informationen zur Stadtgeschichte sind auf der Webseite des Stadtarchivs zu finden (http://www.stadtarchiv. goettingen.de 


\section{Basisinformationen zum Denkmal Wilhelms IV.}

\section{M1 Steckbrief}

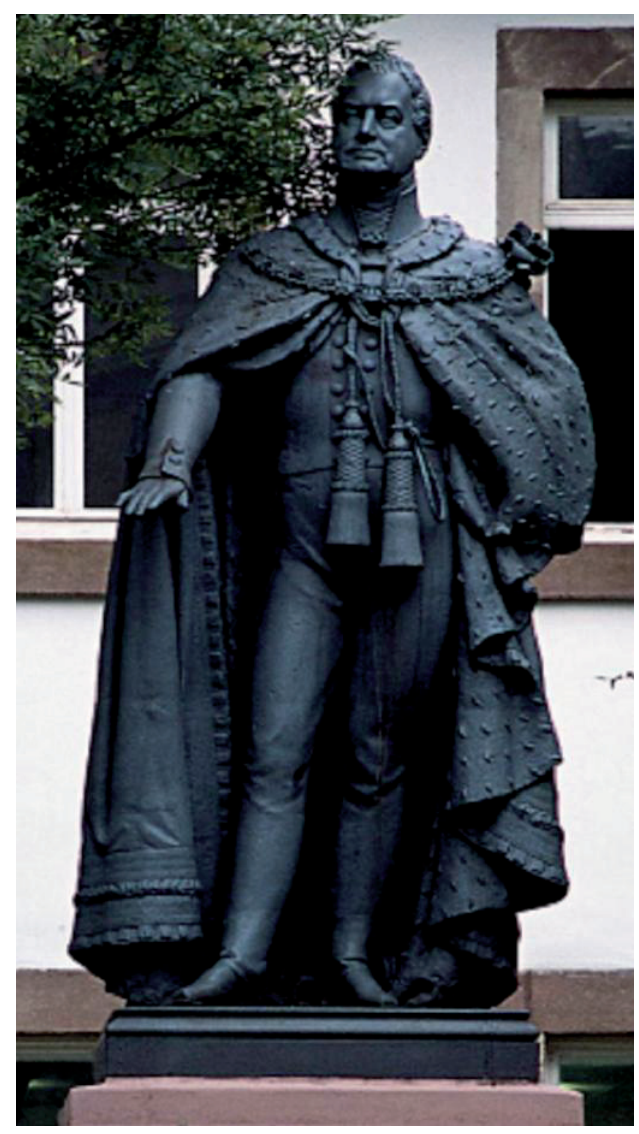

Größe:

ca. $3 \mathrm{~m}$ und Sockel

Material:

Bronze

Standort: Wilhelmsplatz

Erbauer: $\quad$ Ernst von Bandel

Einweibung: 16.-18. September 1837

Anlass: $\quad$ Geschenk der Stadt Göttingen an die Universität zur Feier des 100-jährigen Bestehens

Inschriften: Im Sockel:

„Guilielmus / Quartus / Rex / Pater Patriae“ (Wilhelm / IV. / König / Vater des Vaterlands)

Auf der Bronzetafel:

„Wilhelm IV. / König von / Großbritannien / Irland u. Hannover / 1830-1837“

Standbild Wilhelms IV., 2007

\section{M2 Wichtige Daten zur Geschichte der Universität}

1734/37: Die Universität Göttingen wird gegründet auf Veranlassung des Landesherren Kurfürst Georg August von Hannover, der als Georg II. zugleich König von Großbritannien ist. Die Universität nimmt 1734 den Lehrbetrieb auf und wird 1737 offiziell eingeweiht.

1837: Wilhelm IV. schenkt der Universität zum 100-jährigen Bestehen die Universitätsaula, woraufhin die Stadt ein Ehrenmal für ihn stiftet. Aula und Denkmal werden vom 16. bis 18. September 1837 eingeweiht. Mit dem Tod Wilhelms IV. endet die Personalunion zwischen Hannover und England. Am 1. November hebt König Ernst August von Hannover, der die Nachfolge seines verstorbenen Bruders angetreten hat, die Verfassung des Königreichs auf. Die „Göttinger Sieben“, sieben Professoren der Universität, protestieren gegen dieses Vorgehen und werden daraufhin entlassen und teilweise des Landes verwiesen. 


\section{Das Denkmal Wilhelms IV. - ein Personendenkmal}

\section{M3 Das Wilhelmsdenkmal von vorne}

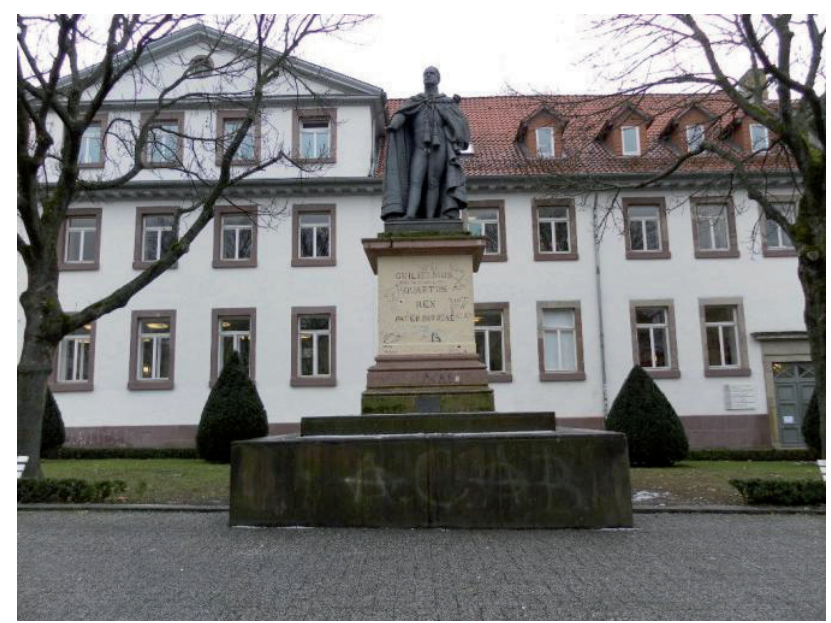

Wilhelmsdenkmal, 2011

\section{M4 Blick auf die Universitätsaula}

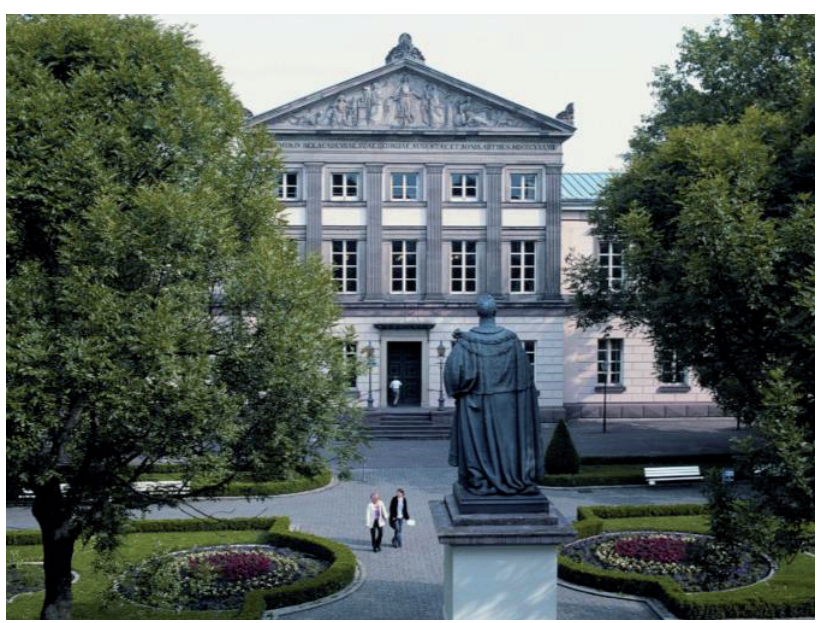

Wilhelmsdenkmal und Universitätsaula, 2007

\section{M5 Die Enthüllung des Wilhelmsdenkmals 1837}

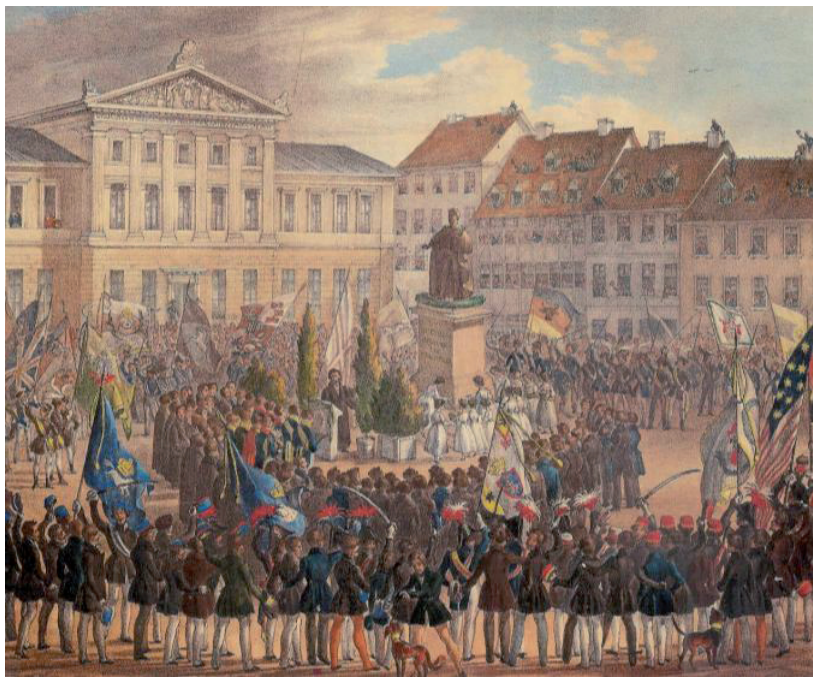

Kolorierte Lithographie von C. Rohde und Lange, um 1837

\section{Arbeitsaufträge}

1. Beschreibt das Aussehen des Standbilds.

2. Nennt einzelne Details, die Wilhelm ein königliches Aussehen verleihen sollen.

3. Vergleicht das Denkmal mit anderen Herrscherbildern, die ihr im Geschichtsunterricht kennen gelernt habt.

4. Das Denkmal war ein Geschenk der Stadt Göttingen an die Universität. Überlegt euch Gründe, warum eine Stadt ein Standbild des Herrschers anfertigen lässt.

\section{Arbeitsaufträge}

Der Wilhelmsplatz mit dem Wilhelmsdenkmal ist ein wichtiger Ort für die Geschichte der Stadt. Informiert euch über die Geschichte der Stadt und die Bedeutung der Universität für ihre Entwicklung.

Einige Leitfragen für eure Recherche können sein:

- Wer war Wilhelm IV. und in welchem Zusammenhang steht er zur Stadt Göttingen?

- Was war die Personalunion zwischen den Königreichen Hannover und Großbritannien?

- Wer waren die „Göttinger Sieben“ und was hat sie so berühmt gemacht? 


\title{
Die Germania in Geismar
}

\author{
Franziska Frome-Ziegler, Daniela Kempe, Theresa Nawroth
}

Germania-Darstellungen, vor allem Denkmäler, waren in der Kaiserzeit ein weit verbreitetes Symbol für die Deutsche Reichsgründung. Das Germania-Denkmal in Geismar wurde 1895 auf Anregung der Gemeinde Geismar errichtet und erinnert an die Soldaten des Dorfes, die im Deutschen Krieg 1866 (für das Königreich Hannover) und im Deutsch-Französischen Krieg 1870/71 kämpften. Die Schülerinnen und Schüler lernen bei der Beschäftigung mit dem Denkmal die Germania als Symbolgestalt kennen und vergleichen ibre Repräsentation in Geismar exemplarisch mit der des Niederwalddenkmals. Sie erkennen die enge Verknüpfung von Gedenken und Gemeinschaftsgefübl in einem Dorf Ende des 19. Jabrhunderts. Das Denkmal lässt sich im Rahmen des im 19. Jahrhundert aufkommenden Nationalbewusstseins und der deutschen Reichsgründung in den Unterricht einbetten und stellt einen regionalen Bezug her.

\section{Erscheinungsbild}

Bei der Germania in Geismar handelt es sich um ein insgesamt 3,90 m hohes Personendenkmal. Eine 1,60 $\mathrm{m}$ große Frauenfigur sitzt auf einem $2 \mathrm{~m}$ hohen Sandsteinsockel, der auf zwei insgesamt $30 \mathrm{~cm}$ hohen Betonstufen ruht. Sie trägt ein Kettenhemd und darüber ein bodenlanges weites Gewand. In der rechten Hand hält sie eine Lanze. An ihrer rechten Seite lehnt ein Schild, auf dem der Reichsadler abgebildet ist und dessen Riemen um das Knie gelegt ist. Auf ihrem rechten Knie liegt ein Helm, den sie mit ihrer linken Hand festhält. Ihr linkes Bein steht leicht erhöht. Auf ihrem Kopf trägt sie eine Krone. Der Blick der Frau ist aufrecht und in die Ferne gerichtet. Die Frauenstatue ist aus Gusseisen und war bei ihrer Errichtung 1895 mit Bronze überzogen.

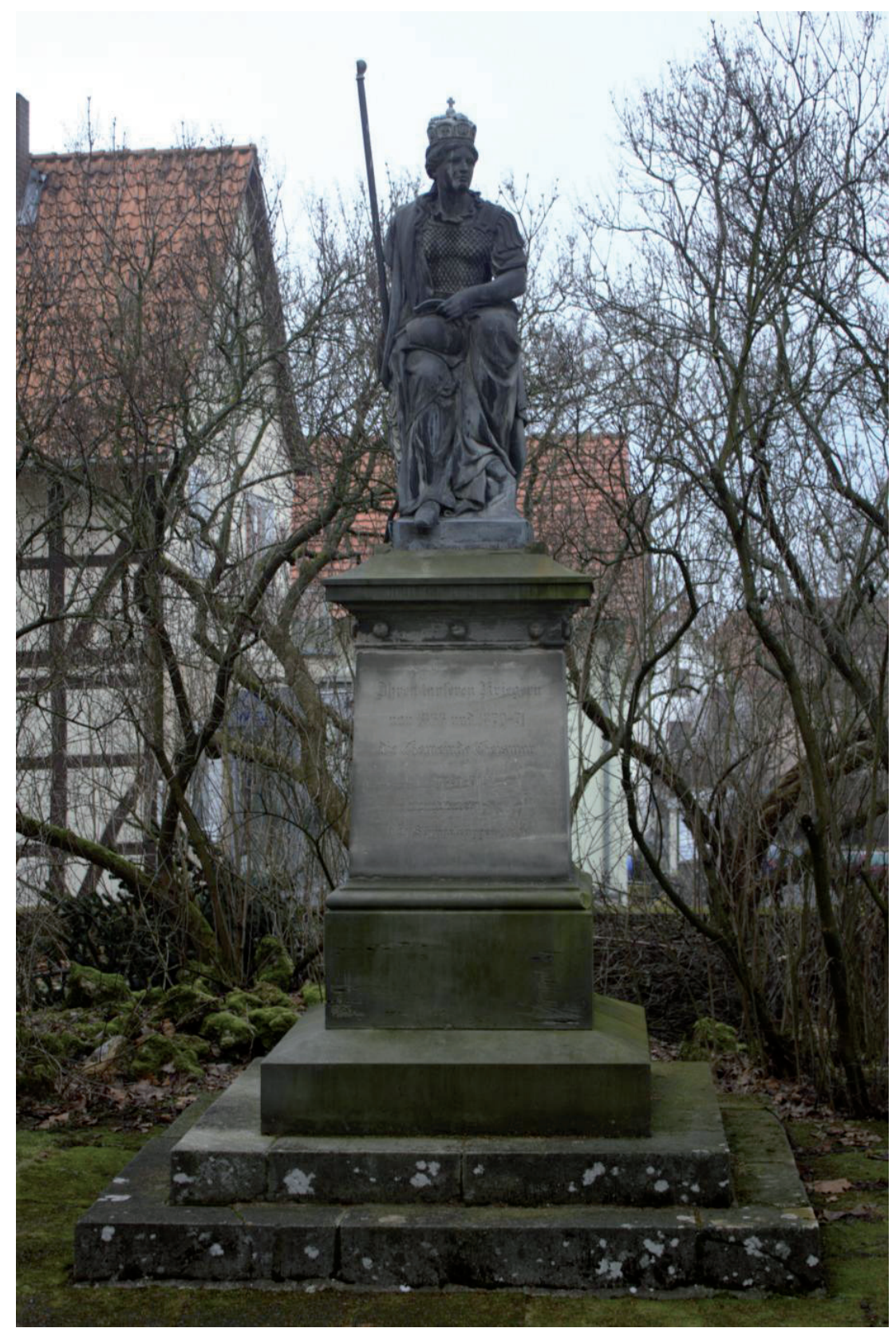

Germania in Geismar, 2011

Die Inschrift lautet: „Ihren tapferen Kriegern / von 1866 und 1870-71 / die Gemeinde Geismar. / 1870-71 / † E. Albrecht A.R. $10 /$ † H. Semmelroggen I.R. 56“. Auf den drei übrigen Seiten des Sockels befinden sich die Namen der an den beiden Kriegen beteiligten Geismarer Sol- daten. Die zentrale Inschrift war ursprünglich vergoldet.

\section{Entstehung und Intention}

Im Protokoll der Gemeindeversammlung Geismar vom 13. Januar 1895 wurde die Errichtung eines 


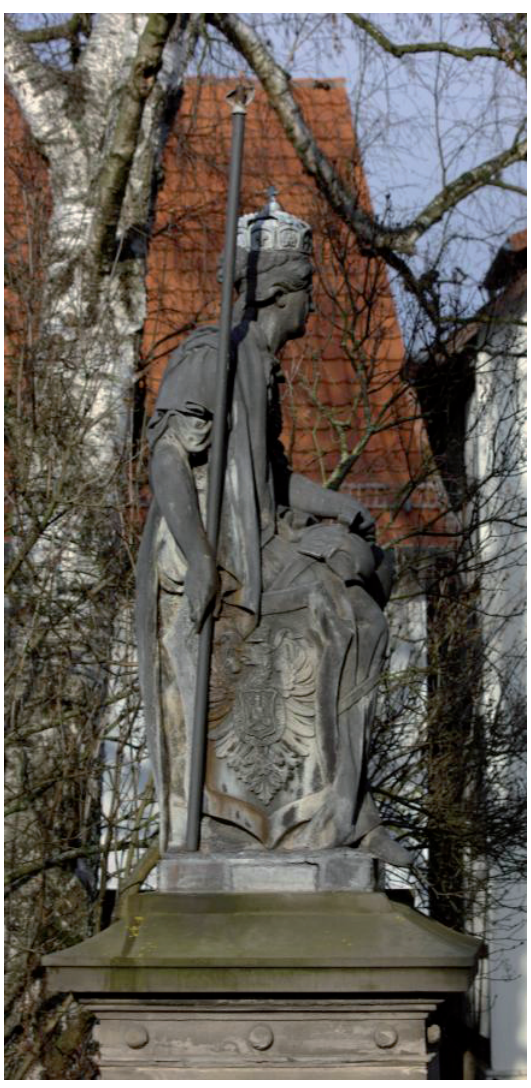

Germania in Geismar, 2011

Denkmals anlässlich des 25-jährigen Jubiläums des Krieges 1870/71 beschlossen. In einem „Verzeichnis der freiwilligen Geber und Gaben zur Errichtung unseres Denkmals für die im Kriege 1870/71 Gefallenen, und diejenigen welche in den Kriegen 1866 und 1870/71 mitgefochten haben" werden die Spender aufgeführt. 166 Einträge, die sich im Wert von wenigen Pfennigen bis hin zu 50 Mark bewegen, sind aufgelistet. Diese finanzielle Unterstützung zeigt, dass die Mitglieder der Gemeinde sehr an der Errichtung des Denkmals interessiert waren. Das Denkmal wurde in einer feierlichen Zeremonie am 16. Juni 1895 enthüllt und mit einer Rede des örtlichen Pastors eingeweiht. Die Feierlichkeiten gingen in das alljährliche Volksfest über, das eng mit der Denkmalsaufstellung verknüpft war. Beide Göttinger Zeitungen, das Göttinger Tageblatt und der Göttinger Anzeiger, berichteten zusammenhängend über die Ereignisse. Sowohl der Steinhauermeister Koch als auch der Maurer Ferdinand Jungehrens, der für die Aufstellung des Denkmals verantwortlich war, wurden teilweise aus Überschüssen des Volksfestes bezahlt.

\section{Germania-Motiv}

Bereits in der Antike stellten die Römer die germanischen Stämme durch eine Frauengestalt dar (in Literatur und Ikonographie, wie z. B. auf Münzen). In der ersten Hälfte des 19. Jahrhunderts gewann der deutsche Nationalismus vermehrt an Bedeutung und die Forderung wurde lauter, das in Kleinstaaten aufgeteilte Deutschland zu vereinigen. Die Germania verkörperte den zu schaffenden Nationalstaat. Diese Darstellung der Nation gewann durch die Ereignisse der Jahre 1870 und 1871 noch mehr an Verbreitung. Das Germania-Motiv fand vielfach Verwendung: bei Siegesund Kriegerdenkmälern, auf Briefmarken, auf Gemälden und in der Poesie. Die Germania verkörperte das Bild einer Kriegerin gegen den „Erzfeind“ Frankreich. Sie trägt zumeist Panzer oder Kettenhemd, Helm und Wehrgürtel, häufig auch Schwert und Schild. Gekrönt ist sie mit der Kaiserkrone oder einem Eichenkranz (als Krone der bürgerlichen Reichsgründer).

Die meisten Denkmäler des 19. Jahrhunderts zeigen die Germania als strahlende Siegerin. Nur in wenigen Denkmälern wird die Germania als Kranzspenderin, die den im Denkmal erinnerten Gefallenen den Siegeslorbeer reicht, oder als um die Gefallenen Trauernde dargestellt z. B. die trauernde Germania auf dem Friedhof von Kissingen (1868).

\section{Besonderheiten des Denkmals}

Eine Besonderheit des GermaniaDenkmals in Geismar ist die Ambivalenz von Symbolik und Aussage. Die Germania ist Zeichen der deutschen Einigung und Einheit. Das Denkmal erinnert aber zugleich an eine deutsch-deutsche Auseinander-

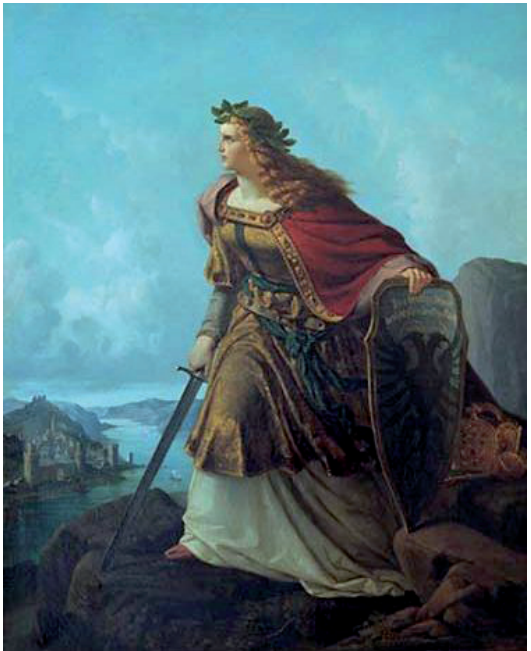

Lorenz Clasen, Germania auf der „W acht am Rhein", Öl auf Leinwand, 1860

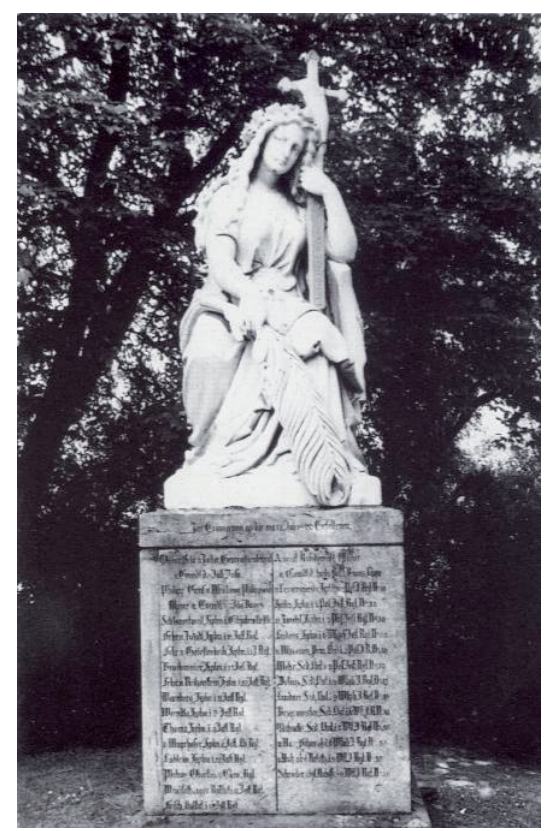

Michael Arnold, Trauernde Germania auf dem Friedhof von Kissingen, 1868

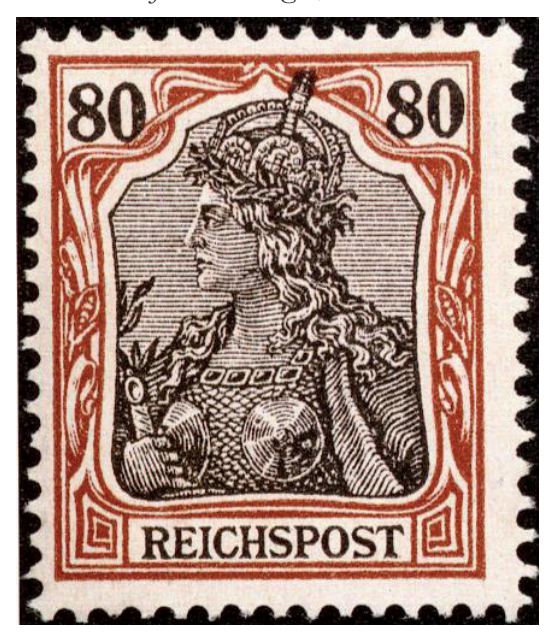

Germania-Briefmarke, 1900 
setzung. Im Unterschied zu anderen Germania-Denkmälern (z. B. dem Niederwalddenkmal) wird nicht die siegreiche, sondern die um die Gefallenen trauernde Germania dargestellt. Die Geismarer Germania symbolisiert einerseits die Trauer um die Opfer, sowohl des nationalen „Bruderkrieges" als auch des Krieges gegen den „Erbfeind“ Frankreich. Andererseits steht sie aber auch allegorisch für die Idee der Versöhnung der Einzelstaaten im Sinne einer nationalen Einheit. Diese Spannung scheint von Zeitgenossen nicht als Diskrepanz wahrgenommen worden zu sein.

\section{Geschichte und Rezeption}

Das Denkmal wurde in den folgenden Jahren zum zentralen Platz des Gedenkens an die Kriegsopfer. Insbesondere von lokalen Kriegerverbänden wurde es als Erinnerungs-, aber auch als Kundgebungsort ge-

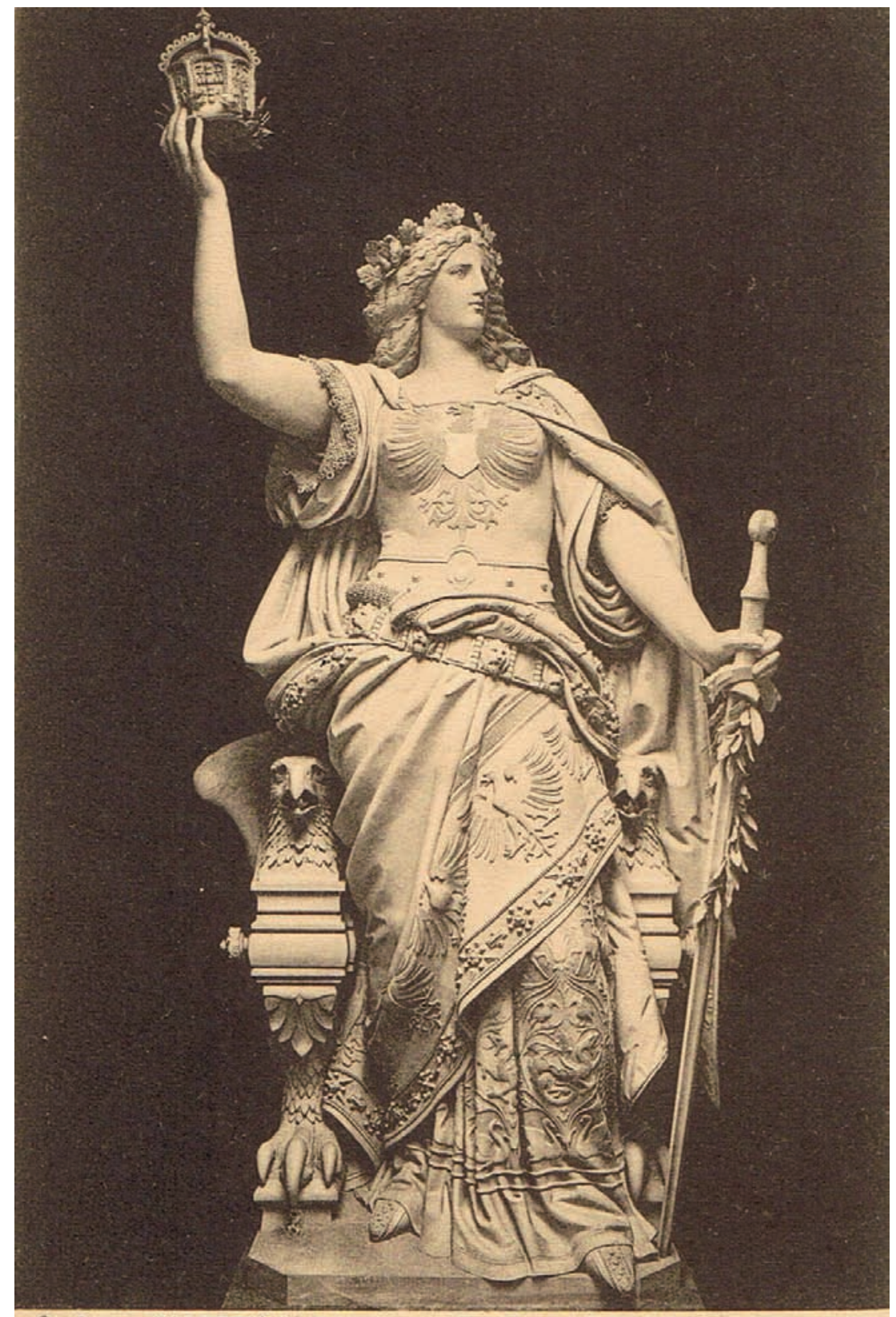

GruB vom NIEDERWALD
Germania auf dem Nationaldenkma

Germania auf dem Niederwalddenkmal, Ansichtskarte um 1920

nutzt - in Verbindung mit dem zu Anfang des 20. Jahrhunderts entstandenen Ehrenmal für die Geismarer Gefallenen des Ersten Weltkrieges gleich gegenüber.

Im Jahr 2000 wurde die gusseiserne Germania-Figur von der Stadt Göttingen restauriert. Für diesen Zweck wurde die Statue abmontiert und nach Vollendung der Restaurationsarbeiten wieder aufgestellt.

\section{Quellenlage}

Sowohl die Planung als auch die Errichtung der Geismarer GermaniaStatue sind schlecht dokumentiert und wenig erforscht. In der Ortsgeschichte der Gemeinde spielt das Denkmal für die Opfer des Ersten Weltkriegs eine größere Rolle, das ebenfalls auf dem Boden der Martini-Kirche steht. Abgesehen von der feierlichen Enthüllung 1895 ist in den Akten der Stadt und historischen Abhandlungen wenig über die Geismarer Germania aufzufinden.

\section{Das Niederwalddenkmal zum Vergleich}

Beim Niederwalddenkmal handelt es sich um eine typische GermaniaDarstellung. Das Denkmal prägte das Bild der Germania im Kaiserreich am nachhaltigsten, da es auf zahlreichen Briefmarken und Postkarten abgebildet wurde.

Das ca. $38 \mathrm{~m}$ hohe Niederwalddenkmal mit seiner 12,5 m hohen Germania-Figur steht auf einem Berg oberhalb von Rüdesheim am Rhein. 1871 wurde ein Wettbewerb um die Gestaltung des Denkmals ausgeschrieben und 1877 der Grundstein durch Kaiser Wilhelm I. gelegt. Nach sechs Jahren Bauzeit fand am 18. September 1883 die Einweihung statt. Insgesamt betrugen die Kosten über eine Million Goldmark. Mit dem Denkmal sollte an den Sieg über Frankreich im Jahr 1870/71 erinnert werden, aber vor allem an die Gründung des Deutschen Kaiserreiches und die Kaiserkrönung in Versailles. 
Die Germania des Niederwalddenkmals hält in der rechten Hand die Kaiserkrone hoch. Mit der linken Hand stützt sie sich auf das $7 \mathrm{~m}$ lange Reichsschwert; das Schwert ist gesenkt und symbolisiert somit das Ende des Krieges. Die Germania ist mit einem Eichenkranz als Ruhmessymbol und mit Siegeszeichen gekrönt und steht vor einem mit Adlerköpfen verzierten Thron. Sie trägt einen Brustpanzer mit aufgeprägtem Reichsadler sowie ein Brokatgewand. Auf ihm kann man Tiermotive der deutschen Sagenwelt erkennen (wie zum Beispiel den Drachen der Nibelungen). Die Germania schaut weit über das vereinigte Deutschland in Richtung Osten. Ihr Blick ist nicht, wie oftmals irrtümlich angenommen wurde, als ,Wacht am Rhein" provozierend nach Westen gegen Frankreich gerichtet.

Der Sockel unter der Germania enthält die Inschrift: „Zum Andenken an die einmütige und siegreiche Erhebung des deutschen Volkes und die Wiederaufrichtung des Deutschen Reiches 1870/71“. Auf dem Germania-Sockel befindet sich ein Fries mit dem Reichsadler und den Wappen der 25 im Kaiserreich vereinten deutschen Bundesstaaten. Das größte Relief zeigt Kaiser Wilhelm I. hoch zu Ross inmitten von Landesfürsten, Heeresführern und Soldaten.

\section{Didaktische Überlegungen}

Das Geismarer Germania-Denkmal lässt sich im Rahmen des Themas „Kaiserreich, Imperialismus und Erster Weltkrieg“" behandeln. Im Niedersächsischen Kerncurriculum für das Gymnasium wird ausdrücklich ein regionalgeschichtlicher Bezug am Beispiel von Denkmälern der Kaiserzeit vorgeschlagen.

Die vorliegenden Materialien und Arbeitsaufträge richten sich an eine 9. Klasse und sind für mindestens zwei Unterrichtsstunden angelegt. Eine Exkursion zum Denkmal in Geismar wird nicht als unbedingt notwendig erachtet, ließe sich aber

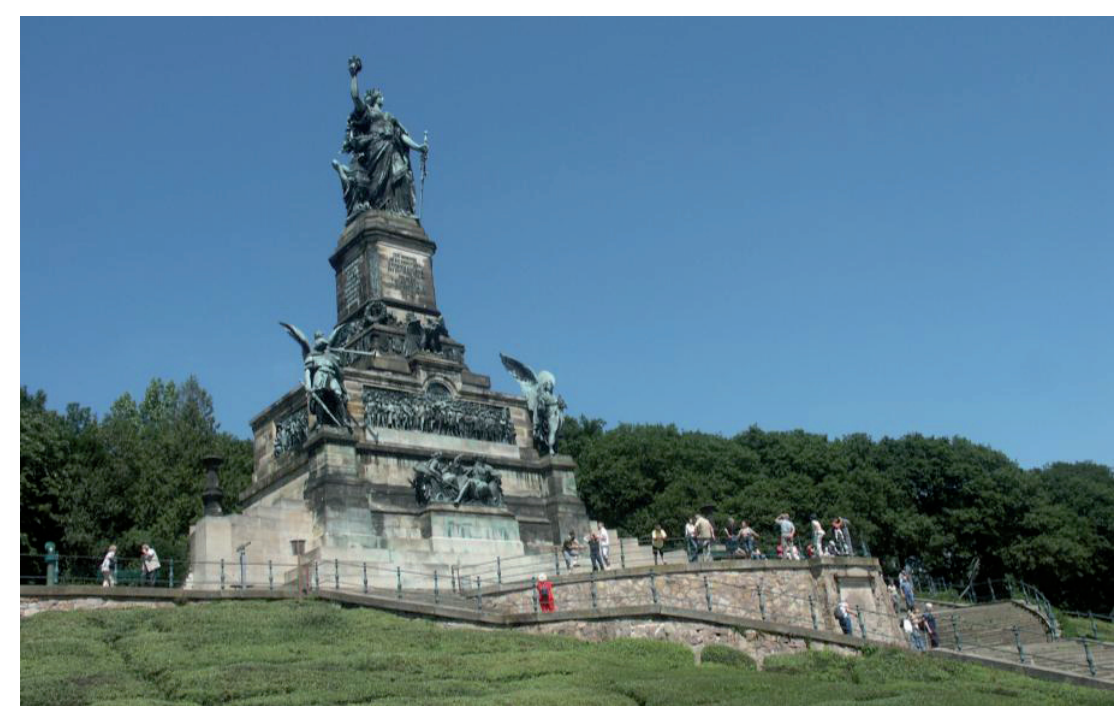

Niederwalddenkmal bei Rüdesheim, 2007

in das Unterrichtskonzept integrieren.

\section{Intentionen}

Die Schülerinnen und Schüler lernen die Germania als deutsche Symbolfigur kennen. Sie unterscheiden Denkmäler von regionaler und nationaler Reichweite sowie deren Bedeutungen für Denkmalsstifter. Der Vergleich zwischen der Geismarer Germania und dem Niederwalddenkmal schult die Fähigkeit zur Analyse von Kunstwerk und Symbolgehalt.

\section{Materialseite 1-3}

Die Schülerinnen und Schüler erhalten Basisinformationen zur Germania als Symbolfigur und einen Überblick über die Geschichte des Denkmals in Geismar. Sie stellen erste Bezüge zwischen dem GermaniaKult und der Regionalgeschichte her. Die Schülerinnen und Schüler erarbeiten die Symbolik der Germania-Darstellungen und ziehen Vergleiche zwischen dem Geismarer Denkmal und der Germania des Niederwalddenkmals. Sie erkennen, dass die Darstellungsformen unterschiedlich sind und Geismar zu den weniger typischen Vertretern des Germania-Bildes gehört. Sie sollen die Germania als Zeichen der Grün- dung des Deutschen Reiches erkennen und mit den im Vorunterricht erarbeiteten Informationen zum Deutsch-Deutschen Krieg (1866) und Deutsch-Französischen Krieg $(1870 / 71)$ in Verbindung setzen. Im Rahmen einer Internetrecherche suchen die Schülerinnen und Schüler zielgerichtet Informationen aus dem Internet und geben diese wieder. Sie lernen Denkmäler als Ausdruck einer bestimmten Erinnerungskultur zu interpretieren und die jeweiligen politischen Implikationen zu reflektieren.

\section{Materialseite 4}

Die Schülerinnen und Schüler setzen sich mit der Denkmalsstiftung und deren Bedeutung für die Menschen der Entstehungszeit auseinander. So sollen sie erkennen, dass es der Gemeinde Geismar ein Anliegen war, ihren Kriegern ein Denkmal zu setzen. Sie fassen den Inhalt von Quellen mit eigenen Worten zusammen und beschreiben die Argumentationsstruktur. Sie lernen historische Handlungen, Ereignisse und Prozesse im Hinblick auf Anlässe, Ursachen, Motive und Folgen $\mathrm{zu}$ untersuchen und zu beurteilen. 


\section{Literatur}

Brandt, Bettina, Germania und ihre Söhne. Repräsentationen von Nation, Geschlecht und Politik in der Moderne, Göttingen 2010 (Historische Semantik, Bd. 10).

Bruchhausen, Esther-Beatrice Christiane von, Das Zeichen im Kostümball. Marianne und Germania in der politischen Ikonographie. Phil. Diss., Halle-Wittenberg 1999. Im Internet unter: http://sundoc.bibliothek.uni-halle.de/diss-online/ 00/01H066/prom.pdf (eingesehen am 22.1.2011).

Dawe, Ewald, Geismar. Platz der sprudelnden Quellen, Göttingen 1987.

Gall, Lothar, Die Germania als Symbol nationaler Identität im 19. und 20. Jahrhundert, Göttingen 1993 (Nachrichten der Akademie der Wissenschaften in Göttingen, Philologisch-Historische Klasse, Nr. 2).

Land Hessen, Verwaltung der Staatlichen Schlösser und Gärten (Hrsg.), Das Niederwalddenkmal bei Rüdesheim. Spaziergänge durch Schlösser und Gärten. Kulturerbe Hessen, Frankfurt am Main 2008.

\section{Unveröffentlichte Quellen}

Verzeichnis der freiwilligen Geber und Gaben zur Errichtung unseres Denkmals für im Kriege 1870/71 gefallenen, und diejenigen welche in den Kriegen 1866 und 1870/71 mitgefochten haben (Stadtarchiv Göttingen).

Gemeinderatsprotokoll, Geismar, 1895 (Stadtarchiv Göttingen).

Kostenaufstellung des Volksfestes Geismar 1895 (Stadtarchiv Göttingen).

\section{Veröffentlichte Quellen}

Einweihung des Kriegerdenkmals, Göttinger Tageblatt, 16.6.1895.

Die Enthüllung des neuen Kriegerdenkmals ..., Göttinger Tageblatt, 18.6.1895.

Gestern und heute beging der hiesige Krieger-Verein ..., Göttinger Tageblatt, 11.7.1900.

\section{Internetseite zum Niederwalddenkmal}

http://www.deutsche-schutzgebiete.de/niederwalddenkmal.htm (eingesehen am 11.2.2011). 


\section{Basisinformationen zur Germania}

\section{M1 Hintergrundinformationen zum Germania-Motiv}

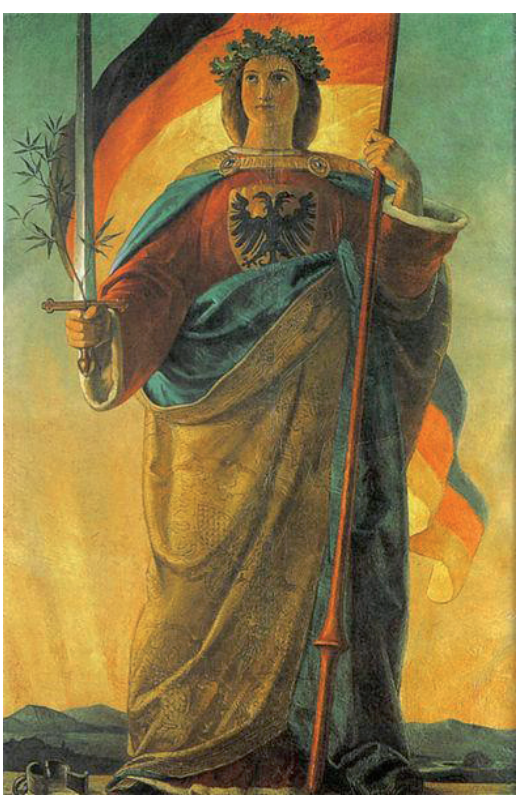

Die deutsche Nation wird seit dem 19. Jahrhundert oft durch die Frauengestalt „Germania“ verkörpert. Diese gilt als ein Gründungssymbol des 1871 entstandenen Nationalstaates. Sie erscheint während der Deutschen Kaiserzeit in Sieges- und Kriegerdenkmälern, in Gemälden und in der Literatur. Die Germania wird oft als siegreiche Kriegerin mit Waffen und Reichsinsignien dargestellt. Nur in wenigen Darstellungen trauert sie um die Gefallenen.

Philipp Veit, Germania, Gemälde von 1848

\section{M2 Zeitstrahl}

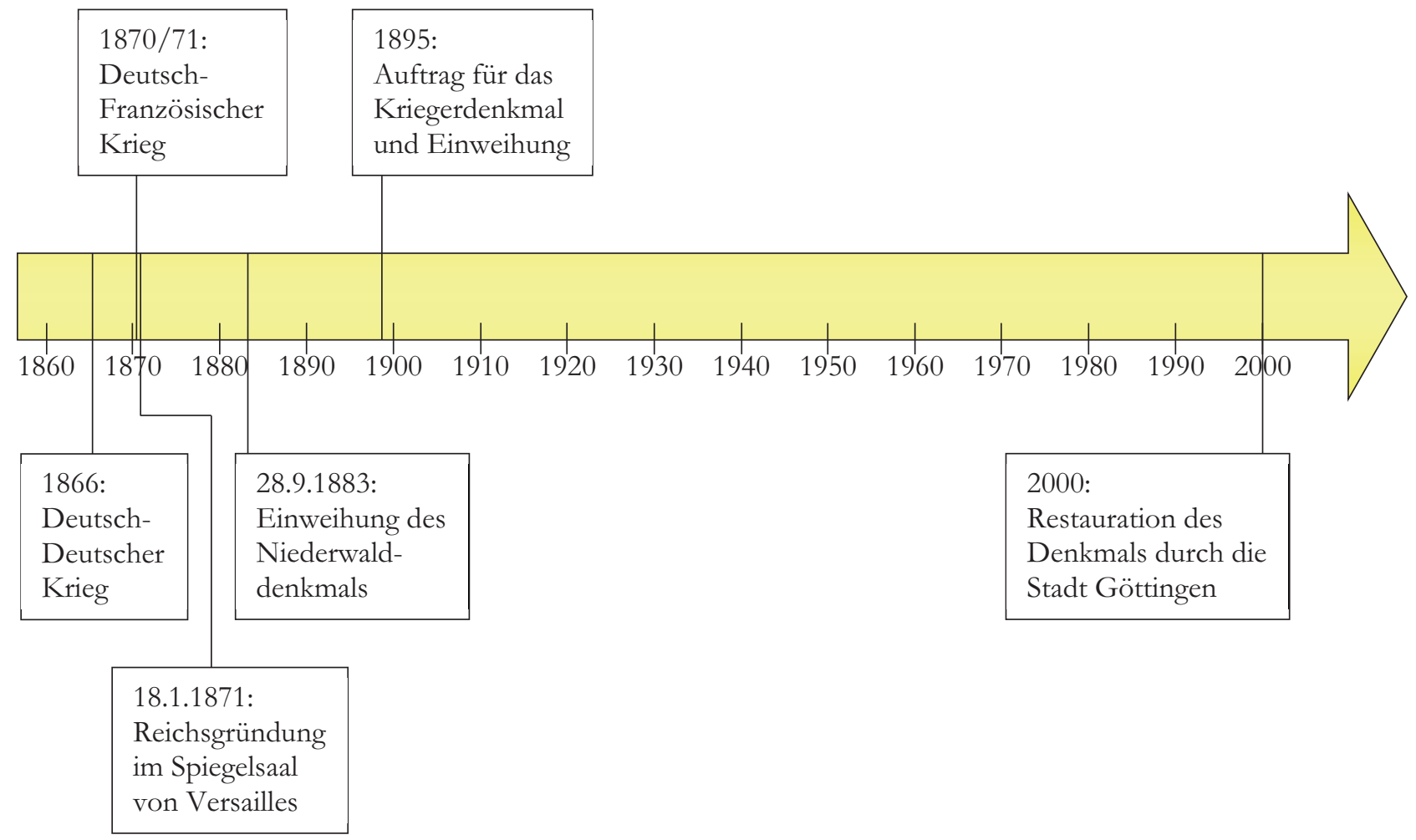




\section{Germania im Vergleich}

M3 Steckbrief Germania in Geismar

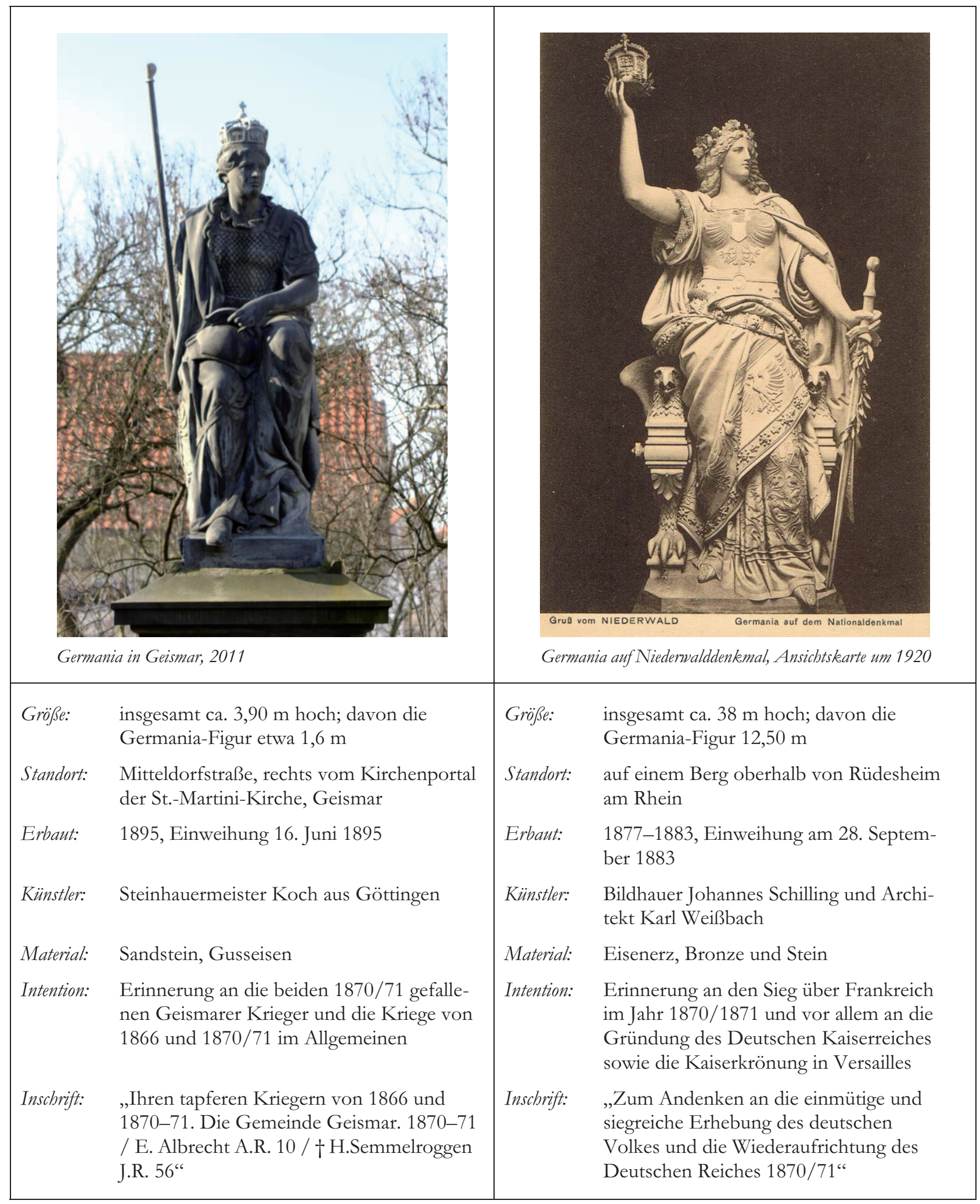

\section{M4 Steckbrief Germania Niederwalddenkmal}




\section{M5 Geismarer Germania (Detailansicht)}

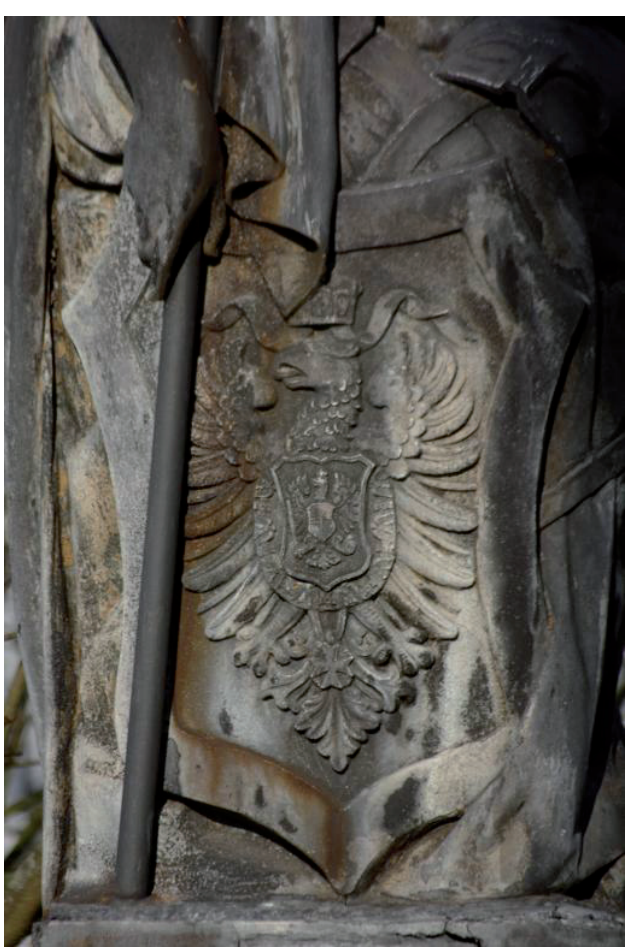

Schild der Germania in Geismar, 2011

\section{M6 Geismarer Germania (Gesamtansicht)}

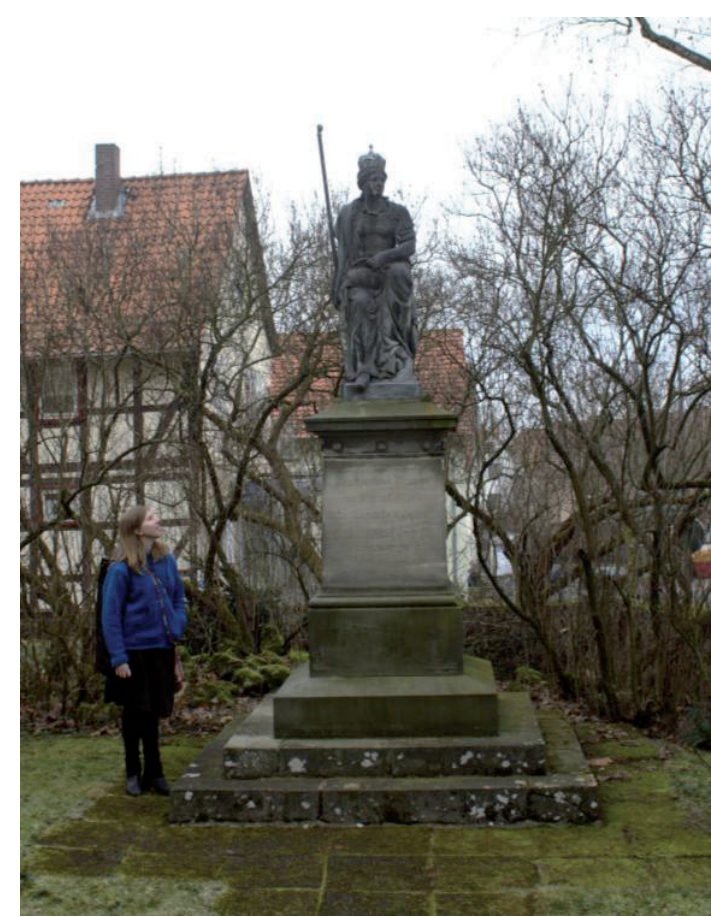

Germania in Geismar, 2011

\section{Arbeitsaufträge}

1. Beschreibe die beiden Germania-Figuren (M3-M7)

2. Analysiere die in den Denkmälern verwendeten Symbole unter Berücksichtigung der Informationen aus M1.

3. Vergleiche die beiden Germania-Darstellungen und ihre Aussageabsichten. Beziehe auch mit ein, für wen das Denkmal errichtet wurde und welche Zielsetzungen hinter der Errichtung stecken.

4. Recherchiere im Internet oder in der Bibliothek nach weiteren Germania-Darstellungen aus der deutschen Kaiserzeit. Zeige Gemeinsamkeiten und Unterschiede zwischen der Niederwälder und der Geismarer Germania auf.

\section{M7 Niederwalddenkmal (Gesamtansicht)}

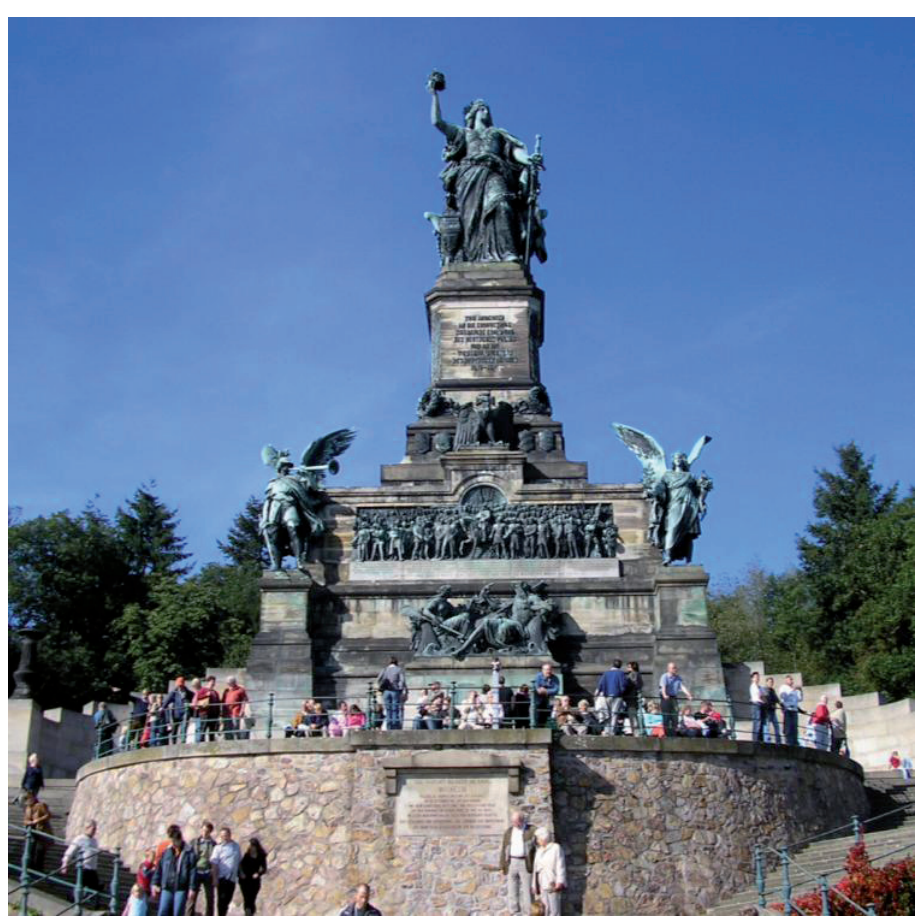

Germania auf dem Niederwalddenkmal, 2006 


\section{Einweihung der Geismarer Germania}

\section{M8 Volksfest zur Einweihung}

Im Göttinger Tageblatt vom 16.6.1895 erscheint folgende Anreige:

\section{Geisrax

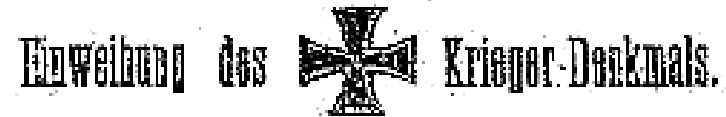

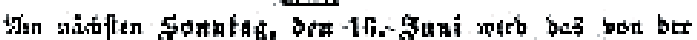

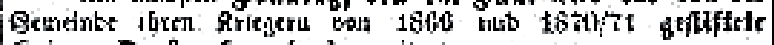

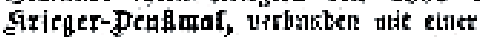

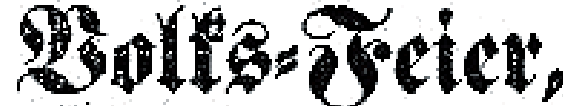

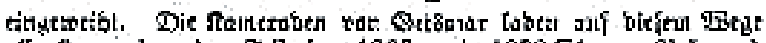

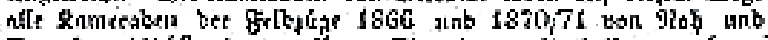

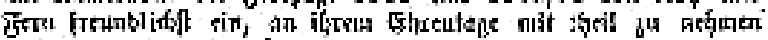

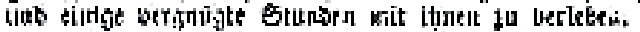

Dit etwaeifatur fubc:

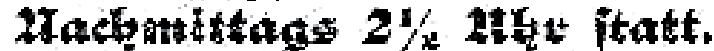

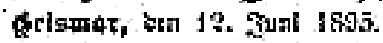
Dle Hamifaden von coispar.

\section{Gevismar.}

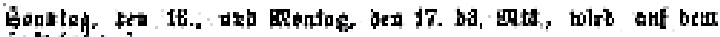
Rakightolyt sis

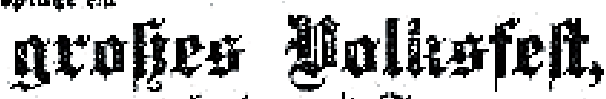

twethathen mit son;

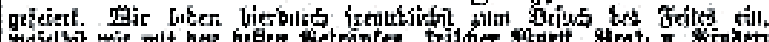

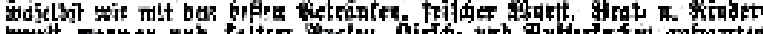

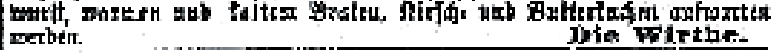

(Göttinger Tageblatt, 16.6.1895)

\section{M9 Einweihungsfeierlichkeiten}

Dieser Bericht über die Einweibungsfeierlichkeiten der Germania ist am 18.6.1895 im Göttinger Tageblatt zu lesen:

Geismar, 16. Juni. Die Enthüllung des neuen Kriegerdenkmals fand gestern in sehr feierlicher und würdiger Weise statt. Unser Ort hatte reichen Flaggenschmuck angelegt und Kränze aus Eichen und Tannengrün 5 überspannten die Straßen. Kurz von 21/2 Uhr setzte sich unter den Klängen eines flotten Marsches ein stattlicher Festzug in Bewegung, voran die Schulkinder mit kleinen bunten Fahnen. Es folgten die jungen Mädchen Geismars, denen sich schließlich die Männer anschlos10 sen: Der Kriegerverein unter Gewehr, der Schützenverein, die freiwillige Feuerwehr und der Gesangverein. Der stattliche Zug defilirte') auch an der Wohnung des Schützenkönigs Herrn Gastwirth August Kerl vorüber, um demselben ein Hoch zu bringen und ihn abzuho15 len. Bei der Kirche angelangt, nahmen die Festtheilnehmer um das rechts vom Kircheneingange stehende verhüllte Denkmal herum Aufstellung, worauf nach einem gemeinsamen gesungenen Choral Herr Pastor Hinrichs die Weiherede hielt. Er gedachte in ernsten 20 Worten der großen Zeit vor 25 Jahren und führte aus, wie das Denkmal zum Denken an die mit Gotteshilfe errungenen herrliche Siege mahne, aber auch ein Dank sein solle den tapferen Kämpfern, die ihr Leben für das Vaterland gelassen, ein Dank dem treuen Gott, der 25 zum Siege geführt. Als nunmehr die Hülle des Denkmals fiel, entblößten sich aller Häupter, erklang eine ernste Weise und wurden die Gewehre präsentiert. Zu Füßen des Denkmals wurden zwei Lorbeerkränze niedergelegt. Das Denkmal stellt eine Germania aus bron30 ciertem Gußeisen in sitzender Stellung auf einem schlanken, hohen Sandsteinpostament dar und macht einen hübschen Eindruck. Auf der Vorderseite leuchten in Goldbuchstaben die Namen der beiden 1870/71 gefallenen Krieger aus Geismar, auf den übrigen Seiten 35 die Namen der Geismar'schen Krieger, welche überhaupt die Feldzüge 1866 und 1870/71 mitgemacht haben. Der Festzug begab sich endlich zum Königsplatz, wo bei begeisterten Hochs und Reden, bei Musik und Tanz das ernst begonnene Fest seinen fröhlichen 40 Abschluss fand. Die Betheiligung auswärtiger Gäste war namentlich aus Göttingen eine sehr große.

1) defilieren: parademäßig vorüberziehen

(Göttinger Tageblatt, 18.6.1895)

\section{Arbeitsaufträge}

1. Gib den Hergang der Einweihungsfeierlichkeiten wieder (M8 und M9).

2. Arbeite heraus, inwiefern das Volksfest und die Denkmalseinweihung miteinander verknüpft sind (M8 und M9).

3. Beurteile, welchen Stellenwert das Denkmal für die Bevölkerung von Geismar hatte. 


\section{Der Bismarckstein}

\section{Anja Groß}

Nach dem Tod Otto von Bismarcks 1898 kam es in ganz. Deutschland zum Bau sogenannter Feuersäulen. Da es in Göttingen schon den Bismarckturm gab, entschied man sich für den Bau eines Feueraltars, des Bismarcksteins. Die Schülerinnen und Schüler erbalten eine Vorstellung von der Verehrung Bismarcks, die in verschiedenen baulichen V arianten ibren Ausdruck fand. Dabei setzen sie sich besonders mit der Rezeptionsgeschichte des Denkmals auseinander. Der Bismarckstein als Alternative oder Vertiefung zur Beschäftigung mit dem Bismarckturm an.

\section{Erscheinungsbild}

Der „Bismarckstein auf dem Top$\mathrm{pe}^{\text {" }}$ ist ein $7 \mathrm{~m}$ hoher und $9 \mathrm{~m}$ breiter Feueraltar aus Kalkstein und Granit. Sein Erscheinungsbild soll an einen Turmsockel erinnern. An beiden Seiten befinden sich Treppenaufgänge. Auf der Aussichtsplattform war ursprünglich eine groBe Feuerschale installiert. Um den Bismarckstein standen im Halbrund sechs Pfeiler, auf denen ebenfalls kleine Feuerschalen montiert waren. Die Inschrift des Bismarcksteins lautet: ,Gedenkstein für Otto von Bismarck 1903“.

\section{Entstehung und Intention}

Das Denkmal wurde nach Bismarcks Tod 1898 von der Deutschen Studentenschaft in Auftrag gegeben. Hintergrund war ein deutschlandweiter Aufruf zur Er-

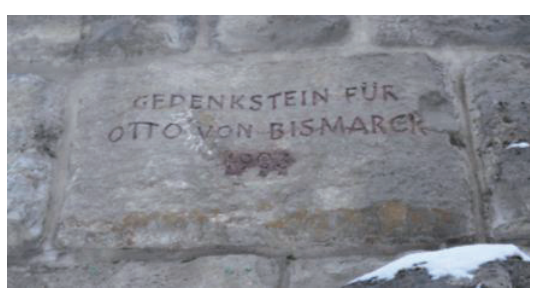

Inschrift des Bismarcksteins, 2010

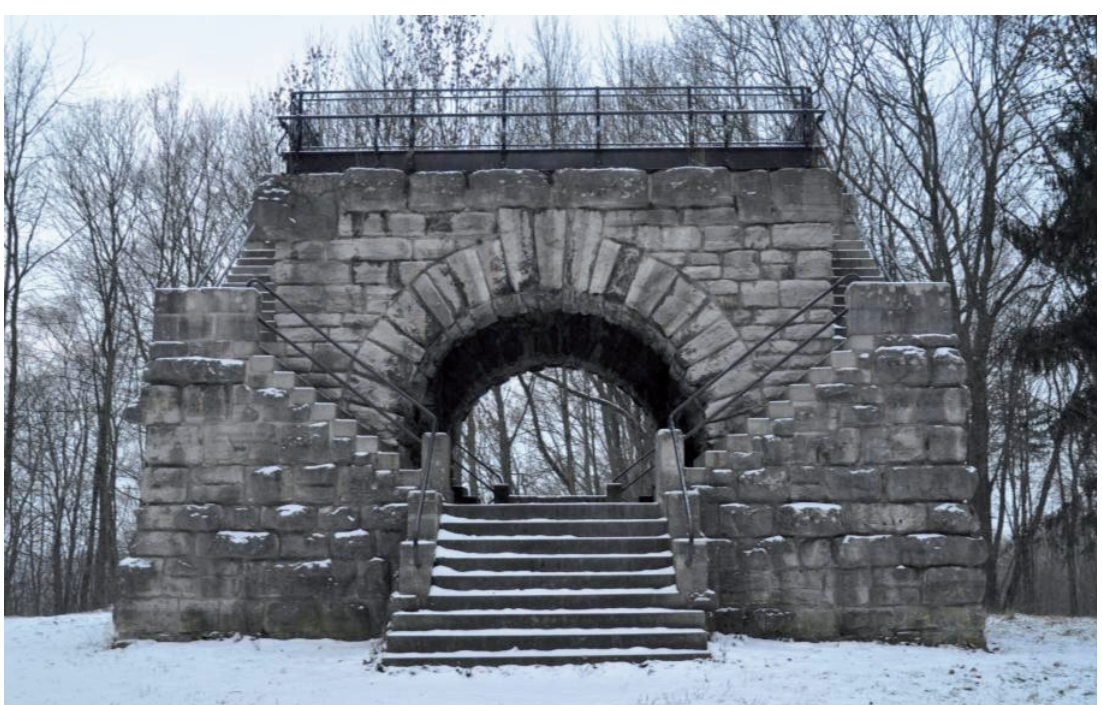

Bismarckstein, 2010

richtung von Bismarck-Feuersäulen. 1899 gründeten der damalige Rektor der Universität Prof. Johannes Merkel und der Göttinger Bürgermeister Georg Calsow den „Verein zur Erbauung einer Bismarck-Säule bei Göttingen“. Unterstützt wurde das Projekt auch von dem Vorsitzenden des „Göttinger-VerschönerungsVereins" Dr. Hermann Eckels. Durch zahlreiche Aktionen des neuen Vereins und viele Spenden der Göttinger Bürgerinnen und Bürger brachte man die benötigten 18.000 Mark auf.

Am 28. Juni 1900 wurde der Standort von den Göttinger Studenten ausgewählt. Man entschied sich für den Entwurf des Stadtbaumeisters Friedrich Jenner (1863-1928). Am 21. Juni 1902 erfolgte die Grundsteinlegung und am 21. Juni 1903 wurde das Denkmal festlich eingeweiht.

Der Bismarckstein wurde an einschlägigen Gedenktagen, z. B. am 1. April (Bismarcks Geburtstag), am 30. Juli (Tod Bismarcks), am 2. September (Sedantag) und am 18. Oktober (Völkerschlacht Leipzig) als Ort für Feiern der Göttinger Stu-

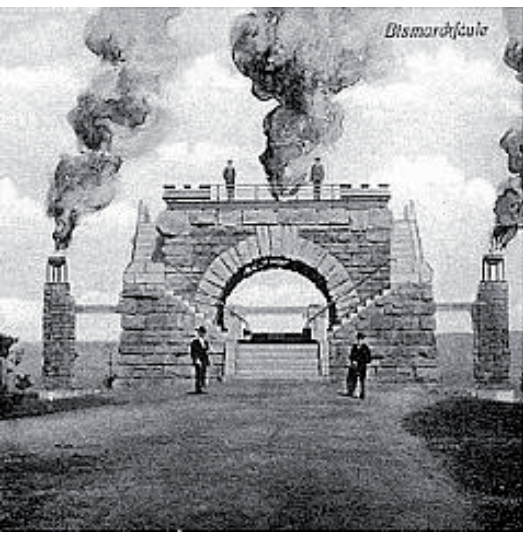

Fotografie, um 1900

denten genutzt. Dabei entzündeten sie Feuer in den Feuerschalen und sangen Lieder, die an Bismarck als Einiger der Nation erinnerten. Aber der Bismarckstein wurde auch für Sonnenwendfeiern benutzt. So fanden sowohl die Grundsteinlegung als auch die Einweihung am Tag der Sommersonnenwende (21. Juni) statt.

\section{Geschichte und Rezeption}

Nach dem Ersten Weltkrieg wurde der Bismarckstein zu einer Anlaufstelle für Konservative, die sich nach 
einem starken deutschen Reich sehnten, wie es Bismarck gegründet hatte. In der NS-Zeit und mit dem aufkommenden Kult um Adolf Hitler verlor der Bismarckstein an Bedeutung. Teilweise wurde er noch für Sonnenwendfeiern genutzt, die als angeblich altgermanisches Ritual im Nationalsozialismus eine wichtige Rolle spielten.

In den 1950er Jahren wurden die sechs Säulen um den Bismarckstein herum abmontiert, in den 1970er Jahren auch die große Feuerschale der Aussichtsplattform. Das Denkmal war in den 1960er Jahren so stark beschädigt worden, dass es wegen Einsturzgefahr geschlossen wurde. Die Kosten für eine Restauration wurden auf 100.000 Mark geschätzt. Diese Summe konnte die Stadt nicht zur Verfügung stellen.

Parallel dazu entstand in Göttingen der allgemeine Wunsch, ein Denkmal für die Opfer des Nationalsozialismus zu errichten. Die SPD wollte nun beide Fragen kombinieren und an Stelle des Bismarcksteins das neue Denkmal errichten. 1965 stellte die SPD-Fraktion den Antrag, den Bismarckstein wegen Baufälligkeit abreißen $\mathrm{zu}$ lassen. Damit löste sie eine heftige Diskussion in der Bevölkerung aus, die über Monate hinweg Platz im „Göttinger Tageblatt" einnahm; sie endete schließlich mit dem Erhalt des

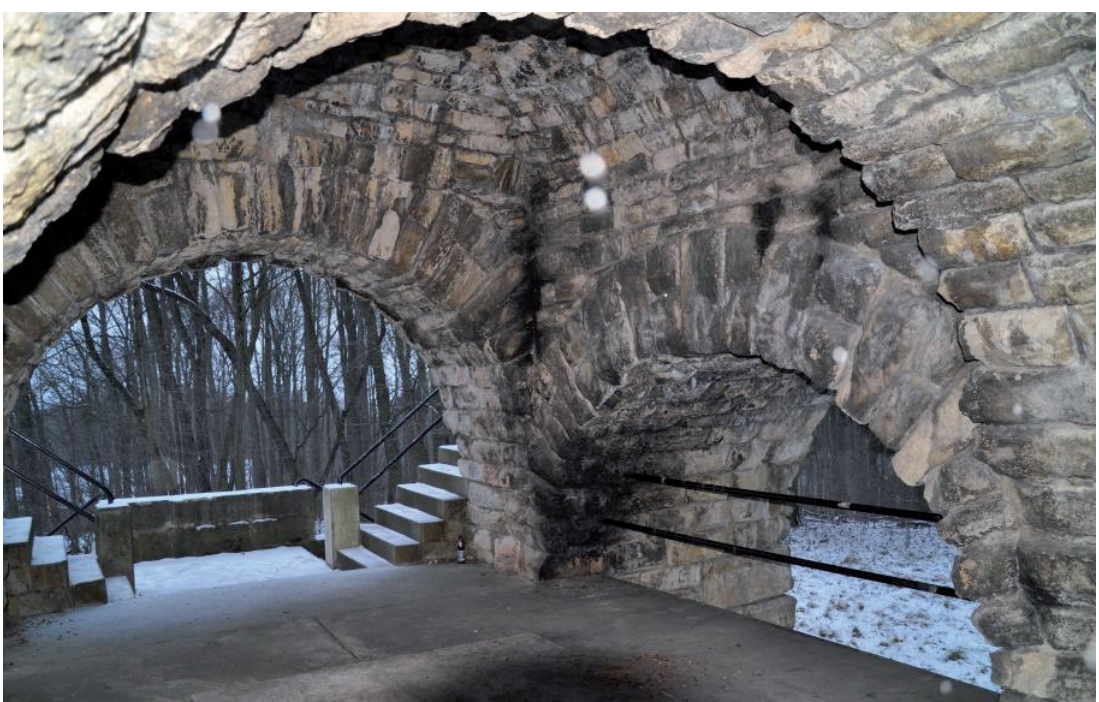

Innenraum des Bismarcksteins, 2010

Bismarcksteins und einer kostengünstigeren Sanierung. Die Pläne für das Denkmal für die Opfer der nationalsozialistischen Gewaltherrschaft wurden wieder verworfen.

Von 2002 bis 2005 wurde das im Volksmund so bezeichnete „Elefantenklo" noch einmal für ca. 15.000 Euro saniert und schließlich am 11. September 2005 wieder für Besucher geöffnet.

\section{Didaktische Überlegungen}

Das Thema „Bismarckstein“ lässt sich innerhalb des Themenkomplexes „Imperialismus und Erster Weltkrieg“ behandeln, den das nieder-

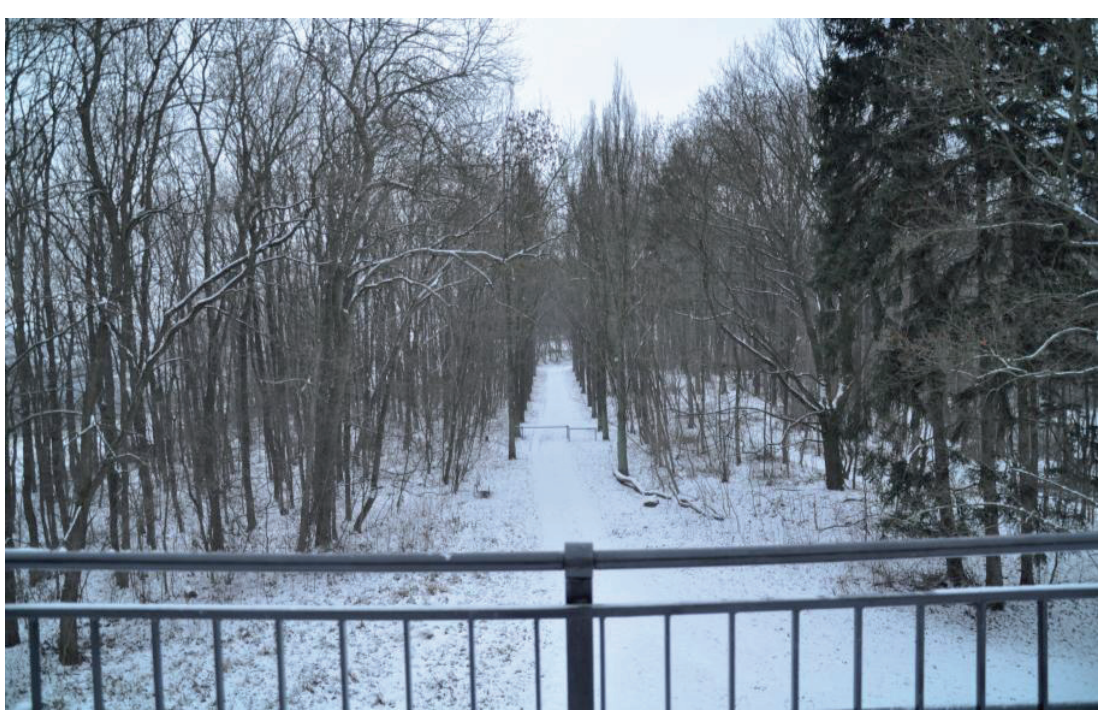

Weg zum Bismarckstein, 2010 sächsische Kerncurriculum für die 9. Klasse vorsieht. Der Bismarckstein steht beispielhaft für ein regionales Denkmal der Kaiserzeit. Der Unterrichtsvorschlag erfordert etwa zwei Unterrichtstunden und ggf. eine dritte Stunde zur Reflexion der Ergebnisse.

\section{Intentionen}

Die hier vorgestellten Materialien sind für eine Auseinandersetzung der Schülerinnen und Schüler mit dem Bismarckstein im Klassenzimmer gedacht. Auf Grund seiner entfernten Lage und der wenigen Erforschungsmöglichkeiten, die sich für die Schülerinnen und Schüler vor Ort bieten, ist eine Exkursion zum Denkmal kaum lohnend.

Im Zentrum steht die Analyse von Text- und Bildquellen. Die Zusammenstellung der Materialien verfolgt das Ziel, den Schülerinnen und Schülern die Entstehungs- und Rezeptionsgeschichte des Denkmals zu erklären. Die Schülerinnen und Schüler sollen den Wandel des Bismarcksteins von einem nationalen Heldendenkmal zu einem touristischen Aussichtspunkt erkennen. Zudem beschäftigen sie sich intensiv mit den allgemeinen Charakteristika eines Denkmals und gewinnen neue Einsichten in die Bedeutung seiner Rezeptionsgeschichte. 


\section{Materialseite 1}

Die erste Materialseite dient der allgemeinen Information der Schülerinnen und Schüler. Der Steckbrief gibt ihnen einen Überblick über die wichtigsten Fakten zur Baugeschichte und zur baulichen Gestalt des Bismarcksteins. Anhand des Zeitstrahls vollziehen die Schülerinnen und Schüler die Daten zur Bau- und Rezeptionsgeschichte des Denkmals nach.

\section{Materialseite 2}

Anhand der hier zusammengestellten Materialien können die Schülerinnen und Schüler erkennen, dass die einzelnen Bestandteile des Bismarcksteins (Aussichtsplattform mit Feuerschale, Treppenaufgänge, Säulenhalbrund mit Feuerschalen und der Innenraum) nicht mehr vollständig erhalten sind. Sie können Mutmaßungen dazu anstellen, dass der Turm seine Funktion als Feueraltar und sein imposantes Aussehen verloren hat. Heute erfüllt er eher die Funktion eines Aussichtspunktes, wobei auch diese durch die Bewaldung beeinträchtigt wird.

\section{Materialseite 3}

Die Schülerinnen und Schüler erarbeiten anhand dieser Materialseite die Intention und die Funktion des Bismarcksteins. Sie können den Tod Bismarcks als Anlass für den Bau des Bismarcksteins erschließen und die Funktion des Denkmals als Feueraltar zu Ehren Bismarcks erkennen. Zudem können sie den Zusammenhang mit dem Bismarckkult nachvollziehen. Die Verherrlichung Bismarcks als Reichseiniger lässt sich an einschlägigen Formulierungen in M6 und M7 festmachen: „Flammen vaterländischer Begeisterung“, „deutschen Dank“, „heiße innige Vaterlandsliebe, deutsche Treue, bis zum Tode“ etc. Mit Hilfe des Internets oder einschlägiger Literatur können die Schülerinnen und Schüler Bismarcks Beziehung zu den
Göttinger Studenten recherchieren. Dabei lässt sich herausfinden, dass Bismarck 1832/33 in Göttingen Jura studierte und dem Corps Hanovera angehörte.

\section{Materialseite 4}

Mit Hilfe der letzten Materialseite sollen die Schülerinnen und Schüler die Abrissdiskussion in den 1960er Jahren nachvollziehen. Dabei sollen sie einige Argumente aus den Quellen erarbeiten und in tabellarischer Form festhalten. Sie versuchen sich in die Befürworter oder Gegner des Bismarcksteins hineinzuversetzen und können so weitere Argumente erschließen.

Schließlich können sie in Partnerarbeit einen Zeitungsartikel aus ihrer Position verfassen. Dadurch stärken sie ihre Kompetenz zur Perspektivenübernahme. Dies könnte ergänzend oder alternativ durch eine nachgestellte Stadtratssitzung mit der ganzen Klasse vertieft werden.

\section{Literatur}

Gottschalk, Carola, Göttingen zu Fuß, Hamburg 1992.

Schoeps, Hans-Joachim, Bismarck über Zeitgenossen. Zeitgenossen über Bismarck, Frankfurt a. M. 1972.

Seele, Sieglinde, Lexikon der Bismarckdenkmäler, Petersberg 2005.

\section{Internet}

www.bismarcktuerme.de.

www.denkmale.goettingen.de. 


\section{Basisinformationen zum Bismarckstein}

\section{M1 Steckbrief}

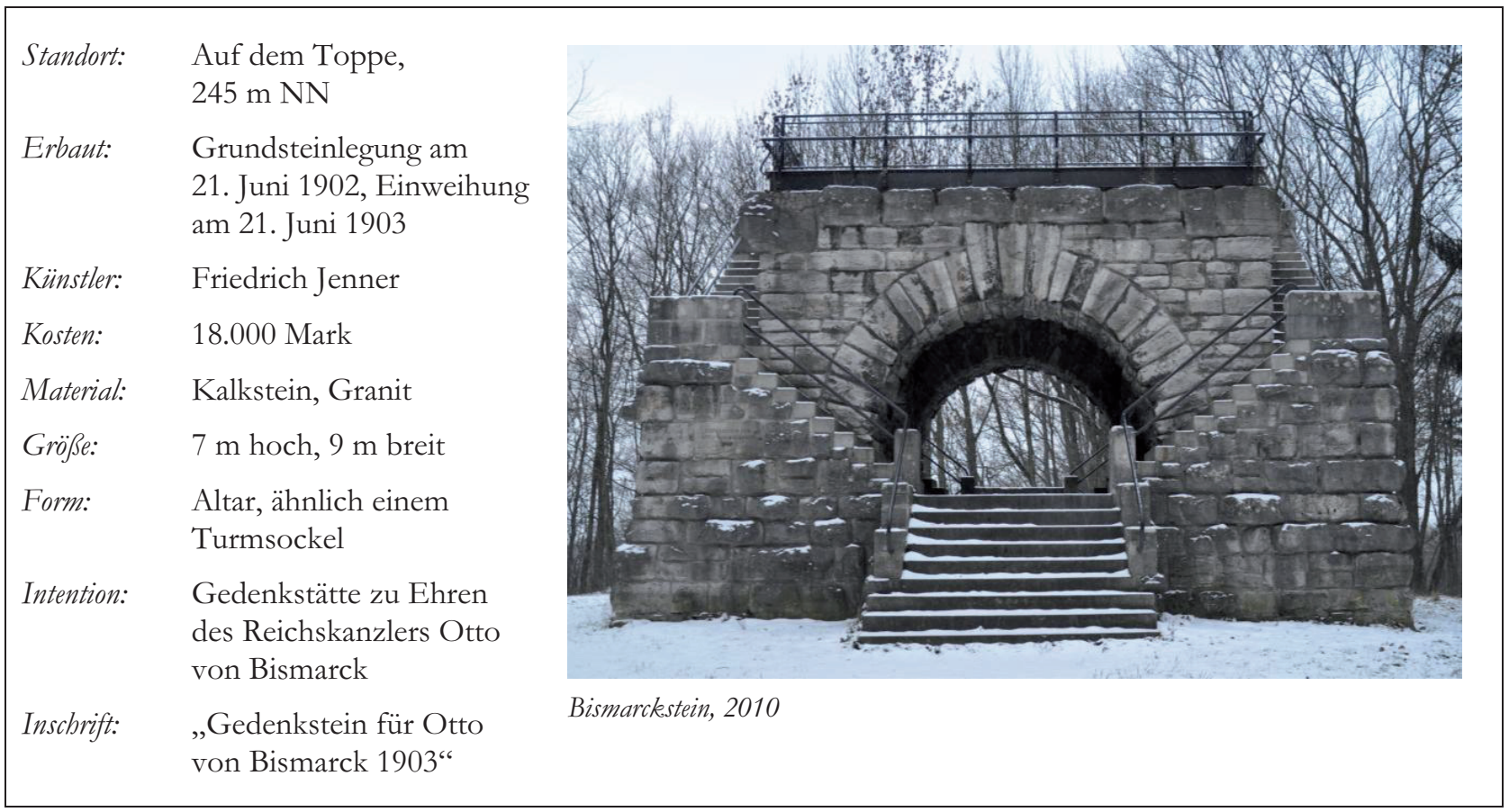

\section{M2 Zeitstrahl}

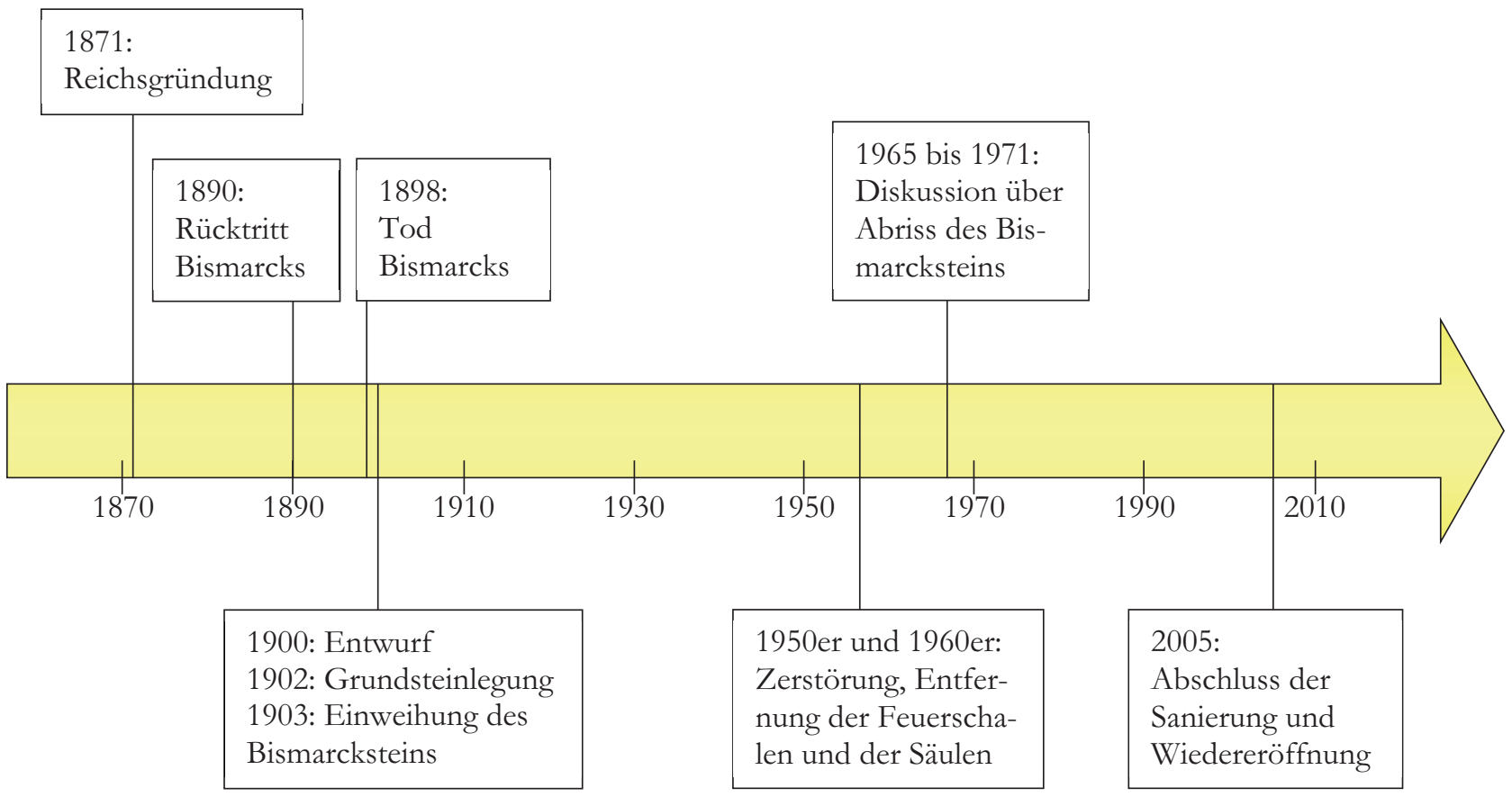




\section{Die bauliche Gestalt des Bismarcksteins}

\section{M3 Der Bismarckstein um 1900}

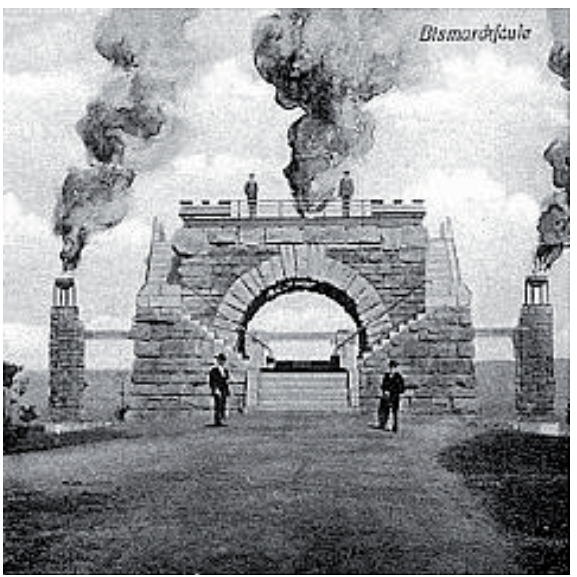

Fotografie, um 1900

\section{M4 Der Bismarckstein 1904}

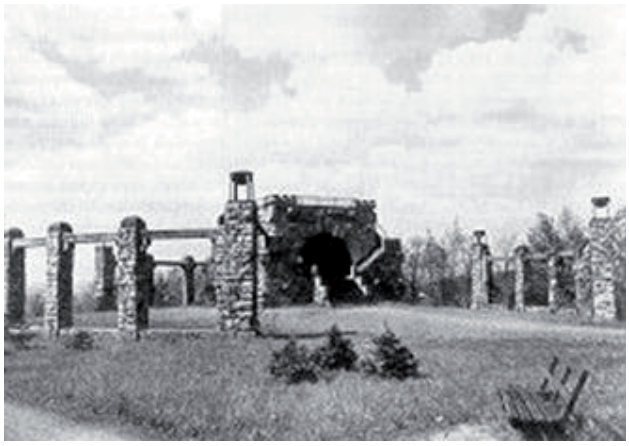

Ansichtskarte, 1904

\section{M5 Der Bismarckstein heute}

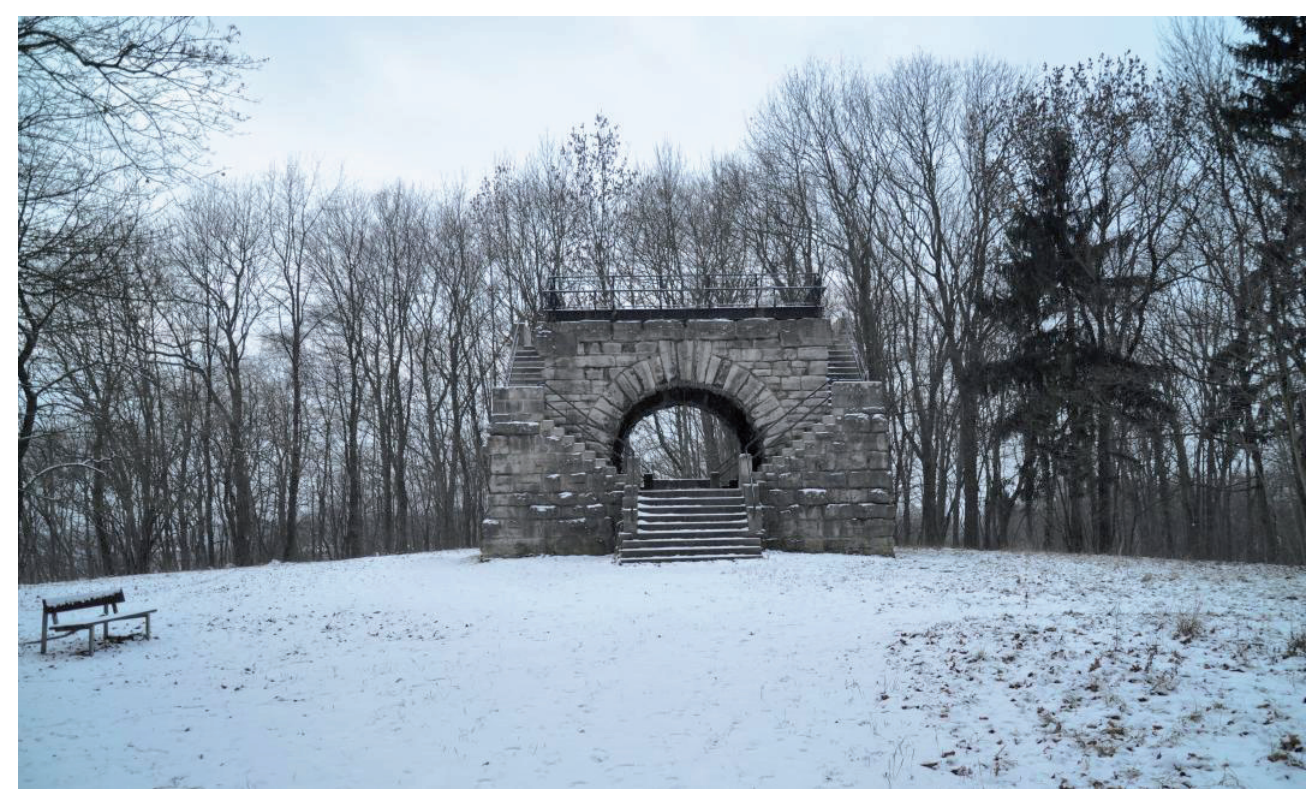

Bismarckstein, 2010

\section{Arbeitsaufträge}

1. Beschreibe das ursprüngliche Aussehen des Bismarcksteins (M3 und M4).

2. Vergleiche deine Ergebnisse mit dem heutigen Erscheinungsbild des Bismarcksteins (M5). Beziehe dabei auch die Umgebung des Denkmals in deine Überlegungen ein.

3. Stelle Vermutungen über die frühere und heutige Funktion des Bismarcksteins an.

4. Beschreibe, wie der Bismarckstein heute auf dich wirkt. Stelle Vermutungen an, wie der Bismarckstein 1903 auf die Menschen gewirkt haben könnte. 


\section{Die „Bismarcksäule“}

\section{M6 „Auf allen Höhen unserer Heimat“}

In einem Aufruf der Deutschen Studentenschaft zum Bau von Bismarcksäulen von 1898 heißt es:

An das deutsche Volk!

Eingedenk ihrer Aufgabe, allzeit Hüterin des nationalen Gedankenguts zu sein, hat die akademische Jugend aller Universitäten und Hochschulen Deutsch5 lands sich geeinigt, eine allgemeine Kundgebung des deutschen Volkes für unseren dahingeschiedenen Altreichskanzler anzuregen [...] Wie vor Zeiten die alten Sachsen und Normannen über den Leibern ihrer gefallenen Recken schmucklose Felsensäulen auftürm-
10 ten, deren Spitzen Feuerfanalen trugen, so wollen wir unserem Bismarck zu Ehren auf allen Höhen unserer Heimat, von wo der Blick über die herrlichen deutschen Lande schweift, gewaltige granitene Feuerträger errichten. Überall soll ein Sinnbild der Einheit 15 Deutschlands, das gleiche Zeichen erstehen, in ragender Größe, aber einfach und prunklos, aus massivem Unterbau eine schlichte Säule.

(Daniel Fischer, Bismarck - historische Persönlichkeit im Spiegel der Zeit, Norderstedt 2009, S. 22)

\section{M7 „Deutschen Dank sollen sie künden“}

\section{In einem weiteren Aufruf der Deutschen Studentenschaft von 1898 wird erklärt:}

„Überall auf den Bergen unserer Heimat, an möglichst vielen geeigneten Stellen, sollen einfache, aber mächtige, durch Eigenart wirksame Bismarcksteine errichtet werden, von deren Spitze an den Bismarck-Gedenk5 tagen mächtige Feuer, Flammen vaterländischer Begeisterung weithin die Nacht durchleuchten sollen.
Von mächtigen Scheiterhaufen auf hoher Plattform, von Berg zu Berg sollen die Feuer grüßen, deutschen Dank sollen sie künden, das Höchste, Reinste, Edels10 te, was in uns wohnt, sollen sie offenbaren, heiße innige Vaterlandsliebe, deutsche Treue, bis zum Tode."

(Hans-Joachim Schoeps, Bismarck über Zeitgenossen. Zeitgenossen über Bismarck, Frankfurt a. M. 1972, S. 254)

\section{Arbeitsaufträge}

1. Recherchiere im Internet, in welchem Verhältnis Bismarck zu der Universitätsstadt Göttingen stand.

2. Erarbeite anhand der Textquellen M6 und M7 den Anlass für den Bau des Bismarcksteins und seine Funktion.

3. Markiere wichtige Schlüsselbegriffe in den beiden Quellen. Erläutere mit ihnen den historischen Zusammenhang. 
Der Bismarckstein in den 1960er Jahren - Abriss oder Sanierung?

M8 Wir haben doch schon den Bismarckturm

Daniel Diesig lässt 1965 im Göttinger Tageblatt den fiktiven Gesprächspartner „Xaver Quosig“ zur Bismarckverehrung in Göttingen zu Wort kommen:

„Gott sei Dank, dass das alte Elefantenklo endlich verschwindet! Ruft Xaver Quosig impulsiv, das stört doch mit seinen verrosteten Geländern den Waldfrieden! Und der sogenannte eiserne Kanzler ist doch im 5 modernen Volksbewusstsein auch schon leicht angerostet!“ - „Aber, aber! Wage ich einzuwenden, schließlich war Bismarck doch ein großer Politiker, und in der Untertertia [8. Klasse] mussten wir sogar einen Aufsatz über ihn schreiben: Bismarck als Staa10 tenlenker!“ - „Was heißt hier Ladenstänker - Entschuldigung: Staatenlenker, kontert Quosig, der gern geistreich tut. Schließlich haben wir doch außer dem Bismarckstein noch den Bismarckturm, die Bismarckstraße und das Bismarckhäuschen $[\ldots]^{\text {“ }}$

(Daniel Diesig, Von Bismarck bis Widukind, Göttinger Tageblatt, 23. März 1965)

M9 Bismarckstein soll bleiben

1965 berichtet das Göttinger Tageblatt über die Petition einiger Bürgerinnen und Bürger:

\section{Bismarckstein soll bleiben}

\section{Bürger richteten eine Petition an den Rat der Stadt}

Fur die Frhaltung den Bismanctesteines haben sich Jetzt 191 Btirger der Wohnsegend am Blemarclcatein in einer Petition an den Rat der Stadt eingesetzt.

$\because$ Die Bürger betonen in ihrem Schreiben, daB die für die Beseltigung vorgebrachten Argumente nicht uberzeugen können. So sel va a. der Bismarckstein nicht $\mathbf{s}^{\circ}$ baufallig, wie er hingestellt werde, sondern er lasee sich durchaus mit geringem tinanziellem Aufwand restaurieren. Auch treifle das Argument, Gottingen verfuge tiber zenugend andere Bismarckgedenkstätten, nicht zu. BB durfe nicht der Grund dafür sein, eine tast tiber eln halbes Jahrhuindert bestehende, flur Göttingen absolut volkstimnifiche, Gedenirstaltte ihres Sinnes zu entkleiden, set doch die ganzo Gegend als "am, Bismarckstein" sepräst.

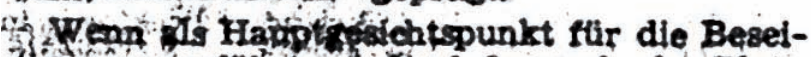
tígung angefuhrt werdés dab gerado der Platz, auf dem der Bismarckstein steht, in gant'Gottingen der einzige geefrenete ort fir dis nei. zu errichteride Gedenkstatte an die Opfer der Jáhre von 1933 bis 1945 sed, so milsed lestgestellt werden, daB es genügend andere Platzo. jebe, ganz abgesehen davon, daß der Bismanck-

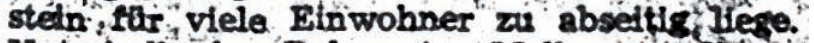
Unterhalb des Rohns, im Molkenizrind, am: Schwänchentelch, aut dem Albanitriedhof oder am Kleinen Hagen sei bestimmt ein geeigneter Platz zu finden.

Zum Faktum der Frrichtung elnes Threnmals betonen die Burger thre poditive Iinstiellung zu diesem Projekt. Sio erklaren Jedoch, daB das Threnmal nach dem Wunsche vleler Mitborger die Gesamtheit der Opter seit 1933 umfassen mibte, also auch die nocti nach 1945 unsctiuldig Umgekommenen: Verschleppte, Vertriebene, Verscholleite nicht aus der Golangenschaft Helioistikesite und diengidentogs Uimgebrachten.

(Göttinger Tageblatt, 26. März 1965)

\section{Arbeitsaufträge}

1. Stelle Argumente für und gegen den Abriss des Bismarcksteins in einer Tabelle gegenüber (M8 und M9).

2. Versetzt euch in Partnerarbeit in die Lage der Befürworter oder der Gegner des Abrisses. Welche Argumente fallen euch noch ein? Verfasst einen Zeitungsartikel, in dem ihr eure Position darstellt. 


\title{
Der Bismarckturm
}

\author{
Melanie Mai
}

In 146 deutschen Orten - und sogar außerhalb Deutschlands - gibt es Bismarcktürme. Sie stellen ein wichtiges Zengnis für die Verehrung Otto von Bismarcks (1815-1898) dar. Das gilt auch für den Bismarckturm auf dem Göttinger Hainberg. Die Schülerinnen und Schüler lernen bei der Beschäftigung mit dem Bismarckturm eine Form der Verehrung Bismarcks kennen. Sie erkennen sie bauliche Besonderheiten des Göttinger Bismarckturms und vertiefen ihre Kenntnisse zum Thema Denkmal. Der Turm lässt sich gut in eine Unterrichtseinheit zum Thema „Kaiserreich" integrieren und bietet sich für eine Exkursion an.

\section{Erscheinungsbild}

Der Göttinger Bismarckturm besteht aus einem $21 \mathrm{~m}$ hohen, sechseckigen und viergeschossigen Hauptturm, an den sich ein $31 \mathrm{~m}$ hoher Rundturm anlehnt. Auf dem Haupt- und auf dem Rundturm befinden sich Zinnenaussichtsplattformen, von denen man auf Göttingen hinunter blicken kann. Auf dem Turm gibt es keine Feuerschale, wie es auf späteren Bismarcktürmen üblich war. Als Material für den Bau wurde Kalkbruchstein und Sandstein aus der Region Göttingen verwendet.

Im zweiten Obergeschoss des Hauptturmes befindet sich die sogenannte Bismarck-Halle. Sie ist mit

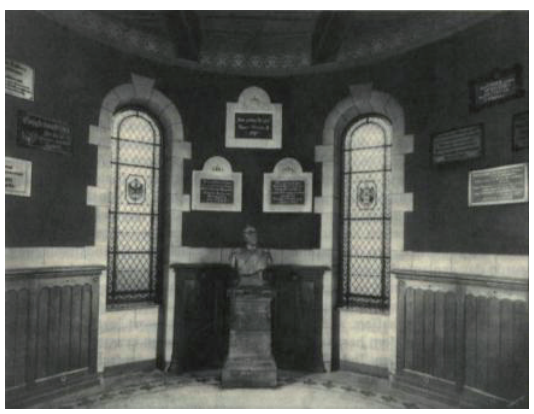

Bismarckimmer, 1896 einer 1,50 m hohen Holzverkleidung aus Eiche ausgestattet. In der Halle wurden die Widmungstafeln der Spender an der Wand angebracht sowie eine bronzene Büste Bismarcks aufgestellt.

Die Widmungstafeln enthalten unter anderem folgende Inschriften: Dem großen Kanzler (Kaiser Wilhelm II.); Dem größten Sohne der gemeinsamen Alma Mater GeorgiaAugusta (Wilhelm König von Württemberg); Was des deutschen Heeres kraft in Treue erkämpft, hast du in weiser Fürsorge geordnet und gekrönt (Friedrich Großherzog von Baden); Dem Einiger unseres Vaterlandes (Deutsche in Moskau); Hoch auf der Warte wie Du, des Reiches eiserner Kanzler, Bleibe Germania stets Friedens Herold und Hort (Deutsch-Amerikaner von New York); Mächtig dröhnte das Erz, da des Reiches Ring du geschmiedet, Funken stoben der Welt in das erstaunte Gesicht. Magst Du nun rasten, Schmied, Dein Werk bleibt immer der Ring, doch, Und Jahrhunderte durch dröhnt Dir vom Danke die Welt (Deutsche in Zürich); In Kampfesglut, in Sturm und Nacht, mit Heldenmut, mit Geistesmacht, hast du des Reiches Bau vollbracht. Dein Name glänzt in deutscher Brust: Groß, ruhmvoll-strahlend, zielbewusst (Ferdinand Levin).

In seiner Form unterscheidet sich der Göttinger Bismarckturm von später entstandenen Türmen. Fast alle diese Türme wurden nach einem Entwurf des Architekten Wilhelm Kreis mit dem Namen „Götterdämmerung“ erbaut. Der Entwurf in Form einer Feuersäule hatte sich bei einem Wettbewerb der Deutschen Studentenschaft durchgesetzt und war ab dem Jahr 1899 charakteristisch für den Bau von Bismarcktürmen. So war eine wuchtige, aber einfache Säule vorgesehen,

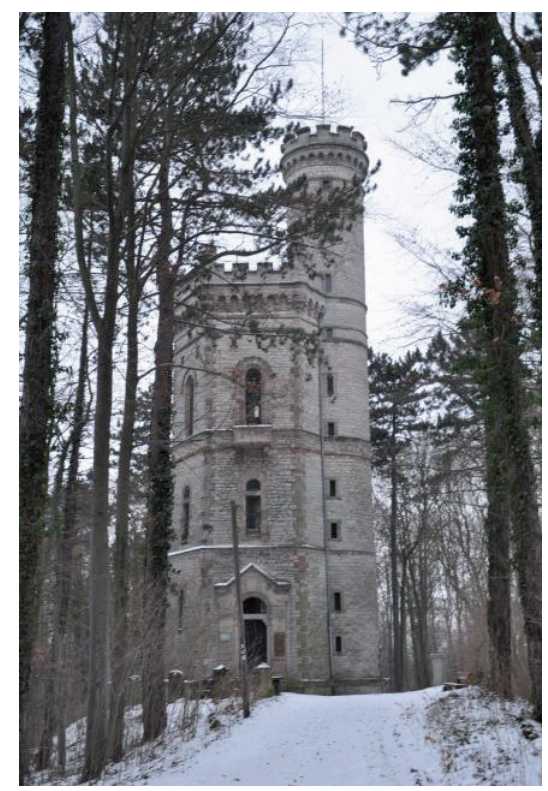

Göttinger Bismarckturm, 2010

die an bestimmten Tagen befeuert werden kann. Auch in Göttingen findet sich ein $\mathrm{zu}$ befeuerndes Denkmal, nämlich der Bismarckstein auf dem Toppe. Dieser wurde im Jahr 1903 eingeweiht.

\section{Entstehung und Intention}

Bismarck studierte in den Jahren 1832/33 Rechtswissenschaften an der Georgia-Augusta und war Mitglied im noch heute existierenden Corps Hannovera. Trotz seiner ausschweifenden Jahre als Student und seiner Verbannung außerhalb der Stadtmauern (das Bismarckhäuschen war damals Teil der Stadtmauer) erfreute sich Bismarck in Göttingen großer Popularität, sodass ihm die Stadt Göttingen im Jahr 1877 die Ehrenbürgerwürde verlieh. Zu seinem 70. Geburtstag wurde ein Platz nach ihm benannt und an seinem 80. Geburtstag eine Bismarckeiche gepflanzt.

Über einen Aussichtsturm wurde im Rat der Stadt Göttingen in den 1880er Jahren schon länger disku- 
tiert. Man entschloss sich dazu, diesen Turm Otto von Bismarck zu widmen. Dies verlieh dem Turm eine neue, nationale und patriotische Bedeutung. Im Jahr 1892 wurde der „Bismarck-Thurmbau-Verein“ gegründet. Er machte es sich zur Aufgabe, Gelder für den Bau eines Bismarckturms zu sammeln.

Der Kleper, höchster Punkt des Hainbergs, wurde als geeigneter Ort ausgewählt, da man bei der damals niedrigen Bewaldung weit über das Göttinger Umland, bis hin zum Harz, blicken konnte. Umgekehrt war der Turm bereits aus weiter Entfernung sichtbar.

Im Mai 1892 bekam der Verein die Zusage Bismarcks, dass dieser sich sehr darüber freuen würde, wenn ihm zu Ehren ein Turm in Göttingen aufgestellt und nach ihm benannt würde. In einer Proklamation des „Bismarck-Thurmbau-Vereins von 1893 wird ein Brief Bismarcks" zitiert: „Die Absicht den Thurm auf dem Hainberge nach mir $\mathrm{zu}$ benennen, ist für mich sehr ehrenvoll und erweckt in mir frohe Erinnerungen an die Zeit, wo ich in meinem ersten Semester [...] vom Hainberge auf die Stadt und das Thal blickte. Ich danke Jedem der beteiligten Herren für die Ehre, welche mir durch die Benennung des Thurmes erzeigt wird [...].“

Die Grundsteinlegung erfolgte im Sommer 1892. Geplant und entworfen hatte den Turm der Göttinger Baurat Heinrich Gerber. Mit der Ausführung wurde der ebenfalls aus Göttingen stammende Architekt Conrad Rathkamp betreut. Um die Finanzierung des Turmes sicherzustellen, wurde auf Initiative von Oberbürgermeister Merkel die Idee umgesetzt, dass jeder, der 500 Mark (entsprach einem Mauerring des Turms) oder mehr gespendet hatte, eine Widmungstafel im Inneren des Turms erhalten sollte. Insgesamt trafen 29 Spenden in dieser Höhe ein, unter anderem von Kaiser Wilhelm II., den Städten Hamburg und Lüneburg, den Corps Hannovera und Saxonia sowie privaten Spendern.
Dank dieser Spenden konnte der Rohbau bereits im Herbst 1894 fertig gestellt werden. Am 18. Juni 1896 kam es zur feierlichen Einweihung; am selben Tag wurde auch das Kyffhäuserdenkmal eingeweiht. Insgesamt kostete der Turm 43.700 Mark.

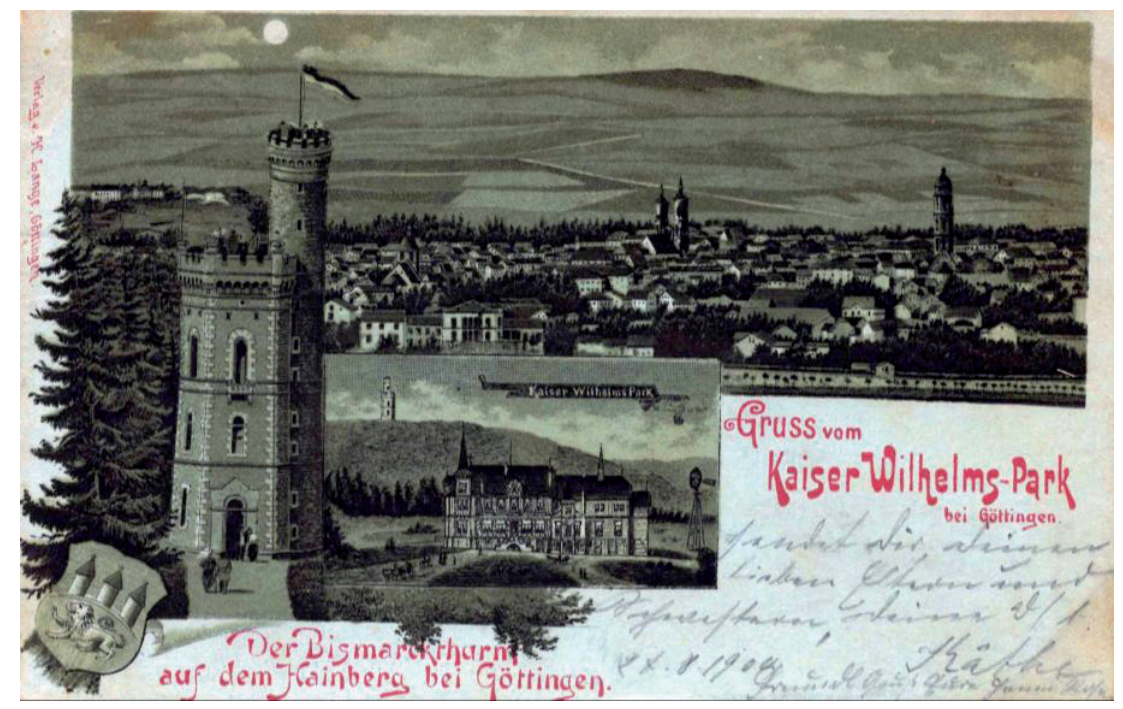

Ansichtskarte des Göttinger Bismarckturms mit Blick auf Göttingen, 1899

In seiner Entstehung unterscheidet sich der Göttinger Bismarckturm, einer von 15 Bismarcktürmen, der bereits zu Bismarcks Lebzeiten errichtet wurde, von späteren Türmen. Die meisten entstanden nach dem Tod Bismarcks. Insgesamt wurden über 700 Denkmäler zu seinen Ehren und seinem Gedenken errichtet und über 300 Bismarckvereine gegründet.

\section{Geschichte und Rezeption}

Genutzt wurde der Turm nach seiner Errichtung als Aussichts- und Ausflugsziel. Der „BismarckThurmbau-Verein" löste sich am 30. März 1898 auf, beschloss aber vorher, dass der Turm jährlich zu Bismarcks Geburtstag angestrahlt und durch Kanonenschüsse an den $\mathrm{Na}$ mensgeber erinnert werden solle. Dies hat wahrscheinlich bis zum Jahr 1915 stattgefunden.

Im Zuge des Bismarckkults, der nach Bismarcks Tod 1898 verstärkt einsetzte, waren auch Ansichtskar- ten mit dem Motiv des Turms sehr beliebt.

Nach Ende des Zweiten Weltkrieges wurde der Bismarckturm geplündert, die Büste entwendet und ein Teil der Widmungstafeln sowie die Fenster zerstört. Im Jahr 1952 nahm sich der Göttinger Verschö-

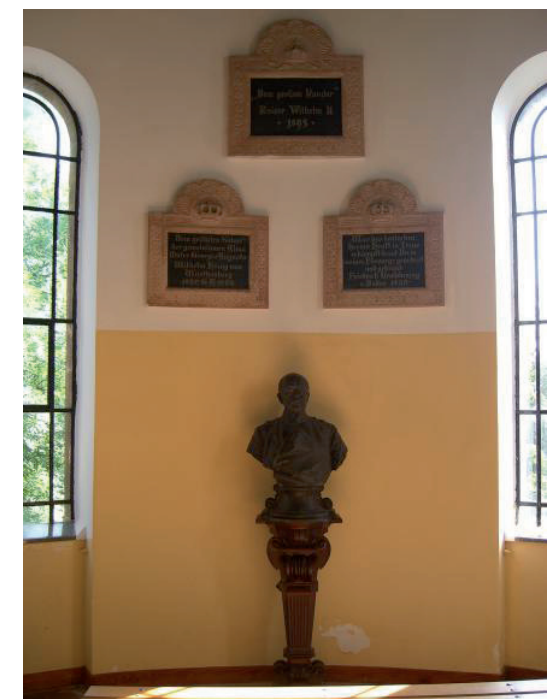

Die Bismarckhalle heute, 2007

nerungsverein des Turmes an und renovierte ihn bis zum Jahr 1953. Auch eine neue Büste wurde in der Bismarckhalle aufgestellt. 1985 kam es zu einer erneuten Renovierung, sodass der Turm heute sehr gut erhalten und in den Sommermonaten weiterhin Besuchern zugänglich ist. Er bildet ein beliebtes Ausflugsziel. 


\section{Didaktische Überlegungen}

Der Bismarckturm lässt sich sinnvoll im Kontext des Themas „Kaiserreich“ im Jahrgang 9 behandeln. Eine Exkursion bietet die Möglichkeit, dass sich Schülerinnen und Schüler vor Ort mit dem Denkmal auseinandersetzen. Außerdem liegt es nahe, den Göttinger Bismarckstein als Vergleich für ein Bismarckdenkmal anderer Art in Augenschein zu nehmen.

\section{Intentionen}

Der Bismarckturm kann als Beispiel für den Kult um den „Reichsgründer" untersucht werden. Die Schülerinnen und Schüler können diese spezielle Form der Verehrung Bismarcks analysieren und mit anderen Formen (z. B. Gläser, Münzen, Fürst Bismarck Korn, Bismarckhering) vergleichen. Sie sollten dafür bereits vorher mit dem Bismarckkult und seinen Ausdrucksformen bekannt gemacht worden sein.

Der Bismarckturm eignet sich außerdem dazu, in die methodische Untersuchung eines Denkmals einzuführen oder diese zu vertiefen. Die Schülerinnen und Schüler ler- nen Denkmäler als eine Form der Vergangenheitsdeutung kennen und analysieren. Anhand der Unterschiede zwischen dem Göttinger Bismarckturm und anderen lassen sich abweichende Intentionen und Funktionen erarbeiten. Die Schülerinnen und Schüler sollten in der Lage sein, die verschiedenen Motivationen (vor und nach dem Tod Bismarcks) für die Errichtung von Bismarcktürmen $\mathrm{zu}$ benennen. Durch die Beschäftigung mit Bismarcktürmen als Teil der Erinnerungskultur gewinnen die Schülerinnen und Schüler letztlich Einsichten in den Konstruktcharakter von Geschichte.

\section{Materialseite 1}

Materialseite 1 vermittelt den Schülerinnen und Schülern allgemeine Informationen zur Entstehung des Göttinger Bismarckturms. Mit Hilfe des Zeitstrahls können sie die Entstehungsgeschichte des Turms in Beziehung setzen zu den wichtigsten Lebensdaten Bismarcks.

\section{Materialseite 2}

Auf Materialseite 2 finden sich einige Inschriften der Widmungstafeln in der Bismarckhalle. Die Schülerinnen und Schüler können mithilfe dieses Materials erarbeiten, dass es verschiedene Arten von Spendern gab (Privatpersonen, Städte, politische Größen, Kommilitonen, Verbindungen etc.). Aus den Inschriften soll den Schülerinnen und Schülern darüber hinaus das Ansehen Bismarcks als Nationalheld und Gründer des Deutschen Reiches deutlich werden, das die Grundlage für den Bismarckkult bildete.

\section{Materialseite 3}

Das Material der Seite 3 soll den Schülerinnen und Schülern vor $\mathrm{Au}$ gen führen, wie es zu der „Mode“ des Baus von Bismarcktürmen kam. Besonders die Rolle der Studenten wird in dem Material deutlich.

\section{Materialseite 4}

Hier sollen die Schülerinnen und Schüler sich noch einmal mit dem Göttinger Bismarckturm beschäftigen. Ziel soll es sein, die Rede zur Grundsteinlegung und zur Einweihung des Bismarckturms im zeitgenössischen historischen Kontext zu analysieren.

\section{Literatur}

Motel, Heinz, Berühmte Persönlichkeiten und ihre Verbindung zu Göttingen, Göttingen 1993.

Nissen, Walter, Göttinger Denkmäler, Gedenksteine und Brunnen, Göttingen 1978.

Seele, Sieglinde, Lexikon der Bismarck-Denkmäler. Türme, Standbilder, Büsten, Gedenksteine und andere Ehrungen. Eine Bestandaufnahme in Wort und Bild, Petersberg 2005.

Stadtforstamt Göttingen, Der Bismarckturm auf dem Hainberg. Dokumente zur Baugeschichte, Göttingen 1996.

Thadden, Rudolf von/Trittel, Günter J. (Hrsg.), Göttingen. Geschichte einer Universitätsstadt. Band 3: Von der preußischen Mittelstadt zur südniedersächsischen Großstadt 1866-1989, Göttingen 1999.

\section{Internetseiten}

www.bismarcktuerme.de (eingesehen am 6.3.2011). 


\section{Basisinformationen zum „Bismarckturm“}

\section{M1 Steckbrief}

\begin{tabular}{lll|}
\hline Standort: & Hainberg in Göttingen \\
Erbaut: & 1892-1896, eingeweiht am 18. Juni 1896 \\
Entwur: & Baurat Heinrich Gerber \\
Material: & Sandstein aus der Umgebung Göttingens \\
Größe: & $31 \mathrm{~m}$, mit Aussichtsplattform auf einer Höhe \\
& von $21 \mathrm{~m}$ \\
Form: & Turm mit sechseckigem Hauptturm und \\
& angelehntem Rundturm \\
Intention: & Verehrung Otto von Bismarcks (1815-1898) \\
Kosten: & ca. 43.700 Mark &
\end{tabular}

\section{M2 Zeitstrahl}

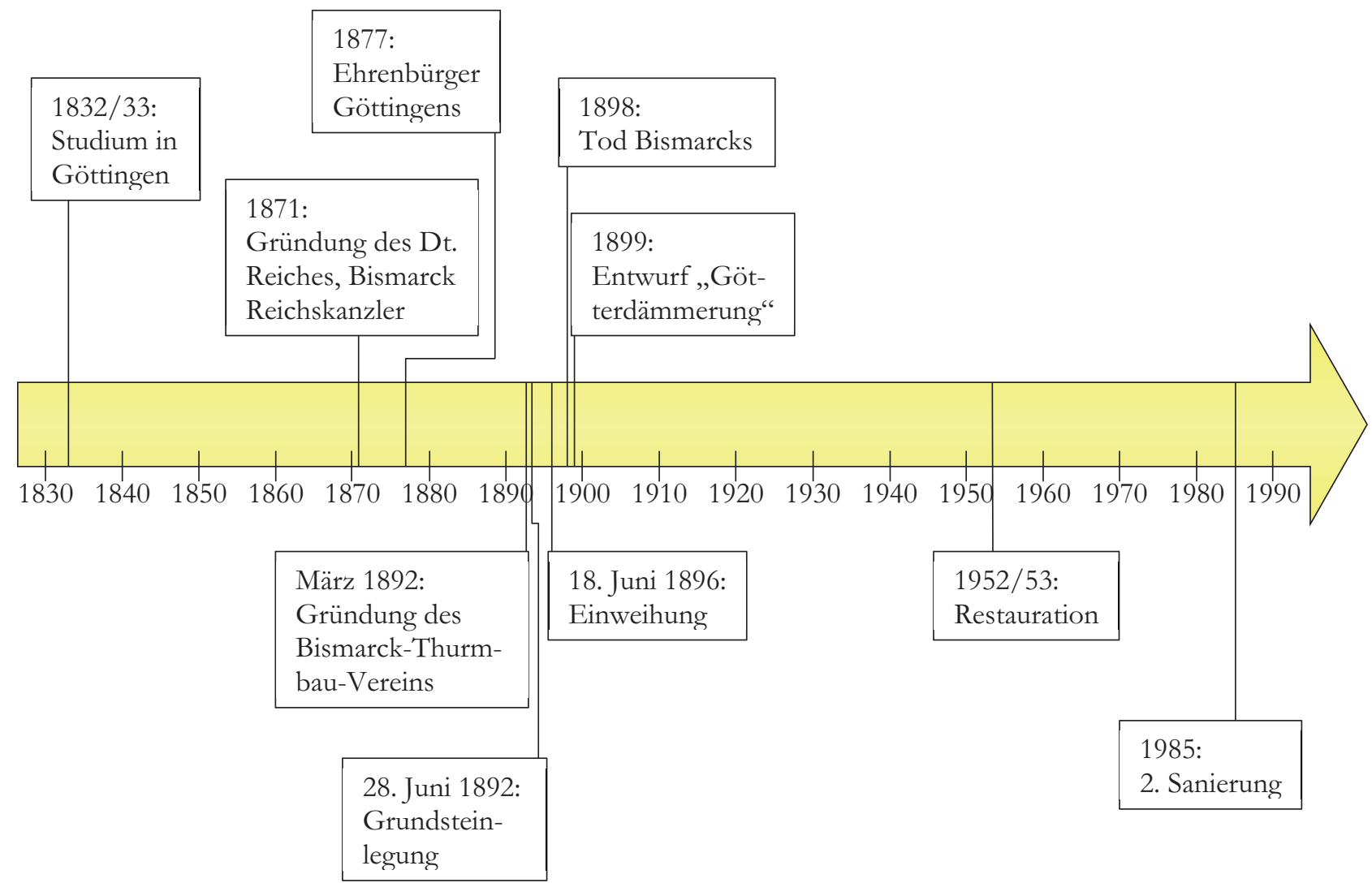




\section{Zeitgenössisches Bismarck-Gedenken}

\section{M3 Inschriften der Widmungstafeln im Bismarcksaal}

„Dem großen Kanzler“ (Kaiser Wilhelm II.)

„Dem größten Sohne der gemeinsamen Alma Mater Georgia-Augusta“ (Wilhelm König von Württemberg)

„Was des deutschen Heeres Kraft in Treue erkämpft, hast du in weiser Fürsorge geordnet und gekrönt.“

(Friedrich Großherzog von Baden)

„Einigkeit macht stark.“ (Der Senat der freien und Hansestadt Lübeck)

„Dem Einiger unseres Vaterlandes“ (Deutsche in Moskau)

„Hoch auf der Warte wie Du, des Reiches eiserner Kanzler, Bleibe Germania stets Friedens Herold und Hort.“ (Treue Deutsch-Amerikaner von New York)

„Mächtig dröhnte das Erz, da des Reiches Ring du geschmiedet, Funken stoben der Welt in das erstaunte Gesicht. Magst Du nun rasten, Schmied, Dein Werk bleibt immer der Ring doch, Und Jahrhunderte durch dröhnt Dir vom Danke die Welt.“ (Deutsche in Zürich)

„Immer deutsch!“ (Das Offizier-Corps des 2. Hessischen Infanterie-Regiments Nr. 82)

„Setzen wir Deutschland in den Sattel! Reiten wird es schon können.“ Bismarck im Reichstag 11. März 1867

(Gewidmet von den Nationalliberalen Göttingens)

„Extra Gotingam non est vita!“‘ Göttingen den 24. Sept. 1893 (Georg Merkel, Ober-Bürgermeister)

„Die Zwietracht vernichtet. Zur Einheit geschlichtet, Das Reich errichtet.“ (Gestiftet von den früheren academischen Bürgern der Georgia August in Hamburg)

„In Kampfesglut, in Sturm und Nacht, mit Heldenmut, mit Geistesmacht, hast du des Reiches Bau vollbracht. Dein Name glänzt in deutscher Brust: Groß, ruhmvoll-strahlend, zielbewusst.“ (Ferdinand Levin)

„Dein Werk wird nimmer schnöder Vergessenheit klanglos verfallen, wohnt doch ein Geist in Dir, Der Welt und Zeit versteht und aufrecht Bleib in beglückten und schweren Tagen." (Ferd. Reibstein, Göttingen)

„Nicht nur in Stein und Erz ist einst Sein Ruhm zu lesen: In aller Herzen lebt, was Bismarck uns gewesen.“

(Gestiftet von des Fürsten Verehrerinnen in Darmstadt und der Provinz Starkenburg)

„Seinem größten Alten Herren das Corps Hannovera“

„Ein fester Thurm stand er im Streit, im Wettersturm Allzeit bereit zu schirmen Deutschlands Herrlichkeit.“

(Gewidmet von der Burschenschaft Brunsviga)

\section{Arbeitsaufträge}

1. Arbeite heraus, von welchen Personengruppen die Widmungstafeln gespendet wurden (M3).

2. Ordne die Rollen ein, die Bismarck in den Widmungen zugeschrieben werden, und erstelle eine Tabelle mit den wichtigsten Aspekten. 


\section{M4 „An das deutsche Volk!“}

\section{Nach dem Tode Bismarcks 1898 ruft die Deutsche Studentenschaft zur Errichtung von Bismarcktürmen auf:}

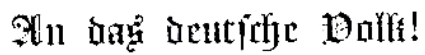

Eingeden" ihrer 2rufgabe, allejeit hiliterin des nationalen Gedarfens ju fein, hat die afademifige Jugent aller Lniver fitäten und Lodffhulen Deutfhlands fid gevinigt, eine allgemene Kundgebung des dentfhen Dolfes für unfern dahingefdjiedenen

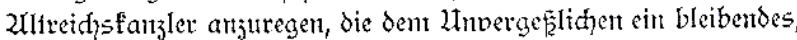

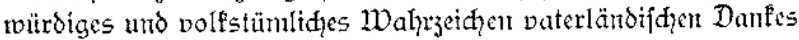
alfrichte.

Zriht ein einzelnes 2Tomment pon biendenter Pradit, mę̧r

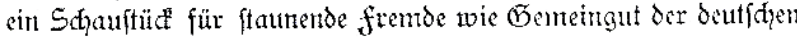
Dolfsaenoffen, foll dent fdilidten Gelden erfteher.

Wie vor Jetten die alten Sadyen und ZTormanten über den Eeibent ihrer gefallenen Reden fĭmuctlofe felfenfüulen auf: tütmtell, derent Spitzen feterfanale 1rugen, fo twollen wir unferm Bismarc? zu Ehren auf allen Göhen unferer heintat, von wo

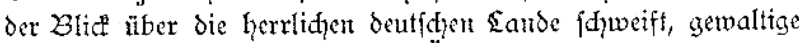
grantitene feuerträzer erriđtent. überall foll, cin Sumbild der Einheit Deutfhlands, bas gleide Jeidzen erftehent, in ragender Gröfse, aber einfah und prunflos, auf naffivem literbau ein fhlihte Säule, nur mil dent Wappen und Wahliprudy des eifernen Kanzlers gefdymült. Témen Kanten foll der gewaltige Stein tragen, aber jedes Kkinto wird ihn dem fremden deuten Föment:

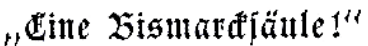

"Kontm ihr vom Weften unferes Reidjes himüber zur DftmarÉ, füh̨t Eun der $\mathfrak{W}_{\mathfrak{e g}}$ von der See ju den allpen -.. übrall wo Deutfige wohnten, werdet itge daffelbe Wahrzeidyen fehin."

Don der Spitze diefer Bismardfüulen follen aus ehernen feuerbehältent flammen weithin durf bie Raḑt leuḑten, fo oft untfer Dolf in gemeinfamer feier feines verfläten belden gederift.

Diefen ibren plan ju vermirfliden, wertoet fiळ dic dentide Gtudentensdaft an das ganze deutíde volt.

Sie tweí, wie viele Gerjen der a fadenifityen Jugend ent.

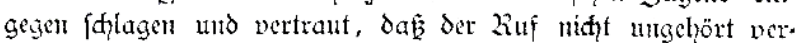
hallen wird, den fie ju bes Rieidyes Ehre erhebt.

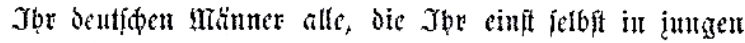

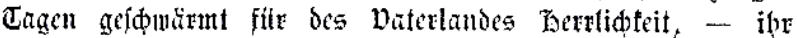
Stäbte unto Genteintoen, die ibr wader anf dem plane fteḅt fiur

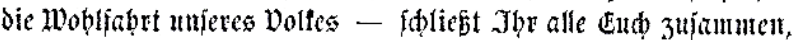
in Gurem beimatgau bisntardfäulen zu bautn!
Dat fe fommenden Gefhledtern erjählen, wie ber Par teien Kader verftumumte vor ber heiligen Stille jener bruft int

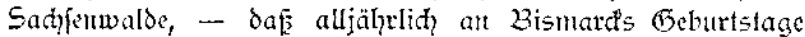
und went forft uns eitt vaterländifdes feft befhert ift, nad, Sommuntergang fin von Berg 3 ll $\mathcal{B e r g}$ die Ladit erhelle mit flanmenfhein, dent grofent Kanzler ju Elyen, der fortlebt in den Eerzen feines Dolfes.

2liogse trene siebe aller Drten in unferer deutidyen heimat (id) regent, in jeder Stadt, in jeder Gentinde ein 2lusfdutis fid bilden, dies Werł deutfher Danfbarfeit ju fördem. Welḑe form der Säule geeiguet fei, unjern Gedantet wirffam ju ver

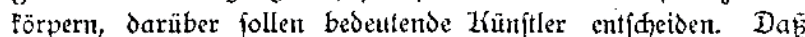
dem Plane die Einheit gewahtt bleibe, ftellen wir pläne und Thoftenarfdaläge Jedermant ju Derfügung.

Wir felbft, die deutjhe Studentenldiaft, werden

\section{jluei Süulcu}

aus den 2rititeln unfes Wedffels erridgten. 2uber damit nidut genug: bei jeder Stadt womöglid, dic der Sits einer dentidgen hodfidyule ift, wollen wir dert Denfftein erftehen laffer. Er wird befontoers an feintem plate feit an diefen Sammelftäften der Jugend aller deulị̂jer Stänmm, wo er alljährlid der zrîttel. punt ciner erhebenden afademifigen feier werden famt. Jede Studentenfthaft wird fid verpflidten, die Säule ihrev hodffidule in ihre befondere Dbhut ju tehnten unto alljäbrita die feuer ju entjültdent.

Dic Lioften für alle diefe Säulen felbit aufjubringen abar überfteigt unfere Kräfte. 2fll alle alten Hlabemifer, an mufre

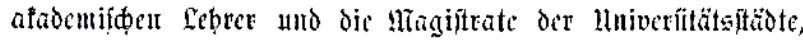
fowic an alle, dic den ibcalen beftrebungen der dentíben afa= demifden Jugend ibre Woblwolten entgegenbritgen, ergebt ocs. balb mire berslide bitte, durd Gelofpenden uner unterneb: men föroer su wollen.

Beiträge jur Erridtung von Bismardłäulen fiił dic beut:

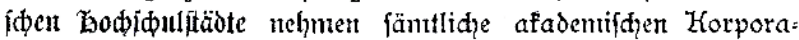
fionen aller deutfden Univerfftäten und Godfifulen, fonvie die unten bejeidyuten Banfen entgegen.

27öge die trene Danfbarfeit und opferfrendige siebe des deutfinen Dolfes uns beiftehen, datis Wahrheit werde, was wir ans eigener Kraft nur platen und antezen fömten, unferm

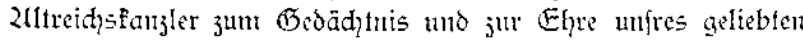
beutfhen Daterlandes.

Die dentfie Studentenfdaft.

(http://www.bismarcktuerme.de/ebene3/historie/bbund.html)

\section{Arbeitsaufträge}

1. Nenne die Gründe, die die Deutsche Studentenschaft für die Errichtung von Bismarcktürmen angibt (M4). 


\section{M5 Mahnung für Kinder und Kindeskinder}

Der Göttinger Oberbürgermeister Merkel bält eine Rede zur Grundsteinlegung des Bismarckturms am 29.6.1892:

„Der patriotische Gedanke, dem ersten Reichskanzler, dem Fürsten Bismarck, unserem Ehrenbürger, auf der Höhe des Hainberges einen mächtigen Turm zu bauen, ist ein alter. [...] Der Turm soll ein Zeichen der 5 unauslöschlichen Dankbarkeit für die Herstellung der deutschen Nation in ihrer Herrlichkeit und Macht sein. Der Turm soll ein Zeichen der unwandelbaren
Treue in einer Zeit sein, wo vaterlandslose Gesinnung an dem alten Löwe zu zerren wagte. Der Turm soll 10 für Kind und Kindeskinder eine Mahnung sein, festzuhalten mit eisernen Klammern an der auf blutigen Schlachtfeldern erkämpften Einheit der Deutschen. [...] Seiner Durchlaucht dem Fürsten von Bismarck, unserem hohen Ehrenbürger, ein dreifaches Hoch!“

(Stadtforstamt Göttingen, Der Bismarckturm auf dem Hainberge. Dokumente zur Baugeschichte, Göttingen 1996 , S. 28-29)

\section{M6 Eine patriotische Feier}

Dr. Eckels bält eine Rede zur Weibe des Bismarckturms am 18.6.1896:

„Hochverehrte Festgenossen! Während wir heute zu patriotischer Feier in kleinem Kreise vereinigt sind, haben sich gleichzeitig in der uns benachbarten goldenen Aue Tausende von deutschen Kriegern versam5 melt, um einen großen nationalen Festtag zu begehen. Auf der Spitze des sagenumwobenen Kyffhäusers hat sich [...] ein stolzer Monumentalbau erhoben, den die deutschen Krieger errichteten zu Ehren ihres unvergesslichen Kriegsherrn des Heldenkaisers Wilhelm I., 10 des Großen. Auf demselben Berg, in dessen Schoß, wie uns die Sage erzählt, Kaiser Friedrich Barbarossa träumend saß und den Zerfall des deutschen Reiches bedauerte, steht heute Kaiser Wilhelm, der mächtigste Fürst Europas [...] Wir aber weihen zu gleicher Zeit 15 diesen Bau, auf dem wir stehen, dem Andenken des
Mannes, ohne den heute keine Nationalfeier am Kyffhäuser stattfände, ohne den es kein Deutsches Reich und keinen deutschen Kaiser gäbe, des ersten, des einzigen, des großen Kanzlers Otto von Bismarck. $20[\ldots]$

Möge [der Turm] stehen stolz und fest, wie der Held, zu dessen Ehren er erbaut ist! Möge er den kommenden Geschlechtern stets ins Gedächtnis rufen die große Zeit der Wiederaufrichtung des Deutschen

25 Reiches! Möge er die Erinnerung daran festigen, wie viel Blut und Tränen vergossen werden mussten, ehe dem deutschen Volke nach hartem Kampfe der Segen der Einheit zu Teil wurde! Möge er in jedem patriotischen Herzen den Entschluss erwecken, das Erreichte 30 festzuhalten in treuem Herzen und mit starker Hand!“

(Stadtforstamt Göttingen, Der Bismarckturm auf dem Hainberge. Dokumente zur Baugeschichte, Göttingen 1996, S. 36-39)

\section{Arbeitsaufträge}

1. Arbeite heraus, welche Gründe und Ziele für den Bau des Göttinger Bismarckturmes in den beiden Reden genannt werden.

2. Analysiere die Parallelen, die in M6 zum Kyffhäuserdenkmal gezogen werden. Informiere dich über das Kyffhäuserdenkmal und vergleiche die beiden Denkmäler in ihrer Bedeutung. 


\section{Das Südwestafrika-Denkmal}

\section{David Meiser}

Zum Gedenken an gefallene Soldaten im „Herero-Krieg" errichteten Angehörige eines Infanterieregiments in Göttingen dieses Denkmal. Im Laufe der Zeit wurde es kritisch rezipiert und beschädigt. In der Beschäftigung mit dem Objekt können Schülerinnen und Schüler anschaulich nachvolliziehen, wie sich der Blick auf den deutschen Kolonialismus im Lauf des 20. Jabrbunderts verändert.

\section{Erscheinungsbild}

Das 1910 errichtete Kriegerdenkmal steht an der Weggabelung Friedländer Weg/Geismarlandstraße, in der Nähe des Geländes der ehemaligen Lüttich-Kaserne - heute der Gothaer Versicherung. Innerhalb eines kleinen umzäunten Bereichs befindet sich auf einem künstlich angelegten Hügel ein Steinsockel. In ihn ist eine Gedenktafel aus Marmor eingelassen, die von einer Plexiglasscheibe überdeckt wird.

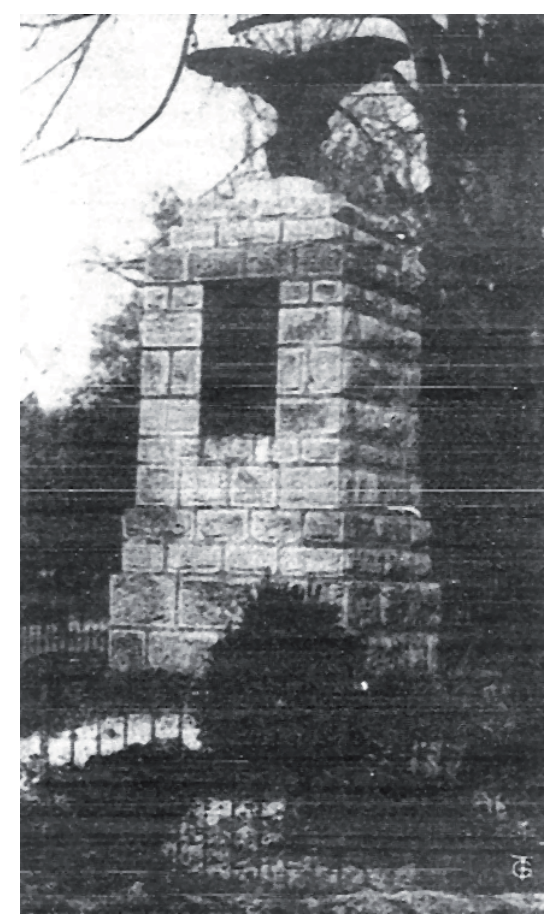

Südwestafrika-Denkmal ,1910

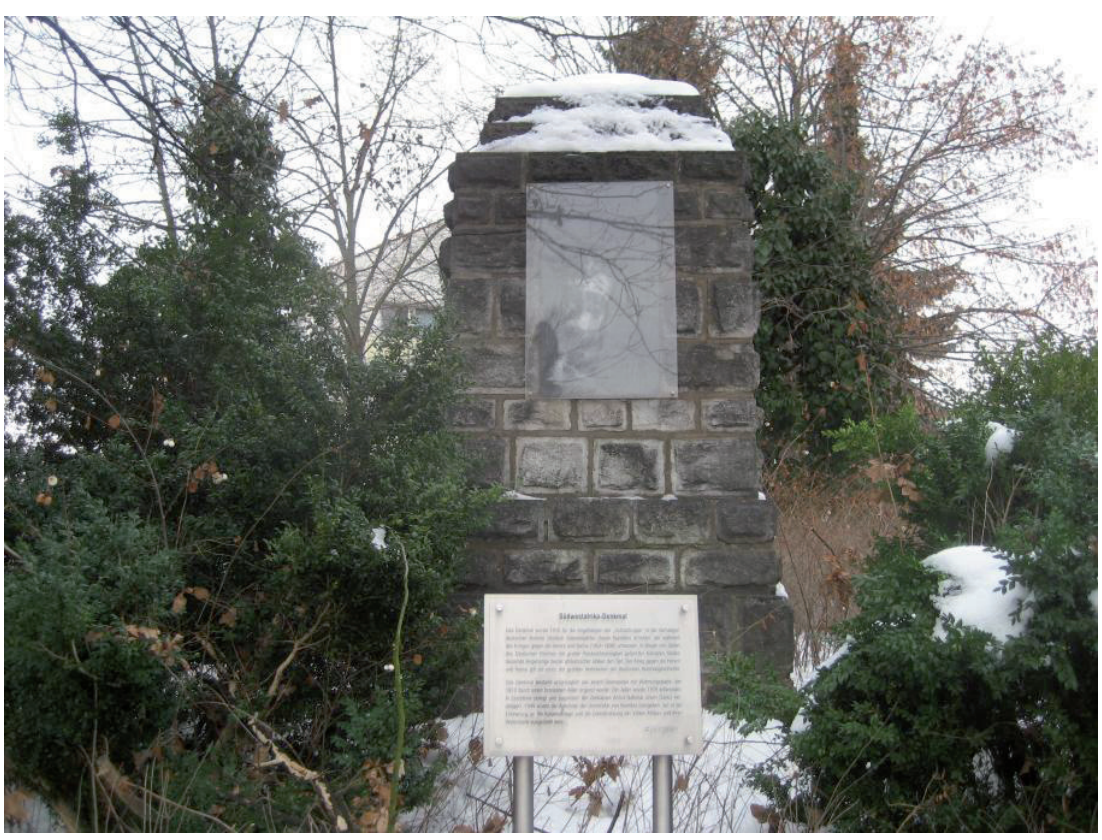

Südwestafrika-Denkmal, 2011

Davor ist eine Informationstafel aus Plexiglas aufgestellt. Wegen der Verkehrssituation vor Ort, der modernen Beschilderung sowie des reichhaltigen Bewuchses der Anlage ist das Denkmal aus der Distanz nicht leicht auszumachen, auch wenn die zur Weggabelung führenden Straßen durchaus langgestreckte Blickachsen bieten. Die eigentliche Bekrönung des Sockels in Form eines Bronzeadlers ist nicht mehr vorhanden.

\section{Entstehung und Intention}

Das Denkmal bestand zunächst nur aus dem Steinsockel. Er wurde von Angehörigen des 2. Kurhessischen Infanterie-Regiments Nr. 82 in Auftrag gegeben, das in einer Kaserne an der Geismarlandstraße beheimatet war. Anlass und zugleich Funktion war die Ehrung von vier in der Inschrift der Gedenktafel genannten Soldaten, die während des „HereroKrieges“ (1904-1908) gefallen waren.
1913 wurde, finanziert durch Spenden, ein „Bronzeadler“ hinzugefügt, der mit ausgebreiteten Flügeln auf einer Weltkugel saß. Dies geschah im Rahmen der 100-JahrFeier des Regiments (5.-7. August). Die Stadt Göttingen stiftete zur Feier ein Kaiserporträt Wilhelms II. für den Speisesaal der Offiziere und Geld für die Angehörigen von Unteroffizieren des Regiments.

Weitere Kolonialdenkmäler in Deutschland sind das „Landes-Kolonialkriegerdenkmal “ in Dresden (1913), das „Reichs-Kolonial-Ehrenmal" in Bremen (1932) - heute „Anti-Kolonialdenkmal“" (1990) - und das Kolonialkriegerdenkmal in Düsseldorf (1909) sowie im ehemaligen Südwestafrika selbst das Reiterstandbild in Windhoek (1912).

\section{Geschichte und Rezeption}

Die weitere Geschichte des Denkmals lässt sich in drei größere Phasen aufteilen. Seine Wahrnehmung folgte dem Wandel der Blickweise 
auf den deutschen Kolonialismus im Allgemeinen: von Zustimmung und Begeisterung zu Kritik und Distanzierung.

Die erste Phase bis Ende der 1970 er Jahre war von der intendierten Wirkung bestimmt. Von Zwischenfällen wurde nicht berichtet. Zum 25-jährigen Jubiläum erschien im Göttinger Tageblatt ein Artikel des Denkmalinitiators Ernst Dieterichs.

Die zweite Phase ab 1978 war von Kritik geprägt. Anfang April 1978 entfernten Unbekannte die Bekrönung des Denkmals sowie die Gedenktafel. Wenig später bekannte sich der Kommunistische Bund Westdeutschland zu diesem Übergriff und versteigerte im Rahmen einer Ortsgruppenversammlung am 1. Mai 1978 den abgesägten Kopf des Adlers. Der Erlös ging an die Befreiungsbewegung ,Zimbabwe African National Union“. Ursprünglich sei geplant gewesen, den Adler einzuschmelzen und „Befreiungsmedaillen" daraus anzufertigen, um Freiheitskämpfer im namibischen Unabhängigkeitskrieg (seit 1966) zu unterstützen. Der Adlerkopf befand sich anschließend in Privatbesitz.

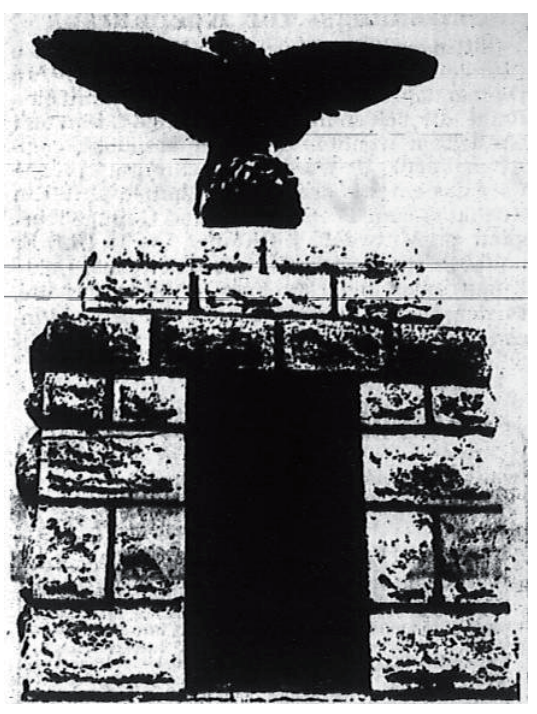

Bekrönung des Südwestafrika-Denkmals, 1913

1981 wurde die gestohlene Gedenktafel von der Stadtverwaltung Göttingen durch eine Replik ersetzt, auf der die Information hinzugefügt wurde: „Der Bronzeadler / und die Gedenkplatte / sind am 7.4.1978 / von Unbekannten / gestohlen worden."

Die dritte Phase ab 1989 war gekennzeichnet durch das Bemühen, das Südwestafrika-Denkmal umzuwidmen - vergleichbar mit der Umwidmung des Bremer Kolonialdenkmals (1990). Die Grün-Alternative Liste beantragte im Stadtrat, anlässlich der Unabhängigkeit Namibias 1990 eine kritische Informationstafel am Denkmal aufzustellen; dieser Antrag wurde jedoch abgelehnt.

1999 gelangte der Adlerkopf in den Besitz der Student-History-Society in Windhoek. Am 100. Jahrestag des „Herero-Krieges“ im Jahr 2004 hielt die „Gesellschaft für bedrohte Völker e.V.“ (GfbV) eine Gedenkveranstaltung am Denkmal ab, um der afrikanischen Opfer des Krieges zu gedenken. Die Aktion fand im Rahmen der deutschlandweit angelegten Kampagne „Der Völkermord an den Herero" statt und forderte vom Deutschen Bundestag, er solle ,[...] den Völkermord an den Herero durch Truppen des deutschen Kaiserreiches Anfang des vergangenen Jahrhunderts in der damaligen Kolonie Deutsch-Südwestafrika offiziell anerkennen“ (Homepage der GfbV). Im selben Jahr wurde der Adlerkopf der ursprünglichen Bekrönung in Berlin und Köln ausgestellt (Ausstellung: Namibia - Deutschland. Eine geteilte Geschichte).

2006 bemühte sich das „Göttinger Antikolonial-Bündnis“, eine Umwidmung vorzunehmen. Am 15. Januar stellten Mitglieder eine zusätzliche Informationstafel auf, die jedoch bereits am 20. Januar im Auftrag der Stadtverwaltung wieder entfernt wurde. Auf dieser Tafel forderte man ,[...] die Bundesrepublik Deutschland auf, endlich ihre Verantwortung anzuerkennen und Entschädigung an die Nachkommen der Opfer zu zahlen“" (Text der Infotafel). Die in der Inschrift des Denkmals genannten Soldaten wur- den wie alle weiteren deutschen Soldaten, die am „Herero-Krieg“ beteiligt waren, als Massenmörder bezeichnet, die Kriegsführung als Genozid. Deshalb sollte eher der Opfer gedacht werden, „,[...] die von den deutschen Kolonialtruppen ermordet wurden“ (Text der Infotafel).

2007 wurde im Auftrag der Stadt eine Plexiglastafel über der marmornen Inschriftenplatte angebracht, um diese vor weiteren Übergriffen zu schützen. Außerdem wurde die heute vorhandene Informationstafel aufgestellt. Am 31. Oktober 2008 erschien im Göttinger Tageblatt ein rekapitulierender Artikel auf Grundlage des Interviews mit einem der unbekannten „Denkmalstürmer“ von 1978.

\section{Didaktische Überlegungen}

\section{Intentionen}

Das Südwestafrika-Denkmal ist eines der wenigen Kolonialkriegerdenkmäler in Deutschland. An diesem Beispiel können Schülerinnen und Schüler die Rezeption des „Herero-Krieges“ untersuchen und Kenntnisse über die Kontroversität von Denkmälern als Fokuspunkte von Erinnerung erwerben. Damit können sie das Thema Kolonialismus an einem deutschen Beispiel bearbeiten.

\section{Sekundarstufe I}

Die Beschäftigung mit dem Denkmal kann in den Unterricht der 9. und 10. Klasse im Rahmen des Themenbereiches „Kaiserreich, Imperialismus und Erster Weltkrieg“" eingebunden werden. In diesem Fall können Schülerinnen und Schüler erarbeiten, wie der deutsche Imperialismus in Deutschland selbst dargestellt wurde. Für diese Einheit sollten zwei bis drei Stunden eingeplant werden.

Auch im Themenbereich ,Geschichte Deutschlands nach 1945 im europäischen und internationalen Kontext" ist unter dem Stichwort 
Dekolonisierung eine Beschäftigung mit dem Denkmal möglich. Für diese Einheit sollten etwa drei Stunden eingeplant werden, wenn die Aufgaben 3 und 4 der vierten Materialseite im Plenum bearbeitet werden. Werden sie in eigenständigen Gruppen behandelt, sollten vier Stunden veranschlagt werden.

\section{Sekundarstufe II}

Die Beschäftigung mit dem Denkmal kann hier innerhalb des Rahmenthemas 3 (,Wurzeln unserer Identität ${ }^{(\prime)}$ erfolgen. Das Wahlmodul 6 („Begegnung mit der Geschichte in der Kultur") und das Wahlmodul „Nationalismus und deutscher Imperialismus" bieten die Möglichkeit, eine Auswahl der Materialseiten zu bearbeiten. Für die Materialseiten 2-3 sollte dann je eine Stunde veranschlagt werden, für Seite 4 zwei Stunden.

Auch im Rahmenthema 4 („Geschichts- und Erinnerungskultur") ist die Auseinandersetzung mit dem Südwestafrika-Denkmal möglich.

\section{Exkursion}

Wegen der Situation vor Ort (vielbefahrene Weggabelung) scheint eine Exkursion zunächst wenig praktikabel. Außerdem ist ein Teil des Denkmals demontiert worden, so- dass eine Annäherung an den früheren Ausdruck heute viel Vorstellungskraft verlangt. Trotzdem kann eine Ortsbegehung speziell für die Bearbeitung der Materialseite 2 ertragreich sein, da dann der Einfluss der Umgebung auf die Wirkung des Denkmals besonders eindrücklich ist.

\section{Materialseite 1}

Dieser Steckbrief fasst grundlegende Informationen zum SüdwestafrikaDenkmal zusammen.

\section{Materialseite 2}

Mit Hilfe dieser Materialien können Schülerinnen und Schüler die Inschrift des Denkmals interpretieren. Hinzugezogen wird ein Zeitungsartikel aus der affirmativen Phase der Denkmalsrezeption. Daran können Schülerinnen und Schüler erarbeiten, dass das Denkmal der Heroisierung deutscher Soldaten diente, die durch die Ehrung ihrer Gegner noch gesteigert wurde. Jedoch erscheinen diese würdigen Gegner nicht in der Inschrift, was einen Kontrast zum Artikel darstellt.

\section{Materialseite 3}

Hier können Schülerinnen und Schüler sich der ehemaligen und heutigen Form des Denkmals annähern. Anhand des Adlersymbols als Bekrönung können Vermutungen über die ehemalige Wirkung des Denkmals angestellt und die Motivation der Denkmalstürmer von 1978 nachvollzogen werden. Im Anschluss können diese Erkenntnisse auf die Gegenwart angewendet werden, indem reflektiert wird, ob eine Veränderung angebracht sein und wie sie aussehen könnte.

\section{Materialseite 4}

Hier können Schülerinnen und Schüler Einblick in die Prozesse einer Umwidmung von Denkmälern erhalten. Als Fallbeispiel dient die versuchte Umwidmung des Südwestafrika-Denkmals von 2006. Sie können die Position des Göttinger Antikolonialbündnisses erarbeiten und dessen Argumentation nachvollziehen. Dieser gescheiterte Versuch wird sodann einer erfolgreich durchgeführten Umwidmung gegenübergestellt, die die Schülerinnen und Schüler in eigenständiger Recherche erarbeiten können. Eine Veränderung am Denkmal kann beispielsweise eine „Umwidmungstafel" wie in Bremen sein oder sogar eine bauliche Umgestaltung wie eine neue Bekrönung, um den 1978 entstandenen Leerraum am Denkmal zu füllen.

\section{Literatur}

Förster, Larissa/Henrichsen, Dag/Bollig, Michael (Hrsg.), Namibia - Deutschland, Eine geteilte Geschichte. Widerstand, Gewalt, Erinnerung, Köln 2004.

Gottschalk, Carola (Hrsg.), Verewigt und vergessen. Kriegerdenkmäler, Mahnmale und Gedenksteine in Göttingen, Göttingen 1992.

Hillebrecht, Werner, Kolonialadler fliegt nach Namibia. Denkmalgeschichte aus dem Namibian Weekender vom 13. August 1999, in: iz3w 241 (1999), S. 4. Im Internet unter: http://www.freiburg-postkolonial.de/Seiten/ kolonialadler.htm (eingesehen am 22.2.2011).

\section{Unveröffentlichte Quellen}

Zur Informationstafel: Antrag der Grün-Alternativen Liste v. 1.12.1989 (Kulturamt der Stadt Göttingen). 


\section{Veröffentlichte Quellen}

25 Jahre Südwestafrika-Denkmal, in: Göttinger Tageblatt, 28./29. Dezember 1935.

Spätes Bekenntnis eine Denkmalstürmers, in: Göttinger Tageblatt, 31. Oktober 2008.

\section{Internet}

http://www.denkmale.goettingen.de/denkmale/suedwestafrikadenkmal.html.

http://www.denkmale.goettingen.de/downloads/suedwestafrika.pdf.

http://www.freiburg-postkolonial.de/Seiten/Goettingen-kolonialadler.htm.

http://www.freiburg-postkolonial.de/Seiten/kolonialadler.htm.

http://www.afrika-hamburg.de/denkmalsturz1.html.

http://www.der-elefant-bremen.de.

http://194.95.254.61/denkmalpflege/index.htm.

http://www.gfbv.de/inhaltsDok.php?id=49\&stayInsideTree=1.

(alle eingesehen am 16.2.2011) 


\section{Basisinformationen zum Südwestafrika-Denkmal}

\section{M1 Steckbrief}

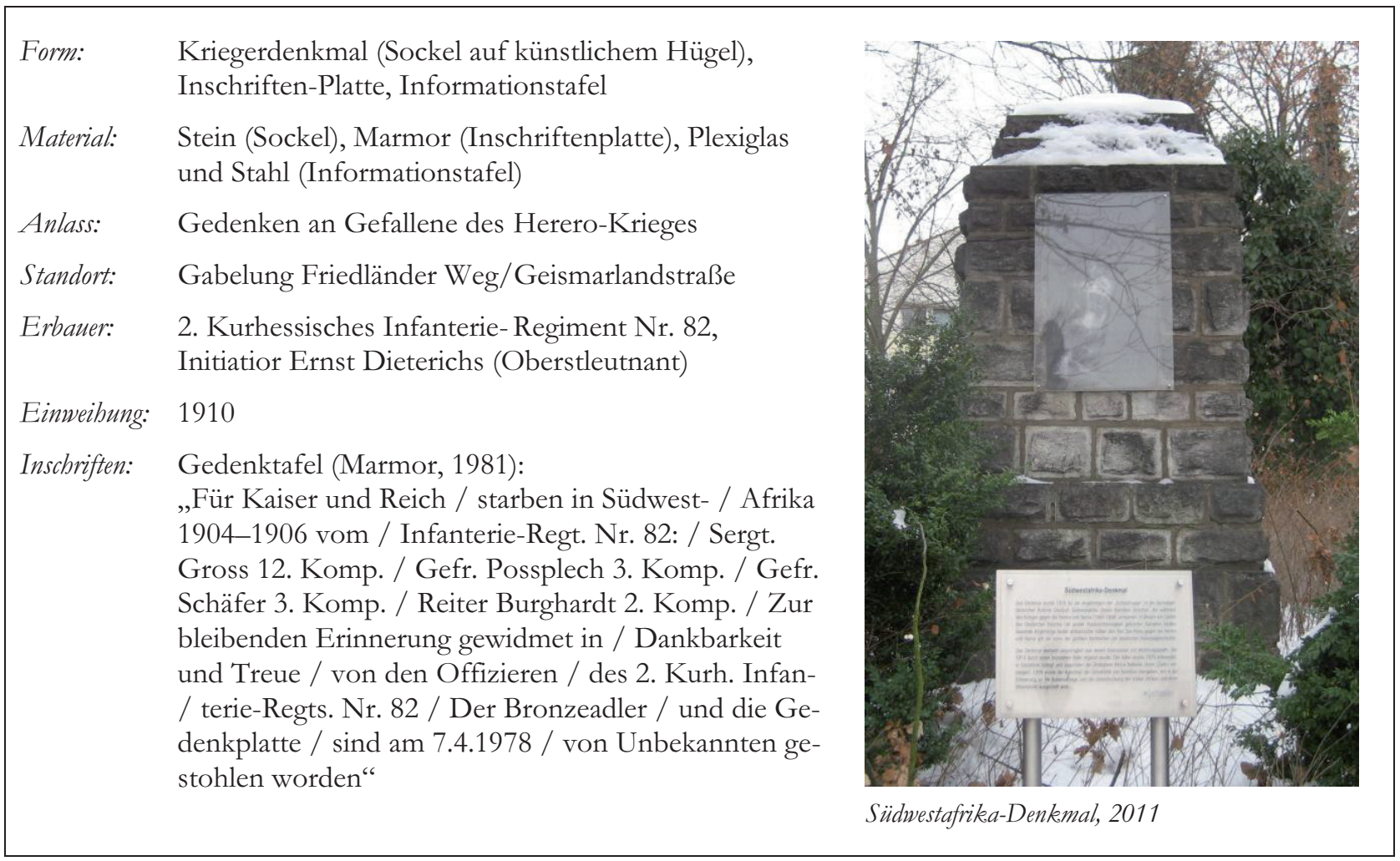

\section{M2 Zeitstrahl}

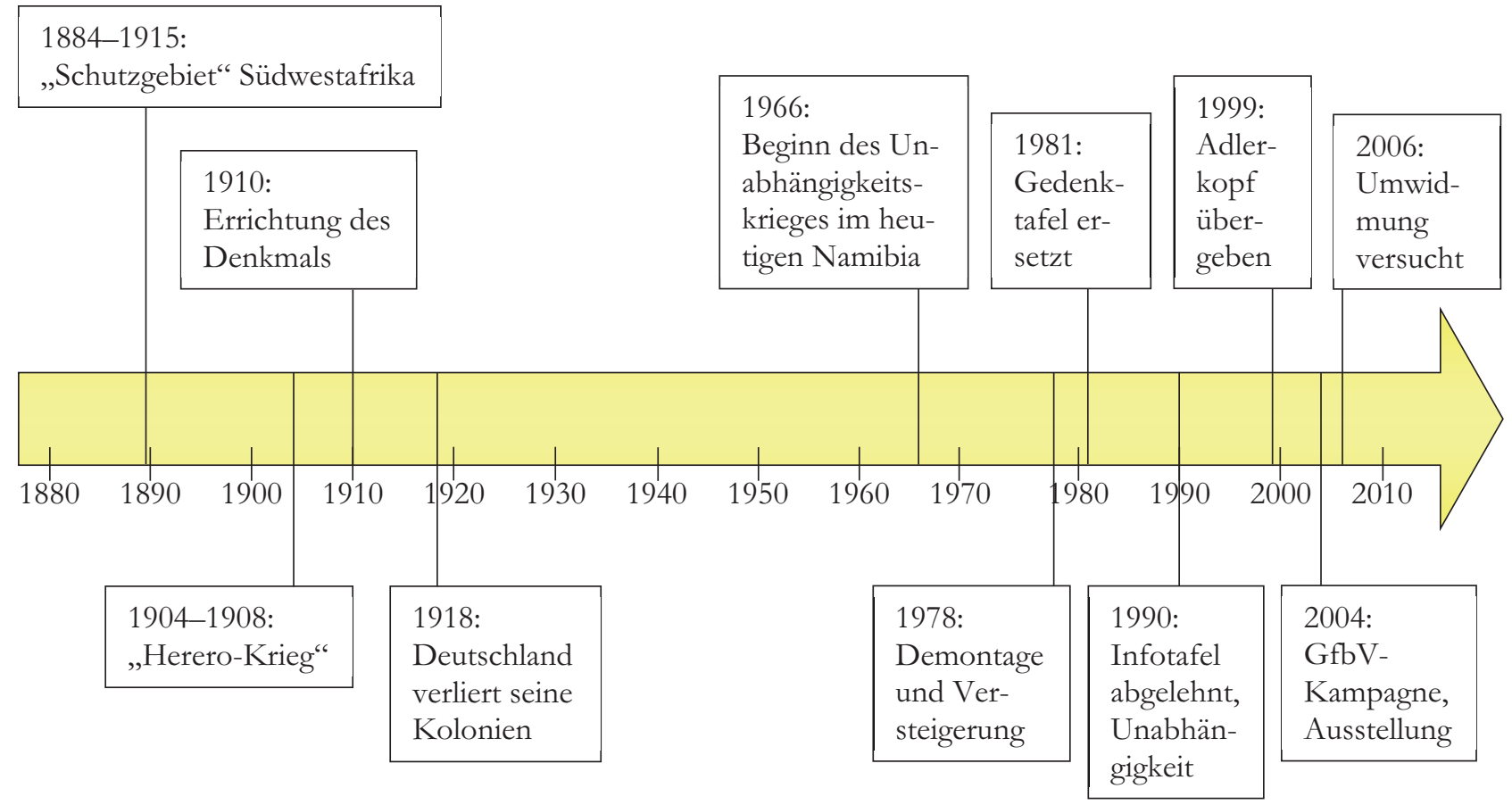




\section{Gedenken im Wandel}

\section{M3 Die Toten ehren}

Text der Inschrift am Südwestafrika-Denkmal (1981). Bis auf die letżten fünf Zeilen entspricht sie im Wortlaut der ersten Inschrift von 1910, die 1978 gestoblen worden war.

Für Kaiser und Reich / starben in Südwest- / afrika 1904-1906 vom / Infanterie-Regt. Nr. 82: / Sergt. Gross 12. Komp. / Gefr. Possplech 3. Komp. / Gefr. Schäfer 3. Komp. / Reiter Burghardt 2. Komp. / Zur 5 bleibenden / Erinnerung gewidmet in / Dankbarkeit und Treue / von den Offizieren / Unteroffizieren / und Mannschaften / des 2. Kurh. Infan- / terie-Regts. Nr. 82 / Der Bronzeadler / und die Gedenkplatte / sind am 7.4.1978 / von Unbekannten / gestohlen 10 worden

\section{M4 Die Toten ehren?}

Der Initiator des Denkmals, Oberstleutnant Ernst Dieterichs, stellt in einem Jubiläumsartikel zum 25-jährigen Bestehen des Südwestafrika-Denkmals Ende 1935 im Göttinger Tageblatt die historischen Umstände dar, die zu dessen Errichtung geführt hatten. Dabei charakterisiert er die kämpfenden Parteien des „Herero-Krieges":

\section{Sahre Siubwejtafrika=Denkmal}

Die Hereros waren keine Wilden, die, wie in den Kolonialkriegen anderer Nationen, mit Schwertern und Spießen in der Hand oder mit Pfeil und Bogen in das Feuer hineinliefen oder sich wie die Mohdisten [An5 hänger des Mahdi] bei Omdurmann von Kitcheners Maschinengewehren leicht niedermähen ließen. Es galt vielmehr einen Feind zu bekämpfen, der vermöge der Zucht seiner Stammesorganisation, seiner modernen Bewaffnung und seiner kriegerischen Gewöhnung

(Göttinger Tageblatt, 28./29. Dezember 1935)
10 ein sehr ernst zu nehmender Gegner war. [...] Nach langen Kämpfen konnte erst Ende März 1907 der Kriegszustand aufgehoben werden. Der große dreijährige Kolonialkrieg hatte den deutschen Soldaten als ganzen Mann gezeigt. Er war ein Held nicht nur der 15 Tat, sondern auch des stillen, geduldigen Leidens und Entbehrens und hat selbst in verzweifeltsten Lagen echt kriegerischen Geist an den Tag gelegt.

\section{Arbeitsaufträge}

1. Fasse die Inschrift zusammen. Beschreibe, um was für Personen es sich handelt und aus welchen Gründen ihrer gedacht werden soll (M3).

2. Vergleiche die Darstellung Dieterichs (M4) mit der Inschrift (M3). Erkläre, wie die militärischen Fertigkeiten der Hereros beschrieben werden. Erläutere, was es für Gründe dafür geben könnte. 


\section{Veränderungen am Denkmal}

\section{M5 Denkmalsturz}

Den Adler, der das Denkmal ursprünglich bekrönte, haben Mitglieder des Kommunistischen Bundes Westdeutschland 1978 demontiert. Mit dieser Aktion wollten sie eine afrikanische Befreiungsbewegung unterstützen. 30 Jahre danach bekennt sich einer der Verantwortlichen öfentlich:

\section{Spätes Bekenntnis eines Denkmalstïrmers}

Der angeblich 2,2 Tonnen schwere Koloss aus Bronze [...] sollte vom Sockel gestoßen werden. Pläne, ihn zu verwerten, waren auch schon geschmiedet. Einschmelzen wollte man den Adler und in Form kleiner 5 Medaillen zur Unterstützung des bewaffneten Kampfes in Simbabwe verkaufen. [...] Es kam anders. Als

(Göttinger Tageblatt, 31. Oktober 2008)

M6 Denkmal 2011

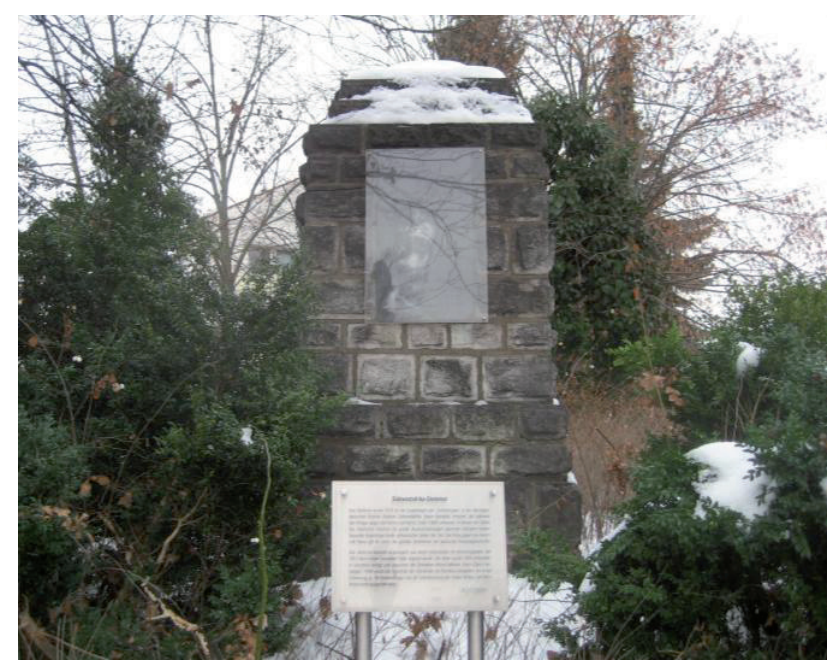

Südwestafrika-Denkmal, 2011 der Adler stürzte, „, hat es nur gescheppert“. Gerade einmal 30 bis 40 Kilogramm wog der irrtümlich als massiv angesehene Vogel. Nur der Kopf war aus Mes10 sing gegossen, der Rest aus Blech angelötet, die Weltkugel aus Bandeisen gefertigt.
M7 Denkmal 1935

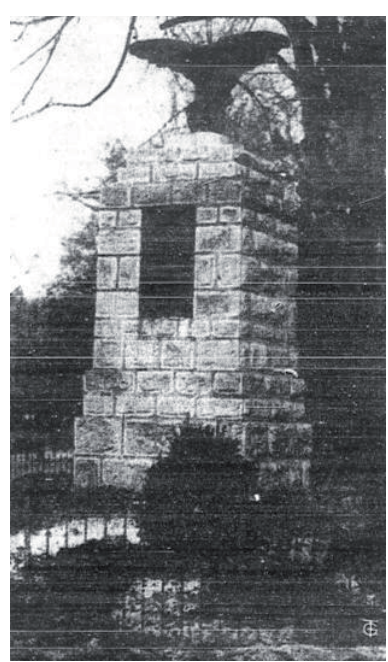

Südwestafrika-Denkmal, 1935

\section{Arbeitsaufträge}

1. Beschreibe die Wirkung, die das Denkmal auf dich hat (M6 und M7).

2. Erläutere anhand des Zeitungsausschnittes, inwiefern das Einschmelzen des Adlers ein Symbol darstellen sollte (M5). Fasse dazu Informationen über den Adler als Symbol zusammen.

3. Erörtert, inwiefern die Entfernung des Adlers die Wirkung des Denkmals verändert hat.

4. Nehmt Stellung dazu, ob es sinnvoll sein könnte, eine neue Bekrönung am Denkmal anzubringen. 


\section{M8 Kritik und Umwidmung}

Am 15. Januar 2006 stellten Mitglieder des Göttinger Antikolonialbündnisses unerlaubt eine Tafel am Südwestafrika-Denkmal auf, die wenige Tage später von der Stadtverwaltung entfernt wurde. Der Text lautete:

Die deutsche Kolonialgeschichte ist eine blutige Geschichte. In allen Ländern, die Deutschland als „Schutzgebiete“ für sich beanspruchte, wurde die einheimische Bevölkerung brutal ausgebeutet und unter5 drückt. Als sich 1904 in „Deutschsüdwestafrika“ - dem heutigen Namibia - die Herero und Nama gegen die Besatzer zu wehren begannen, reagierte die deutsche Kolonialarmee mit einem Völkermord. Von 80.000 Herero überlebten nur 16.000. Von 20.000 10 Nama wurde mehr als die Hälfte umgebracht.

Wir Göttingerinnen und Göttinger gedenken der Menschen, die von den deutschen Kolonialtruppen ermordet wurden. Wir fordern die Bundesrepublik Deutschland auf, endlich ihre Verantwortung anzuerkennen und Entschädigung an die Nachkommen der Opfer zu zahlen.

Mit dem Denkmal, vor dem diese Tafel steht, hält die Stadt Göttingen bis heute das ehrende Gedenken an Massenmörder aufrecht. Seit 1910 erinnert es „in 20 Dankbarkeit und Treue" an gefallene deutsche Soldaten, die am Genozid an den Herero und Nama in „Deutschsüdwestafrika“ beteiligt waren. 1978 holten Mitglieder des Kommunistischen Bundes Westdeutschland in einer antikolonialen Aktion den auf
25 dem Denkmal thronenden Bronze-Adler von seinem Sockel. Die ebenfalls entwendete Gedenktafel ließ die Stadt Göttingen neu anfertigen und wieder anbringen - mit dem Originalwortlaut. Bis heute weigert sich die Stadt das Denkmal mit einer neuen Tafel zu versehen 30 und es umzuwidmen zu einem Mahnmal für die Opfer des deutschen Kolonialismus.

\section{Arbeitsaufträge}

1. Beschreibe den Aufbau des Textes (M8). Charakterisiere seine Argumentationsweise.

2. Erörtert in der Klasse, ob der Text und die Form der Tafel für das Anliegen, das sie vermitteln sollen, angemessen sind. Nehmt Stellung zu der Frage, ob die aufgestellten Forderungen realistisch sind.

3. Recherchiert über das Anti-Kolonialdenkmal in Bremen. Beschreibt dafür den Aufbau des Denkmals, die Entstehungsgeschichte und seine Umwidmung. Vergleicht die Ergebnisse mit dem Südwestafrika-Denkmal.

4. Erörtert in der Klasse, wie eine Umwidmung des Südwestafrika-Denkmals durchgeführt werden könnte. Entwickelt ein Konzept, wie eine mögliche Umsetzung aussehen könnte.

\section{M9 Infotafel}

\section{Diese Informationstafel aus Plexiglas wurde 2007 angebracht:}

Südwestafrika-Denkmal / Das Denkmal wurde 1910 für die Angehörigen der „Schutztruppe“ in der damaligen deutschen Kolonie Deutsch Südwestafrika (heute Namibia) errichtet, die während des Krieges gegen 5 die Herero und Nama (1904-1908) umkamen. In diesen von Seiten des Deutschen Reiches mit großer Rücksichtslosigkeit geführten Kämpfen fanden tausende Angehörige beider afrikanischer Völker den Tod. Der Krieg gegen die Herero und Nama gilt als 10 eines der größten Verbrechen der deutschen Koloni- algeschichte. Das Denkmal bestand ursprünglich aus einem Steinsockel mit Widmungsplatte, der 1913 durch einen bronzenen Adler ergänzt wurde. Der Adler wurde 1978 entwendet, in Einzelteile zerlegt und 15 zugunsten der Zimbabwe Africa National Union (Zanu) versteigert. 1999 wurde der Adlerkopf der Universität von Namibia übergeben, wo er zur Erinnerung an die Kolonialkriege und die Unterdrückung der Völker Afrikas und ihren Widerstand ausgestellt wird.

\section{Arbeitsaufträge}

1. Entwickle einen Zusatz zur Inschrift, der die Opfer auf Seiten der Hereros berücksichtigt.

2. Erörtert in der Klasse, ob die heutige Inschrift angemessen ist oder ob sie umgestaltet werden sollte. 


\title{
Das Ehrenmal für die Gefallenen des Reserve-Infanterie-Regiments 91
}

\author{
Alexander Tietz
}

Das symbolische Gedenken an gefallene Soldaten in Form von Kriegerdenkmälern erreichte in Deutschland nach dem Ersten Weltkrieg seinen Höhepunkt. Eines von mehreren Göttinger Beispielen ist das Denkmal für die Gefallenen des ReserveInfanterie-Regiments 91 am Theaterplatr. gegenüber dem Max-Planck-Gymnasium. Als lokalhistorisches Relikt eröffnet es in $V$ erbindung mit den zeitgenössischen Quellen zur Denkmalseinweibung und den $\mathrm{R} e$ gimentsfeiern Einblicke in die Geschichte der Weimarer Republik. Bei der Einbindung in den Geschichtsunterricht lernen Schülerinnen und Schüler an einem repräsentativen Beispiel, sich kritisch mit der Kriegsdeutung von Regiments- und Kriegervereinen in den 1920er Jabren auseinanderzusetzen, die die betrauerten Frontsoldaten als beldenhafte, „im Felde unbesiegte" Kämpfer des Vaterlandes für eine nationalistisch-revanchistische Propaganda vereinnahmten.

\section{Erscheinungsbild}

Das Ehrenmal für die Gefallenen des Reserve-Infanterie-Regiments 91 steht auf einem halbrundförmigen Platz gegenüber dem Göttinger Max-Planck-Gymnasium, der der Straße zugewandt ist und sich dem Blick des Passanten daher sofort erschließt.

Vor dem Hintergrund von Bäumen und Büschen erhebt sich ein mehrfach abgestufter, über $3 \mathrm{~m}$ hoher und dadurch sehr mächtig wirkender Sockel, auf dem die lebensgroße, in antikem Stil gestaltete Plastik eines unbekleideten, muskulösen jungen Kriegers ruht. Seine Haltung erinnert in spiegelverkehrter Variation an die oft imitierte römische Marmorskulptur des „Sterbenden Galliers“. Das linke Bein und Gesäßteil des Jünglings ruhen auf dem Boden, mit dem linken Arm stützt er sich ab. Die rechte Hand umfasst

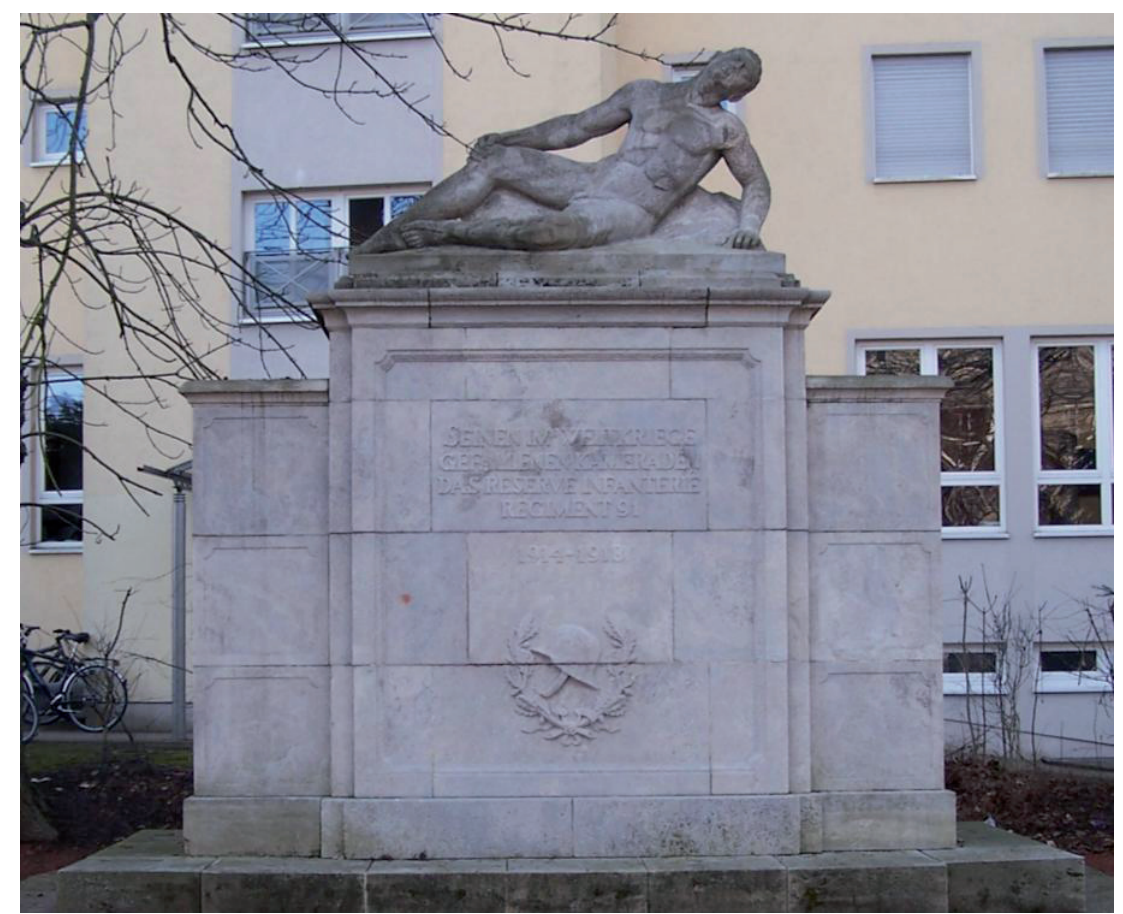

Denkmal für die Gefallenen des 91er-Regiments, 2011

das angewinkelte rechte Knie. Der Oberkörper neigt sich in einem Winkel von ca. 45 Grad, der schräg nach hinten geneigte Kopf noch stärker zur Erde. Zwar lassen sich die Gesichtszüge des Kriegers wegen der starken Verwitterung nicht mehr genau ausmachen, doch vermittelt seine gesamte Haltung den Eindruck, dass er unter Schmerzen sterbend zu Boden sinkt.

Der Denkmalssockel trägt auf allen Seiten Reliefdarstellungen mit Inschriften und für Kriegerdenkmäler dieser Zeit typischen Symbolen. Die Vorderseite nennt die Widmung und ihren Urheber: „Seinen im Weltkriege / gefallenen Kameraden / Das Reserve Infanterie Regiment 91 / 1914-1918“ - und zeigt darunter als Zeichen der militärischen Ehre einen mit Eichenlaub umkränzten Stahlhelm. Auf der linken und rechten Sockelseite sind in jeweils drei vertikal angeordneten Teilreliefs die Schlachten bzw. die

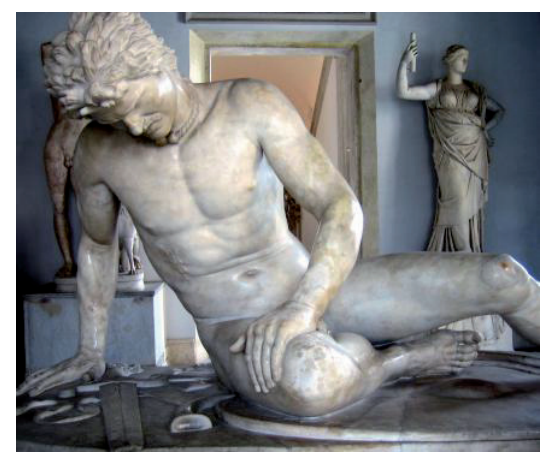

Sterbender Gallier: Marmorskulptur, Kapitolinische Museen, Rom 2005

Schlachtorte des Regiments an der Westfront aufgelistet. Die Rückseite schließlich gibt die Zahlen der gefallenen Soldaten in militärischer Rangfolge an: „Für ihr Vaterland / starben vom Regiment / 104 Offiziere / 326 Unteroffiziere / 2702 Mannschaften“. Über der Inschrift prangt die Darstellung eines Eisernen Kreuzes, das seit 1813 als Auszeichnung für Leistungen im Krieg in Form eines Ordens verliehen wurde 
und auch auf Kriegerdenkmälern als Symbol Verbreitung fand.

\section{Entstehung und Intention}

\section{Das Reserve-Infanterie-Regiment 91}

Im Zuge der Mobilmachung für den Ersten Weltkrieg waren in Göttingen Anfang August 1914 zwei Bataillone des Reserve-Infanterie-Regiments 91 aufgestellt worden. Ihre Mannschaften rekrutierten sich vor allem aus dem südhannoverschen Gebiet, aus Göttingen, Duderstadt, Einbeck und Osterode. Aus Hameln schlossen sich dem Regiment ein drittes Bataillon und eine Maschinen-Gewehr-Kompanie an. An der Westfront war das Regiment fast viereinhalb Jahre im Einsatz, bevor es am 17. Dezember 1918 wieder in Göttingen einzog - statt anfänglich rund 3.300 Mann noch 700 Mann stark (GT 12./13. Juli 1930).

\section{Die Denkmalsinitiative}

Nach Kriegsende gründete sich der „Verein ehemaliger Angehöriger des Reserve-Infanterie-Regiments 91“, der es sich zur Aufgabe machte, „durch regelmäßige Zusammenkünfte die Kameradschaft zu pflegen, gemeinsame Erinnerungen aufzufrischen und das Andenken an die großen Taten des Regiments wachzuhalten" (Denkmalsurkunde). In einem Brief vom 26. Juli 1923 wandte sich der Verein an den Magistrat der Stadt Göttingen mit dem Anliegen, seinen ,gefallenen Helden hier in Göttingen ein Denkmal zu errichten" (Akta betreffend Einrichtung eines Denkmals). Als Standort favorisierte man den Theaterplatz, in dessen Nähe die Bataillone im August 1914 zusammengestellt und wo sie in einem Feldgottesdienst eingesegnet worden waren. Die Stadt stellte für das Denkmal einen Platz gegenüber dem Max-Planck-Gymnasium zur Verfügung und erteilte im Februar 1924 die Baugenehmigung. Der Denkmalsentwurf stammt aus der Feder eines ehemaligen Leutnants des Regiments namens Zimmermann. Auch die Finanzierung versuchte der Verein selbst zu tragen, geriet durch steigende Kosten (insgesamt 21.000 Rentenmark) allerdings in eine finanzielle Schieflage und wurde 1925 von der Stadt nachträglich mit 1.500 Rentenmark bezuschusst.

\section{Die Einweihung}

Der Verein der ehemaligen Regimentsangehörigen legte die Einweihung des Denkmals auf den 10. August 1924, den zehnten Jahrestag des Ausrückens an die Front, und machte dieses Ereignis zum Anlass seiner fünften Jahrestagung. Nach einem Festkommers am Vorabend fand am Sonntagvormittag ein Feldgottesdienst statt, nach dessen Abschluss sich ein musikalisch untermalter Festzug in Richtung des Denkmalsplatzes bewegte. Hier hielt Pastor Saathoff, der die Bataillone 1914 eingesegnet hatte, vor über tausend Zuhörern die Weiherede. Es folgte eine Ansprache des Vereinsvorsitzenden Brandes. Zur Enthüllung des Denkmals erklang das Lied „Ich hatt' einen Kameraden" und drei Ehrensalven wurden abgefeuert.
Nach der Hauptansprache des ehemaligen Leutnants Steinberg wurde die Übergabe des Denkmals an die Stadt, vertreten durch Oberbürgermeister Calsow, vollzogen. Die Feier endete mit Kranzniederlegungen am Denkmal und dem Schlusslied „Auf? Bleibet treu und haltet fest, so wird euch mehr gelingen“. Die Regimentstagung wurde durch die Hauptversammlung des Vereins fortgesetzt und durch einen montäglichen Frühschoppen beschlossen (GZ 12. August 1924, GT 13. August 1924).

\section{Die Wirkungsabsicht}

Das Motiv des Sterbens, die antikisierende Darstellung des Jünglings mit nacktem, muskulösem Körper, seine halb liegende „Pose“ auf einem altarartigen Sockel - all diese Elemente verleihen dem Denkmal ein hohes Maß an Pathos und stilisieren den Soldaten zu einem Heros, der „für eine gerechte Sache“ - das Vaterland - stirbt. Dem Tod wird also mit einer Rechtfertigung, einer positiven Sinnstiftung verbunden. Wie die Plastik verweisen die Reliefs einerseits auf die Schwere der menschlichen Verluste, andererseits auf die Leistungen und Verdienste

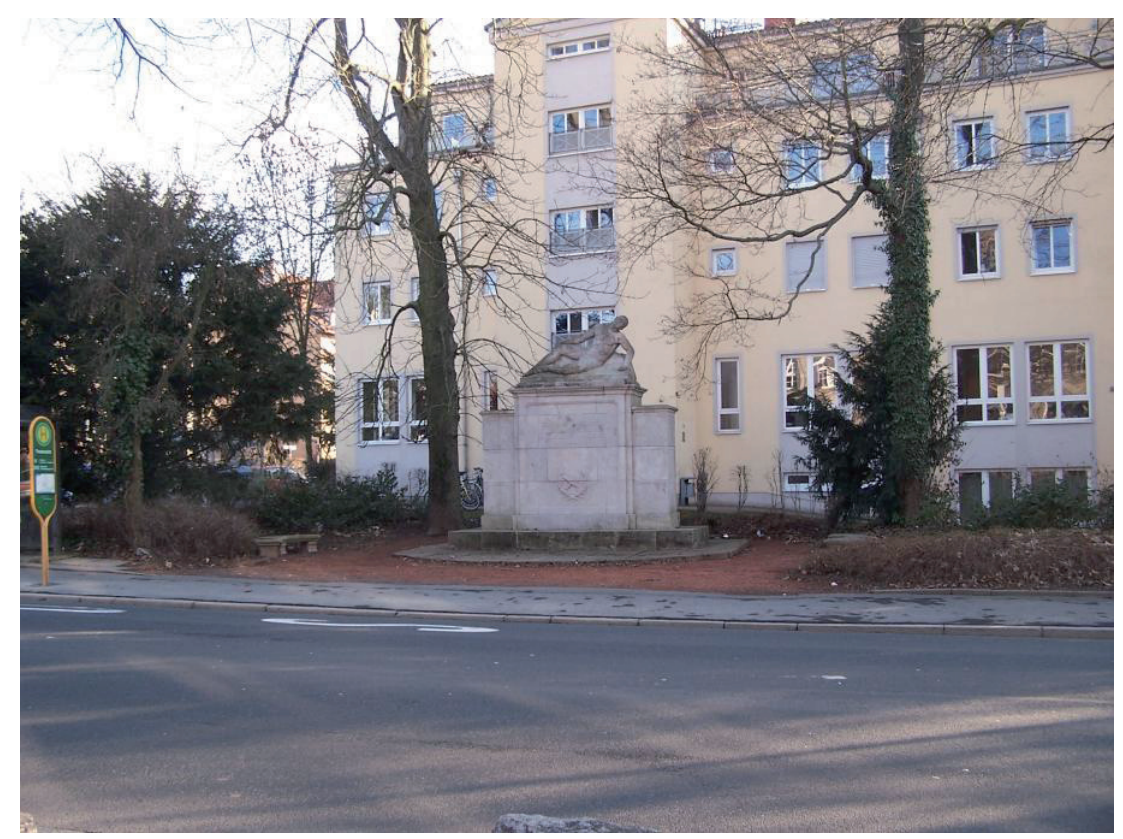

Blick auf das Denkmal von der gegenüberliegenden Straßenseite, 2011 
der gefallenen Soldaten, die mit militärischen Ehrenzeichen symbolisch gewürdigt und dadurch $\mathrm{zu}$ Vorbildern erklärt werden, denen man nacheifern soll.

Mit seiner Idealisierung des Kriegstodes betont das Ehrenmal, dem „Mainstream“ der Kriegerdenkmäler in der Weimarer Republik folgend, Werte und Tugenden wie Vaterlandsliebe, Treue, Gehorsam, Pflichterfüllung und Opferbereitschaft als Teil einer nationalen Gesinnung. Die Gefallenen sollten nicht nur betrauert und vor dem Vergessen bewahrt werden, sondern auch geehrt und den nachfolgenden Generationen als leuchtendes Beispiel vor Augen geführt werden.

\section{„Dolchstoß“ und Aufforderung zur Revanche}

Dass die Denkmalsstifter aus der Vergangenheit eine revanchistischnationalistische Botschaft ableiteten, dass der nackte Jüngling also ,nicht etwa Trauer, sondern Vergeltung“" (Gottschalk 1992, S. 38) fordert, zeigt sich vor allem in der von Regimentsleutnant a. D. Steinberg gehaltenen Hauptansprache zur Denkmalsweihe (GT 13. August 1924) und der ebenfalls von ihm verfassten, in das Denkmal eingemauerten Urkunde, die auch in der zur Regimentstagung herausgegebenen Festschrift abgedruckt wurde.

In Steinbergs Rede und Urkunde dominieren zwei Deutungsmuster der Vergangenheit: die Glorifizierung der patriotischen Taten des Regiments und das Nichteingestehen der Kriegsniederlage. Steinberg rühmt Kampfkraft, Durchhaltevermögen, Kameradschaftsgeist, Mut und Tapferkeit der Regimentsangehörigen - sie seien 1918 zwar ,nicht als Sieger", ,aber auch nicht als Besiegte" zurückgekehrt. Für den Ausgang des Krieges und den „Schmachfrieden von Versailles“ macht Steinberg die ,unselige Revolution“ und das „Entwaffnungsgebot“ (Denkmalsurkunde) aus der Heimat verantwortlich.
Hier schlägt sich die von der Obersten Heeresleitung nach dem Krieg in die Welt gesetzte ,Dolchstoßlegende" nieder, wonach die parlamentarische Regierung und die politische Linke dem im Feld unbesiegten Frontheer in den Rücken gefallen seien und damit die Niederlage verursacht hätten - eine Tatsachenverdrehung, denn der Krieg war bereits vor den Auflösungserscheinungen an der Westfront militärisch verloren. An Steinbergs Ansprache und der Denkmalsurkunde lässt sich exemplarisch die Wirkmächtigkeit der „Dolchstoß“-Propa- ganda festmachen, die vom rechtsradikalen Lager und der DNVP über die Freikorps und die Reichswehr bis zu den bürgerlichen Parteien und Kirchen weite Teile der Bevölkerung erreichte.

Diese Deutung der Vergangenheit verknüpft Steinberg mit der Aufforderung zur Revanche und zum unbedingten Einsatz für das Vaterland in der Zukunft: Die Opfer dürften - ein verbreiteter Topos bei der Gefallenenehrung in der Weimarer Republik - nicht vergeblich gebracht worden sein, vielmehr müsse „der Geist opferfreudiger Vater-

\section{$\mathfrak{u} \mathfrak{i} \mathfrak{k} \mathfrak{u} \mathfrak{n d e}$ \\ (Im Dentmal eingemauert.) Derfaffer: Ramerab $\theta_{\text {teinberg. }}$}

Zll im Serbft 1918, infolge ber unjeligen Revolution alles zuíammenbrad), tebrte aud) das

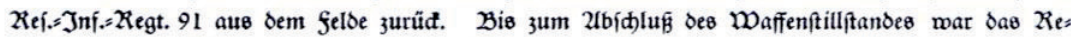
giment bart am feinde gewejen und hatte in fo oft bewäbrter Tapferteit jeden 2lngriff abgemiefen.

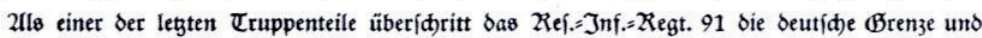
am 17. Dezember 1918 3og es in Göttingen ein, nid)t als Oieger, wie wir gehofft batten, als wir 1914 die Stabt in frober Begeifterung verliefen, um oas Daterlano vor feindlidem ifinfall 3 u idützen, aber au() nid)t als 2Bejiegte. So oft bas 2Regiment an ben 2Brennpunten ber Rampffront im Weften eingejeft war, ftets ift es feiner Zufgabe geted)t geworden. 2fls einer ber beften Truppenteile hat

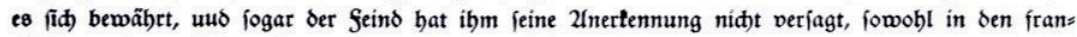

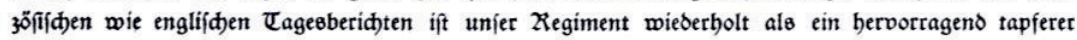
Begner erwäbnt.

Dem intwaffinungrgebot muß̈te folge geleiftet werben, bas ftolze Regiment wurbe aufges

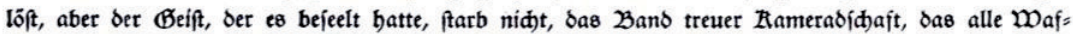
fengefäbrten umílalang, wurbe nid)t gelodert, es entftaito der "Derein ehemaliger 2lnyehöriger oes $2 i e f_{.}=I n f=2 R e g t .91^{\prime \prime}$. Der Derein bat fid) zur 2fufgabe gemad)t, ourd) regelmäjige Juíammentünfte

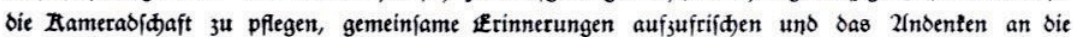
grobien Taten bes 2iegiments wachjubalten.

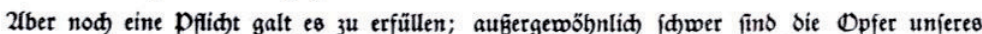
Regiments gemeien, es galt die Toten zu ebren, fo wurbe denn 1923 auf dem Regimentstag in Tortbeim Ser einftimmige Beíhlufi gefafft, unjern gefallenen Rameraben ein würbiges Dentmal зи

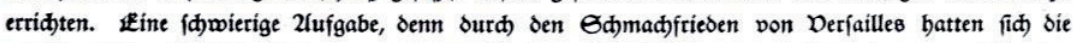
wirt(f)aftliden Derbältniffe immer mebr verí(bled)tert, bie Geldentwertung hatte immer verbãngnio= vollere formen angenommen, uno bie meiften Rameraben batten fidwer um den Sebensunterbalt zu

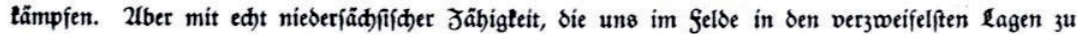
IEtfolg verbalf, wurbe das wert in Zlngriff genommen und im Laufe eines Jabres ourd)gefübrt.

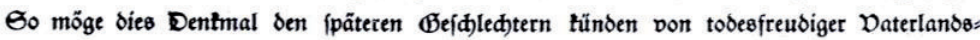
liebe, aber aud) von treuer Zamerabidaft bis über bas Grab hinaus.

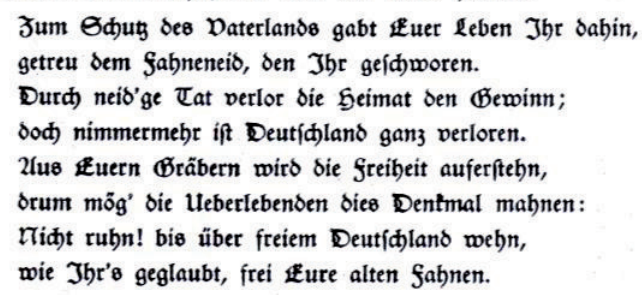

$\begin{array}{ccc}\text { Brandes } & \text { Geije } & \text { frembling } \\ \text { Dorfigender. } & \text { Sd)riftiübrer. } & \text { Raffierer. }\end{array}$

In das Denkmal eingemauerte Urkunde von 1924 
landsliebe $[. .$.$] im deutschen Volk$ wieder lebendig" werden, damit Deutschland die durch den Versailler Vertrag angelegten „Ketten der Knechtschaft" abschütteln, vom „Erbfeind“ Frankreich „Rechenschaft fordern“ und dadurch „Freiheit" erlangen könne (Ansprache Steinberg, GT 13. August 1924).

In der Denkmalsrhetorik haben also weder Trauerbekundungen mit pazifistischen Aussagen noch politische Bekenntnisse für eine demokratisch verfasste Gesellschaft Platz. Das Gedenken an die gefallenen Soldaten diente dem Veteranenverein zur Veranstaltung einer aggressiven nationalistischen Propaganda mit dem Ziel, Deutschlands Position als Großmacht wiederherzustellen. Ergänzend dazu sollte durch das die Denkmalseinweihung umrahmende Programm der Regimentstagung Festkommers, Frühschoppen, Ausflüge etc. - der Kameradschaftsgeist der ehemaligen Regimentsangehörigen neu belebt und für alle Beteiligten ein Identifikationsangebot geschaffen werden.

\section{Geschichte und Rezeption}

In den 1920er und 1930er Jahren wurde das Denkmal bei den mehrmals in Göttingen abgehaltenen „Regimentstagen der 91er“ zur zentralen Anlaufstelle für „Gedächtnisfeiern". Dabei etablierte sich ein leicht variiertes Programm von rituellen Abläufen, das sich an den Einweihungsfeierlichkeiten des Jahres 1924 orientierte: Die im Göttinger Tageblatt dokumentierten Feiern vom 10. Juli 1927, 13. Juli 1930 und 11. Juli 1937 umfassten das Antreten der Festteilnehmer auf dem alten Kasernenhof am Geismartor, den Marsch durch die Stadt zum Denkmal, die Ansprache des Pastors und/oder des Vereinsvorsitzenden Brandes sowie die Darbietung von Soldatenliedern.

Die Ansprachen blieben der rechtsnationalen Propaganda verpflichtet, indem sie die ,vorbildliche Treue“ der gefallenen Soldaten für sich vereinnahmten und der „Untreue“ und „Unehre“ (Rede Brandes, GT 12. Juli 1937) der „Novemberverbrecher" gegenüberstellten. In Brandes' Ansprache von 1937 ist dann deutlich die Euphorie über Hitlers Revisionspolitik und die Wiedereinführung der Wehrpflicht spürbar, die in den Worten gipfelt: „Im neuen Reich, im dritten Reich vom Geist Adolf Hitlers, des Frontsoldaten, sind wieder alle heldischen Tugenden und Ideale zur höchsten Geltung und Ehre gekommen."

\section{Didaktische Überlegungen}

Bei der Behandlung des Themas im Geschichtsunterricht sollte der zeitliche Fokus auf der Entstehungsgeschichte und Einweihung des Denkmals, also den frühen Jahren der Weimarer Republik liegen. Die Unterrichtseinheit lässt sich innerhalb des niedersächsischen Kerncurriculums somit im Themenbereich für die 9./10. Klasse „Veränderungen in Europa und der Weimarer Republik“ (von 1917 bis 1933) verorten. Die Materialien gewinnen mit einem größeren Vorwissen der Schülerinnen und Schüler über die Ereignisgeschichte von 1918 bis 1924 deutlich an Aussagekraft. Aufgrund ihrer Komplexität machen die Quellen mit etwas anders akzentuierter und strukturierter Fragestellung auch eine Einbindung in der Oberstufe möglich.

Eine Exkursion zum Denkmal bietet sich für Göttinger Schulklassen an, ist jedoch nicht unbedingt nötig, da sich die Denkmalsformen und -inschriften durch relativ wenige Fotos zügig erschließen lassen. Insgesamt ist die Unterrichtseinheit auf etwa vier Stunden angelegt.

\section{Intentionen}

Methodisch lernen die Schülerinnen und Schüler, die ausgeprägt intentionale Gattung „Denkmal“ aus unterschiedlichen Perspektiven in den Blick zu nehmen: ikonographischkunsthistorisch, sozialgeschichtlich und vor allem semantisch. Sie stellen Fragen nach Größe, Material, Formen, Symbolen etc. des Denkmals, nach den Aussagen der Inschriften und Reden und nach den gesellschaftlichen Bedingungen und politischen Absichten zur Entstehungszeit. Sie setzen sich mit historischer Erinnerungskultur auseinander und erhalten dadurch Einsicht in die Perspektivität von Vergangenheitsdeutungen und den Konstruktcharakter von Geschichte; damit soll zugleich die Fähigkeit zum kritischen Umgang mit Darstellungen von Geschichte, mit historischen Erinnerungsprozessen und in die Zukunft gerichteten Geschichtsdeutungen geschult werden.

\section{Materialseite 1}

Diese Seite soll den Schülerinnen und Schülern durch eine Aufstellung ikonographischer und historischer Details einen möglichst detaillierten Eindruck von dem Denkmal verschaffen. Sie dient damit zugleich als Grundlage für die folgenden Materialseiten. Durch die Arbeitsaufträge sollen die Schülerinnen und Schüler von der Beschreibung des Denkmals über die Analyse der Formen und Inschriften bis $\mathrm{zu}$ ersten eigenen Deutungsansätzen gelangen und auf diese Weise lernen, sich systematisch mit der Quelle auseinanderzusetzen.

\section{Materialseite 2-3}

Auf diesen Seiten sind die zentralen Quellen zu den Einweihungsfeierlichkeiten zusammengestellt: die Zeitungsberichte über den Festkommers und die Denkmalsweihe, der Text des Liedes „Der gute Kamerad" (von dem sich im Internet zahlreiche Aufnahmen finden) sowie die Hauptansprache von Leutnant a. D. Steinberg. Auf dieser Basis können die Schülerinnen und Schüler die Bedeutung der Festsemantik für die Aussage des Denkmals erfassen und die nationalistisch-revanchistische Vereinnahmung der Gefallenen durch den Verein der ehe- 
maligen Angehörigen des Regiments erkennen, reflektieren und historisch einordnen. Am Ende steht die Auseinandersetzung mit der Frage nach dem Sinn des Kriegerdenkmals in der aktuellen Erinnerungslandschaft.

\section{Materialseite 4}

Auf dieser Seite befassen sich die Schülerinnen und Schüler anhand zweier Quellen exemplarisch mit der Dolchstoßlegende. Sie lernen, die Dolchstoßlegende in der Denkmalsurkunde und Brandes' Ansprachen zu der Regimentsfeier von 1937 als rechtsnationale Geschichtsfälschung $\mathrm{zu}$ identifizieren und historisch zu dekonstruieren. Durch den Bezug zur NS-Zeit können die Schülerinnen und Schüler die Wirkmächtigkeit der Dolchstoßlegende und die auch daran anknüpfende Verehrung Hitlers als „Heilsbringer" in der NSIdeologie nachvollziehen.

\section{Literatur}

Gottschalk, Carola (Hrsg.), Verewigt und vergessen. Kriegerdenkmäler, Mahnmale und Gedenksteine in Göttingen, Göttingen 1992.

Koselleck, Reinhart, Kriegerdenkmale als Identitätsstiftungen der Überlebenden, in: Marquard, Odo/Stierle, Karl-Heinz (Hrsg.), Identität, München 1979, S. 255-276.

Koselleck, Reinhart/Jeismann, Michael (Hrsg.), Der politische Totenkult. Kriegerdenkmäler in der Moderne, Bonn 1994. Schneider, Gerhard, Kriegerdenkmäler, in: Geschichte lernen H. 8 (1989), S. 52-58.

Weigand, Katharina, Kriegerdenkmäler. Öffentliches Totengedenken zwischen Memoria-Stiftung und Politik, in: Herzog, Markwart (Hrsg.), Totengedenken und Trauerkultur. Geschichte und Zukunft des Umgangs mit Verstorbenen, Stuttgart 2001, S. 201-218.

\section{Unveröffentlichte Quellen}

Akta betreffend Einrichtung eines Denkmals für die Gefallenen des Reserve-Infanterie-Regiments 91 gegenüber dem Gymnasium, StA Göttingen, Alte Hauptregistratur, Abteilung I, Abschnitt A, Fach 40, Nr. 28 (1923-1925).

\section{Veröffentlichte Quellen}

Urkunde (im Denkmal eingemauert), Verfasser: Kamerad Steinberg, abgedruckt in: Gottschalk, Carola (Hrsg.), Verewigt und vergessen. Kriegerdenkmäler, Mahnmale und Gedenksteine in Göttingen, Göttingen 1992, S. 37.

Die Denkmalsweihe für die Gefallenen des Res.-Inf.-Regts. Nr. 91, Göttinger Zeitung, 12. August 1924.

Fünfter Regimentstag der 91er, Göttinger Tageblatt, 13. August 1924.

Regimentstag der 91er, Göttinger Tageblatt, 12. Juli 1927.

Der Tag der 91er!, Göttinger Tageblatt, 12./13. Juli 1930.

Regimentstag der 91er, Göttinger Tageblatt, 14. Juli 1930.

Wiedersehensfeier der 91er, Göttinger Tageblatt, 12. Juli 1937. 


\section{Basisinformationen zum Ehrenmal für die Gefallenen des Res.-Inf.-Regts. 91}

\section{M1 Steckbrief}

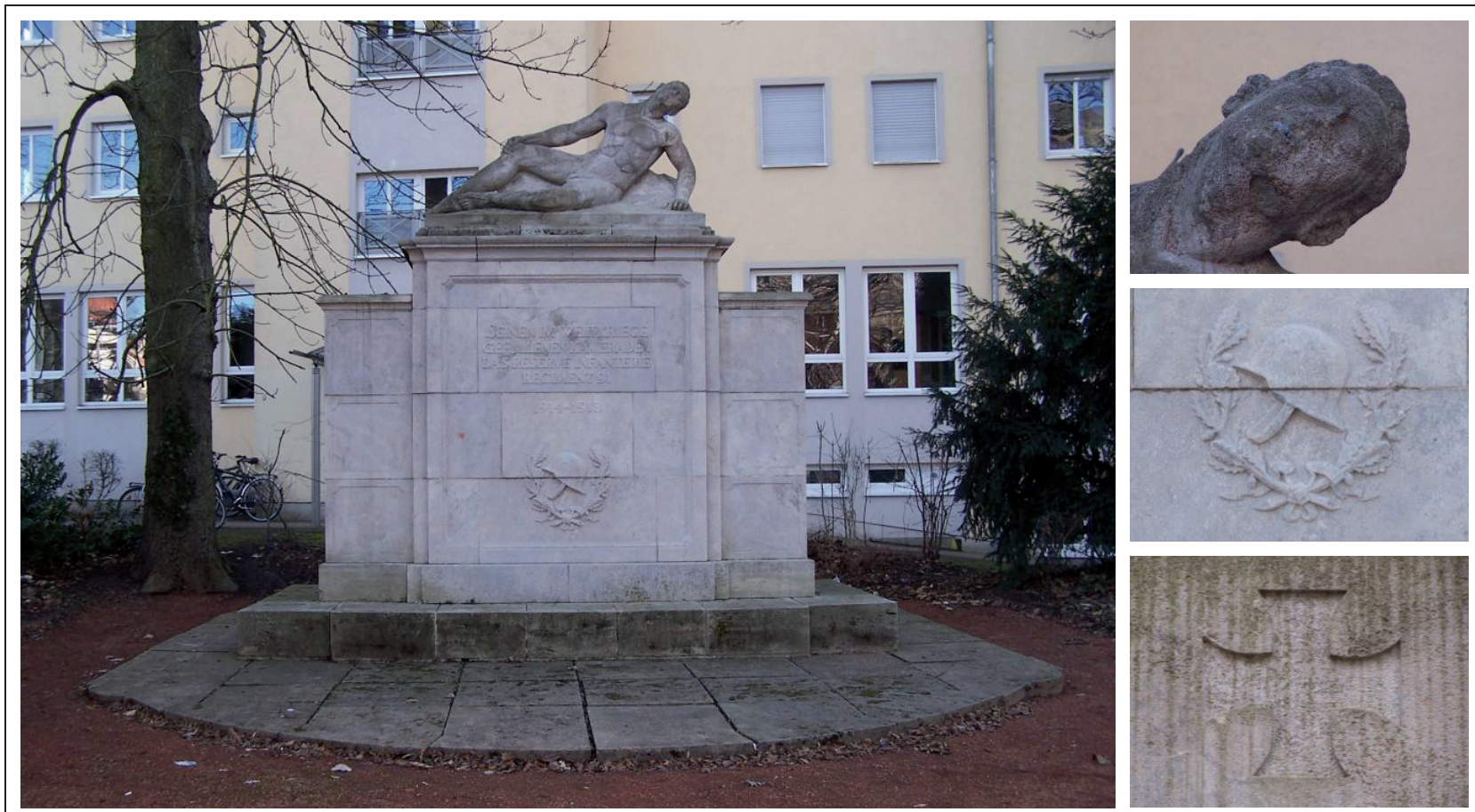

Denkmal für die Gefallenen des 91er-Regiments, 2011 (Ausschnitte: Kopf der Plastik, Stablhelm, Eisernes Kreuz)

Standort: Theaterplatz 10,37073 Göttingen

Typus/Form: Kriegerdenkmal, Sockel mit Plastik

Maße: $\quad$ ca. 5 x $4,40 \mathrm{~m}$ (mit Sockel)

Material: $\quad$ grauer Muschelkalk

Einweihung: 10. August 1924 (10. Jahrestag des Ausrückens des Res.-Inf.-Rgts. 91)

Symbole: $\quad$ Stahlhelm, umrahmt von Eichenlaub (Front), Eisernes Kreuz (Rückseite)

Stifter: $\quad$ Verein ehemaliger Angehöriger des Res.-Inf.-Rgts. 91

Entwurf: $\quad$ Zimmermann (ehem. Leutnant des Res.-Inf.-Rgts. 91)

Intention: $\quad$ Erinnerung an die im Ersten Weltkrieg gefallenen Soldaten des Res.-Inf.-Rgts. 91

Inschriften:

Vorderseite: „Seinen im Weltkriege / gefallenen Kameraden / Das Reserve Infanterie Regiment 91 / 1914-1918““

Rückseite: „Für ihr Vaterland / starben vom Regiment / 104 Offiziere / 326 Unteroffiziere / 2702 Mannschaften“

Linke Seite: „Lagnicourt / Queant / Riencourt / Flandern 1917 / Langemark / St. Julien // Armentieres / Ostneukerke / März-Offensive 1918 / Noreuil / Ervillers / Arras // Achiet le Petit / Logastwald / Achiet le Grand / Dury / Neu Chapelle / Tournai“

Rechte Seite: „Vormarsch 1914 / Marbaix-Gozee / St. Quentin / Le Breuil / Petit Morin / Marne-Reims // Allger-Auberge / Argonnen / Vouquois / La Bassee / Loos-Hulluch / Kiesgrube / Richebourg Lavue / Sommeschlacht 1916 / Bucquois-Essarts / Bazentin le Petit / Ovillers / Grandcourt“

\section{Arbeitsaufträge}

1. Beschreibe das Denkmal und seine Wirkung auf dich.

2. Analysiert in Partnerarbeit die Bedeutung der Figur, der Symbole und der Inschriften.

3. Diskutiert in der Klasse, welche Botschaft(en) das Denkmal insgesamt vermitteln soll. 


\section{Das 91er-Denkmal: Einweihung und Sinnstiftung}

Das Kriegerdenkmal am Göttinger Theaterplatz wurde durch den nach dem Ersten Weltkrieg gegründeten „Verein ehemaliger Angehöriger des Reserve-Infanterie-Regiments 91" errichtet und am 10. August 1924 im Rahmen der festlich gestalteten 5. Regimentstagung mit einer feierlichen Zeremonie eingeweiht.

\section{M2 Der Festkommers}

Das Göttinger Tageblatt und die Göttinger Zeitung berichten von der Feier am Vortag der Denkmalseinweihung (9. August 1924):

[GT:] Der weite Stadtparksaal vermochte kaum die Menge der erschienenen Regimentsangehörigen und Gäste [...] zu fassen. [...] Der Vorsitzende Brandes wies [...] auf den Charakter der Feier als einer Ge5 denkfeier für die Gefallenen des Regiments hin, betonte aber auch, daß daneben der Regimentstag den [sic] Zweck dienen solle, die alte Kameradschaft, die bei den 91ern in hohem Ansehen gestanden habe, zu festigen und neu zu beleben. Ausgezeichnete turneri10 sche Vorführungen einer Riege der Turn- und Sportvereinigung am Barren und Reck, einige Vorträge eines Männer-Doppelquartetts des Gesangvereins „Liederfranz“ sowie gemeinschaftliche Gesänge füll- ten den gemütlich verlaufenen Abend aus. Von den 15 Militärmärschen war es besonders der „Peiner Einzugmarsch“, der früher im Felde stets von einem Leutnant dirigiert wurde, welcher jubelnde Begeisterung auslöste.

[GZ:] Die Verteilung der schön ausgestatteten 20 Festschrift, die auf dem Titelblatt das Bild des Denkmals zeigt, und die neben dem Festprogramm Episoden aus der Geschichte des Regiments und die Liedertexte der Kommerslieder [Festlieder] enthält, trug nicht wenig zur Abwechslung bei. Erst spät trennte 25 man sich in dem frohen Gefühl, einen schönen Abend verlebt zu haben.

(Göttinger Tageblatt, 13. August 1924 / Göttinger Zeitung, 12. August 1924)

\section{M3 Die Einweihungszeremonie}

Das Göttinger Tageblatt und die Göttinger Zeitung berichten von der Einweihung des Denkmals am 10. August 1924:

[GT:] Der Sonntag brachte bei lachendem Sonnenschein als Einleitung um $9 \frac{1}{2}$ Uhr in der Waldkirche im Molkengrund in Gestalt eines Feldgottesdienstes eine Stunde ernster Einkehr und ruhiger Sammlung 5 als Vorbereitung zur Einweihung des Denkmals. [...]

Von dort aus zog man wieder in geschlossenem Zuge zum Gymnasium, um dort mit der Einweihung des Gefallenendenkmals den Höhepunkt der ganzen Regimentsfeier unter Beteiligung einer nach Tausen10 den zählenden Menge zu begehen. Nachdem ein Gebet die [von Pastor Saathoff gehaltene] Weiherede geschlossen hatte, bot der Vorsitzende Brandes Bilder aus der Feldzugsgeschichte des Regiments und ge- dachte der furchtbaren Verluste, die es an Offizieren 15 und Mannschaften erlitten hat. Es war ein tiefergreifender Augenblick, als unter den Klängen des Liedes „Ich hatt' einen Kameraden“ die Hülle von dem Denkmal fiel, die Fahnen sich senkten und drei Ehrensalven gen Himmel donnerten. [...]

20 Herr Brandes empfahl das Denkmal dem Schutz der Öffentlichkeit und der Stadt. [GZ:] Es legten Kränze am Denkmal nieder die Ortsgruppe der Mitglieder des Regiments 77, des Regiments 91, die Ortsgruppe Northeim, die Offiziersvereinigung des Regi25 ments 91, der Reichsverband jüdischer Frontsoldaten, der Kriegerverein Bovenden.

(Göttinger Tageblatt, 13. August 1924 / Göttinger Zeitung, 12. August 1924) 


\section{M4 „Ich hatt' einen Kameraden ...“}

Bei der Denkmalsenthüllung erklang das Lied „Der gute Kamerad“ (links Strophe 1-2), das in der Zeit des Ersten Weltkriegs auch auf vielen Feldpostkarten abgedruck.t wurde (bier Strophe 3):

1. Ich hatt' einen Kameraden,

Einen bessern findst du nit.

Die Trommel schlug zum Streite,

Er ging an meiner Seite

Im gleichen Schritt und Tritt.

2. Eine Kugel kam geflogen:

Gilt sie mir oder gilt sie dir?

Ihn hat es weggerissen,

Er liegt mir vor den Füßen

Als wär's ein Stück von mir.

Text: Ludwig Uhland (1809)

Melodie: trad., 18. Jh.

(http://www.volksliederarchiv.de)

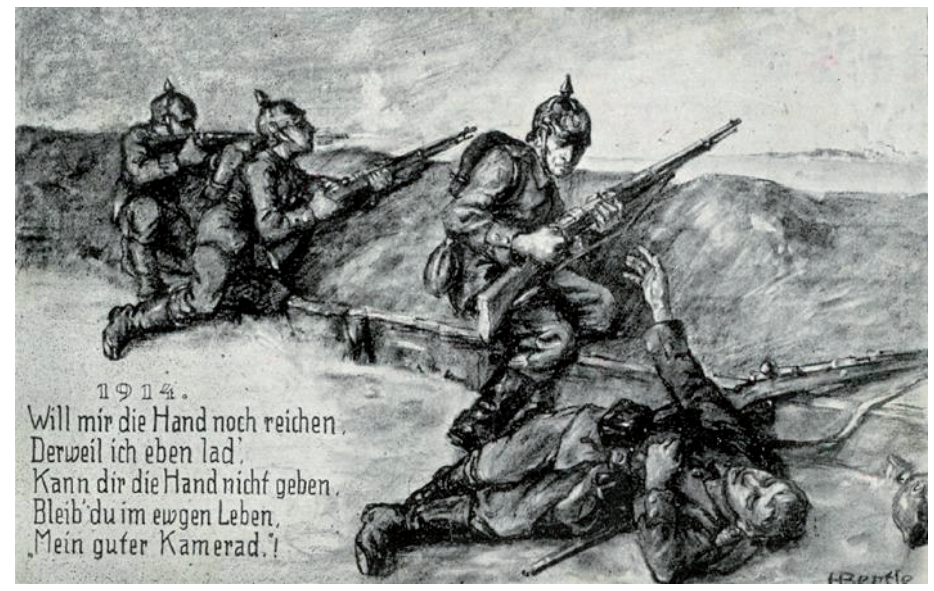

Feldpostkearte mit Poststempel von 1916

\section{M5 „Und all diese Opfer sollten vergeblich gebracht sein?“}

\section{Ausqug aus der von Leutnant a. D. Steinberg unmittelbar nach der Denkmalsenthüllung gehaltenen Hauptansprache:}

„Und all diese Opfer sollten vergeblich gebracht sein?

- Nein ich kann es und will es nicht glauben. [...] Wir müssen alle daran arbeiten, daß der Geist von 1914 wieder allgemein lebendig wird im deutschen Volke, 5 den [sic!] Geist der uns erfüllte, als wir hinauszogen, die Heimat vor dem Feinde zu schützen, der Geist treuer Kameradschaft, der unser Regiment besonders auszeichnete, der Geist opferfreudiger Vaterlandsliebe, der unsere lieben Kameraden ihr Leben dahinge10 ben ließ für Deutschlands Größe. Und wenn dieser Geist im deutschen Volke wieder lebendig wird, dann wird Deutschland die Ketten der Knechtschaft abschütteln, dann wird es wieder groß und mächtig dastehen wie je zuvor; dann wird der Tag kommen, an
15 dem wir Rechenschaft fordern von unserm Erbfeind, und dieser Tag wird auch die alten 91er auf ihrem Platze finden, das sind wir unsern gefallenen Kameraden schuldig.

So hat dieses Denkmal, das treue Kameradschaft 20 erstehen ließ, eine zweifache Aufgabe, es soll das Gedächtnis an unsere treuen Toten und ihre unvergänglichen Taten wachhalten, es soll eine Stätte sein, an der die Gedanken der Hinterbliebenen weilen können, die das Grab ihrer Lieben nicht kennen, und es soll die 25 Überlebenden mahnen, nicht nachzulassen in der Arbeit für das Vaterland, für das kein Opfer zu groß sein darf."

(Göttinger Tageblatt, 13. August 1924)

\section{Arbeitsaufträge}

1. Gib den Ablauf der Regimentstagung wieder (M2-M5).

2. Analysiere mit Schwerpunkt auf M5 und durch Einordnung in den historischen Kontext, welche Zwecke das Denkmal aus Sicht des Regimentsvereins erfüllen sollte.

3. Sollte man das Denkmal heute entfernen, verändern (wenn ja, wie?) oder es in seinem jetzigen Zustand belassen? Nimm begründet Stellung. 


\section{Das Reserve-Infanterie-Regiment 91 und die „Dolchstoßlegende“}

\section{M6 Die Denkmalsurkunde}

Regimentsleutnant a. D. Steinberg verfasste 1924 eine Urkunde, die in das Denkmal eingemauert und in einer Festschrift abgedruckt wurde. In ibr beschreibt er das Kriegsende:

\section{$\mathfrak{u} \mathfrak{r} \mathfrak{k} \mathfrak{u} \mathfrak{d e}$. \\ (Im Dentmal eingemauert.) Derfaffer: Rameras $\theta_{\text {teinberg. }}$}

Als im Herbst 1918 infolge der unseligen Revolution alles zusammenbrach, kehrte auch das Res.-Inf.-Regt. 91 aus dem Felde zurück. Bis zum Abschluß des Waffenstillstandes war das Regiment hart am Feinde ge5 wesen und hatte in so oft bewährter Tapferkeit jeden Angriff abgewiesen. Als einer der letzten Truppenteile überschritt das Res.-Inf.-Regt. 91 die deutsche Grenze und am 17. Dezember 1918 zog es in Göttingen ein, nicht als Sieger, wie wir gehofft hatten, als wir 1914
10 die Stadt in froher Begeisterung verließen, um das Vaterland vor feindlichem Einfall zu schützen, aber auch nicht als Besiegte. [...] Dem Entwaffnungsgebot mußte Folge geleistet werden, das stolze Regiment wurde aufgelöst, aber der Geist, der es beseelt hatte, 15 starb nicht, das Band treuer Kameradschaft, das alle Waffengewährten umschlang, wurde nicht gelockert, es entstand der Verein ehemaliger Angehöriger des Res.-Inf.-Regt. 91.

(aus: Carola Gottschalk (Hrsg.), Verewigt und vergessen. Kriegerdenkmale, Mahnmale und Gedenksteine in Göttingen, Göttingen 1992, S. 37)

\section{M7 Regimentsfeier 1937: Hitler als „Heilsbringer“}

Das Göttinger Tageblatt veröffentlicht am 12. Juli 1937 einen Artikel über die Wiedersehensfeier des 91 er-Regiments und die traditionelle Gefallenenehrung am Denkmal:

[Auf dem Kameradschaftsabend im Stadtpark führte der Vereinsvorsitzende der ehemaligen 91er Brandes aus:] Heute wissen wir, daß die Opfer der Kriegsgeneration nicht umsonst waren. Aus ihnen ist die Saat für 5 ein neues Deutschland aufgegangen. [...] Und schließlich kam der Führer, der Frontsoldat Adolf Hitler, [...] er gab dem deutschen Volk die von allen Frontsoldaten schon lange ersehnte Wehrpflicht wieder und verschaffte Deutschland aufs neue Weltgeltung.

10 Am Sonntagmorgen traten die Festteilnehmer auf dem Alten Kasernenhofe am Geismartor an und marschierten in geschlossenem Zug unter Vorantritt der alten Regimentsfahne und der hiesigen Regimentska- pelle zur Gefallenenehrung, die auf dem Adolf15 Hitlerplatz vor dem Denkmal der 91er stattfand. [...] Dann gedachte Kamerad Brandes als Vereinsführer in einer kernigen Rede der Gefallenen. [...] Sie wußten, um was es ging, während die Heimat das nicht oder nur unvollkommen ahnte. Deshalb wurde unseren 20 Helden der Sieg entrissen, deshalb konnte die Untreue des Unheldischen die Treue der Helden erschlagen. [...] Kamerad Brandes legte am Schluß seiner zu Herzen gehenden Ausführungen das Gelöbnis ab, daß das Vorbild der Frontsoldaten rein und wach erhalten 25 bleiben soll als ständige Mahnung zum Einsatz für Volk und Vaterland.

(Göttinger Tageblatt, 12. Juli 1937)

\section{Arbeitsaufträge}

1. Recherchiere und erläutere, was man unter der „Dolchstoßlegende“ versteht.

2. Erkläre mit Hilfe der Dolchstoßlegende Steinbergs Deutung der Kriegsniederlage (M6).

3. Untersuche, inwiefern die Dolchstoßlegende in Brandes’ Äußerungen zur Regimentsfeier von 1937 fortwirkt und welche Rolle Hitler in diesem Zusammenhang zugewiesen wird (M7). 


\title{
Das Ehrenmal des Infanterie-Regiments Nr. 82
}

\author{
Marco Dräger
}

Die wechselvolle Geschichte des 82er-Ehrenmals dokumentiert exemplarisch einen Wandel in Geschichtsbewusstsein und Geschichtskultur. Das Ehrenmal wurde 1925 zum Gedenken an die im Ersten Weltkrieg gefallenen Soldaten errichtet; nach dem Zweiten Weltkrieg wurde das Denkmal auf die ostpreußischen Divisionen erweitert. In den folgenden Jahrzebnten fanden dort regelmäßig Treffen von Soldaten- und Vertriebenenverbänden statt. In den 1980er Jabren verstärkt geäußerte Kritik an den alljährlichen Feierlichkeiten führte schließlich zu einem Sturz des Denkmals.

\section{Erscheinungsbild}

Der Göttinger Stadtarchivar Walter Nissen beschreibt das Werk mit diesen Worten: „Das Denkmal im Rosengarten stellt die Figur eines unbekannten Soldaten in feldgrauer Uniform dar, 2,30 $\mathrm{m}$ hoch mit einem Gewicht von etwa 35 Zentnern. Der Sockel ist aus grünem Eruptivgestein des Porphyrs ausgeführt, der als nahezu unvergängliches Material gilt. Die Stufen und die Plattform des Denkmals sind aus Fichtelgebirgsgranit, einem graugrünlichen Material. Die Inschrift rund um den Sockel des Postaments lautet: 1870-71. Bis zum Tode getreu. 1914-18،. Und auf der Rückseite: ,Zur Erinnerung an das 2. Kurh.Inf.Rgt. 82 und seine gefallenen Helden. Errichtet Aug. 1925'. Die Eingravierung nach 1945 lautet: ,Dem Gedächtnis der im Kriege 1939/45 gefallenen Soldaten des Inf.Regiments 82, späteren Grenadier-Regiments 82‘. Ausgeführt wurde dieses Denkmal von den vereinigten Fichtelgebirgs-Granit-SyenitMarmorwerken in Wunsiedel" (Nissen 1987, S. 8). Den Aufbau des Denkmals leitete der Göttinger Bildhauer Rudolf Eckardt.

\section{Entstehung und Intention}

Oberst a. D. Georg Schmidt unterrichtete im Frühjahr 1925 den Oberbürgermeister Calsow davon, dass der Verein der ehemaligen 82er, deren Garnisonsstadt Göttingen von der Reichsgründung bis zur Auflösung des Regiments nach dem Ersten Weltkrieg war, ein Denkmal für seine gefallenen Soldaten zu errichten beabsichtigte. Zugleich bat er in diesem Brief um finanzielle Unterstützung sowie um Überlassung eines geeigneten Platzes für das Ehrenmal.

Die Stadt Göttingen spendete 3.000 Mark und beschloss, als Standort ,die Anlagen in der Bürgerstraße - Ecke Reinhäuser Landstraße $[\ldots]$ unter Beseitigung des dort noch stehenden Bedürfnishäuschens" (Nissen 1987, S. 7) zur Verfügung zu stellen. Mit der Ausführung des Denkmals wurde der Hannoveraner Bildhauer Roland Engelhardt (1868-1951) beauftragt, der als einer der führenden Künstler für Kriegerdenkmäler galt.

Bereits im August 1925 wurde das Denkmal mit einem dreitägigen Fest, verbunden mit einem Regimentsappell, feierlich eingeweiht. Nach einem Festkommers am Samstagabend, dem 22. August 1925, erfolgte am darauffolgenden Tag nach dem „Großen Wecken“ und einem „Feldgottesdienst“ die Denkmalsweihe. An die Enthüllung des Denkmals durch Oberst a. D. Georg Schmidt und die Übergabe in die Obhut der Stadt Göttingen schloss sich ein Festzug durch die Stadt an. Am Nachmittag und am Abend zeigten die Göttinger Kinos ,Lichtbilder" (Nissen 1987, S. 10) aus der Geschichte des Regiments, die von Major a. D. Emil Ahlhorn erläutert wurden. Die Feierlichkeiten endeten am Montag mit einem Frühschop-

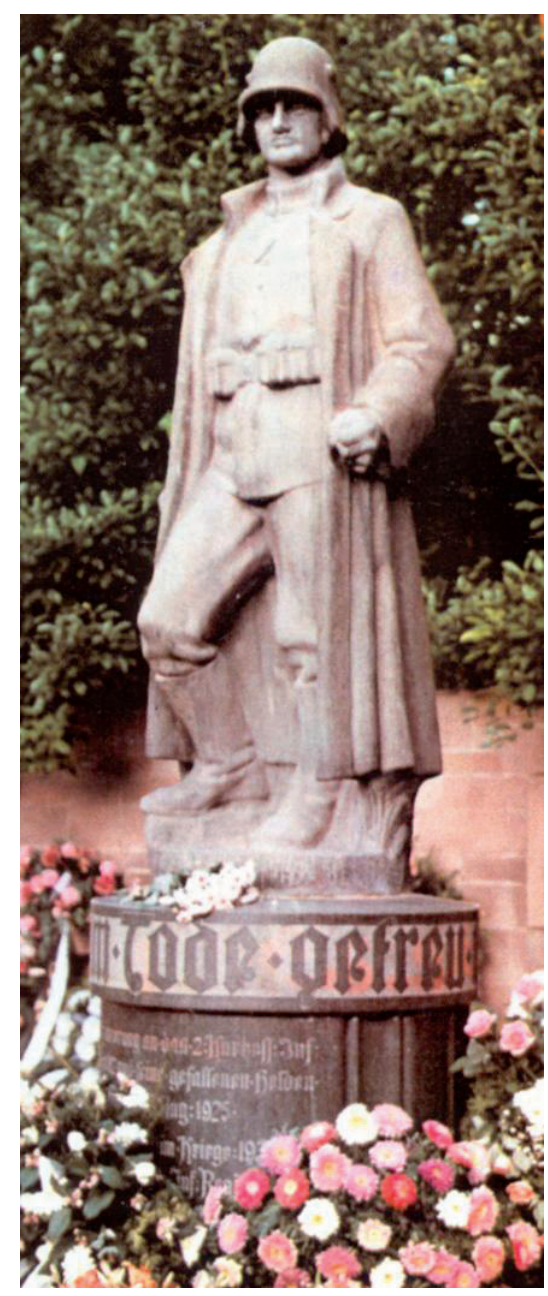

Das Ehrenmal Mitte der 1980er Jahre

pen und einem Platzkonzert vor dem Alten Rathaus.

\section{Geschichte und Rezeption}

\section{Umsetzung und Umwidmung 1953}

Im Sommer 1952 ergriff der in Göttingen lebende General der Infanterie a. D. Friedrich Hoßbach (18941980) die Initiative und reichte bei der Stadt den Vorschlag ein, bei der aus verkehrstechnischen Gründen dringend notwendigen Umsetzung des Ehrenmals die Gelegenheit zu einer Umwidmung zu nutzen und 
das Ehrenmal zu ergänzen, so dass auch für die ,Soldaten aus den heimatlos gewordenen ostpreußischen Divisionen eine Stätte ehrenden Gedenkens an ihre gefallenen Kameraden" (Nissen 1987, S. 11) geschaffen werden könne. Die Stadt Göttingen griff diesen Plan auf und setzte ihn um; Friedrich Hoßbach wurde auf diese Weise, ,zeitlebens der Beschirmer der ganzen Ehrenmalanlage“ (Nissen 1987, S. 11).

Die Umsetzung erfolgte im Frühjahr 1953, als ,neuer, der Unruhe des Alltags entrückter" (Nissen 1987, S. 12) Standort wurde der Rosengarten ausgewählt. Walter Nissen beschreibt die Einweihung folgendermaßen: „Am Sonntag, dem 30. August 1953 vormittags, fand in der parkähnlichen Anlage des Rosengartens die Einweihung des Ehrenmals an seinem neuen Standort statt. Eingefaßt durch eine große Sandsteinmauer, in die die Truppenkennzeichen zur Erinnerung an die einzelnen Formationen eingelassen sind, steht das nach dem 1. Weltkrieg im Jahre 1925 geschaffene Denkmal an seinem neuen Platz, ,sinnvoll eingerahmt von einer Schule, dem Ort jungen aufstrebenden Lebens und einem Zeichen der Vergangenheit, einem alten Friedhof, aus dessen Gräbern Beziehungen bis in unseren heutigen Kreis reichen“ (Hoßbach). Es ist in seiner neuen Form eines der schönsten Soldatendenkmäler, das wir kennen', so schreibt die Zeitschrift ,Kyffhäuser‘. Teilnehmer waren im Rahmen des Soldatentreffens und in Erinnerung

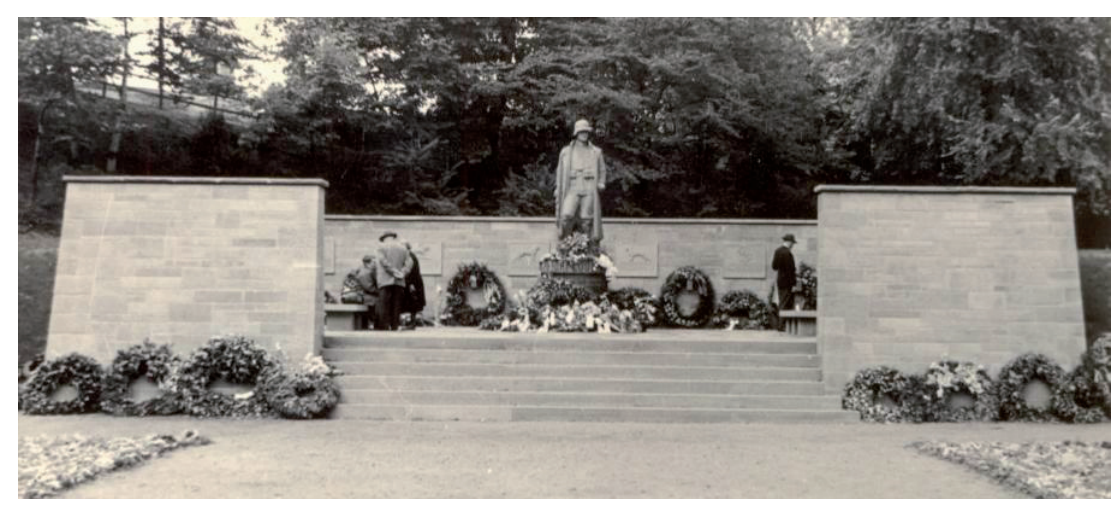

Das Ehrenmal nach seiner Umsetzung 1953

Das Ehrenmal an seinem ursprünglichen Standort an die gemeinsam gebrachten Opfer die Angehörigen der niedersächsischen 31. Division sowie die Soldaten ostpreußischer Truppenverbände des Heeres, der Kriegsmarine und der Luftwaffe" (Nissen 1987, S. 12f.).

Bei der Denkmalsweihe hielten ein katholischer und ein evangelischer Geistlicher sowie der Oberbürgermeister Dr. Föge Ansprachen. Nach der Übergabe des Ehrenmals an die Traditionsverbände der auf den Tafeln genannten ostpreuBischen und niedersächsischen Einheiten durch Dr. Föge dankte General a. D. Hoßbach der Stadt und allen am Zustandekommen der Denkmalsanlage Beteiligten, besonders aber den Lehrern und Schülern der Bonifatius- und der Mädchenmittelschule, weil sie sich dazu bereiterklärt hatten, das Denkmal zukünftig zu pflegen.

Unter dem Glockengeläut der Göttinger Kirchen und dem Lied „Ich hatt' einen Kameraden“ legte -

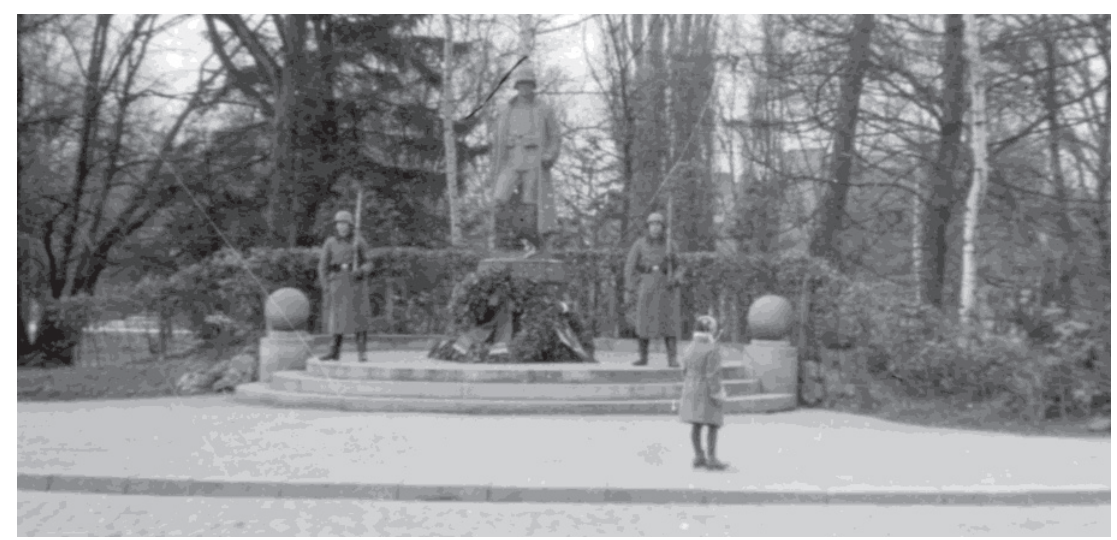

neben den lokalen Honoratioren auch überregionale politische Prominenz Kränze nieder, wie z. B. der niedersächsische Ministerpräsident Hinrich Wilhelm Kopf und Ministerialrat von Zahn als Vertreter des Bundesministers für gesamtdeutsche Fragen.

\section{Die soziale Praxis in den folgenden Jahrzehnten}

Bereits in der Zeit zwischen den Weltkriegen hatten am Göttinger Ehrenmal Zusammenkünfte von Soldatenverbänden stattgefunden, allerdings nur sporadisch. Zu nennen sind hier insbesondere die „Wiedersehens-Feier“ im Juli 1928 sowie die Feier zur Wiedererrichtung des Infanterie-Regiments $\mathrm{Nr}$. 82 im Mai 1937.

Seit 1953 fanden im Rosengarten regelmäßige, jährliche Soldatentreffen statt, die von Soldatenverbänden und Vertriebenenorganisationen organisiert wurden. Sie wurden meistens auf den ersten Sonntag im September terminiert, den so genannten „Tag der Heimat“, dessen Einführung als Gedenktag 1949 in Göttingen beschlossen wurde und der an das Schicksal der aus den ehemaligen deutschen Ostgebieten Vertriebenen erinnern soll.

Walter Nissen spricht von einem „festen Brauch“ (Nissen 1987, S. 14), der sich im Laufe der Zeit für Gestaltung und Ablauf der Feierstunde herausgebildet habe: „Schon früh am Sonntagmorgen wird der 
Schauplatz im Rosengarten durch das Auslegen von Tausend und Abertausenden von Blumensträußen festlich geschmückt. Mitglieder der Frauengruppe der Landsmannschaft Ostpreußen haben kleine Sträuße gebunden und diese mit einem weiBen Namensband speziell für jeden gefallenen Soldaten versehen. Hierbei wird auch nicht versäumt, an die toten Männer und Frauen zu denken, deren Gräber aus den bekannten Gründen zur Zeit nicht besucht werden können. Ausgebreitet in bunter Fülle liegen die Blumenspenden auf dem Platz und geben nur einen schmalen Raum frei für den Weg, auf dem die Kränze und Blumenangebinde tragenden Abordnungen unter den feierlichen Klängen der Heeresmusikkapelle zum Denkmal schreiten.

Nach dem Einmarsch der Fahnengruppen und den Ansprachen der Geistlichen beider Konfessionen folgen die Reden der in- und ausländischen Persönlichkeiten, die zum Ausdruck bringen, wie die Versöhnung zwischen einst feindlichen Nachbarvölkern erfreuliche Fortschritte macht. Es erfolgt sodann die Niederlegung der Kränze am Denkmal, während die Fahnen gesenkt werden und das Lied vom guten Kameraden leise erklingt. Mit dem Ausmarsch der Ehrenkompanien der ausländischen Staaten und der Bundeswehr enden die Ehrenmalsfeiern im Göttinger Rosengarten“" (Nissen 1987, S. 14f.).

\section{Kritik und Denkmalsturz in den 1980er Jahren}

In den 1980er Jahren wurde verstärkt öffentliche Kritik an diesem Ritual laut. Sie richtete sich vor allem gegen die Form des „Heldengedenkens" und kritisierte die Kontinuität und Tradition ,ehrenwerter Tugenden" (Biermann/Lindloff 1992, S. 55). Sie verherrliche den Militarismus, verstelle dadurch den Blick auf Täter, Opfer, Schuld sowie „echte“ Trauer und verschleiere den Umstand, dass die in Denkmälern

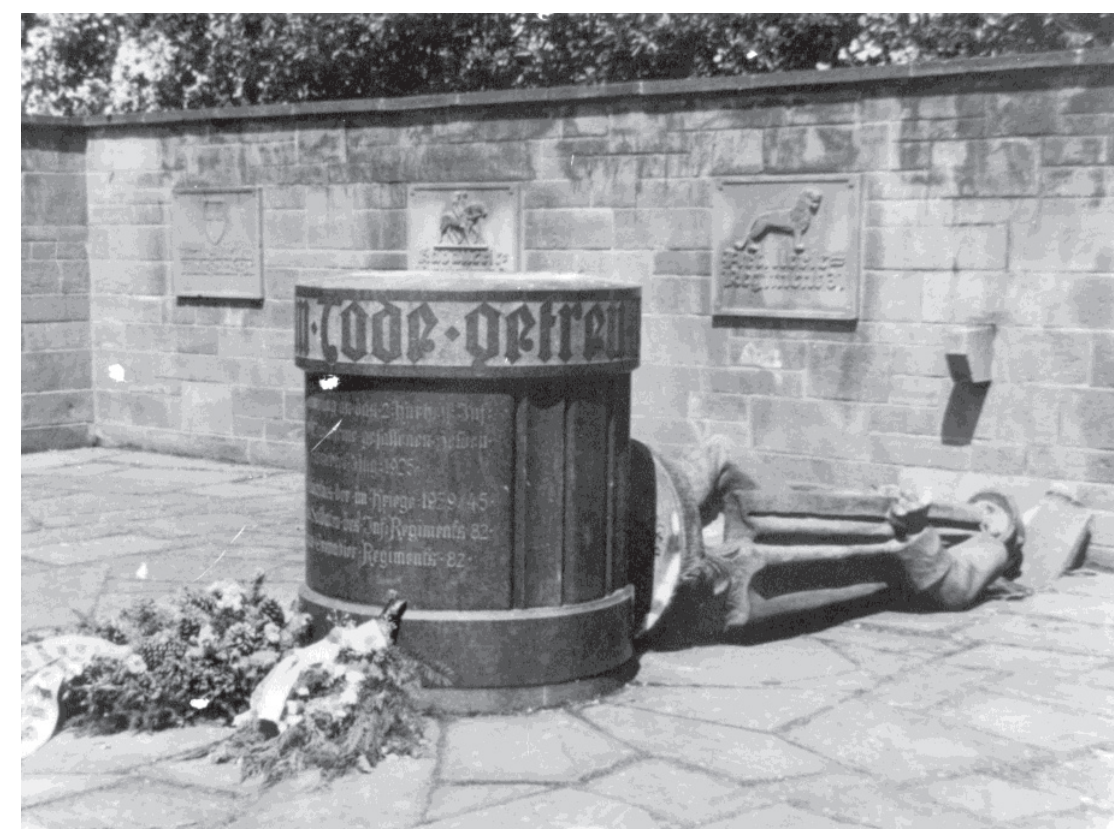

Der Denkmalsturzvon 1987 und Gedenkveranstaltungen angepriesenen Eigenschaften wie Opferbereitschaft, Treue, Unterordnung und Gehorsam totalitäre Regime förderten (vgl. Gottschalk 1992, S. 9-18).

Diese Proteste entluden sich schließlich in mehreren Denkmalstürzen. In den Jahren 1959, 1980 und 1987 wurde die Figur des ,steinernen Soldaten" zwar vom Sockel gestürzt, sie blieb jedoch immer unbeschädigt und wurde jeweils wenige Tage nach dem Sturz wieder aufgestellt. Beim Sturz von 1988 wurde der ca. 1,7 Tonnen schweren Figur der Kopf abgeschlagen und gestohlen. Daraufhin brachte man den „kopflosen Soldaten“ zur Restaurierung und Einlagerung in die Rommel-Kaserne nach Osterode und versah ihn dort mit einem neuen Kopf. An Stelle der Figur wurde im Rosengarten ein einfaches Holzkreuz aufgestellt. Im April 1994 wurde der abgeschlagene Kopf im Schaufenster eines Tauchladens in Bad Karlshafen wiedergefunden; der Inhaber hatte ihn 1991 in einem See in der Nähe von Barterode entdeckt und geborgen.

In den 1990er Jahren kam es zu weiteren Zerstörungen und Beschmierungen am Ehrenmal. Heute ist das Ehrenmal fast vergessen, es liegt unbeachtet am Rand eines

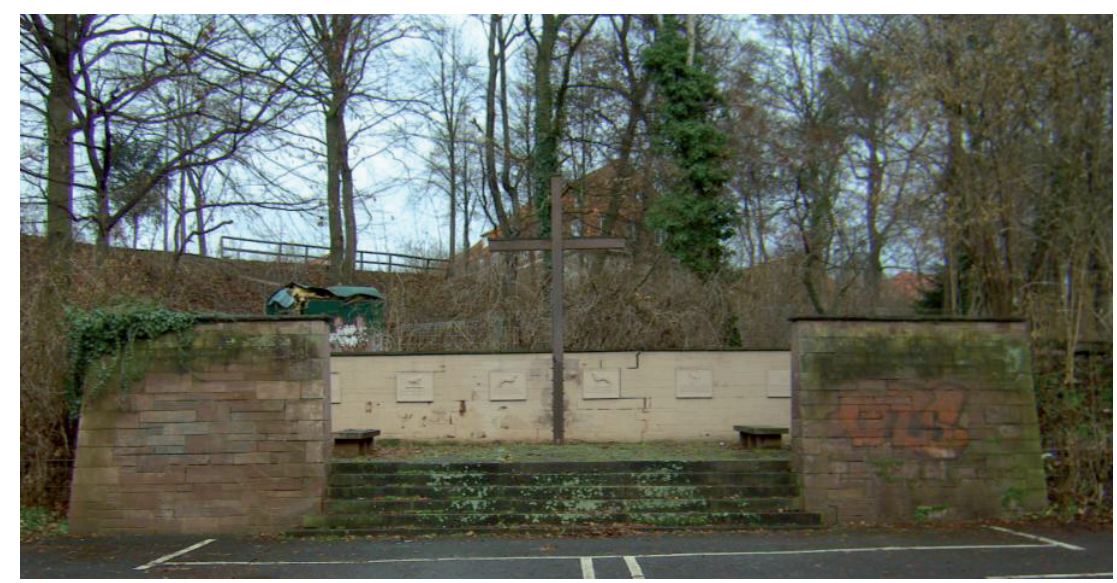

Der Zustand der Ehrenmalanlage im Jahr 2011 
Parkplatzes und befindet sich in einem ungepflegten und verwahrlosten Zustand.

\section{Didaktische Überlegungen}

Das Ehrenmal kann im Kontext des Themas „Veränderungen in Europa und die Weimarer Republik" im 9. Schuljahr behandelt werden. Da die Denkmalsfigur 1988 gestürzt wurde, ist eine Exkursion wenig sinnvoll. Für die Durchführung dieser Einheit werden ca. vier Unterrichtsstunden benötigt.

\section{Intentionen}

Schülerinnen und Schüler können am Beispiel des Ehrenmals lernen, dass Geschichtsbewusstsein zeitlichem Wandel unterliegt und wie sich diese Veränderungen in der Geschichtskultur niederschlagen. Sie erkennen verschiedene Phasen der Rezeption und können die jeweilige zeitgebundene politische Dimension des Denkmals reflektieren. Die Schülerinnen und Schüler lernen die inneren Belastungen der Weimarer Republik kennen, die aus der nicht eingestandenen Niederlage im Ersten Weltkrieg resultierten. Symptomatisch dafür ist die Vielzahl von Kriegerdenkmälern, die in jener Zeit entstanden und von denen das Ehrenmal im Göttinger Rosengarten exemplarisch behandelt wird. Durch diesen lokalgeschichtlichen Bezug im Geschichtsunterricht wird das Interesse der Schülerinnen und Schüler am eigenen Lebensraum gefördert. Ferner erwerben die Schülerinnen und Schüler Erkenntnisse und Einsichten in den Konstruktcharakter von Geschichte, indem sie mit kontroversen und multiperspektivischen Quellen konfrontiert werden. Dafür wird ein breites Spektrum an Quellengattungen angeboten, das vom Lied über Bilder, Reden und Zeitungsartikel bis hin zum Ratsprotokoll reicht.

\section{Materialseite 1}

Steckbrief und Zeittafel mit grundlegenden Informationen geben den Schülerinnen und Schülern einen ersten Überblick über die wichtigsten Daten und Fakten zum Denkmal und seiner Geschichte.

\section{Materialseite 2-3}

Die Schülerinnen und Schüler erhalten Einblicke in die Wahrnehmung des Denkmals zur Zeit seiner Stiftung und die kontroverse Beurteilung seiner Deutung in den verschiedenen politischen Lagern.

\section{Materialseite 4}

Die Schülerinnen und Schüler beschäftigen sich mit der Einbindung des Denkmals in die nationalsozialistische Ideologie.

\section{Materialseite 5-6}

Die Schülerinnen und Schüler setzen sich mit der in den 1980er Jahren verstärkt geäußerten Kritik am Denkmal auseinander. Durch Handlungsorientierung und historische Perspektivenübernahme vertiefen und reflektieren sie ihr eigenes Geschichtsbewusstsein und erwerben zugleich wichtige Einsichten, Handlungsweisen und Verhaltensregeln zur Teilhabe an demokratisch verfassten, politischen Institutionen.

\section{Literatur}

Biermann, Holger/Lindloff, Frauke, „Alle werden fallen“. Das Kriegerdenkmal im Rosengarten, in: Gottschalk, Carola (Hrsg.), Verewigt und Vergessen. Kriegerdenkmäler, Mahnmale und Gedenksteine in Göttingen, Göttingen 1992 , S. $54-66$.

Bund der ehemaligen 82er e. V. Göttingen (Hrsg.), 82er Ehrenmal - 35 Jahre im Göttinger Rosengarten, Göttingen 1988.

Dieterichs, Ernst, Festschrift zur Denkmalsweihe und Regimentsappell des ehemaligen 2. Kurhessischen Infanterie-Regiments Nr. 82. Göttingen, 22.-24. August 1925, Göttingen 1925.

Gottschalk, Carola, Einleitung, in: Gottschalk, Carola (Hrsg.), Verewigt und Vergessen. Kriegerdenkmäler, Mahnmale und Gedenksteine in Göttingen, Göttingen 1992, S. 9-18.

Nissen, Walter, Das Ehrenmal in Göttingens Rosengarten, Göttingen 1987. 


\section{Basisinformationen zum Ehrenmal des Infanterie-Regiments Nr. 82}

\section{M1 Steckbrief}

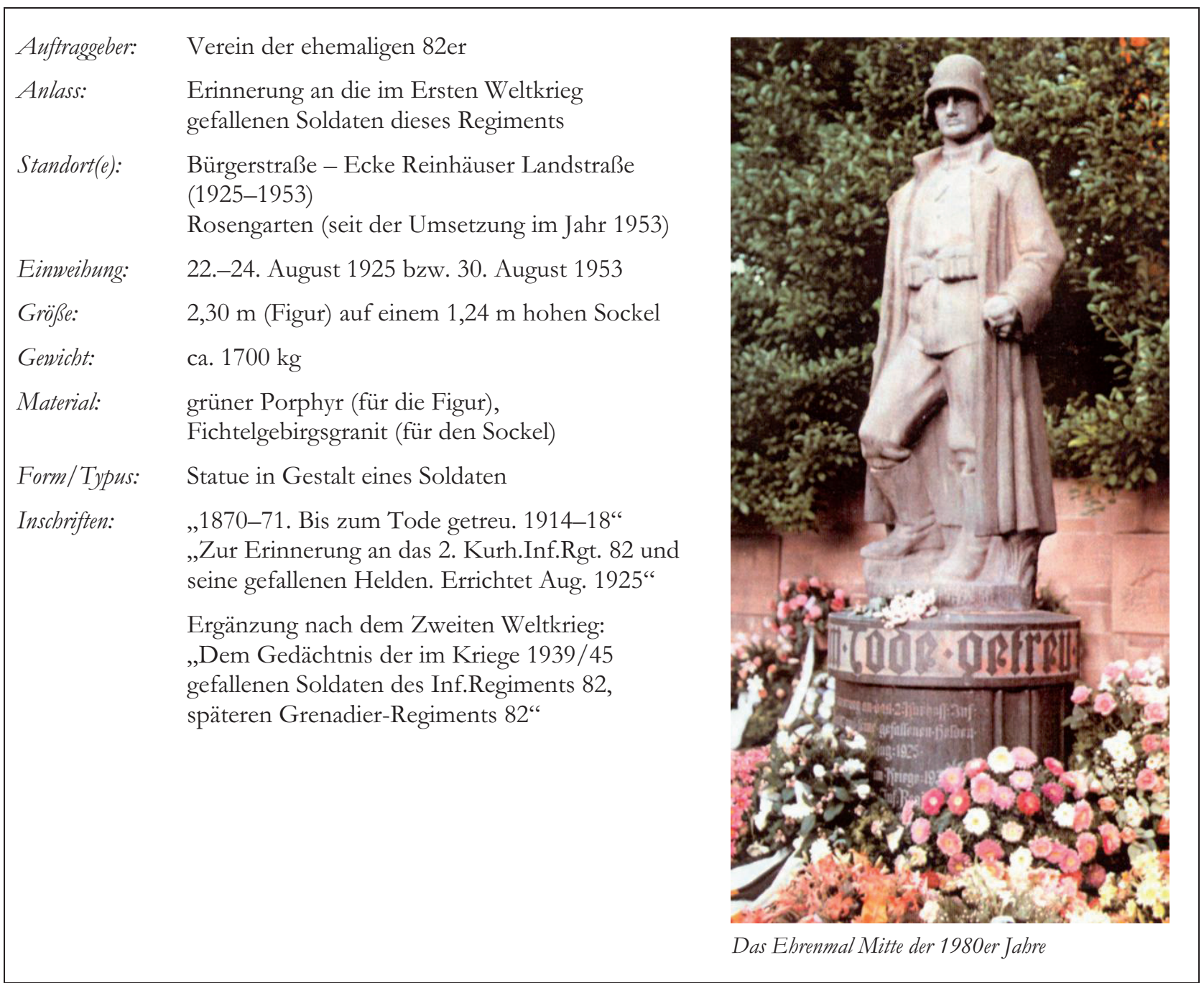

\section{M2 Zeittafel}

$1925 \quad$ Einweihung

1937 Wiedererrichtung des 82er Regiments

1953 Umsetzung in den Rosengarten und Erweiterung auf die gefallenen Soldaten des Zweiten Weltkriegs, von 1953 bis Anfang der 1990er Jahre jährliche Gedenkveranstaltungen

1959 1. Denkmalsturz, die Figur bleibt unbeschädigt und wird wieder aufgestellt

1980 2. Denkmalsturz, die Figur bleibt unbeschädigt und wird wieder aufgestellt

1987 3. Denkmalsturz, die Figur bleibt unbeschädigt und wird wieder aufgestellt

1988 4. Denkmalsturz; der Figur wird der Kopf abgeschlagen, daraufhin wird sie aus der Ehrenmalanlage entfernt und als Ersatz wird ein schlichtes Holzkreuz aufgestellt 


\section{Unterschiedliche Wahrnehmungen in der Vergangenheit}

\section{M3 Das Heldenlied der 82er Soldaten}

Anlässlich von Denkmalsweihe und Regimentsappell im August 1925 erscheint eine Festschrift. Ihr ist das folgende Lied vorangestellt:

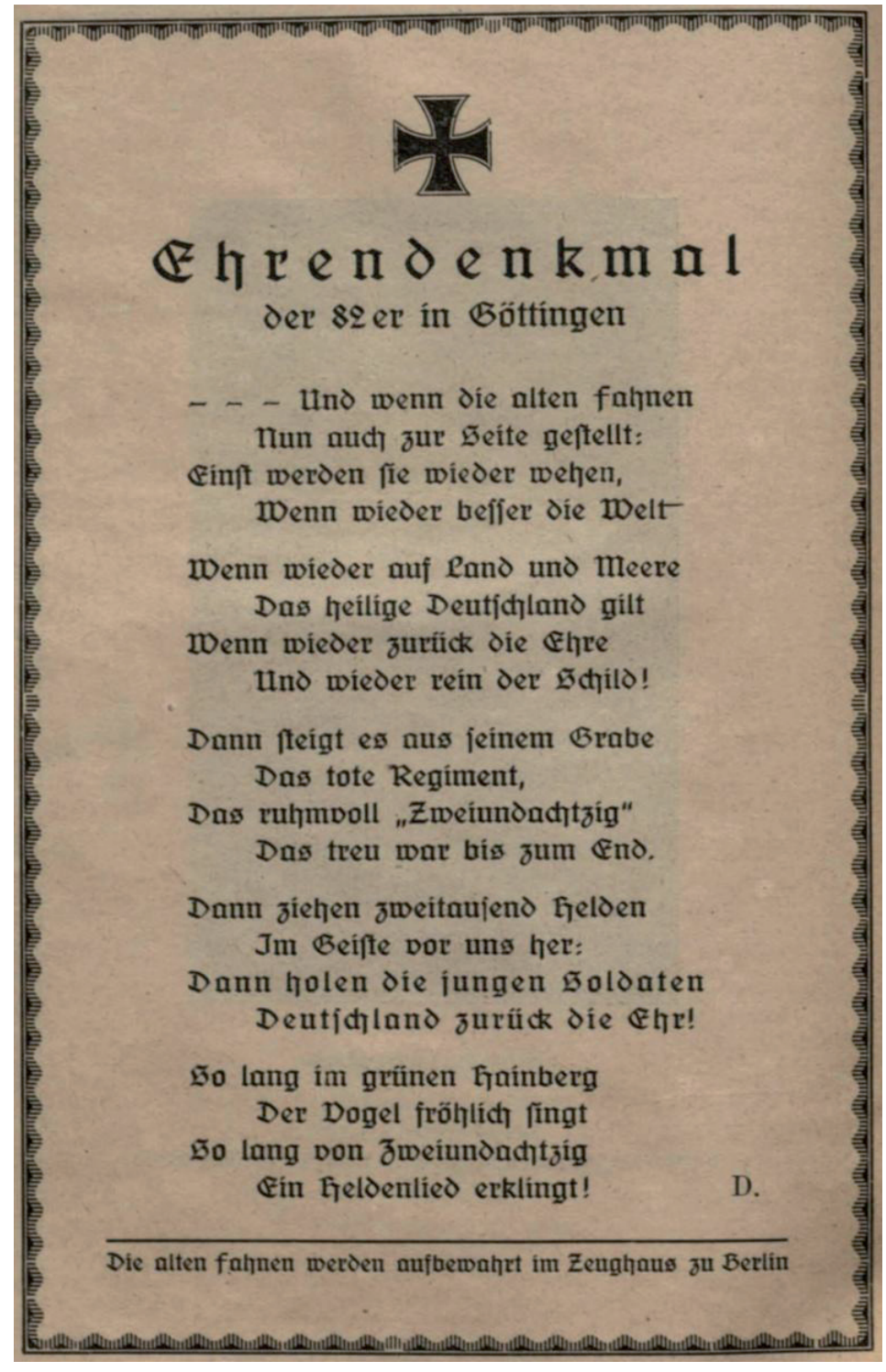

Zeughaus = Lager für Waffen und Kriegsgerät

(Ernst Dieterichs, Festschrift zur Denkmalsweihe und Regimentsappell des ehemaligen 2. Kurhessischen InfanterieRegiments Nr. 82. Göttingen, 22.-24. August 1925, Göttingen 1925, S. 4)

\section{Arbeitsaufträge}

1. Beschreibe die Vorstellung von Ehre, auf der das Lied beruht.

2. Erläutere, welche Sehnsüchte und Forderungen im Lied zum Ausdruck kommen.

3. Stelle dir eine Situation vor, in der das Lied gesungen wurde. Stelle Vermutungen darüber an, welche Wirkung das Lied gehabt haben könnte. 


\section{M4 Wider die „rückwärtsgewandten Sentimentalitäten“}

In der Zeitung „Volkesblatt" erscheint am 25. August 1925 dieser Artikel, der aus zeitgenössischer Perspektive Denkmalsweihe und Regimentstage kommentiert (Auszug):

\section{3u Regimentstagen.}

Und trotz dieses ganzen Sachverhaltes [nämlich der Wiedersehensfreude, MD], und trotz dieser Szenen auf den Straßen, das ist doch nicht der Grund solcher Tage [der Regimentstage, MD]. Der Grund ist ein 5 politischer. Das zeigte die Beflaggung, das zeigten die Reden und das zeigte der Festzug. Hier ist wieder einmal Gelegenheit, von Seiten des Offizierkorps, in ihrem politisch reaktionären Sinne ins Breite zu wirken, indem sie massenpsychologisch recht geschickt, 10 gerade die oben gezeigten menschlichen Neigungen für ihre politischen Zwecke benutzen. Denn daß eine ganze solche Veranstaltung nichts weiter als eine raffinierte Inszenierung einer politischen, nicht aber einer Erinnerungs-Angelegenheit ist, das beweist wohl zur 15 Genüge die Zulassung eines Hakenkreuzverbandes, u. ä. düstere Organisationen zum Festzuge. Und so muß die Konsequenz für jenen Klassenbewußten und sich politisch verantwortlich fühlenden Sozialisten sein, wie sehr ihm [sic] auch die oben zuerst aufgezeigten 20 psychologischen Gründe [nämlich Wiedersehensfreude, MD] zur Teilnahme an einer solchen Veranstaltung reizen mögen, solche spitzfindigen Unternehmungen unter allen Umständen zu meiden und gegen sie zu protestieren. Ja, wie mancher nicht ganz Gesin25 nungsbewußte hat sich nicht verleiten lassen von seiner Erinnerungssentimentalität und hat nun dadurch, $\mathrm{da}$ er hier mit aufmarschierte, gegen sich selbst gezeugt, und hat dadurch, daß er seiner Erinnerungsliebe, seiner Vergangenheit nachging, seiner Zukunft ge30 schadet. Uns aber gilt die Zukunft, und ihr sind wir verpflichtet. Drum weg mit jenen rückwärtsgewandten Sentimentalitäten.

(Volksblatt. Organ für die werktätige Bevölkerung der Stadt Göttingen und der südhannoverschen Kreise Nr. 197 vom 25.8.1925, S. 5)

\section{Arbeitsaufträge}

1. Stelle fest, aus welcher politischen Richtung der Zeitungsartikel stammt. Nenne Begriffe und Formulierungen, an denen du das sprachlich festmachen kannst.

2. Erläutere die Argumentationsschritte des Artikels.

3. Nimm Stellung dazu, wie das „Volksblatt“ Denkmalsweihe und Regimentsappell bewertet. 


\section{M5 Vom ewigen deutschen Soldatentum}

Zum 15. Jahrestag der Denkmalsweihe im August 1940 wird ein Artikel von Oberstleutnant a. D. Ernst Dieterichs im Göttinger Tageblatt veröffentlicht:

\section{Dom ewigen deut/hen Soldatentum} 3um 15. Jahrestag dec Retidtuag oes 3wetiutiouthijget-Denkmals

Wenig Schlagwörter haben solche Berechtigung und solchen inneren Wert als das vom „Ewigen Soldatentum“. Das künden wieder Haltung und Tat des Millionenheeres, das jetzt unter Waffen steht. Umschlos5 sen wird dies glorreiche Soldatentum großer Tage und Stunden von dem großen Zauber des Soldatentums, der täglichen und stündlichen Auswirkung der besten menschlichen Eigenschaften von Mensch zu Mensch: der Kameradschaft.

10 Von dieser Kameradschaft im militärischen Alltagsleben und ihrer höchsten Vollendung in Not und Tod zeugen die Soldatendenkmäler, auch die in unserer Stadt. Das erste war das Studentendenkmal vor dem Auditorium. Zu seiner Einweihung kam der 15 Feldmarschall von Hindenburg nach Göttingen, wie ein Volksheld begrüßt von allen, die guten Sinnes waren.

Wenige Monate nachdem der Feldmarschall Reichspräsident geworden war, wurde das Denkmal

(Göttinger Tageblatt Nr. 186 vom 10. und 11.8.1940, S. 3)
20 des 2. Kurhessischen Infanterie-Regiments Nr. 82 errichtet. Das war am Sonntag, dem 23. August 1925, vor nunmehr bereits 15 Jahren! So groß wie der jämmerliche Niedergang, so groß der Aufstieg durch die elementare Kraft einer Volksbewegung und den ener25 giegeladenen Willen ihres Führers.

An diesem sonnenglänzenden prächtigen Sonntag vor 15 Jahren schwamm Göttingen in einem Meer von Fahnen, mehr als 8000 ehemalige 82er aus allen Teilen Deutschlands und aus dem Ausland und aus 30 den vom Feind besetzen Gebieten waren unter groBen persönlichen Opfern herbeigekommen - ihre Treue war ewiges Soldatentum. [...]

Damals blutete Deutschland aus tausend Wunden, aber es hoffte auf tausend Knospen neues Lebens. 35 Wer aber konnte wissen, daß aus der Hoffnung im Jahre 1925 die Erfüllung des Jahres 1940 werden würde.

\section{Arbeitsaufträge}

1. Benenne und erläutere die im Zeitungsartikel besonders betonten menschlichen Eigenschaften.

2. Stelle dar, welche Traditionslinien und Kontinuitäten der Artikel aufzeigt.

3. Arbeite unter Berücksichtigung des historischen Kontextes die Zielsetzung des Zeitungsartikels heraus. 


\section{Pro und Contra Ehrenmalfeiern}

\section{M6 „Nie wieder Krieg“}

Hermann-Christian Thomasius, Sprecher des Kuratoriums „Soldaten-Ehrenmal Göttingen“, formuliert in einer Pressemitteilung die Sicht der Veranstalter:

\begin{abstract}
„Die Angehörigen der Generationen, die das Grauen des Krieges selbst erlebt haben, finden sich in Göttingen zusammen. [...] Sie gedenken der Toten beider Weltkriege dieses Jahrhunderts, der vermißten Kame5 raden und der umgekommenen Angehörigen in der Heimat, auf der Flucht und in Deportationslagern. Sie gedenken der Toten aller Nationen, die an diesen beiden Kriegen teilgenommen haben. Eine Heldenfeier von Revanchisten ist die Gedenkfeier nicht, son-
\end{abstract}

10 dern in erster Linie ,Mahnfeier' mit dem Motto ,Nie wieder Krieg'.

An der Veranstaltung nehmen Veteranen ausländischer Armeen sowie Abordnungen befreundeter Streitmächte teil. Dadurch wird die Absicht zum Aus15 druck gebracht, daß sich ehemalige Gegner die Hand zur Versöhnung über den Gräbern reichen. Wir wollen niemanden stören und wir möchten auch nicht gestört werden.“

(Göttinger Tageblatt Nr. 203 vom 31.8.1988, S. 15)

\section{M7 Totengedenken}

\section{Ingeborg Heckendorf, Vorsitzende der Landsmannschaft Ostpreußen in Göttingen, äußert sich in einem Interview mit dem „Göttinger} Tageblatt":

„Wir gedenken am 4.9. [1988, MD] der Toten aller Nationen in der ganzen Welt, die im Kampf für Bestand und Freiheit ihres Landes den Tod gefunden haben. Wir gedenken aller Menschen, die starben, weil 5 sie die Gebote der Menschlichkeit höher achteten als die Befehle einer Politik der Unmenschlichkeit. Wir gedenken der Männer, Frauen und Kinder, die auf der Flucht vor den Schrecken des Krieges und bei der Zerstörung der Städte ums Leben kamen.“

(Göttinger Tageblatt Nr. 203 vom 31.8.1988, S. 15)

\section{M8 „Daß der steinerne Soldat nicht wieder aufersteht!“ - Der Antrag der GAL-Fraktion}

Andrea Obergöker, Ratsfrau der Grünen Alternativen Liste (GAL), stellt in der Ratssitzung vom 2. September 1988 den Antrag, dass die Stadt Göttingen ab sofort keine offiziellen Vertreter zu den Ehrenmalfeiern im Rosengarten entsenden solle, und begründet dies folgendermaßen:

„Jahr für Jahr lädt die Landsmannschaft Ostpreußen in Zusammenarbeit mit dem Kuratorium ,Ehrenmal zur sogenannten ,Feierstunde ${ }^{6}$ ein. Ehrenzüge der Bundeswehr und ausländischer Militärangehöriger so5 wie Ehrenwachen geben dem ganzen militärisches Gepräge und einen offiziellen Anstrich. Die Bundeswehr sieht sich ganz offensichtlich in der Tradition der heimatlosen ehemaligen ostpreußischen Divisionen, deren Soldaten geehrt werden sollen. Es geht den 10 Initiatoren um Ehrung der soldatischen Tugenden, nicht um Trauer, wie uns die Veranstalter weismachen wollen. Es geht um ,Heldengedenken` und nicht um einen Appell ,Krieg dem Krieg‘. Es geht um die Verherrlichung von Militär und Krieg. [...]
15 Und es geht den Initiatoren um die Verbreitung revanchistischen Gedankenguts. Es geht ihnen darum, immer wieder - sozusagen jährlich - zu betonen, es handele sich um deutsches Gebiet, das von den Sowjets und den Polen besetzt sei. Die Ehrenmalfeier 20 dient dem Zweck, ein Vergessen zu verhindern. [...] Es ist unerträglich, daß die Stadt Göttingen an dieser Feier teilnimmt oder Teilnehmer durch Empfänge ehrt, und diese Veranstaltung dadurch aufwertet und gesellschaftsfähig macht.

25 Wenn es Ihnen ernst ist mit einer Arbeit für Frieden und Völkerverständigung, dann sorgen Sie bitte dafür, daß diese Art von Feiern unterbunden werden und das Symbol dieser Feier, der steinerne Soldat, nicht wieder aufersteht." 


\section{M9 Die Reaktionen der anderen Ratsfraktionen}

\section{Nach der Antragsbegründung entwickelt sich die folgende Debatte, die im Sitzungsprotokoll festgehalten ist:}

Ausdrücklich wendet sich Beigeordneter Dr. Block [Ratsherr der CDU-Fraktion, MD] auch gegen die unwahren Behauptungen hinsichtlich der Durchführung der Ehrenmalfeier im Rosengarten. Entgegen der 5 Unterstellungen der Antragsteller hätte die Landsmannschaft Ostpreußen und das Kuratorium Ehrenmal sehr früh die Erinnerungen an das Kriegsleid als Mahnung zum Friedenswillen und zur Versöhnung herausgestellt. Hinter diesem Antrag verberge sich 10 eine inhumane Denkweise. Seine Fraktion lehne ihn daher mit Empörung ab.

Ratsherrin Frau Schneider Ratsfrau der CDUFraktion, MD] unterstreicht die Bedeutung der Feierstunden am Rosengarten und stellt fest, sie sei keines15 wegs ein Treffpunkt für Revanchisten und die ewig Gestrigen. Vielmehr seien dort Angehörige von Gefallenen und Opfern beider Weltkriege versammelt, um an dem Mahnmal der Gefallenen zu gedenken. [...]

Oberbürgermeister Levi [SPD, MD] stellt in sei20 nem Wortbeitrag insbesondere heraus, er sei kein Freund der Landsmannschaft Ostpreußen, habe nie in irgendeinem Militär gedient, sei nie Faschist gewesen und habe auch nie in irgendeiner Weise revanchistische Gelüste geäußert. Man müsse sehr wohl die 25 Landsmannschaft Ostpreußen von der hiesigen Landsmannschaft Ostpreußen trennen. Die hiesige Landsmannschaft Ostpreußen habe nunmehr seit 25 Jahren jährlich ehemalige Kriegsgefangene aus Belgien und Frankreich eingeladen, um an der Gedenkfeier 30 teilzunehmen. Eingehend auf die vorhergehenden Wortbeiträge teilt Oberbürgermeister Levi sodann mit, er habe seit mindestens 15 Jahren kontinuierlich an den Empfängen der Stadt und davon auch zweimal an den Feiern im Rosengarten teilgenommen und das, 35 was in den vorhergehenden Wortbeiträgen teilweise skizziert wurde, nicht miterlebt. In den jährlich wiederkehrenden Ehrenmalsfeiern durch die örtliche Landsmannschaft Ostpreußen sehe er ein echtes Bemühen um Verständigung und Aussöhnung. Zusam-

40 menfassend stellt Oberbürgermeister Levi abschlieBend fest, es bestehe aufgrund seiner Erfahrungen in Göttingen keinerlei Anlaß für den hier vorliegenden Antrag und empfehle daher der antragsstellenden Fraktion, diesen zurückziehen. [...]

45 Ratsherrin Frau Sakowsky [Ratsfrau der GALFraktion, MD] stellt zunächst fest, es seien von den Vertretern der CDU-Ratsfraktion schwere Vorwürfe gegen ihre Fraktion erhoben worden. Einige Ausführungen hätten sie allerdings sehr nachdenklich ge50 macht. Die in den Wortbeiträgen dargestellte Form der Feiern am Ehrenmal könne von ihr nicht akzeptiert werden. Es müsse in diesem Zusammenhang die Frage erlaubt sein, wie der Wille nach Frieden und Völkerverständigung zu vereinbaren sei mit der Tole55 rierung von militärischen Ehren- und Trauerfeiern, mit Orden, Uniformen und militärischen Zeichen.

(Niederschrift über die 23. Sitzung des Rates der Stadt Göttingen am Freitag, dem 2. September 1988, S. 10f.)

\section{Arbeitsaufträge}

1. Sammelt in Partnerarbeit die Argumente, die für eine Durchführung der Ehrenmalfeiern sprechen (M6, M7 und M9).

2. Sammelt in Partnerarbeit die Argumente, die gegen eine Durchführung der Ehrenmalfeiern sprechen (M8 und M9).

3. Stellt auf der Grundlage der von euch gesammelten Argumente in der Klasse die Ratssitzung nach und führt selbst eine Debatte darüber, ob die Stadt Göttingen offizielle Vertreter zu den Ehrenmalfeiern entsenden soll. Stimmt am Ende darüber ab. 


\section{Das Ehrenmal für die Gefallenen der Universität}

\section{Carina Marunde}

Auf dem Platr, vor dem Auditorium wurde im November 1923 das Denkmal der Gefallenen der Universität errichtet. Die Schülerinnen und Schüler lernen in der Auseinandersetzung mit diesem Denkmal die mit ihm verbundenen Intentionen kennen. Das Zusammenspiel zwischen Denkmal und Umgebung spielt dabei ebenfalls eine wichtige Rolle. Das Denkmal lässt sich im Zusammenhang mit dem Thema Erster Weltkrieg behandeln.

\section{Erscheinungsbild}

Am Wall und an einer vielbefahrenen Kreuzung, auf dem Platz direkt vor dem Auditorium der Universität steht das „Denkmal der Gefallenen der Universität“". Mit Sockel erreicht es eine Höhe von 5,10 m. Die Plastik ist aus drei großen Dolomitblöcken gefertigt. Sie besteht aus acht nackten herkulischen Männergestalten, die auf ihren Schultern einen Toten tragen. Sie nehmen eine gebeugte Haltung ein. Ihre Gesten und Gesichtszüge drücken Schmerz aus. Die Größe und Darstellung der Figuren erinnert an die Heldenvorstellungen der germanischen Mythologie. Das Motiv „Transport eines Toten" ist für ein Kriegerdenkmal jedoch eher ungewöhnlich. In den So-

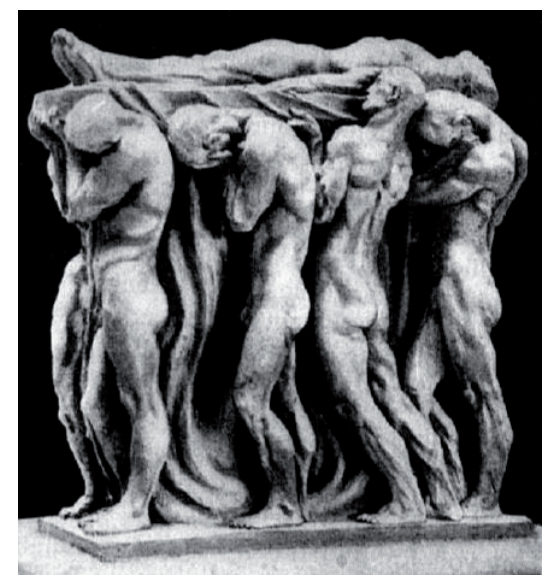

Tonmodell des Denkmals von 1921

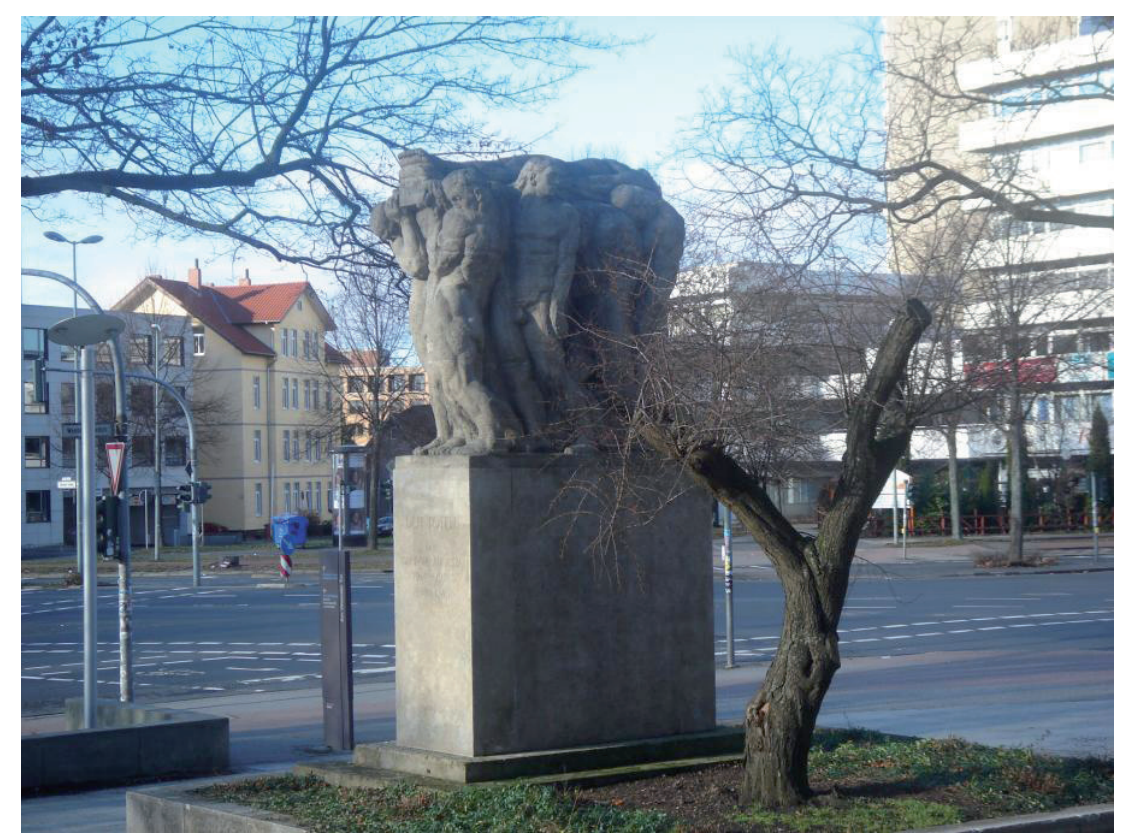

Denkmal der Gefallenen der Universität, 2011

ckel sind, in alphabetischer Reihenfolge, getrennt nach Lehrenden und Lernenden, die Namen der insgesamt 748 im Ersten Weltkrieg gefallenen Universitätsangehörigen eingemeißelt. Außerdem befand sich dort zunächst die Inschrift: „Ihren im Weltkrieg Gefallenen. Die Georgia Augusta“. 1957 wurde diese Inschrift durch eine neue ersetzt: „Den Toten / der / Georgia Augusta / 1914-1918 / 1939-1945“. Weitere Symbole oder Schmuckelemente wurden dem Denkmal nicht hinzugefügt.

\section{Entstehung und Intention}

Das Denkmal für die Gefallenen der Universität wurde am 23. November 1924 (Totensonntag) enthüllt. Bereits seit 1914 waren Spendengelder ehemaliger Studenten eingegangen, um ein solches Vorhaben zu realisieren. 1915 wurde diese Idee von der Universität selbst aufgegriffen. Das geplante Denkmal sollte an den Ersten Weltkrieg erinnern, dessen Dau- er und Ausgang zum damaligen Zeitpunkt noch nicht bekannt waren.

Nach der Niederlage geriet die Planung des Denkmals, das ursprünglich ein Löwe (Symbol der Stärke) oder eine (Sieges-)Säule hätte sein sollen, ins Stocken. 1921 wurde die Idee auf Betreiben der Studentenschaft wieder aufgegriffen. Der Bildhauer Josef Kemmerich, der als Zeichenlehrer an der Universität arbeitete, erklärte sich bereit, kostenlos ein Modell zu planen und dieses umzusetzen. Das ausdrucksstarke Profil der Figurengruppe, die an die Plastik „Bürger von Calais“ von $\mathrm{Au}$ guste Rodin erinnerte, ging allerdings bei der Ausarbeitung in hartem Dolomit teilweise verloren. Die Materialkosten dieses Projektes trug die Universität.

Der Bezug des Denkmals auf die germanische Mythologie wurde auch in der Einweihungsrede von Rektor Binder angesprochen: Die Toten seien wie ,eine stolze Schar von Einheriern nach mutigem Kampfe 
in Walhall eingezogen“. Einherier sind nach der nordischen Göttersage die im Kampf gefallenen Helden, die von Odin in die Toten- und Ruhmeshalle Walhall berufen werden, wo sie weiterhin ein Leben in Kampf und Ehre führen, um einst im letzten Kampf den Göttern zu Hilfe zu eilen.

Es gibt allerdings auch eine andere Lesart des Denkmals. Der getragene Tote wird dabei verstanden als Darstellung der zu tragenden Last des Friedensvertrages, des Elends, der Demütigungen und Kränkungen, die dem deutschen Volke aufgebürdet wurden. Dies knüpft an die in den 1920er Jahren geläufige Dolchstoßlegende an, deren Ursprung in der Nibelungensage liegt. In dieser wird vom Mord an Siegfried berichtet, der hinterlistig mit einem Speer von Hagen getötet wurde. Nach dem Ersten Weltkrieg wurde in Anlehnung daran die Schuld an der Niederlage im Krieg nicht dem Versagen der eigenen Soldaten, sondern der Sozialdemokratie zugeschrieben, die mit einem Dolchstoß von hinten die an der Front kämpfenden Truppen niedergestreckt habe.

Das Denkmal dient nicht nur der Klage um die Toten, sondern stellt auch einen Appell an die Lebenden dar. Dies machte auch der Ehrengast der Einweihungsfeier, der spätere Reichspräsident von Hindenburg, in seiner Rede vor 7000 Zuhörern deutlich (Gottschalk 1992, S. 26-33):

„Unsere Toten haben im festen Glauben an Deutschlands Größe ihr Leben dahingegeben. Ihr Blut darf nicht umsonst geflossen sein! Darum laßt uns, ein jeder an seiner Stelle, dahin wirken, daß der Geist von 1914, der Geist der Treue, der Vaterlandsliebe und der Aufopferung für das Allgemeinwohl, wieder Gemeingut des deutschen Volkes werde. Dann wird unser Deutschland mit Gottes Hilfe wieder zu Ehren kommen, und damit ehren wir am besten unsere gefallenen Brüder!“"

\section{Geschichte und Rezeption}

Nach 1933 stieß das Denkmal auf Ablehnung. Die Thematisierung von Schmerz und Trauer seien nicht akzeptabel (Lurz 1995, S. 233): „Vor dem Auditorium der Universität steht in Überlebensgröße das Denkmal der gefallenen Studenten. Acht Männer tragen ihren toten Kameraden. Unendlicher Schmerz liegt in jedem Antlitz, in jeder Bewegung der Körper. Die Köpfe sind gesenkt, die Körper gramgebeugt, die Gesichter, soweit sie dem zudringlichen Auge des Betrachters nicht ganz verborgen sind, sind schreiender Ausdruck tiefster Trauer. Dieses Denkmal ist in einer Zeit und in einem Geiste geschaffen worden, die uns heute fremd sind und dem deutschen Soldaten wohl immer fremd gewesen sind. Es ist sinnlos zu fragen, weshalb brechen die Männer zusammen, wenn der Tod in ihre Reihen fährt, denn der müde Schmerz, der hier festgehalten wurde, ist nicht das Wesensmerkmal des deutschen Soldaten gewesen."

Es missfiel auch die Darstellung der nackten Männerkörper, die Assoziationen zu homoerotischen Szenen hervorrufen. Darauf spielten später die Studenten der 68er-Bewegung an, als sie das Denkmal mit Spraydosen pink färbten. Sie wandten sich damit jedoch nicht gegen die vermeintliche Darstellung von Homosexualität, sondern vielmehr gegen Kriegsverherrlichung durch Kriegerdenkmäler.

Heute wird das Denkmal nur noch im Zusammenhang mit Graffiti-Aktionen bewusst wahrgenommen. Diese sollten in den letzten Jahren immer wieder Protest gegen Krieg und Bundeswehr zum Ausdruck bringen.

\section{Didaktische Überlegungen}

Die Auseinandersetzung mit dem Denkmal bietet sich für Schülerinnen und Schüler der Sekundarstufen I und II gleichermaßen an. Sie kann stattfinden im Kontext des Ersten
Weltkriegs und seiner Verarbeitung. Alle Materialien können unabhängig voneinander im Unterricht eingesetzt werden. Eine Exkursion zu dem Denkmal bietet den Mehrwert, dass sich das Denkmal in seiner Größe, Gestalt und seiner jetzigen Umgebung besser wahrnehmen lässt.

\section{Materialseite 1}

Anhand dieses Materials können Schülerinnen und Schüler einen Einblick in die verschiedenen Intentionen bekommen, die sich mit dem Denkmal verbinden lassen. Dafür sollten die Schülerinnen und Schüler zunächst das Denkmal in seiner Gestalt und Materialität beschreiben und interpretieren. In einem weiteren Schritt können sie sich in die Entstehungszeit des Denkmals zurückversetzen und unter jeweils verschiedenen Gesichtspunkten eine Rede zur Eröffnung schreiben. Das Arbeitsblatt ist auf Grund seines geringeren Schwierigkeitsgrads für die Sekundarstufe I geeignet.

\section{Materialseite 2}

Material 2 bietet ebenfalls Einblick in die Intentionen, die sich bei der Einweihung mit dem Denkmal verbanden. Jedoch ist das Arbeitsblatt anspruchsvoller und lediglich in der Sekundarstufe II einsetzbar. Im Vorfeld der Erarbeitung sollte die Lehrperson das Gedicht vortragen, sodass die Schülerinnen und Schüler einen ersten auditiven Eindruck erhalten können.

Mit dem Vergleich der Bildmaterialien 3 und 4 lässt sich erarbeiten, welche Bedeutung für die Wahrnehmung und Wirkung eines Denkmals seine Umgebung und Inszenierung hat. Die Umgebung des Denkmals der Gefallenen der Universität hat sich im Laufe der Zeit gewandelt. War der Platz um das Denkmal herum zu Anfang so gestaltet, dass seine Wirkung unterstrichen wurde, so wird die räumliche Situation heute durch die Verkehrsinfrastruktur 
dominiert. Diesen Umgebungs- und damit verbundenen Wahrnehmungswandel sollen die Schülerinnen und Schüler auf Grundlage der Materialien herausarbeiten.

\section{Materialseite 3-5}

Das zweiseitige Arbeitsblatt kann bei einer Exkursion eingesetzt wer- den. Schülerinnen und Schülern können ohne vorherige Kenntnisse in der Denkmalsanalyse mit Hilfe dieser Materialseite alle wichtigen Elemente des Denkmals erkunden und zusammenstellen. Dafür sind eine Leiter und ein Maßband als $\mathrm{Zu}$ satzmaterial wichtig. Material 5 bietet zusätzliche Informationen für die Erkundung.

\section{Literatur}

Gottschalk, Carola, Götterdämmerung. Das Denkmal für die Gefallenen der Universität, in: Gottschalk, Carola (Hrsg.), Verewigt und vergessen: Kriegerdenkmäler, Mahnmale und Gedenksteine in Göttingen, Göttingen 1992, S. $26-33$.

Lurz, Meinhold, Kriegerdenkmäler in Deutschland. Bd. 4: Weimarer Republik, Heidelberg 1985.

Thadden, Rudolf von/Trittel, Günter J. (Hrsg.), Göttingen. Geschichte einer Universitätsstadt. Band 3. Von der preußischen Mittelstadt zur südniedersächsischen Großstadt 1866-1989, Göttingen 1999.

\section{Internet}

http://stadtarchiv.goettingen.de/chronik/1924_11.htm (zuletzt eingesehen: 3.2.2011). 


\section{Basisinformationen zum Ehrenmal für die Gefallenen der Universität}

\section{M1 Steckbrief}

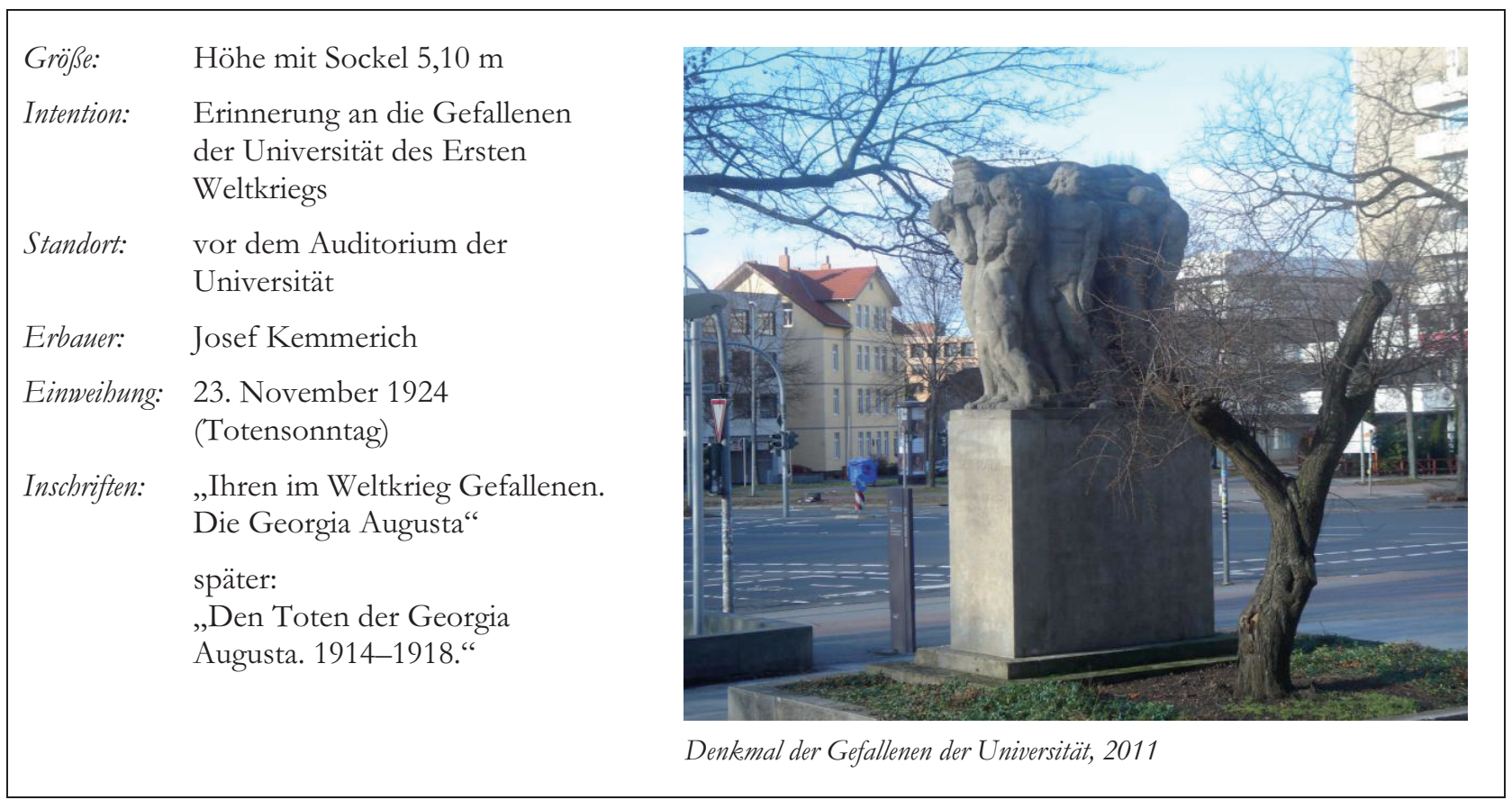

\section{Arbeitsaufträge}

1. Beschreibe das Denkmal der Gefallenen der Universität (M1). Untersuche es im Hinblick auf die Darstellung und die Wirkung der Figuren. Nimm den Steckbrief zur Hilfe.

2. Verfasst aufgeteilt in zwei Gruppen eine Rede, die zur Einweihung des Denkmals vorgetragen worden sein könnte.

Gruppe 1: Setzt beim Verfassen der Rede euren Schwerpunkt auf den Tod und das Leiden der vielen im Ersten Weltkrieg gefallenen deutschen Soldaten. Bezieht dabei auch eure Beschreibungen des Denkmals mit ein.

Gruppe 2: Setzt beim Verfassen der Rede euren Schwerpunkt auf den gemeinsamen deutschen Kampfesgeist, der in diesem Krieg zum Vorschein getreten ist und weiter erhalten bleiben soll. Zeigt Angriffslust gegenüber den Kriegsgegnern. Bezieht dabei auch eure Beschreibungen des Denkmals mit ein. 


\section{Die Einweihung des Denkmals / Denkmalsumgebung}

\section{M2 Gedicht zur Einweihung des Denkmals der Gefallenen der Universität 1924}

\section{Denkma!smeihe ber Eeorgia=2ugufta.}

Ŝ̉ic oräugte nturntelno bic bervegte Menge Roch lag vcrkinilit bas hohe Éhrenmal.

2Bir laüichten ouf bes Traucrhors (Sejänge, Der flov Der jabnen welte fdrmar; unb

fohmal ...

Daut priejen Rebner Der Eefalluen Treue,

Bejdymoren ihren bleik)en (jeifterzug -

Ergrifien fotsute jeber heut anfs giente

Ein 9 intlik, bas veritante 3üge trug.

D Trene! Treue! Sörit on hiex uts ruen? PHd ftarbcit Dut? Ritr bu fannit uns befrein

luns jeht: - jowt: fleht fie an beś Tcuimals

Rebentig - traftwoll! vor bem kalten Etcin!

1) „Walhall“: Ursprung in der nordischen Mythologie, Halle der Gefallenen

2) „lieblich Weib [...] in starker Rechten einen Lorbeerkranz": gemeint ist die Germania

(Göttinger Tageblatt, 25. November 1924, S. 6)

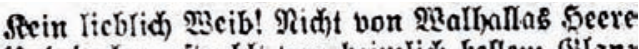

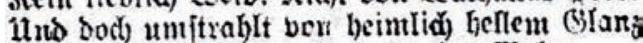

Ein areijer selb! Die sinte an ber webre,

in flarter Red)ten einen Sorbeerfrait;.

unb voll rllinget auझ bes इerzents Tiefen

Die gütge Stinme. Ientichlants bejtex Phaum

Brübt chrend, bie bem Rateriand entidicfen, 3wingt die \&ebendigen in jeinen Bantu.

Die Ireue lebt!! Ius unferm trüben STlagen

Dedt ivetterleuchtent uns ihr mahnent Fort.

Sie werben ummer, ninmer uns zerfhlagen,

Nod) lebt uts Sindenbuxg, ber trelte நort.

Die serzen borb! \&apt Der Begcijtemutg Flamme

Dem sert ber Toten Iobern heif unb rein! Ein Sott! E in Reich! Hub jeb'm beutid)en

Eoll Sintenturg bes Eieges Lojung fint.

$$
\begin{aligned}
& \text { Slamme } \\
& \text { na fritt. } \\
& \text { Simnns. }
\end{aligned}
$$

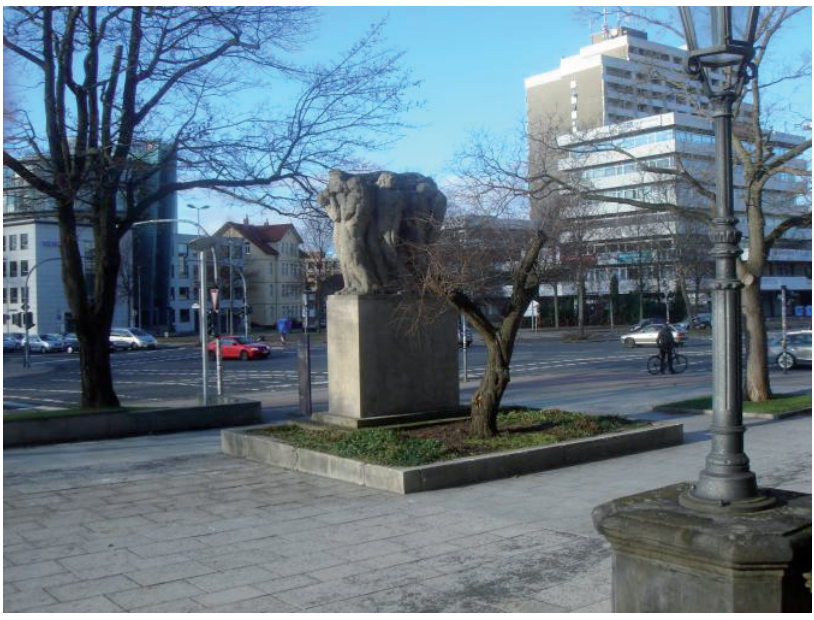

Denkmal der Gefallenen der Universität, 2011

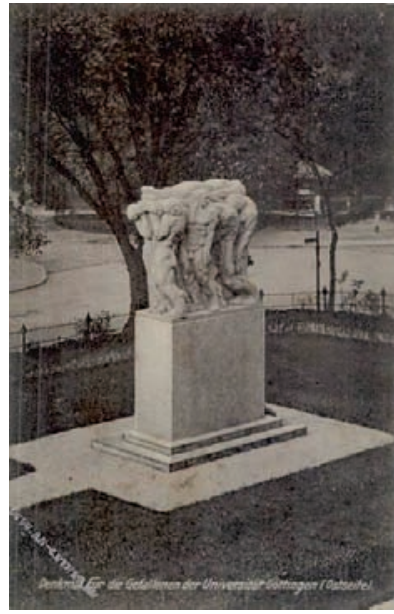

Ansichtskarte von 1930

\section{Arbeitsaufträge}

1. Analysieren Sie mit Hilfe des Gedichts die verschiedenen Interpretationsmöglichkeiten des Denkmals (M2).

2. Beschreiben Sie beide Bilder. Vergleichen Sie die unterschiedlichen Umgebungen des Denkmals.

3. Stellen Sie Vermutungen darüber an, wie die jeweilige Umgebung die Wirkung des Denkmals beeinflusst.

4. Formulieren Sie Ideen, wie man heute die Umgebung des Denkmals gestalten könnte. 


\section{Arbeitsblatt zur Denkmalserkundung}

\section{Erscheinungsbild}

Denkmalstyp:

Größe:

Material:

Gestaltung des Denkmals:

Dargestellte Personen / Szene:
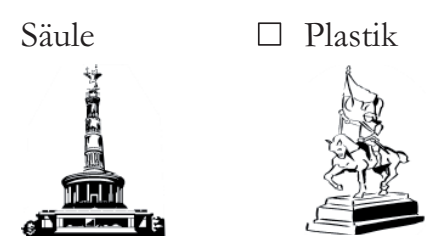

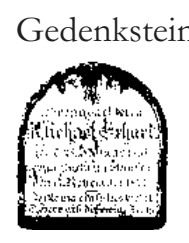

$\square$ Gedenktafel

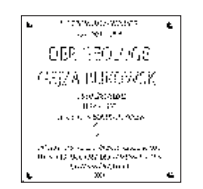

Inschrift:

Standort:

Momentaner Zustand: 


\section{Skizze (von selbstgewähltem Standort aus):}

\section{Planungs- und Realisierungsphasen}

Ursprüngliche Planung:

Realisierung:

Auftraggeber:

Künstler:

Tag / Jahr der Errichtung:

Grund / Anlass der Errichtung:

Nachträgliche bauliche Veränderungen:

\section{Arbeitsaufträge}

1. Untersucht und erkundet das Denkmal in Gruppen. Tragt eure Ergebnisse in das Arbeitsblatt ein.

2. Wertet die „Hintergrundinformationen zum Denkmal“ (M5) zur Beantwortung der noch offenen Aspekte aus. 


\section{M5 Hintergrundinformationen zum Denkmal vor dem Auditorium}

Das Denkmal, das sich vor dem Alten Auditorium am Weender Tor befindet, erinnert an die Gefallenen der Georg-August-Universität Göttingen. Der Sockel enthält die Namen der insgesamt 748 im Ersten Welt5 krieg gefallenen Universitätsangehörigen - sortiert nach Lehrenden und Studierenden.

Schon im Jahr 1914 wurde die Errichtung eines Denkmals vorgeschlagen. Die Universität setzte dafür im darauffolgenden Jahr eine Kommission ein, die un10 ter anderem zuständig war für die Finanzierung, die Motivauswahl und die Wahl des Künstlers. 1916 wurden erste Entwürfe diskutiert. Diese gingen von einem Sieg Deutschlands aus - beispielsweise überlegte man, einen Löwen als Motiv zu verwenden oder eine Sie15 gessäule zu errichten.

Nach der Kriegsniederlage wurde die Planung erst ab 1921 auf Betreiben der Studentenschaft weiter vorangetrieben. Aus finanziellen Gründen wollte man nun auf ein Denkmal verzichten und kostengünstigere 20 Namenstafeln aufstellen. Der belgische Bildhauer Josef Kemmerich, der an der Göttinger Universität als Zeichenlehrer arbeitete, machte jedoch ein Angebot für ein plastisches Denkmal. Er übernahm kostenlos den Entwurf und die künstlerische Ausführung, so25 dass die Universität nur noch die Materialkosten und die Löhne für die Hilfsarbeiter übernehmen musste. Diese Kosten wurden durch Spendengelder getragen.

Das Denkmal wurde am Totensonntag-1), dem 23. November 1924, feierlich enthüllt. Bis 1957 trug das 30 Denkmal die Inschrift „Ihren im Weltkrieg Gefallenen. Die Georgia Augusta“. Danach wurde die Inschrift ersetzt, da auch der Gefallenen aus dem Zweiten Weltkrieg gedacht werden sollte.

1) Der „Totensonntag“ ist der letzte Sonntag vor dem ersten Advent und in der evangelischen Kirche in Deutschland ein Gedenktag für die Verstorbenen des letzten Jahres.

(nach: Gottschalk, Carola (Hrsg.), Verewigt und vergessen: Kriegerdenkmäler, Mahnmale und Gedenksteine in Göttingen, Göttingen 1992, S. 27-33 und Thadden, Rudolf von/Trittel, Günter J. (Hrsg.), Göttingen. Geschichte einer Universitätsstadt. Band 3. Von der preußischen Mittelstadt zur südniedersächsischen Großstadt 1866-1989, Göttingen 1999, S. 849f. Angepasst von Daniela Kempe) 


\title{
Das Mahnmal Synagoge
}

\author{
Franziska Frome-Ziegler, Daniela Kempe, Theresa Nawroth
}

\begin{abstract}
Die Göttinger Synagoge wurde in der Reichspogromnacht 1938 zerstört. 1973 wurde auf ibrem ehemaligen Platz ein Mahnmal im Gedenken an die Opfer des Holocausts errichtet. Die Schülerinnen und Schüler lernen bei der Beschäftigung mit dem Mahnmal die verschiedenen Schritte der Aufarbeitung des Nationalsozialismus kennen, setzen sich mit der Bildsprache des Mahnmals auseinander und reflektieren über mögliche Formen der Erinnerungskultur. Das Mahnmal lässt sich im Kontext der Nachkeriegsgeschichte oder im Rahmen einer Einheit zur Erinnerungskultur behandeln und bietet sich sehr für eine Exkursion an.
\end{abstract}

\section{Erscheinungsbild}

Die 5,60 $\mathrm{m}$ hohe Plastik befindet sich am „Platz der Synagoge“ an der Gabelung „Obere/Untere Maschstraße" und besteht aus Stahlröhren sowie Wasch- und Sichtbeton. Das Mahnmal steht leicht erhöht auf einem Erdhügel. Darauf liegen sechs Stahlträger, die die Plastik tragen. Unterhalb der stählernen Plastik ist ein betonverkleideter Raum eingelassen, der von sechs Seiten über

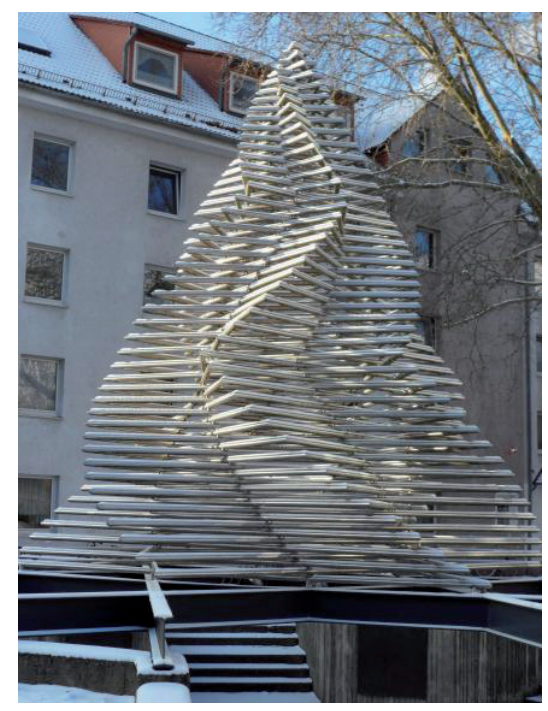

Mahnmal Synagoge, 2010

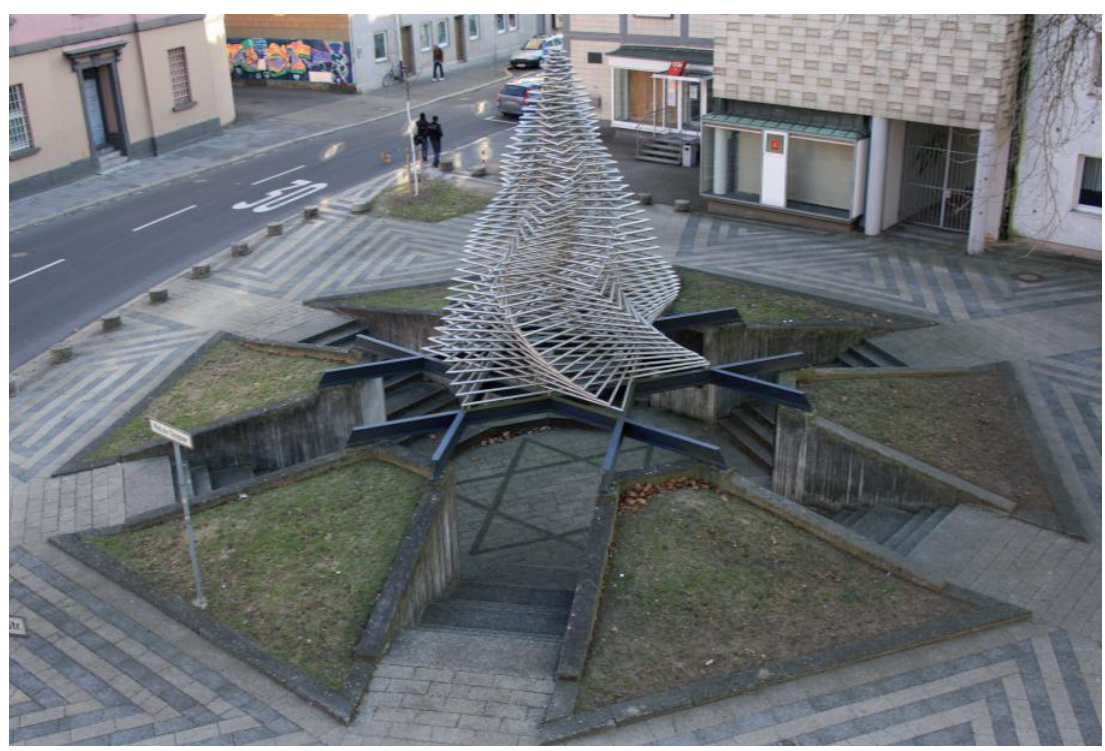

Mahnmal Synagoge, 2011

Treppen wie ein Amphitheater begehbar ist. Die Plastik besteht aus 86 gleichschenkligen Dreiecken aus Stahl, die um zwei Achsen rotierend aufeinander geschichtet sind und nach oben hin kleiner werden. Jeweils zwei der Dreiecke ergeben zusammen das Grundmotiv des Davidsterns. Das Material der Dreiecke wurde gewählt, um Reflexionseffekte zu erzeugen: Tagsüber bricht sich das Sonnenlicht darin und nachts werden die Stangen angestrahlt.

Das Motiv des Davidssterns lässt sich besonders gut erkennen, wenn man die Plastik von unten betrachtet. Dafür muss man über eine der sechs Treppen zwei Meter tief hinab steigen. Im Raum unterhalb der Plastik befindet sich eine Steintafel mit einer Inschrift. Zunächst war dafür folgender Vers vorgesehen: „O, hätte ich Tränen genug zu weinen über die Erschlagenen meines Volkes (Jeremia 8, 23)“. Die Stadt Göttingen entschied sich jedoch für den weit versöhnlicheren Vorschlag der Jüdischen Gemeinde Hannover, die zu diesem Zeitpunkt die Göttin- ger Juden mit repräsentierte. Bei dieser Inschrift verweile der Blick nicht im Gestern und sei auf Gegenwart und Zukunft gerichtet: „Berge werden weichen / und Hügel werden wanken, / aber meine Gnade / wird von dir nicht weichen / (Jesaja 54,10) / Zur Erinnerung an die 1938 / niedergebrannte Synagoge / und den Leidensweg der / Jüdischen Gemeinde / Stadt Göttingen“.

1995 wurde das Mahnmal ergänzt um fünf Bronzetafeln mit den Namen der 282 jüdischen Bürger aus Stadt und Kreis Göttingen, die Opfer der nationalsozialistischen Gewaltherrschaft wurden.

\section{Neue Bildsprache}

Prof. Corrado Cagli (1910-1976) aus Rom, als Maler, Graphiker, Bildhauer und Bühnengestalter international anerkannter Künstler jüdischer Abstammung, gestaltete das Mahnmal. Er präsentierte im Mai 1970 eine Ausstellung im Städtischen Museum Göttingen. Sein grafisches Werk enthält neben anderen Kriegsdoku- 
menten eindringliche Zeichnungen von ausgemergelten Opfern im Konzentrationslager Buchenwald. Cagli war nach dem Krieg Mitbegründer einer neuen Kunstsprache,

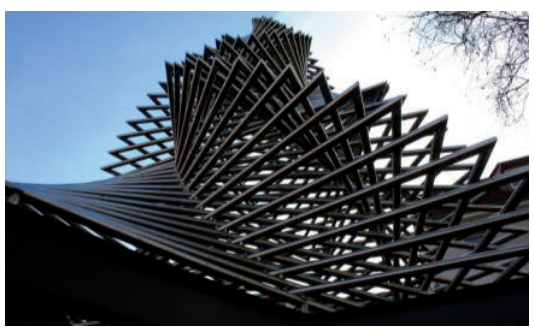

Mahnmal Synagoge, 2011

in die abstrakte, figürliche, antike und avantgardistische Elemente einflossen.

Seine Plastik in Göttingen eröffnet durch Begehbarkeit eine neue Form der Denkmalsgestaltung. Der Künstler überlegte in den ersten Entwürfen sogar, das Mahnmal mit einer Zone von Grün zu umrahmen und auch Kinder in diesem Bereich spielen zu lassen. Es ging ihm um ein offenes, im aktuellen Leben angesiedeltes Denkmal.

Caglis Plastik lässt aufgrund ihrer Abstraktion viele Interpretationsmöglichkeiten zu. Die Schichtung der Davidsterne kann beispielsweise als Berg Sinai, als Ort der Begegnung mit Gott interpretiert werden.
Die Plastik lässt sich aber auch als Himmelsleiter wahrnehmen, die Freiheit und Erlösung schenkt. AuBerdem ist die Deutung des Mahnmals als Flamme möglich. Das Motiv des Feuers nimmt einerseits direkten Bezug auf die Pogromnacht und die Krematorien in den Konzentrationslagern, andererseits kann die Lichtsymbolik als Zeichen der Hoffnung interpretiert werden.

Die Suche nach einer neuen Denkmalssprache findet sich zum Beispiel auch in der Debatte um das Berliner Holocaust-Mahnmal wieder. Hier bieten sich mögliche Anknüpfungspunkte.

\section{Entstehung und Intention}

\section{Ehemalige Synagoge}

Am heutigen Platz des Mahnmals stand früher die 1870 im neuromanischen Stil erbaute und 1895 erweiterte Synagoge der Jüdischen Gemeinde Göttingen. In der Pogromnacht vom 9. auf den 10. November 1938 wurde sie durch Brandstiftung vernichtet, nachdem sie bereits bei Übergriffen im März 1933 erstmals verwüstet worden war. Insgesamt wurden in dieser Nacht in Deutschland 1.406 Synagogen beschädigt und zerstört.

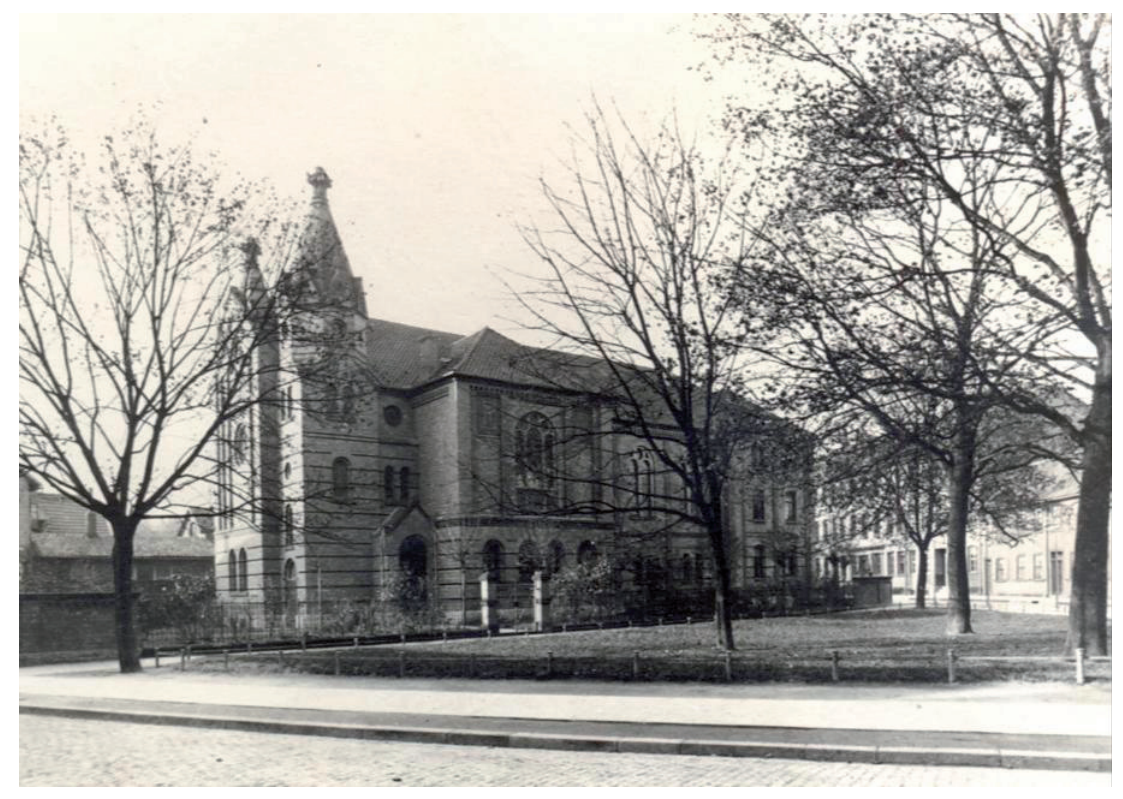

Göttinger Synagoge in intaktem Zustand

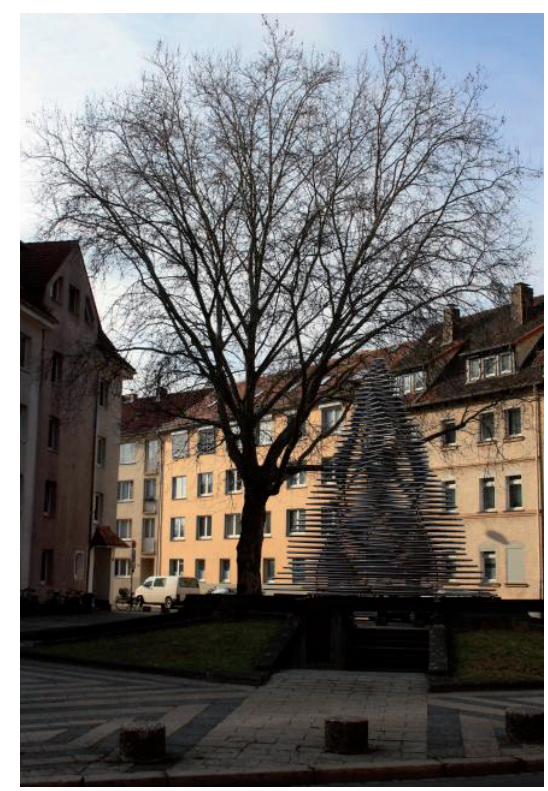

Mahnmal Synagoge, 2011

Gedenkstein auf dem Jüdischen Friedhof

Der Gedenkstein auf dem Jüdischen Friedhof stellt das erste Gedenken an die Göttinger Opfer des Holocausts dar. Ernst Engwicht, der damalige Vorsteher der Jüdischen Gemeinde Göttingen, entwarf den von der Stadt Göttingen finanzierten Gedenkstein, der 1955 aufgestellt wurde. Die Inschrift beginnt mit einem Vers aus dem Klagelied sowohl auf Hebräisch als auch auf

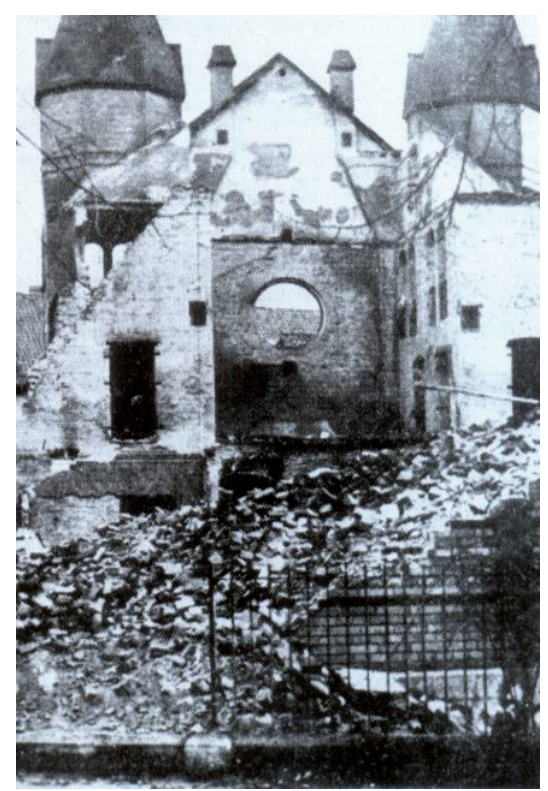

... und nach der Zerstörung 1938 


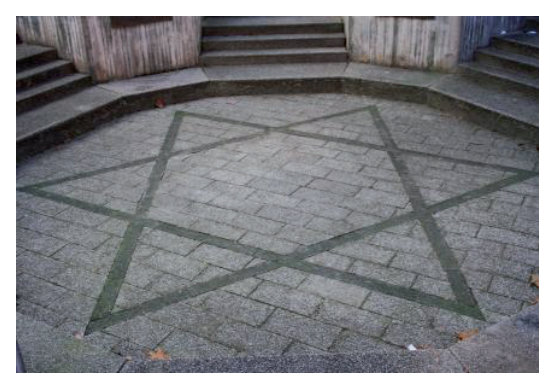

Davidsstern im Mahnmal Synagoge, 2011

Deutsch: „Mein Auge rinnt / und ruht nicht, / keine Linderung / Klagelieder III 49“. Darunter steht: „Zum Andenken an / die Mitglieder unserer / Gemeinde, die in einer / Zeit ihr Leben lassen / mußten, in der die Liebe / und die Achtung / vor den Menschen / gestorben waren / 1933-1945“.

Für das Unfassbare konnten noch keine Worte gefunden werden - im Vordergrund stehen die Opfer, die Täter und Verbrechen werden hingegen nicht konkretisiert.

\section{Gedenktafel von 1960}

1960 wurde auf Betreiben der Jüdischen Gemeinde eine bronzene Gedenktafel für die HolocaustOpfer am Gewerkschaftshaus in der Oberen Maschstraße 10 angebracht. Die Tafel enthält folgende Inschrift: „An diesem Platz stand die Synagoge / der Jüdischen Gemeinde Göttingen. / Sie wurde am 9. November 1938 ein / Opfer des Nationalsozialistischen / Rassenwahns. Die Gemeinde zählte / im Jahre 1939 noch 196 Mitglieder. / Diese wurden bis auf wenige ver- / nichtet. Den Toten zum Gedenken / Den Lebenden zur Mahnung. / Die Stadt Göttingen“. Diese deutlichen Worte überraschen zu einer Zeit, in der im öffentlichen Diskurs noch die Verdrängung der Verbrechen des „Dritten Reiches" dominierte.

Die 1940 vollzogene Enteignung des Grundstückes der ehemaligen Synagoge wurde 1952 rückgängig gemacht. Die Jüdische Gemeinde Göttingen verkaufte es dem Deutschen Gewerkschaftsbund, weil die Gewerkschaften ebenfalls unter der nationalsozialistischen Verfolgung gelitten hatten. Von 1971 bis 1994 gab es keine Jüdische Gemeinde in Göttingen mehr.

\section{Entstehungskontext des Mahnmals}

In den 1970er Jahren trugen viele Faktoren dazu bei, dass der Wunsch aufkam, ergänzend zur Gedenktafel ein Mahnmal zu errichten. Dr. Hannah Vogt, Ratsfrau (SPD) und damalige Vorsitzende der Gesellschaft für christlich-jüdische Zusammenarbeit, kommt in diesem Zusammenhang eine zentrale Vermittlerrolle $\mathrm{zu}$ - wie auch bei vielen anderen Gedenkprojekten. Oberbürgermeister Artur Levi, ein aus dem englischen Exil zurückgekehrter Jude, unterstützte das Vorhaben aktiv. Zeitgleich befassten sich sowohl das Städtische Museum als auch das Kulturamt und die Universität mit der Geschichte der Juden im Raum Göttingen. seien der Stadt Göttingen bereits mit gutem Beispiel vorangegangen. Der Antrag wurde anschließend an den Kulturausschuss weitergeleitet. Hier wurde angeregt, bei dem italienischjüdischen Künstler Cagli, dessen Werke gerade in Göttingen ausgestellt wurden, ein Objekt in Auftrag zu geben. Insgesamt dauerte es von der Antragstellung bis zur Errichtung des Denkmals drei Jahre. Mit diesem Beitrag zur Erinnerungskultur an den Holocaust war Göttingen jedoch im Vergleich zu anderen deutschen Städten ungewöhnlich früh. In den meisten deutschen Städten wurden erst in den 1990er Jahren Synagogenmahnmale aufgestellt.

\section{Einweihungsfeierlichkeiten}

Am 8. November 1973 fand in der Stadthalle eine Gedenkfeier statt, zu der hohe geistliche und weltliche Amtsträger und Persönlichkeiten aus dem In- und Ausland geladen

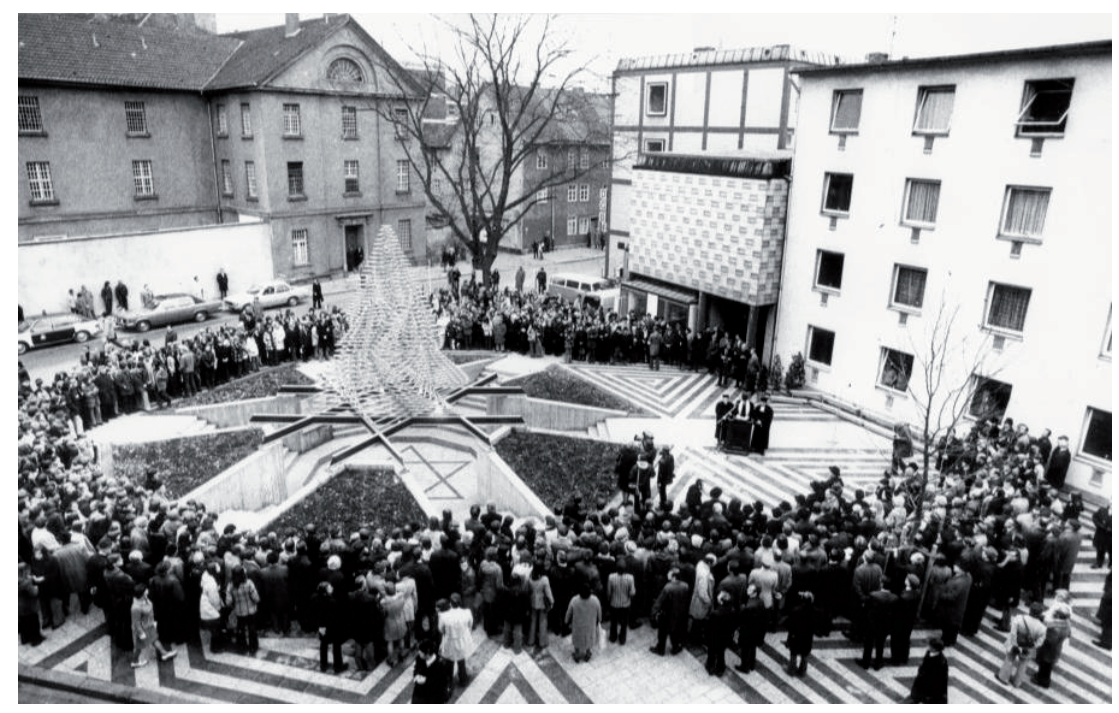

Einweibung des Synagogen-Mahnmals am 9.11.1973

Am 6. März 1970 regte Frau Vogt auf einer Ratssitzung die Mahnmalsstiftung an. In ihrer Begründung betonte sie, dass die Bronzegedenktafel am Gewerkschaftshaus für die Stadt Göttingen keine angemessene und würdige Form des Gedenkens darstelle. Kleinere Städte in der näheren Umgebung wie z. B. Einbeck waren. Die Gedenkfeier gewann vor dem Hintergrund des Jom-KippurKrieges und der umstrittenen neutralen Haltung der Bundesrepublik eine hohe politische Brisanz.

Die Einweihung des Mahnmals fand am 9. November 1973 statt, 35 Jahre nach der Zerstörung der Synagoge). Unter anderen sprach der 
Göttinger Oberbürgermeister Levi. Zur Feierlichkeit waren auch ehemalige jüdische Bürger Göttingens eingeladen worden. Die Einweihung des Mahnmals erfolgte unter dem Schutz eines großen Polizeiaufgebots.

\section{Geschichte und Rezeption}

Im Dezember 1991 beschloss der Rat der Stadt Göttingen, das Gelände, auf dem das Synagogen-Mahnmal steht, in "Platz der Synagoge“ umzubenennen.

Am 22. Oktober 1995 wurden zusätzlich fünf Bronzetafeln mit den Namen und Geburtsdaten der verstorbenen Göttinger Juden am Mahnmal angebracht. Sie befinden sich im begehbaren Raum unterhalb der Plastik. Die Inschrift zu den Tafeln lautet: „Die jüdischen Bürger / der Stadt und des Kreises Göttingen / Kinder, Frauen und Männer / ermordet in dunkler Zeit / 19331945“. Mehr als zwanzig Jahre nach der Einweihung des Mahnmals erhielten nun die Opfer ihre Namen zurück, was im jüdischen Glauben von besonderer Bedeutung ist.

Jährlich finden am Mahnmal Gedenkfeiern zum 9. November statt, bei deren Vorbereitung auch Jugendliche mit einbezogen werden.

Im Juli 1999 beschmierten Unbekannte das Mahnmal mit schwarzen Hakenkreuzen.

\section{Didaktische Überlegungen}

Die Behandlung des Mahnmals am Platz der Synagoge lässt sich in den Unterricht der Klassenstufe 10, aber auch der Oberstufe einbetten. Die vorliegenden Arbeitsblätter richten sich an eine 10. Klasse und sind im Idealfall für vier Unterrichtsstunden (plus Exkursion) angelegt.

Das Mahnmal bietet Anknüpfungspunkte für die Behandlung der Nachkriegsgeschichte und der Aufarbeitung des Nationalsozialismus. An seinem Beispiel können aber auch allgemeinere Fragen der Erinnerungskultur und des Umgangs mit
Geschichte in der heutigen Zeit erörtert werden.

\section{Intentionen}

Die Schülerinnen und Schüler lernen, dass es verschiedene Stufen der Erinnerung an den Holocaust gab. Sie erwerben exemplarisch Wissen über eine neue Bildsprache von Denkmälern. Außerdem erkennen sie die Kontroversität von Denkmälern und setzen sich mit der Bedeutung des Denkmals heute auseinander. Die Schülerinnen und Schüler erwerben Kompetenzen im Umgang mit der Sachquelle Denkmal und mit Textquellen.

\section{Materialseite 1}

Die Seite dient der grundlegenden Information der Schülerinnen und Schüler. Sie bietet die Basisdaten zum Mahnmal und seiner Entstehung. Die Schülerinnen und Schüler vollziehen anhand des Zeitstrahls den chronologischen Ablauf nach und machen sich mit dem Mahnmal vertraut.

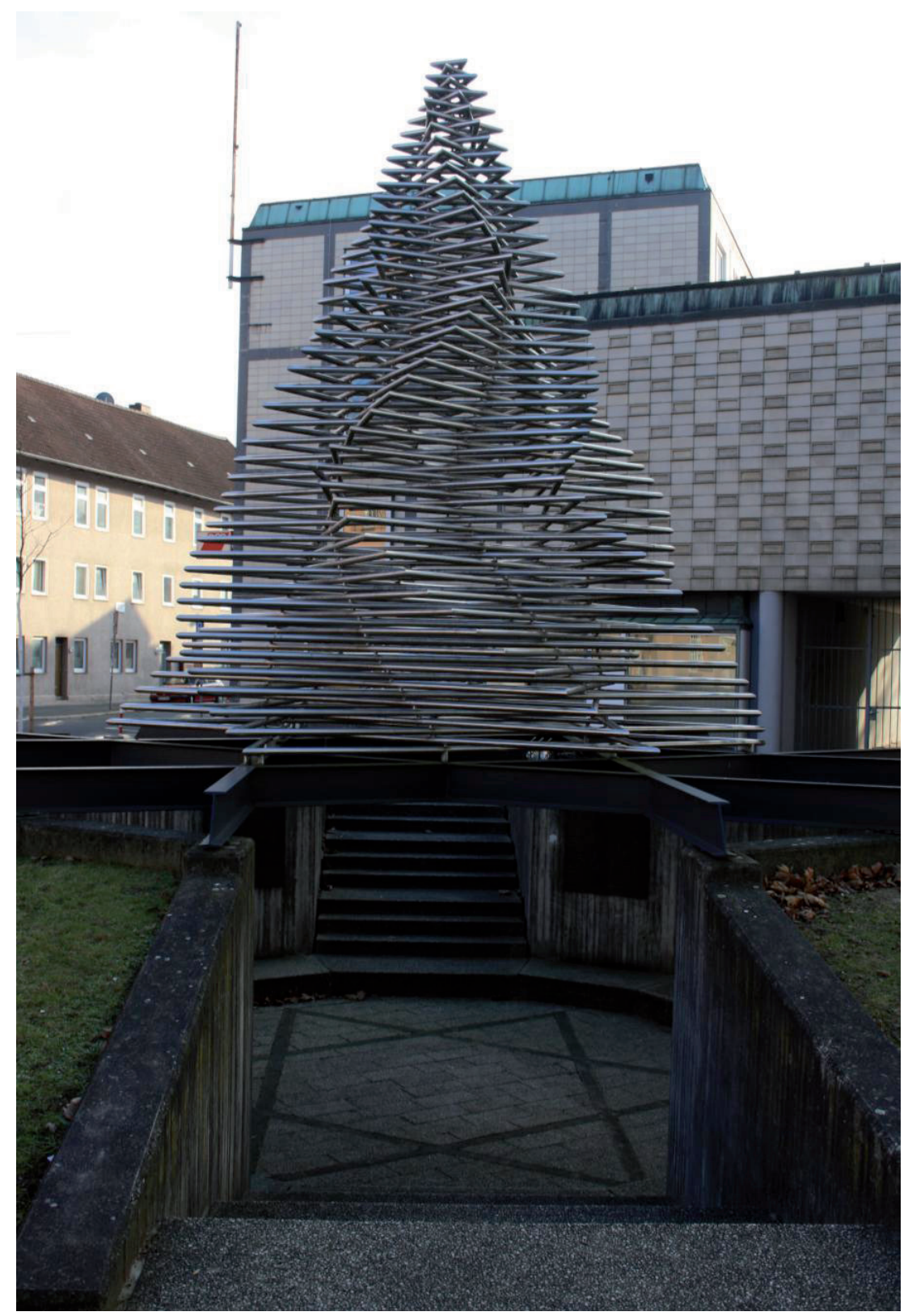

Mabnmal Synagoge, 2011 


\section{Materialseite 2}

Die Schülerinnen und Schüler lernen anhand verschiedener Inschriften von Göttinger Erinnerungsstätten zur Vernichtung der jüdischen Bevölkerung exemplarisch den Wandel der gesellschaftlichen Mentalität in der BRD kennen, indem sie Aussagen und Form der Gedenktexte vergleichen. Methodisch lernen sie, Denkmäler als Ausdruck einer jeweils zeitgenössischen Erinnerungskultur $\mathrm{zu}$ interpretieren und die jeweiligen politischen Implikationen zu reflektieren.

\section{Materialseite 3}

Die Schülerinnen und Schüler beschreiben das Mahnmal und setzen sich mit dessen künstlerischer Gestaltung auseinander. Insbesondere der erste Arbeitsauftrag stellt eine gute Beobachtungsfrage im Rahmen einer Exkursion dar. Die Schülerinnen und Schüler erarbeiten verschiedene Ansätze zur Deutung der Plastik (z. B. die Flamme als Symbol für den Synagogenbrand und als Symbol für Hoffnung, der Davidstern als jüdisches Symbol oder die Himmelsleitermetaphorik) und beziehen persönlich Stellung zum Mahnmal als Erinnerungsort. Des Weiteren setzen sie sich mit der Frage auseinander, ob das Mahnmal opfergruppenspezifisch ist. Hier wäre eine Ausweitung des Unterrichtsgesprächs zum Berliner HolocaustMahnmal und zum Diskurs über die „Opfer-Hierarchisierung“ denkbar.

\section{Materialseite 4}

Die Schülerinnen und Schüler befassen sich weiterführend mit der Gestaltung und Konzeption des Mahnmals und dessen heutiger Nutzung. Sie stellen einen lebensweltlichen Bezug zum Mahnmal Synagoge dar und setzen sich mit ihrer eigenen Position im Erinnerungsdiskurs auseinander. Sie sollen aus Wissen und Einsichten über die Vergangenheit Beurteilungsmaßstäbe und Handlungsalternativen für die Gegenwart entwickeln.

\section{Literatur}

Hofmann, Carolin, Holocaust-Mahnmale auf Plätzen ehemaliger Synagogen (Magisterarbeit), Osnabrück 2000.

Kratz-Ritter, Bettina, Das Göttinger Mahnmal am Platz der Synagoge (Schriften der Göttinger Gesellschaft für christlich-jüdische Zusammenarbeit, Heft 3), Göttingen 2004.

Kulturamt der Stadt Göttingen (Hrsg.), Einweihung des Mahnmals am Platz der ehemaligen Synagoge in Göttingen, Untere Maschstraße am 9. November 1973 und Begleitveranstaltungen. Dokumentation, Göttingen 1974.

Nissen, Walter, Göttinger Denkmäler, Gedenksteine und Brunnen, Göttingen 1978.

Schaller, Berndt, Synagogen in Göttingen. Aufbrüche und Abbrüche jüdischen Lebens, Göttingen 2006.

Schurr, Susanne, Zeugnis der Aufarbeitung? Das Mahnmal am Platz der zerstörten Synagoge, in: Gottschalk, Carola (Hrsg.), Verewigt und Vergessen. Kriegerdenkmäler, Mahnmale und Gedenksteine in Göttingen, Göttingen 1992 , S. 85-92.

Thadden, Rudolf von/Trittel, Günter J. (Hrsg.), Göttingen. Geschichte einer Universitätsstadt. Band 3. Von der preußischen Mittelstadt zur südniedersächsischen Großstadt 1866-1989, Göttingen 1999.

\section{Unveröffentlichte Quelle}

Stadt Göttingen, Kulturamt, Pressemitteilung zur Enthüllung der Gedenktafeln am Mahnmal Synagoge. Göttingen 1995.

\section{Internetseiten zum Mahnmal}

http://www.denkmale.goettingen.de/denkmale/mahnmalsynagoge.html (eingesehen am 11.2.2011). http://www.kaee.uni-goettingen.de/studium/denkmal/synagoge.htm (eingesehen am 11.2.2011).

Eine Übersicht von verschiedenen Synagogen-Mahnmalen vieler Städte hat die Stadt Hameln zusammengestellt: http://www.gelderblom-hameln.de/juedischegeschichte/synagoge/teil3gedaechtnis/inschriften60er.html (eingesehen am 11.2.2011). 


\section{Basisinformationen zum Mahnmal Synagoge}

\section{M1 Steckbrief}

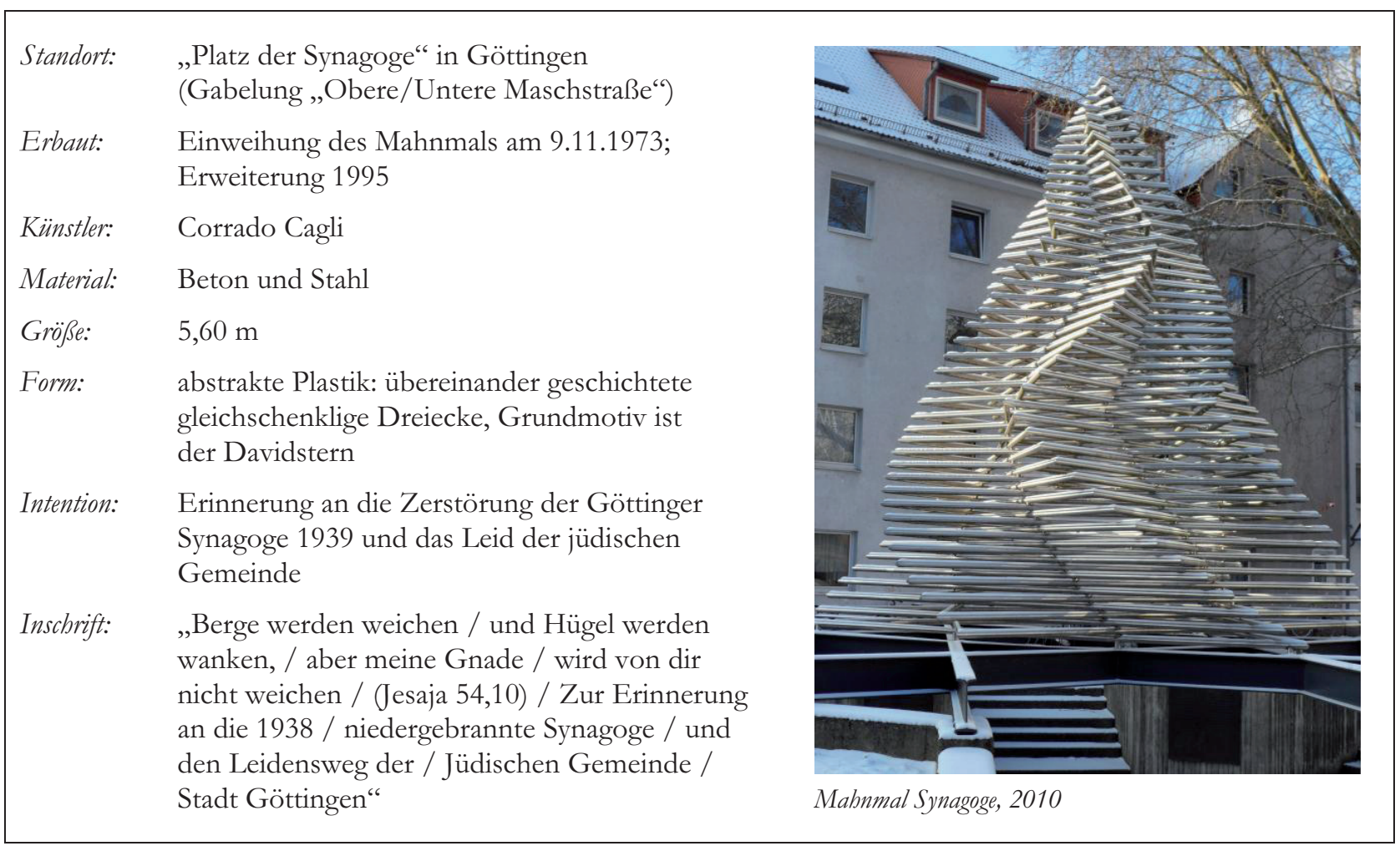

\section{M2 Zeitstrahl}

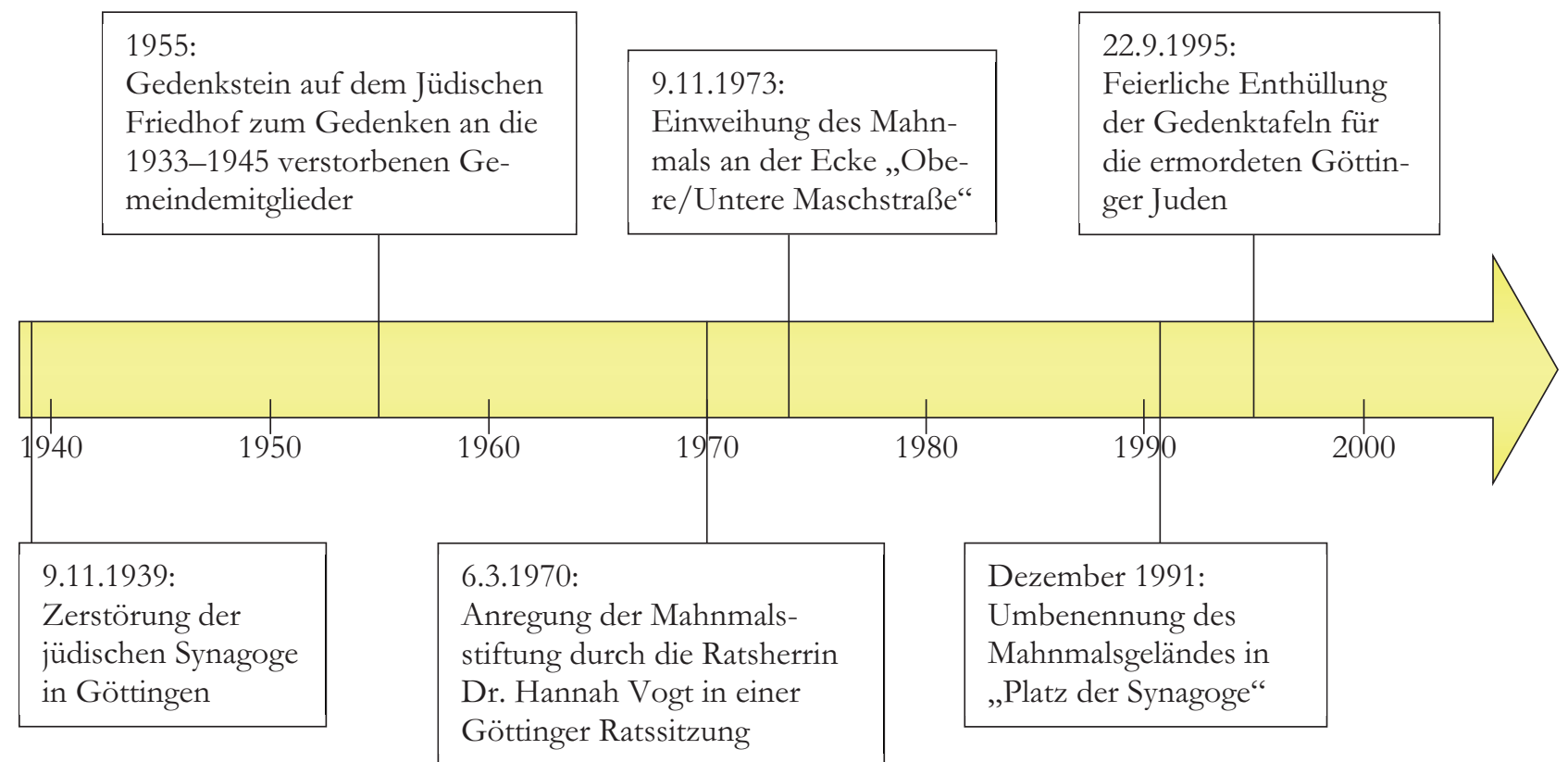




\section{Inschriftenvergleich}

Bevor das Mahnmal Synagoge 1973 eingeweiht wurde, gab es in Göttingen bereits einen Gedenkstein und eine Gedenktafel für die jüdischen Opfer des Holocaust. Der Gedenkstein wurde 1955 von der Jüdischen Gemeinde auf dem Jüdischen Friedhof aufgestellt und von der Stadt Göttingen finanziert. 1960 wurde ebenfalls auf Betreiben der Jüdischen Gemeinde eine Gedenktafel am Gewerkschaftshaus an der Oberen Maschstraße 10 angebracht. Gedenkstein und Gedenktafel tragen folgende Inschriften:

\section{M3 Inschrift des Gedenksteins auf dem Jüdischen Friedhof (1955)}

„Mein Auge rinnt / und ruht nicht, / keine Linderung / Klagelieder III 49“

\section{Darunter steht:}

„Zum Andenken an / die Mitglieder unserer / Gemeinde, die in einer / Zeit ihr Leben lassen / mußten, in der die Liebe / und die Achtung / vor den Menschen / gestorben waren / 1933$1945^{\prime 6}$

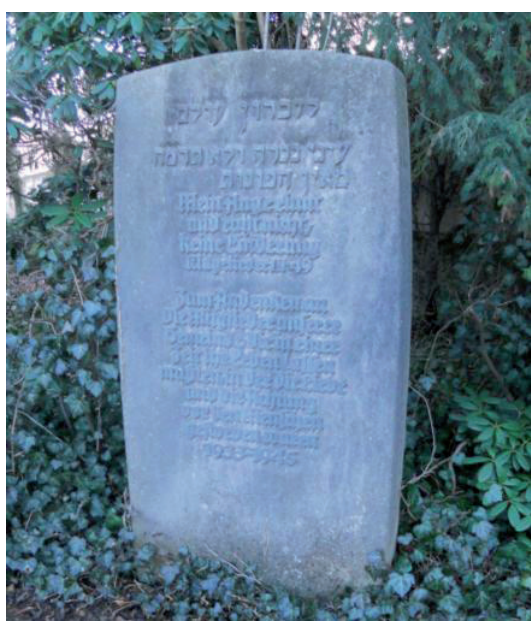

Gedenkstein auf dem Jüdischen Friedhof, 2011

\section{M4 Gedenktafel am Gewerkschaftshaus (1960)}

„An diesem Platz stand die Synagoge / der Jüdischen Gemeinde Göttingen. / Sie wurde am 9. November 1938 ein / Opfer des Nationalsozialistischen / Rassenwahns. Die Gemeinde zählte / im Jahre 1939 noch 196 Mitglieder. / Diese wurden bis auf wenige ver- / nichtet. Den Toten zum Gedenken / Den Lebenden zur Mahnung. / Die Stadt Göttingen“"

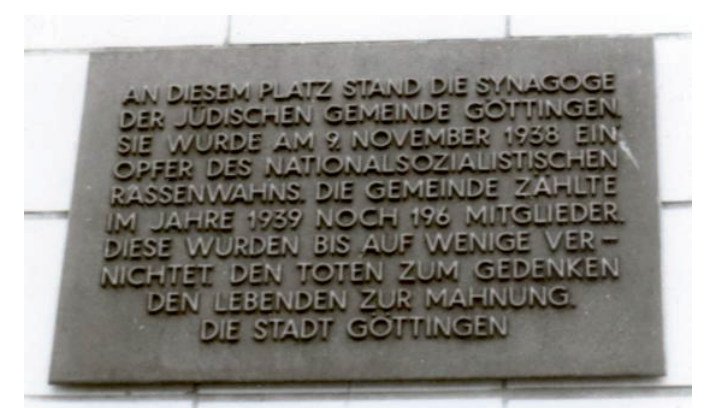

Gedenktafel am Gewerkschaftshaus, 1971

\section{Arbeitsanfträge}

1. Untersuche, wie Täter, Opfer und die Zeit des Nationalsozialismus in den Inschriften des Gedenksteins, der Gedenktafel und des Mahnmals Synagoge angesprochen werden.

2. Nimm begründet Stellung, inwiefern sich die Inschriften in ihrer Aussage unterscheiden. 


\section{Bildsprache des Mahnmals}

\section{M5 Mahnmal Synagoge (1973)}

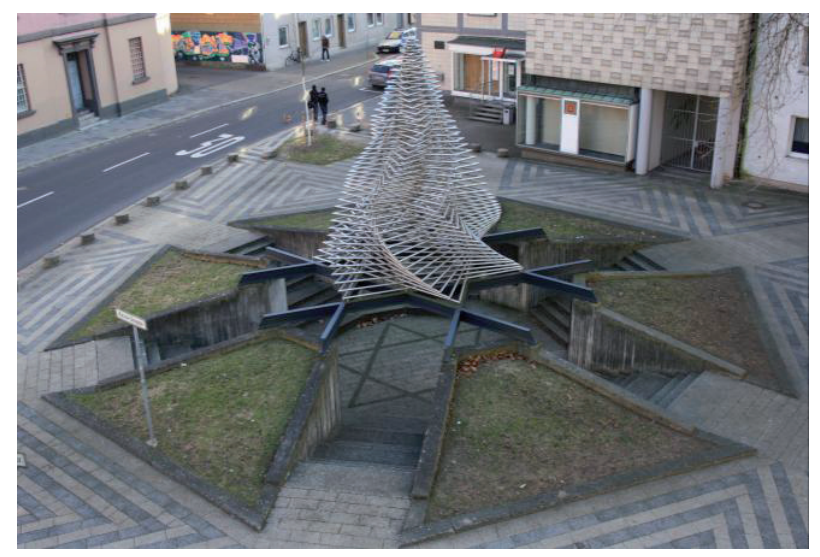

Mahnmal Synagoge, 2011

\section{M6 Mahnmal Synagoge (1973): Blick von unten}

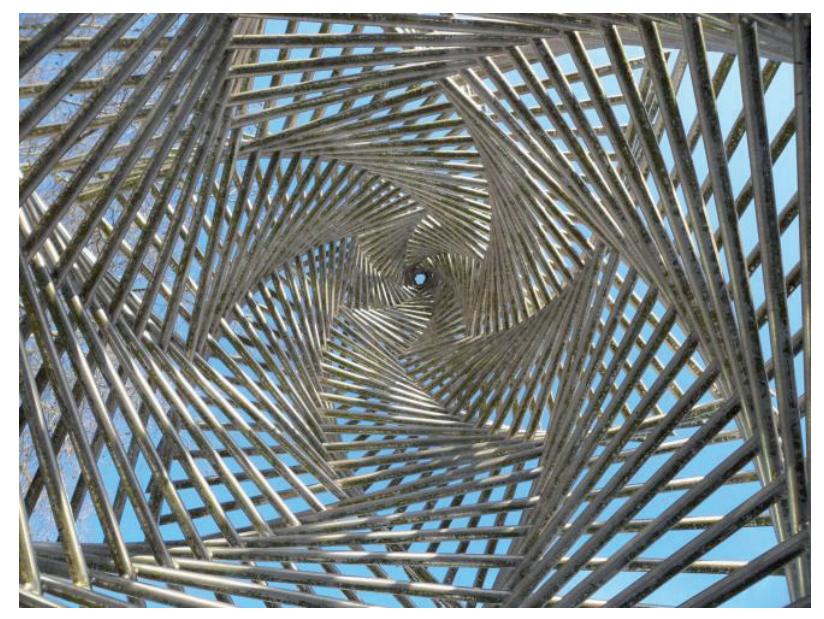

Mabnmal Synagoge, 2010

\section{M7 Neue Formen des Erinnerns}

Artur Levi, Göttinger Oberbürgermeister, äußert sich bei den Einweibungsfeierlichkeiten über die Form des Mabnmals (1973):

„Beiden - den Ratsmitgliedern wie auch dem Künstler - ging es nun darum, eine Form zu finden, durch die nicht in künftigen Zeiten der Blick nur in die Vergangenheit gerichtet wird. Wir alle wollten bewußt eine 5 Stätte mit Aussagekraft sowohl für die Gegenwart wie für die Zukunft; eine Stätte, an der Menschen unserer wie der künftigen Generation besinnlich verweilen können und wollen, ohne sich dabei angeklagt zu fühlen für Vorgänge, die viele von ihnen altersbedingt 10 selbst gar nicht miterlebt haben."

(Kulturamt der Stadt Göttingen (Hrsg.), Einweihung des Mahnmals am Platz der ehemaligen Synagoge in Göttingen, Untere Maschstraße am 9. November 1973 und Begleitveranstaltungen. Dokumentation, Göttingen 1974, S. 61)

\section{Arbeitsanfträge}

1. Beschreibe das Aussehen des Mahnmals und seine Wirkung auf dich (M5 und M6).

2. Stelle Vermutungen an, warum eine abstrakte Plastik als Mahnmal gewählt wurde.

3. Interpretiere die Symbolik des Mahnmals. Diskutiere mit deinem Nachbarn.

4. Nimm Stellung zur Aussage von Artur Levi und beurteile, ob das Mahnmal seinem Anspruch gerecht werden kann (M7).

5. Heinrich Wurm schreibt in seiner Dokumentation zur Einweihung des Mahnmals, dass „das Werk ganz allgemein den Opfern des Nationalsozialismus“ gilt. Nimm dazu Stellung. 


\section{Umgang mit dem Mahnmal}

\section{M8 Kritische Stellungnahme zum Mahnmal}

Wilhelm Illemann schreibt in einem Leserbrief im Göttinger Tageblatt vom 19.7.1972:

Wem ist geholfen?

Betr.: Jüdisches Ehrenmal

Der Kulturausschuß der Stadt hat beschlossen, ein jüdisches Ehrenmal an der Stelle der früheren Syna5 goge zu errichten und hierfür einen Beitrag in Höhe von DM 220.000,-- im Nachtragshaushalt eingesetzt. Bei einer derartigen Entschließung drängt sich unwillkürlich die Frage auf, wem eigentlich mit der Erstellung einer derartigen Gedenkstätte wirklich geholfen 10 ist.

Keinesfalls soll die schreckliche Zeit im Dritten Reich mit den verabscheuungswürdigen Judenverfol- gungen totgeschwiegen werden; aber ein Ehrenmal, womöglich noch in einer Gestaltung, die ein normaler

15 Mensch nicht als solches erkennt, für DM 220.000,zu erstellen, werden sicher nicht einmal unsere jüdischen Mitbürger als sinnvoll anerkennen.

Ein schlichter Gedenkstein würde den gleichen Zweck erfüllen und somit würde ein bedeutender 20 Beitrag frei für wirkliche Hilfe an notleidende Menschen, die unter dem Naziregime gelitten haben. Es gibt z. B. jüdische Altersheime und andere Institutionen, wo noch echte Not herrscht und denen mit weit geringeren Mitteln sehr geholfen wäre.

(Göttinger Tageblatt, 19.7.1972)

\section{M9 Gedenkfeiern}

Jedes Jahr finden am 9. November Gedenkfeiern am Mahnmal Synagoge statt, die im Auftrag der Stadt Göttingen von der Gesellschaft für christlich-jüdische Zusammenarbeit durchgeführt werden. Bei der Gestaltung des inhaltlichen Programms wirken auch wechselnde Gruppen von Jugendlichen mit. Folgendes Gedicht wurde am 9.11.2003 von Schülerinnen und Schülern des Max-Planck-Gymnasiums Göttingen vorgetragen:

Schmutzig-grau ist das Denkmal.

Der Wind bläst Papierfetzen über den Platz.

Hier stand die Synagoge.

Hier wurden Menschen vertrieben.

5 Hier schauen uns Häftlinge zu.

Hier finden die Bedürftigen eine Schlafstatt.

Über unseren Köpfen die lodernde Flamme.

Das Feuer hat vernichtet,

zuerst Synagogen, später Menschen.
10 Aber das Feuer ist auch Zeichen der Hoffnung, es gibt Wärme und spendet Licht in der Dunkelheit. Passt auf, wenn ihr geht! Geht nah an das Feuer: Plötzlich gibt der Boden nach.

15 Eine Grube tut sich auf, eine Grube in der Erde.

Wenn ihr hinabsteigt, seid ihr unter dem Feuer.

Und ganz nah bei den Toten.

(Bettina Kratz-Ritter, Das Göttinger Mahnmal am Platz der Synagoge (Schriften der Göttinger Gesellschaft für christlich-jüdische Zusammenarbeit, Heft 3), Göttingen 2004, S. 14)

\section{Arbeitsaufträge}

1. Benenne die im Leserbrief geäußerten Kritikpunkte (M8).

2. Schreibe selbst einen Leserbrief, in dem du zu M8 Stellung nimmst.

3. Entwickle Ideen dafür, wie ein heutiges Synagogen-Mahnmal in Göttingen aussehen könnte.

4. Nenne die Aspekte, die die Schülerinnen und Schüler im Gedicht ansprechen (M9).

5. Erstelle einen eigenen Text, der bei einer Gedenkfeier vorgetragen werden könnte. 


\section{Lageplan}

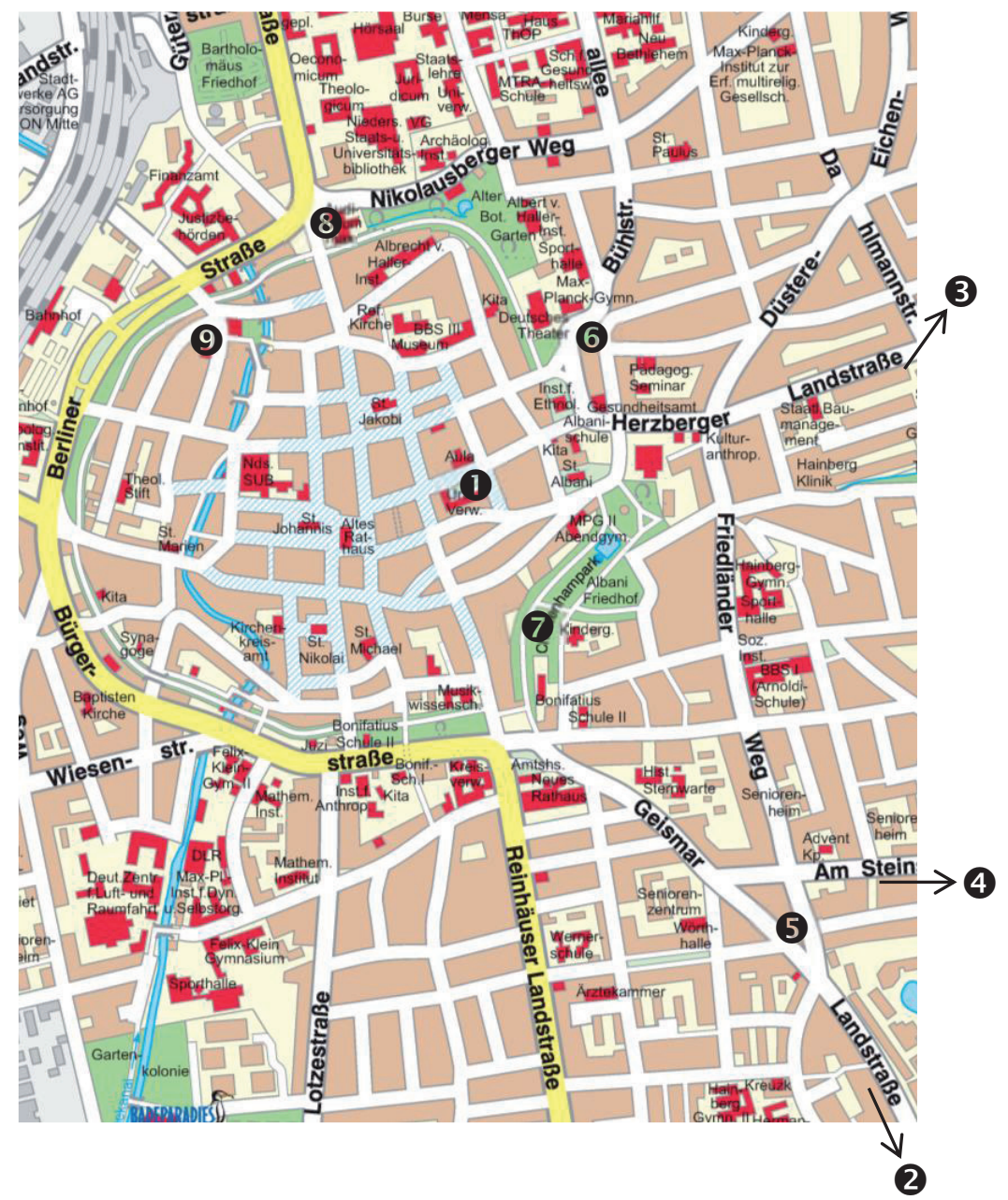

Maßstab: $1: 16.700$
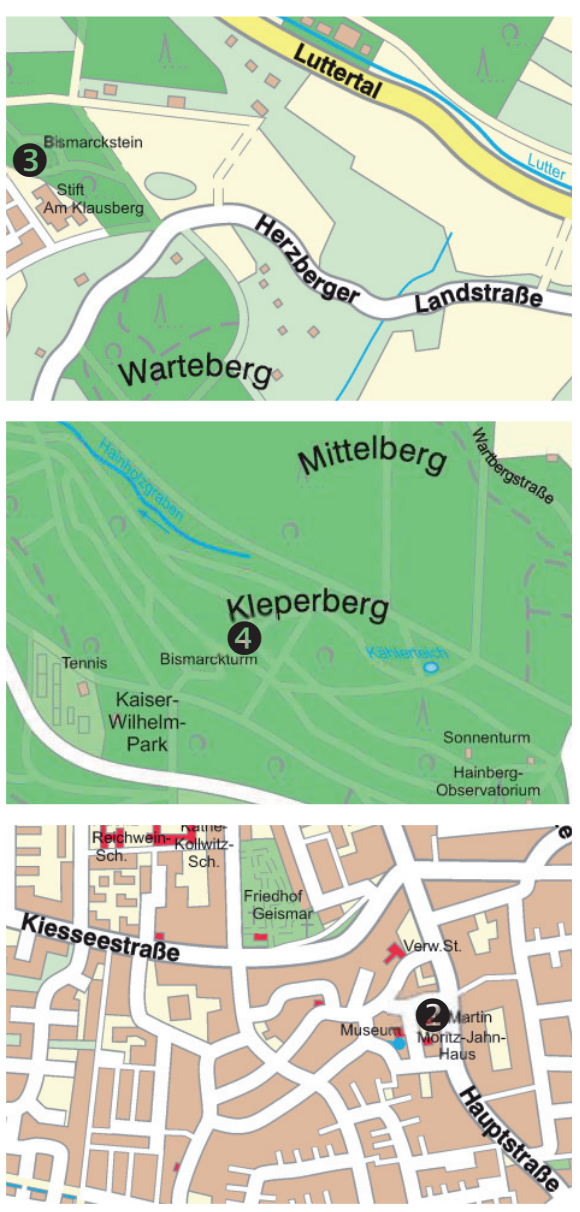

\section{Legende}

( Denkmal Wilhelms IV.

(2) Germania in Geismar

(3) Bismarckstein

4 Bismarckturm

(5) Südwestafrika-Denkmal

(6) Ehrenmal Res.-Inf.-Reg. 91

(7) Ehrenmal Inf.-Reg. 82

8 Ehrenmal Universität

(9 Mahnmal Synagoge 


\section{Abbildungsverzeichnis}

\section{Sauer: Denkmäler im Unterricht}

S. 6 oben rechts: http://commons.wikimedia.org/wiki/File:Arminius2.jpg (Foto: Benutzer Nawi112).

S. 7 oben links: http://commons.wikimedia.org/wiki/File:Holocaust-Mahnmal_Berlin_2006.jpg?uselang=de (Foto: K. Weisser 2008).

\section{Bartsch: Denkmal Wilhelms IV.}

S. 10 oben rechts: Foto: Pressestelle Universität Göttingen.

S. 10 unten links: http://commons.wikimedia.org/wiki/File:S\%C3\%A4kularfeier_Denkmalsenth\%C3\%BCllung_ 1837.jpg?uselang $=$ de.

S. 11 oben links: http://commons.wikimedia.org/wiki/File:William.IV.of.Great.Britain.JPG?uselang=de (Foto: Benutzer Gustav VH).

S. 11 oben rechts: Foto: Städtisches Museum Göttingen.

S. 11 unten rechts: Foto: Pressestelle Universität Göttingen.

S. 12 oben links: Foto: Pressestelle Universität Göttingen.

S. 13 oben links: Foto: Bartsch 2011.

S. 13 oben rechts: Foto: Pressestelle Universität Göttingen.

S. 13 unten links: http://commons.wikimedia.org/wiki/File:S\%C3\%A4kularfeier_Denkmalsenth\%C3\%BCllung_ 1837.jpg?uselang $=$ de.

\section{Frome-Ziegler/Kempe/Nawroth: Germania}

S. 14 oben rechts: Foto: Picht 2011.

S. 15 oben links: Foto: Picht 2011.

S. 15 oben rechts: http://commons.wikimedia.org/wiki/File:Lorenz_Clasen_1860_-_Germania_auf_der_Wacht_am_ Rhein.png?uselang $=$ de.

S. 15 Mitte rechts: Gall, Lothar, Die Germania als Symbol nationaler Identität im 19. und 20. Jahrhundert, Göttingen 1993 (Nachrichten der Akademie der Wissenschaften in Göttingen, Philologisch-Historische Klasse, Nr. 2), S. 45.

S. 15 unten rechts: http://commons.wikimedia.org/wiki/File:DR_1900_62_Germania_Reichspost.jpg?uselang=de

S. 16 unten links: Ansichtskarte, Privatbesitz.

S. 17 oben rechts: http://commons.wikimedia.org/wiki/File:Niederwald_memorial_1.JPG?uselang=de

(Foto: Benutzer Moguntiner 2006).

S. 19 oben links: http://commons.wikimedia.org/wiki/File:Image_Germania_\%28painting\%29.jpg?uselang=de.

S. 20 oben links: Foto: Picht 2011.

S. 20 oben rechts: Ansichtskarte, Privatbesitz.

S. 21 oben links: Foto: Picht 2011.

S. 21 unten links: Foto: Picht 2011.

S. 21 unten rechts: http://commons.wikimedia.org/wiki/File:NiederwaldDenkmalHB001.jpg?uselang=de

(Foto: Hubert Berberich 2004).

\section{Groß: Bismarckstein}

S. 23 oben rechts: Foto: Mai 2010.

S. 23 unten rechts: http://blog.deklein.de/wp-content/uploads/2008/12/bismarckstein.jpg.

S. 23 unten links: Foto: Mai 2010. 
S. 24 oben rechts: Foto: Mai 2010.

S. 24 unten links: Foto: Mai 2010.

S. 26 oben rechts: Foto: Mai 2010.

S. 27 oben links: http://blog.deklein.de/wp-content/uploads/2008/12/bismarckstein.jpg.

S. 27 oben rechts: http://www.stadtarchiv.goettingen.de/texte/stadtgeschichte_1734_1866.htm.

S. 27 unten links: Foto: Mai 2010.

\section{Mai: Bismarckturm}

S. 30 oben rechts: Foto: Mai 2010.

S. 30 unten links: Thadden, Rudolf von/Trittel, Günter J. (Hrsg.), Göttingen. Geschichte einer Universitätsstadt. Band 3: Von der preußischen Mittelstadt zur südniedersächsischen Großstadt 1866-1989, Göttingen 1999, S. 827.

S. 31 oben rechts: http://www.zeno.org/nid/20000606901.

S. 31 unten rechts: http://commons.wikimedia.org/wiki/File:Bismarckraum_Goettingen.jpg?uselang=de (Foto: Benutzer Times).

S. 33 oben rechts: Foto: Mai 2010.

\section{Meiser: Südwestafrika-Denkmal}

S. 37 oben rechts: Foto: Meiser 2011.

S. 37 unten links: Foto: Göttinger Tageblatt, 28./29. Dezember 1935.

S. 38 unten links: Foto: Göttinger Tageblatt, 5. Mai 1978.

S. 41 oben rechts: Foto: Meiser 2011.

S. 43 unten links: Foto: Meiser 2011.

S. 43 unten rechts: Foto: Göttinger Tageblatt, 28./29. Dezember 1935.

\section{Tietz: Ehrenmal Reserve-Infanterie-Regiment 91}

S. 45 oben rechts: Foto: Tietz 2011.

S. 45 unten rechts: http://commons.wikimedia.org/wiki/File:Dying_gaul.jpg?uselang=de

(Foto: Benutzer antmoose 2005).

S. 46 unten rechts: Foto: Tietz 2011.

S. 47 unten rechts: abgedruckt in: Gottschalk, Carola (Hrsg.), Verewigt und vergessen. Kriegerdenkmäler, Mahnmale und Gedenksteine in Göttingen, Göttingen 1992, S. 37.

S. 50 oben: Foto: Tietz 2011.

S. 52 oben rechts: Goethezeitportal, http://www.goethezeitportal.de/index.php?id=3991 (aus der Sammlung historischer und politischer Bildpostkarten von K. Stehle, München).

\section{Dräger: Ehrenmal Infanterie-Regiment 82}

S. 54 oben rechts: Foto: Städtisches Museum Göttingen.

S. 55 oben rechts: Foto: Städtisches Museum Göttingen.

S. 55 unten links: Foto: Städtisches Museum Göttingen.

S. 56 oben rechts: Foto: Städtisches Museum Göttingen.

S. 56 unten rechts: Foto: Dräger 2011.

S. 58 oben rechts: Foto: Städtisches Museum Göttingen.

\section{Marunde: Ehrenmal Universität}

S. 64 oben rechts: Foto: Marunde 2011. 
S. 64 unten links: Thadden, Rudolf von/Trittel, Günter J. (Hrsg.), Göttingen. Geschichte einer Universitätsstadt. Band 3: Von der preußischen Mittelstadt zur südniedersächsischen Großstadt 1866-1989, Göttingen 1999, S. 850.

S. 67 oben rechts: Foto: Marunde 2011.

S. 68 unten links: Foto: Marunde 2011.

S. 68 unten rechts: http://www.ansichtskarten-center.de/studenten-sonstiges/3400-goettingen-denkmal-fuer-diegefallenen-der-uni-goettingen?isSearchRequest=Y.

\section{Frome-Ziegler/Kempe/Nawroth: Mahnmal Synagoge}

S. 72 oben rechts: Foto: Loebell 2011.

S. 72 unten links: Foto: Kempe 2010.

S. 73 oben links: Foto: Loebell 2011.

S. 73 oben rechts: Foto: Loebell 2011.

S. 73 unten links: Foto: Städtisches Museum Göttingen.

S. 73 unten rechts: Foto: Städtisches Museum Göttingen 1938.

S. 74 oben links: Foto: Loebell 2011.

S. 74 unten rechts: Foto: Städtisches Museum Göttingen 1973.

S. 75 unten rechts: Foto: Loebell 2011.

S. 77 oben rechts: Foto: Kempe 2010.

S. 78 oben rechts: Foto: Frome-Ziegler 2011.

S. 78 unten rechts: Foto: Städtisches Museum Göttingen 1971.

S. 79 oben links: Foto: Loebell 2011.

S. 79 unten links: Foto: Kempe 2010.

\section{Lageplan}

S. 81: Stadtplan 1:20.000 - Stadt Göttingen - Der Oberbürgermeister, Fachdienst Bodenordnung, Vermessung und Geoinformation, 10.05.2012, Az. 61.22372.

Alle Internetseiten wurden zuletzt eingesehen am 25.04.2012. 
Denkmäler bieten für den Geschichtsunterricht erhebliche Lernpotentiale. Sie sind Manifestationen vergangener oder auch gegenwärtiger Geschichtskultur. Sie geben Auskunft über intendierte Sinnstiftungen und über Funktionalisierungen von Vergangenheit sowie den späteren Umgang damit.

Die Beiträge dieses Bandes sind aus einem Didaktik-Seminar hervorgegangen, das im Wintersemester 2010/11 an der Universität Göttingen stattgefunden hat. Sie enthalten Unterrichtsanregungen zu ausgewählten Denkmälern Göttingens. Diese sollen Schülerinnen und Schülern die exemplarische Beschäftigung mit der lokalen Erinnerungslandschaft ermöglichen. Alle Beispiele können auch im Kontext klassischer Themen in den Geschichtsunterricht einbezogen werden.

Die Beiträge sind nach einem festen Muster aufgebaut. Einführend dokumentieren sie das aktuelle Erscheinungsbild jedes Denkmals und skizzieren seine Geschichte von der Errichtung bis in die Gegenwart. Es folgen Hinweise für die Unterrichtsarbeit. Die anschließend zusammengestellten Materialien können unmittelbar im Unterricht eingesetzt werden. 